\title{
INVESTOR SENTIMENT IN THE FINANCIAL MARKET: A SURVEY
}

by

Charles A. Aziegbemhin

B.Eng. University of Benin, Nigeria, 1998.

\section{A Project}

presented to Ryerson University

in partial fulfillment of the

requirements for the degree of

Master of Engineering

in

Electrical and Computer Engineering

Toronto, Ontario, Canada,

(C) Charles A. Aziegbemhin 2013 


\section{DECLEARATION}

I hereby declare that I am the sole author of this MRP. This is a true copy of the MRP, including any required final revisions.

I authorize Ryerson University to lend this MRP to other institutions or individuals for the purpose of scholarly research.

I further authorize Ryerson University to reproduce this MRP by photocopying or by other means, in total or in part, at the request of other institutions or individuals for the purpose of scholarly research.

I understand that my MRP may be made electronically available to the public. 


\title{
INVESTOR SENTIMENT IN THE FINANCIAL MARKET: A SURVEY
}

\author{
by \\ Charles A. Aziegbemhin \\ Master of Engineering in Electrical and Computer Engineering \\ Department of Electrical \& Computer Engineering \\ Ryerson University \\ Toronto, Ontario, Canada, 2013
}

\begin{abstract}
Many techniques like technical analysis, fundamental analysis, neural networks etc are used to forecast market behavior but none of these methods has been consistently acceptable forecasting tool. This thesis surveys more than 200 related published articles that study investor sentiment techniques as derived and applied to forecasting equity, debt and alternative markets. From the literatures, it shows that the application of investor sentiment for evaluating market behavior is gaining wide acceptance. Changes in investor sentiment can trigger changes in the valuation and pricing of assets, therefore offering the ability to forecasting market directions more accurately than other techniques. This study is the most comprehensive survey on investor sentiment techniques and its impact on forecasting a panel of assets in the equity, debt, derivative and other alternative investment markets. It examines forecasting as it affects sentiment, investor sentiment, it influence on market returns, news analytics and its use as profit and risk management tool.
\end{abstract}




\section{ACKNOWLEDGEMENT}

I offer my gratitude to the faculty, staff and my fellow students at Ryerson University, who have inspired me to continue my work in this field. I owe particular thanks to Dr. Kaamram Raahemifar, for his patience and friendly guidance. Without his support, I would not have been able to complete my research.

I would like to appreciate Ryerson University for a friendly researching environment, and valuable resources.

Finally, I would like to thank my wife, Comfort O. Aziegbemhin, and children - Ehi, Ose and Ebun for their constant love and supports. 


\section{DEDICATION}

This work is dedicated to my wife, Comfort O. Aziegbemhin, and my children, Ehi, Ose and Ebun. Their love and support keep me going.

I further dedicate this work to those who will further the research in investor sentiment. 


\section{TABLE OF CONTENTS}

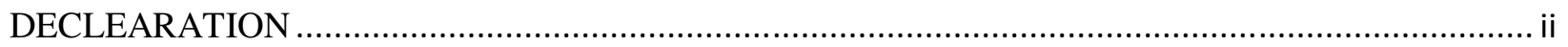

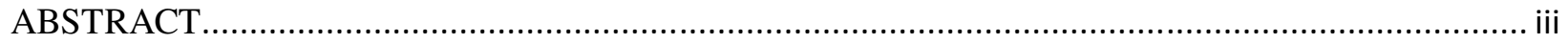

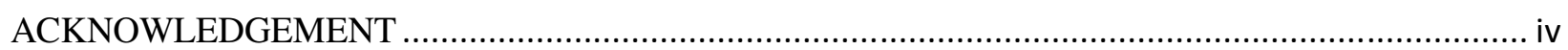

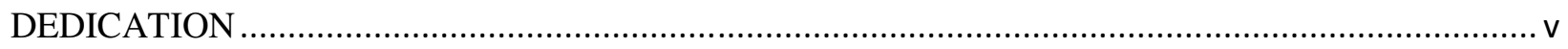

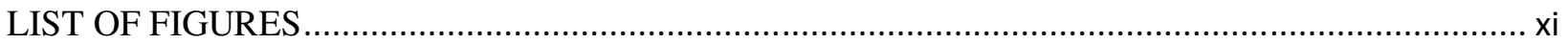

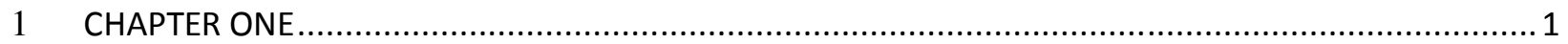

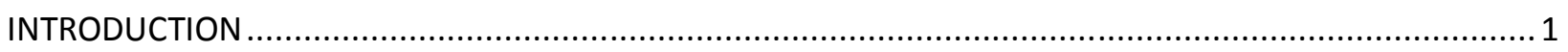

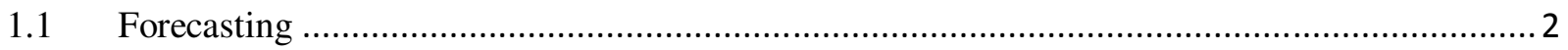

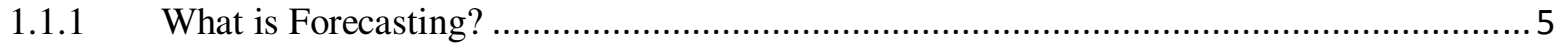

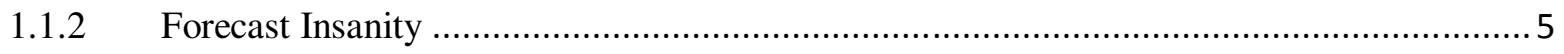

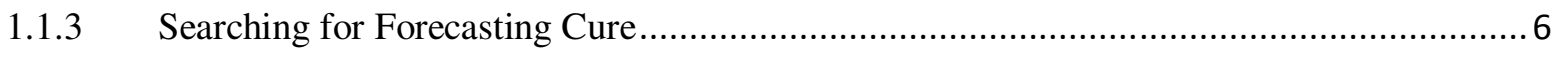

1.2 Overview of Market Forecasting Methods ....................................................................... 7

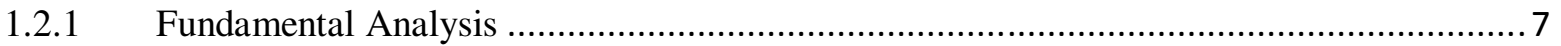

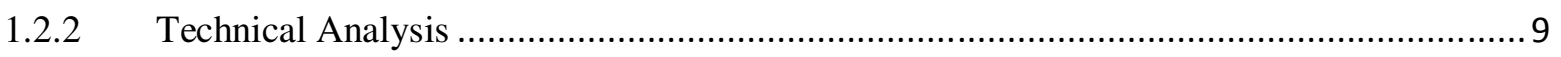

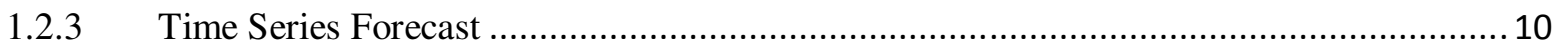

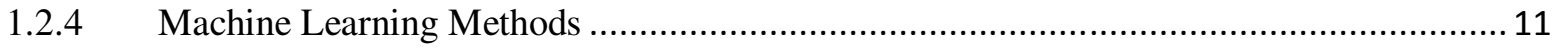

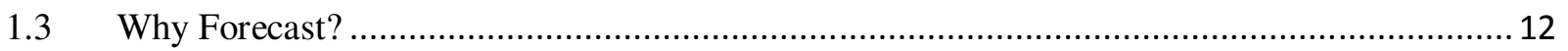

1.4 Measuring the Success or Failure of a Forecast........................................................... 14

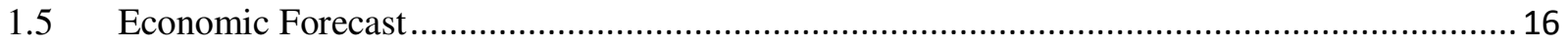

1.5.1 Survey of Professional Forecasters …..................................................................... 17

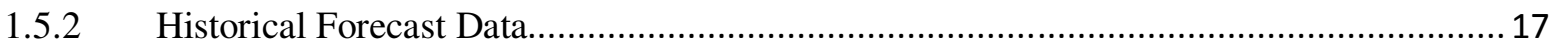

1.5.3 Special Variables and Special Questions .............................................................. 17

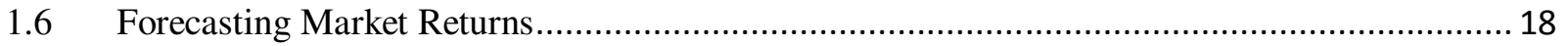

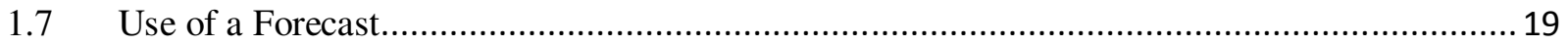

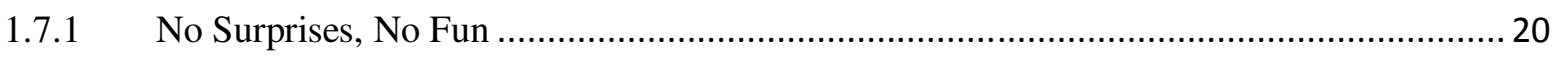

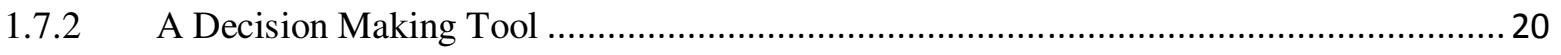

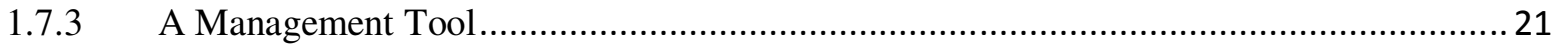

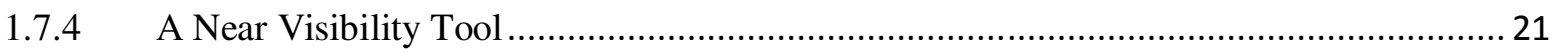

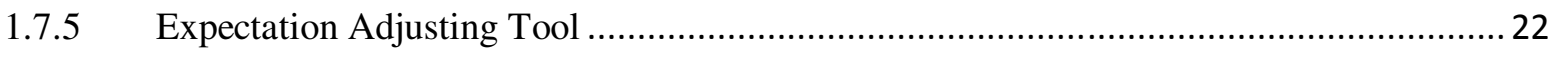




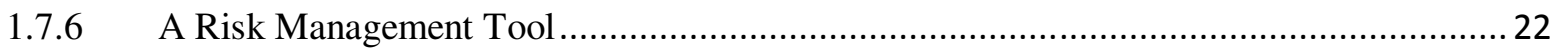

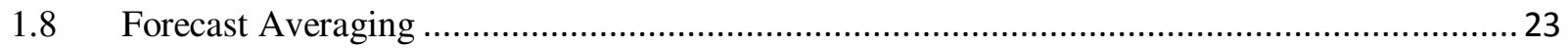

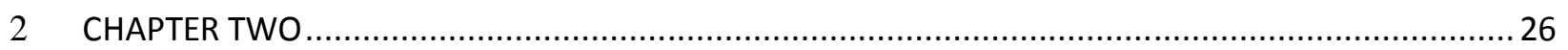

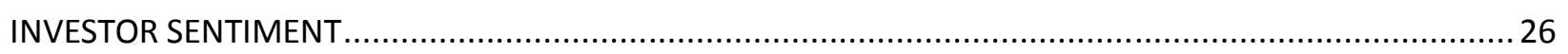

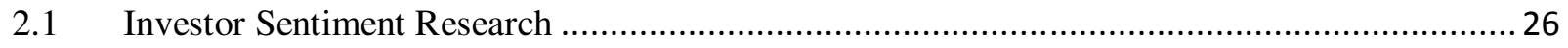

2.1.1 Investor Sentiment and Classical Finance ….......................................................... 27

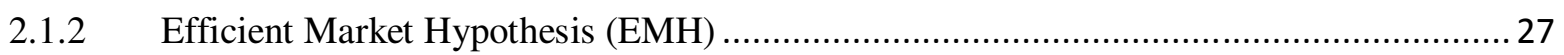

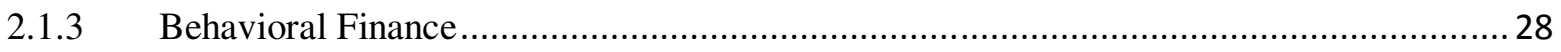

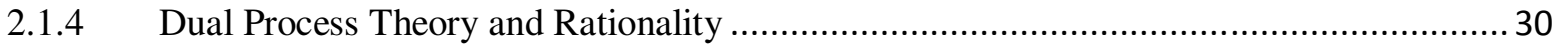

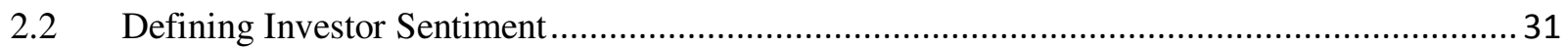

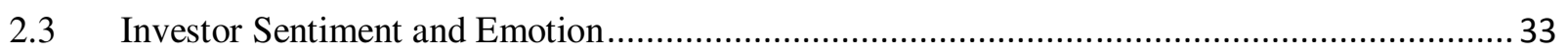

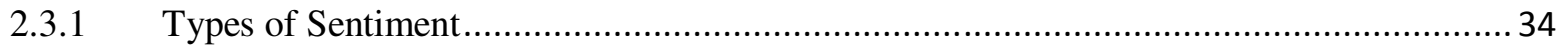

$2.4 \quad$ Investor Sentiment or Consumer Sentiment ….............................................................. 35

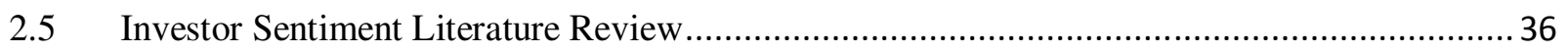

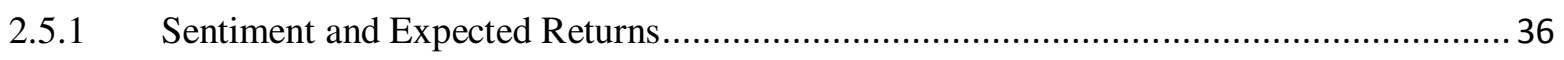

2.5.2 Forecasting Power of Sentiment Proxies …............................................................ 37

2.5.3 Impact of Individual Investor Sentiment on Trading................................................ 39

2.5.4 Bearish vs. Bullish and Fear vs. Exuberance Sentiments ........................................... 39

2.5.5 Investor Sentiment and Societal Mood State .............................................................. 39

2.5.6 Sentiment and its Relationship with Macro-Economic Indicators ................................. 41

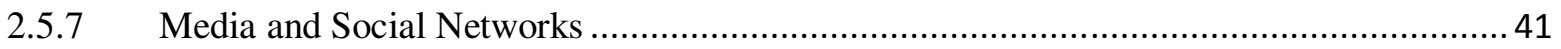

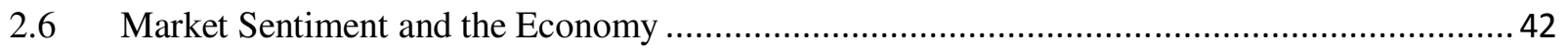

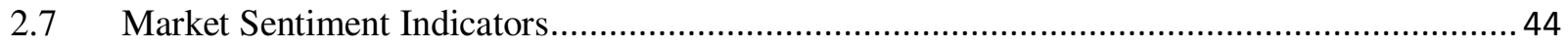

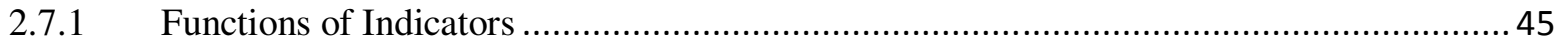

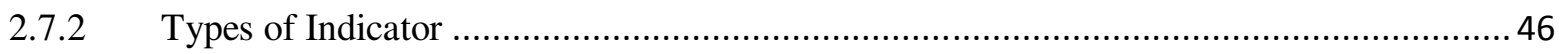

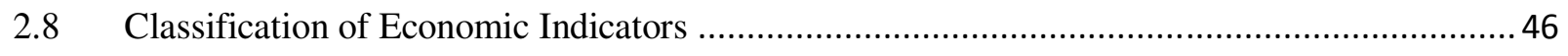

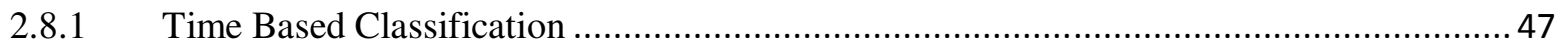

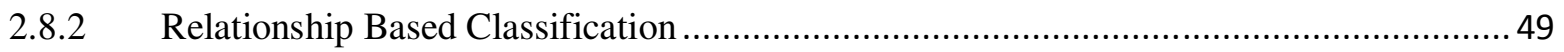

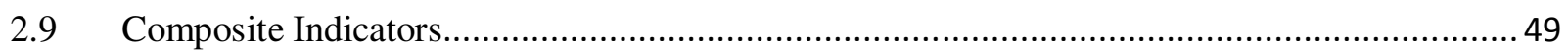

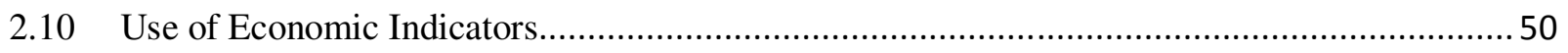

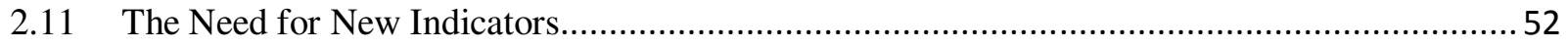

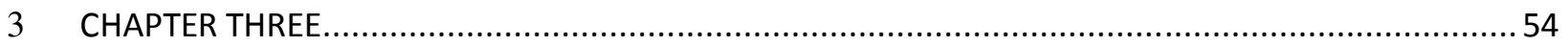




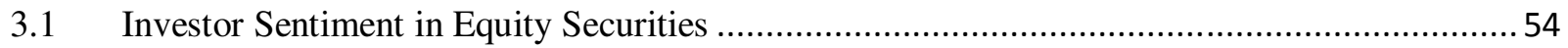

3.2 How Investor Sentiment Affect Stock Price ................................................................. 56

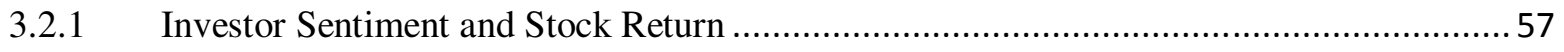

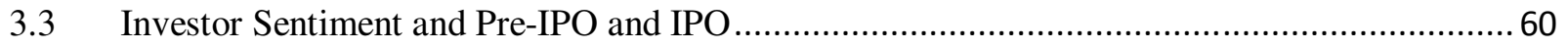

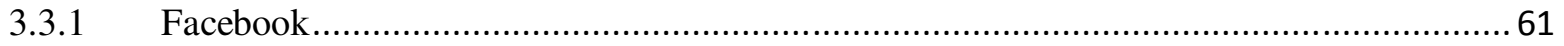

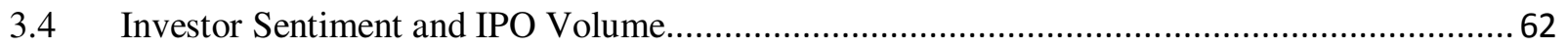

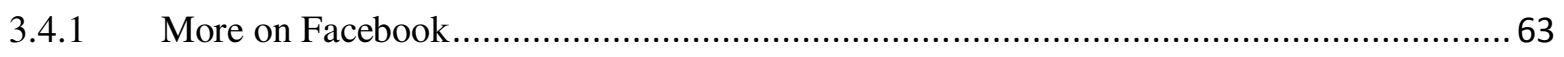

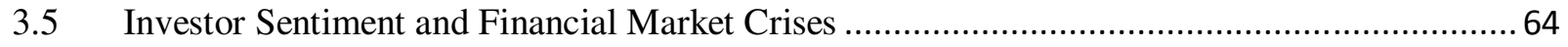

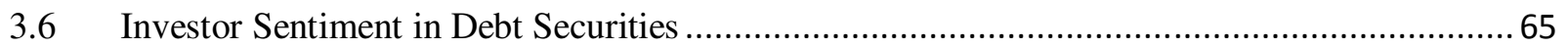

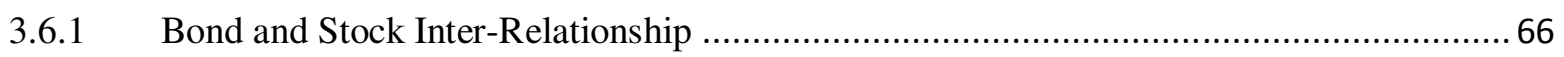

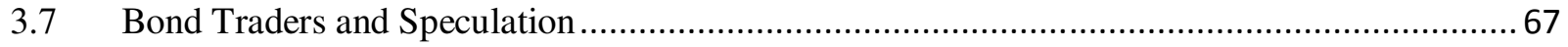

3.7.1 Market Data Measure: Put/Call Ratio............................................................................ 68

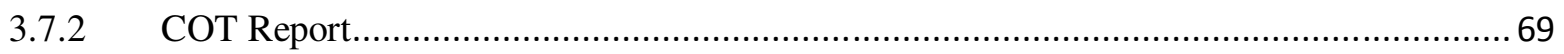

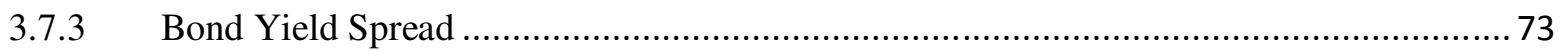

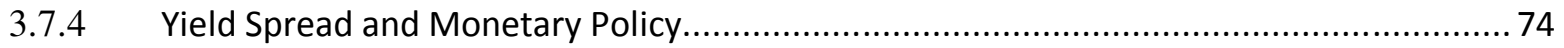

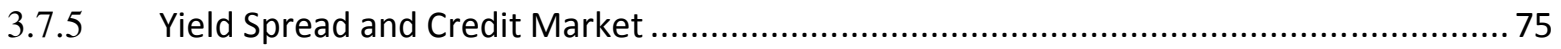

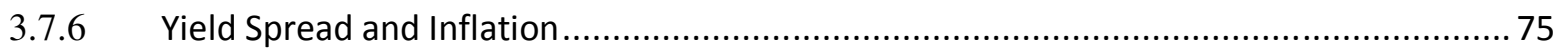

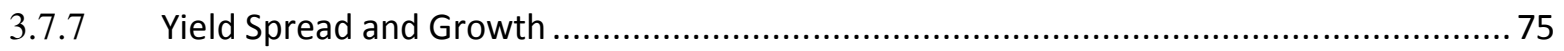

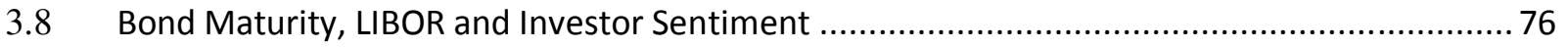

3.9 Investor Sentiment and Sovereign Bond Yield Spreads ................................................... 76

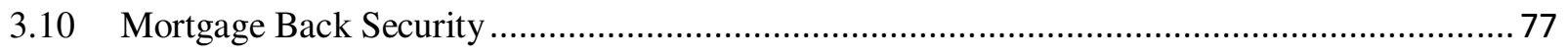

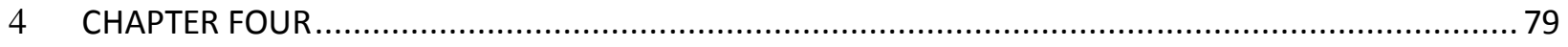

INVESTOR SENTIMENT IN MANAGED FUNDS AND ALTERNATIVE INVESTMENTS ................................ 79

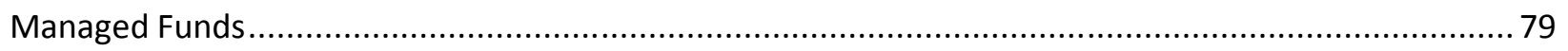

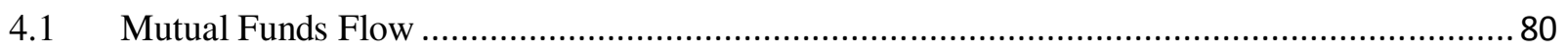

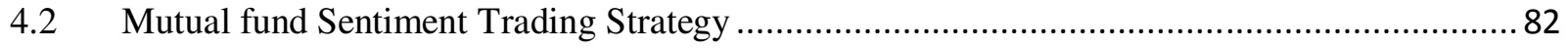

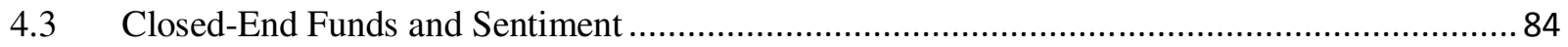

4.4 INVESTOR SENTIMENT IN ALTERNATIVE INVESTMENTS .................................... 86

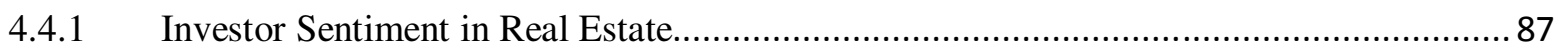

4.4.2 Sentiment in Public and Private Real Estate Market ..................................................... 89

4.4.3 Investor Sentiments and Hedge Funds.............................................................. 91 


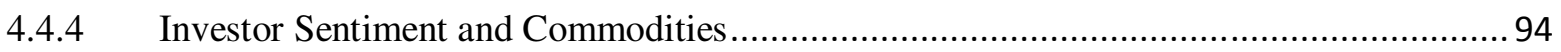

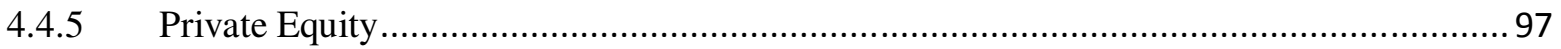

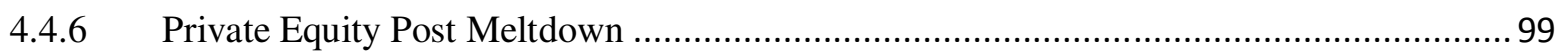

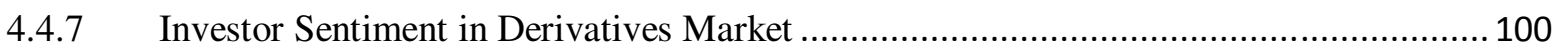

4.4.8 Investor Sentiment and Energy Futures.................................................................. 103

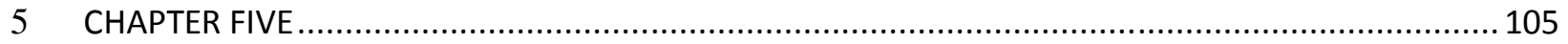

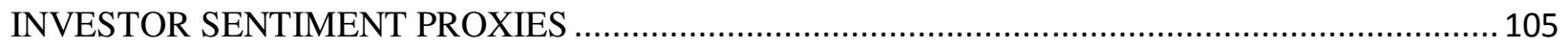

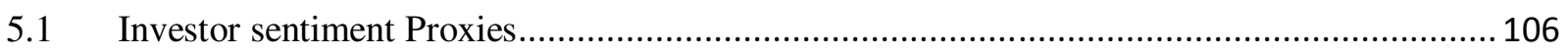

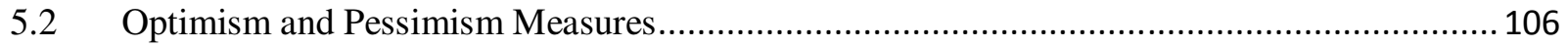

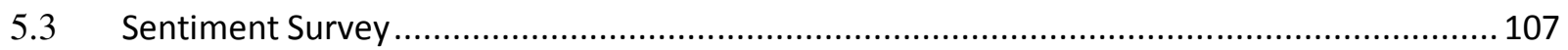

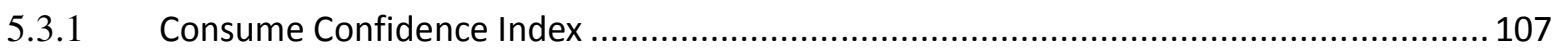

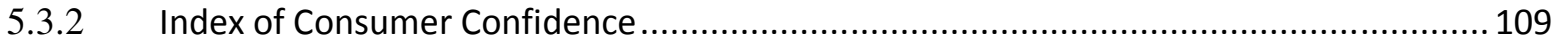

5.3.3 Bloomberg Consumer Comfort Index................................................................... 111

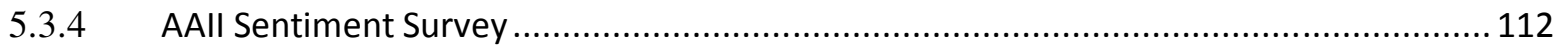

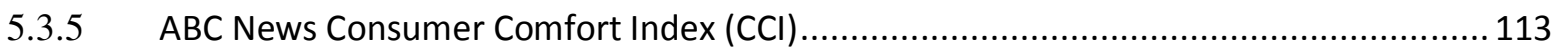

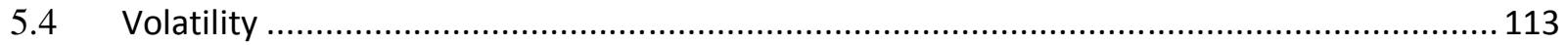

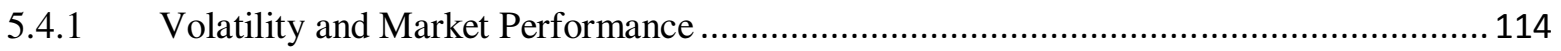

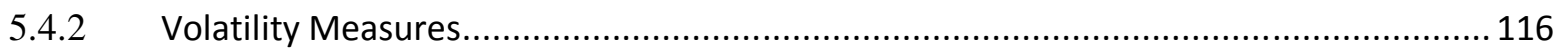

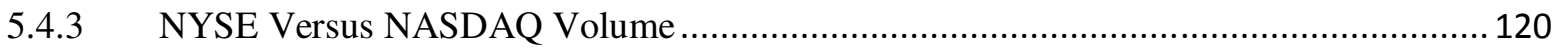

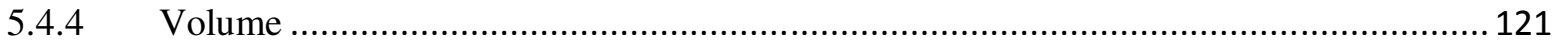

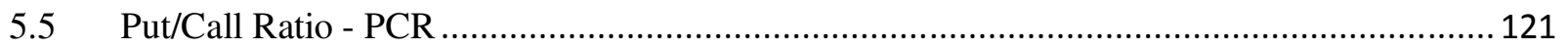

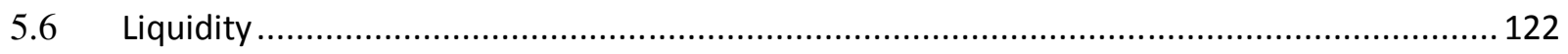

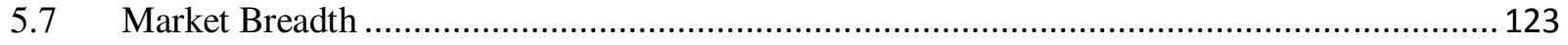

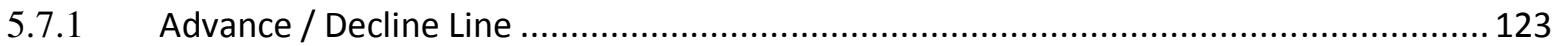

5.7.2 New High - New Low Ration ...................................................................... 124

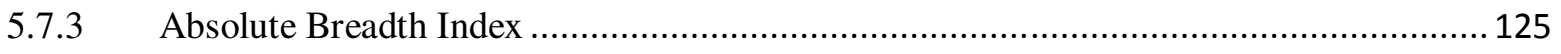

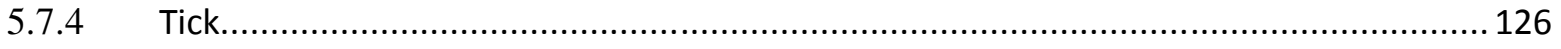

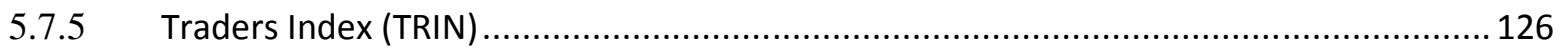

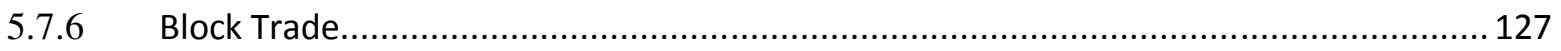

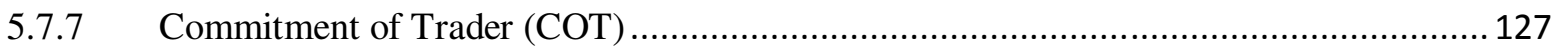

$5.8 \quad$ News Analytics and Investor Sentiments …................................................................ 129

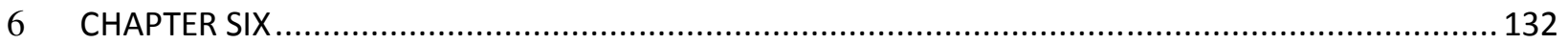




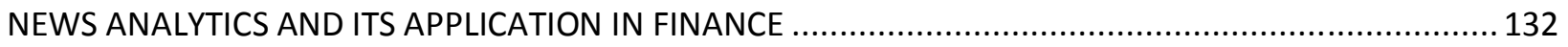

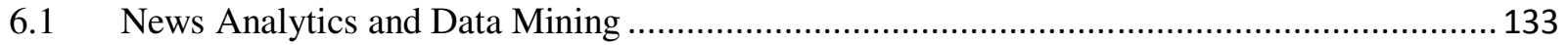

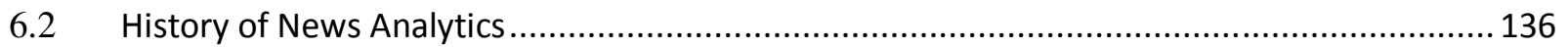

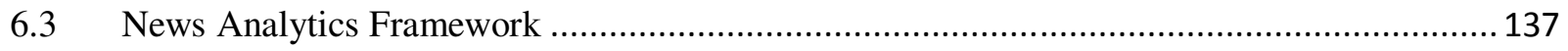

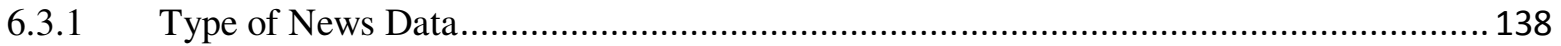

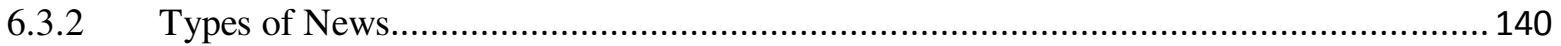

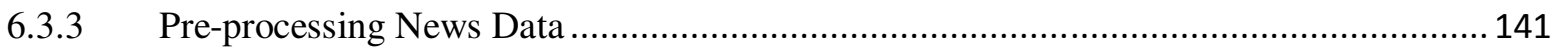

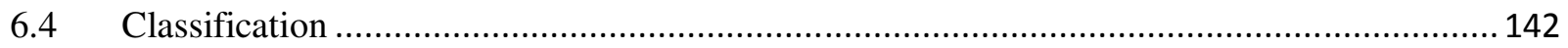

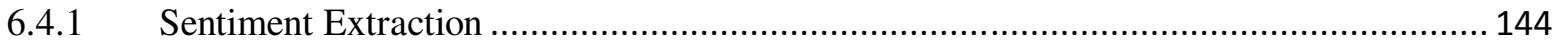

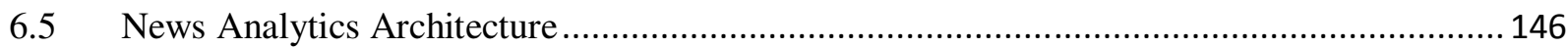

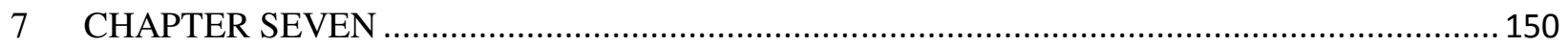

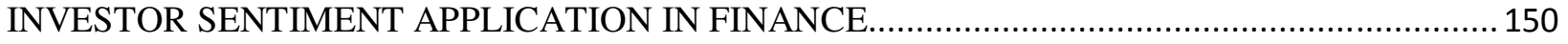

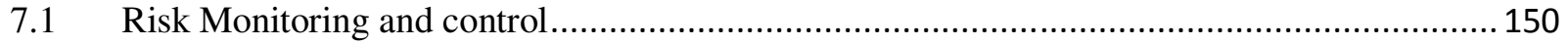

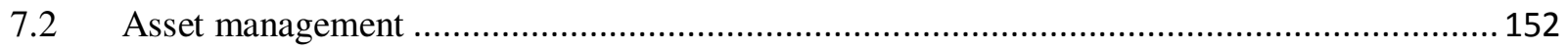

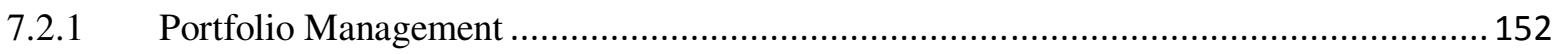

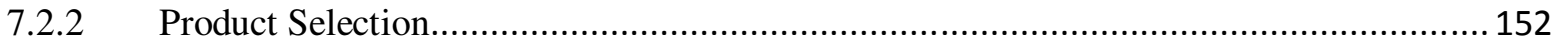

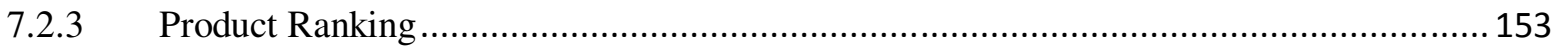

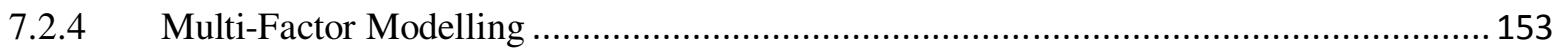

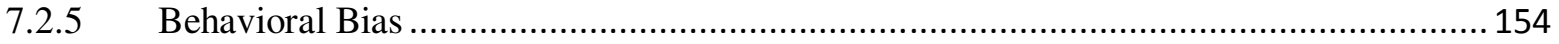

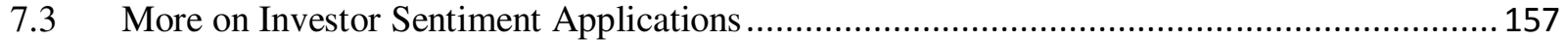

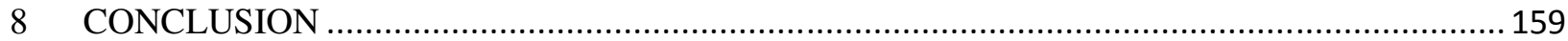

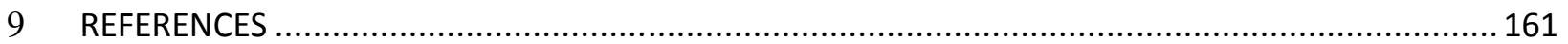




\section{LIST OF FIGURES}

Figure 1 Reactions of stock price to new information in efficient and inefficient markets (Source:

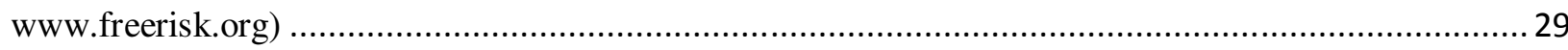

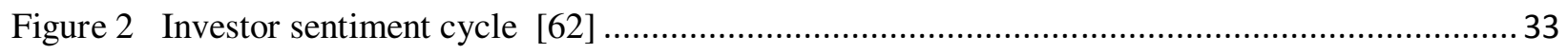

Figure 3 Historical graph of economic indicators (Source: www.twentythirdfloor.co.za)...................... 47

Figure 4 AAII Bullish sentiment 2009 - 2011 (Source: AAII) ........................................................ 58

Figure 5 Facebook Pre-IPO investor sentiment (Source: General Sentiment 2012) ..............................62

Figure 6 University of Michigan Consumer sentiment (Source: www.calculatedriskblog.com)............ 109

Figure 7 Index of consumer confidence (Source: Conference Board of Canada) .................................. 110

Figure 8 Bloomberg Confidence Index (Source: www.pollingreport.com) ....................................... 111

Figure 9 AAII Survey vs Log DJA (Source: www.kirklindstron.com) ............................................ 112

Figure 10 Relationship of volatility and market returns (S\&P 500 Index: 1962 - Dec 31, 2011) [203].. 115

Figure 11 Percentage change in DJIA (Source: Vanguard \& DJIA) ............................................... 116

Figure 12 Moving average with Bollinger band 2 standard deviation (www.stockchart.com)............... 117

Figure 13 VIX and S\&P 500 Index (1990 - 2011) [207] .......................................................... 118

Figure 14 Five years change in CBOE NASDAQ-100 volatility vs. S\&P 500 Index [208].................. 119

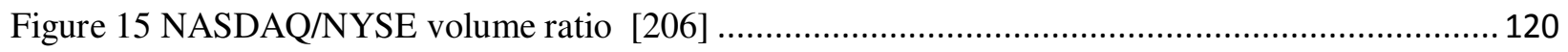

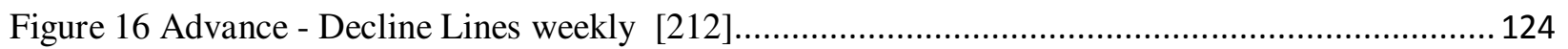

Figure 17 Stock Market diary (Source: Wall Street Journal) ....................................................... 125

Figure 18 Commitment of Traders historical graph showing open interest, large and small speculators and

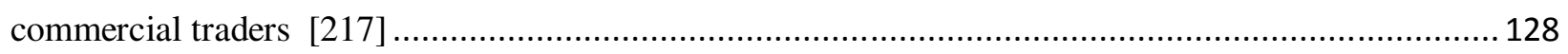

Figure 19 Architecture of typical data mining system [218] .......................................................... 135

Figure 20 Architecture of web crawler (Source: http://pravin.insanitybegins.com) ............................. 139

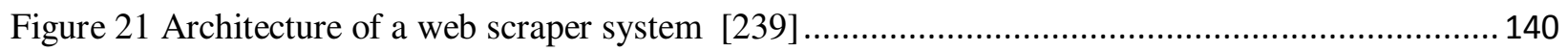

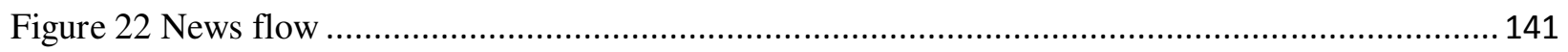

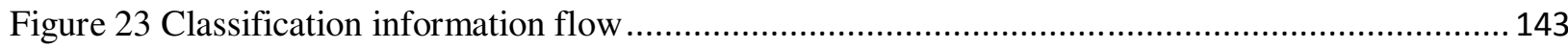

Figure 24 Schematic of the Algorithms and system design used for sentiment extraction [247] ........... 145

Figure 25 Information flow and computer architecture of News Analytics ..................................... 147

Figure 27 Relationship between S\&P and Ravenpack Sediment Index (Ravenpack) ......................... 148

Figure 29 Average Stock price reaction after negative neutral and positive news events (Source:

RavenPack, Macquarie Capital (USA), May 2009) ........................................................................ 156 


\section{CHAPTER ONE}

\section{INTRODUCTION}

The prevailing notion in society is that wealth brings comfort and luxury, so it is not surprising that there have been so much work done on ways to forecast the markets. From the day the equity market was born, the movement of forecasting has been the interest for years since it can yield significant profits and loss. There are several motivations for trying to forecast stock market prices. The most basic of these is financial gain. Any system that can consistently pick winners and losers in the dynamic market place would make the owner of the system very wealthy. Thus, many individuals including researchers, investment professionals, and average investors are continually looking for this superior system which will yield them high returns.

There is a second motivation in the research and financial communities. It has been proposed in the efficient market hypothesis (EMH) that markets are efficient in that opportunities for profit are discovered so quickly that they cease to be opportunities. The EMH effectively states that no system can continually beat the market because if this system becomes public, everyone will use it, thus negating its potential gain [1] One of the bigger debates in financial economics concerns the possible effect of investor sentiment on asset prices. Many respected researchers have entered on both sides of the argument as to whether the stock price run-up and subsequent market collapse of 1929 was rational or not [2] [3] Perhaps "irrational exuberance" [4] drove prices above fundamental values. The existence of systematic mispricing in the market remains contentious because of the difficulty in examining the issue empirically. The absence of precise valuation models for stocks makes it difficult to measure deviations from theoretical prices. Similar problems arise from the difficulty in measuring investor sentiment.

Recent papers identify examples that are difficult to reconcile with rational pricing. [5] Examine 3Com's spinoff of Palm. In this transaction, the market valuations of the companies implied the 3Com share less the claim on Palm was $\$ 63$, a violation of the law of one price. [6] Discusses the heavy trading in Massmutual Corporate Investors (ticker MCI) around Worldcom's acquisition 
of MCI Communications (ticker MCIC). Apparently, these investors were unable to determine the correct ticker symbol and mistakenly placed trades in Massmutual, and their trading drove the price away from its intrinsic value. [7] Discuss a variety of examples from the Internet sector in developing a "strong, circumstantial case against market efficiency." While these papers provide interesting evidence of misvaluation, they are specific to either a few companies or an industry that is admittedly difficult to value. [8] In the financial markets, trading is traditionally influenced by information, and, especially in computerised markets, trade execution is nowadays algorithmically triggered by certain signals or events. Market movements can be very sensitive to new information. Therefore, gathering and understanding news announcements of public, company-specific, macroeconomic or political sources is essential for successful forecast.

In my opinion, this is the first research to cohesively present investor sentiment and investor sentiment techniques applied to all asset classes in the financial markets. It provides a detail foundation to new and advanced researchers into the growing field of investor sentiment study and news analytics. This survey will serve as a good base for investor sentiment evaluation and comparative studies of sentiment effect in all asset classes. This thesis has been organized into seven chapters. Chapter one introduces forecasting and provides a summary of previous work on forecasting, why we forecast, what to and not to do with a forecast. Chapter two provides a background and literature review on investor sentiment. It also covers investor sentiment indicators. Chapter three discusses the presence of investor sentiment in the equity and debt market while chapter four presents investor sentiment in managed funds and alternative investments. Chapter five discusses how investor sentiment is measured. Chapter six introduces news analytics and mining of investor sentiment. Chapter six concludes with a discussion on the structure and implementation process of news analytics. The last chapter focus on the application of investor sentiment data in finance.

\subsection{Forecasting}

The ability to accurately forecast the future is fundamental to many decision processes in planning, scheduling, purchasing, strategy formulation, management and investing. Market movement forecasting has become an important field of research in finance because of obvious reasons but it is a very difficult task as its dynamics are complex and non-linear. For instance, stock return series are generally noisy and may be influenced by many factors; such as political 
events, firms' policies, general economic conditions, commodity price change, interest rate, investors expectations, institutional investors choices, movements of other stock market and psychology of investors. The equity and debt market are public market where large amount of capital are deployed and traded around the globe. Many researchers claim that the market is dynamic, non-linear, complicated and chaotic in nature but it is forecastable. There is no consensus as to how well, if possible, financial time series are forecastable and how to forecast them. Linear methods are easy to develop and implement and they are also relatively simple to understand and interpret. However, linear models have serious limitation in that they are not able to capture nonlinear relationships in the data. The application of linear models to complicated nonlinear relationships is often unsatisfactory. [9] As a result of the dynamic, nonlinear, complicated, nonparametric, and chaotic nature, the time series are multi-stationary, noisy, random, and has frequent structural discontinuities.

Some say market return forecastability is contrary to market efficiency. The canonical random walk model used historically by researchers and operators, popularized by [10] implies that future stock returns are unforecastable on the basis of currently available information. While the random walk model is consistent with market efficiency, so is a forecastable return process, since forecastability is consistent with exposure to aggregate risk. It is only when the risk-adjusted return - after further adjusting for transaction costs and other trading frictions (e.g., liquidity and borrowing constraints, research costs) - becomes economically positive can we say that the market is inefficient. Theoretically, asset returns are functions of the state variables of the real economy, and the real economy itself displays significant business-cycle fluctuations. If the quantity and price of aggregate risk are linked to cyclical fluctuations, then we should expect return forecastability, even in an efficient market. But theory does impose certain bounds on the maximum degree of return forecastability consistent with market efficiency. To the extent that return forecastability exceeds these bounds, it can be interpreted as evidence for market inefficiency stemming from, for example, information processing limitations and/or the types of psychological influences emphasized in behavioral finance.

Forecasting has long been important to marketing practitioners. In 1987, the survey of 134 companies in the United States found that 99 percent prepared formal forecasts when they used 
formal marketing Plans. In 1975, 93 percent of the companies sampled indicated that sales forecasting was one of the most critical' aspects, or a 'very important' aspect of their company's success. The survey of 353 marketing directors from British textile firms, found that sales forecasting was the most common of nine activities on which they reported [11]. Several intelligent systems have in recent years have been implemented for modeling expertise, decision support and complicated automation tasks. New architecture for graded forecasting using an arrayed probabilistic network (APN) and a "mistake chart" to compare the accuracy of learning systems against default performance based on a constant forecast has been developed. Probabilistic fuzzy systems to developing financial models where one can identify different states of the market for modifying ones actions have been proposed. Takagi-Sugeno (TS) probabilistic fuzzy systems that combine interpretability of fuzzy systems with the statistical properties of probabilistic systems has been experimented. If it is truly unforecastable and irregular, why are we interested and are spending millions of dollars in the development of algorithms for to forecast irregularity?

It is a disappointing that collectively, forecasting experts have not been able to improve forecasts more since this venture over two decades and half ago. The level of forecasting skill achieved so far seems out of proportion to the enormous efforts and resources devoted to the research and forecasting. This leads to the pessimistic view that forecaster's ability to forecast accurately is so low that current skill is already close to its limit. However, some recent studies by the Organization for Economic Co-operation and Development (OECD) [12] have shown reasons for optimism and prospects for further advances. The fault is not in the stars but in us, and that the shortcomings in models and data assimilation schemes are the principal problem [13], is the conclusion reached by experts in the field of forecasting. For the uninitiated the reason irregularity is unforecastable lies in the name but the science and art of forecasting disagree. Dake Chen, a director of the State Key Laboratory of Satellite Ocean Environment Dynamics in Hangzhou, China, and also Doherty Senior Research Scientist at the Lamont-Doherty Earth Observatory of Columbia University in New York, USA concur. 


\subsubsection{What is Forecasting?}

A forecast is any statement about the future. Such statements may be well founded, or lack any sound basis; they may be accurate or inaccurate on any given occasion, or on average; precise or imprecise; and model-based or informal. Forecasts are produced by methods as diverse as welltested systems of hundreds of econometrically-estimated equations, through to methods which have scarcely any observable basis. Consequently, forecaster put their focus on extrapolating from past and present information using systematic forecasting methodology. While many such extrapolative methods do at least exist, they face the difficulty that the future is uncertain - for two reasons. The first is uncertainty where we understand the probabilities involved, so can incorporate these in (say) measures of forecast uncertainty. The second is uncertainties we do not currently understand, and is the more serious problem, particularly in stock market where nonstationary behavior is the norm. It is very important for the users of forecast to remember that, forecasts are just forecast and they are subject to error, so judgement must be used. Frederick L. Joutz, a director of program on forecasting at The George Washington University, quoted Henry (1999) and Maxine Singer (1997) saying, Two reasons forecasting the future is uncertain. Because of the things we don't know [that] we don't know, the future is largely unforecastable and secondly because some developments can be anticipated, or at least imagined, on the basis of existing knowledge. The first source is the basic problem. The second one can make us too confident or arrogant of our ability to forecast. [14]

\subsubsection{Forecast Insanity}

Since it is merely a statement about the future, anything can be forecasted, ranging from next month's rate of consumer price inflation, tomorrow's weather patterns, the average rise in sea levels by the end of the third millennium, through the earth's population at the same date, to the value of the Dow Jones index at the start of 2014. The claim is not that the resulting forecasts are necessarily useful in any sense: consider, for example, a forecast that the first Extra Terrestrial to land on Earth will be six meters tall, blue, and will arrive in New York on July 4th, 2276 to celebrate the quincentenary of the U.S.A. Even if such a claim were to prove correct, it would be of no value for the next 260 years; and of course, it is anyway essentially certain to be incorrect.

In response, the Supreme Court rendered the opinion that "the professional literature uniformly establishes that such forecastings are fundamentally of very low reliability, and that psychiatric 
testimony and expertise are irrelevant to such forecastings. In view of these findings, psychiatric testimony on the issue of future criminal behavior only distorts the fact-finding process." [15] In a 1976 article in the Rutgers Law Review, authors Henry Steadman and Joseph Cocozza had also concluded, "There is no empirical evidence to support the position that psychiatrists have any special expertise in accurately forecasting dangerousness." [16] With 20 more years of research to draw from, Terrence Campbell wrote in a 1994 article in the Michigan Bar Journal, "The accuracy with which clinical judgment forecasts future events is often little better than random chance. The accumulated research literature indicates that errors in forecasting dangerousness range from 54\% to 94\%, averaging about 85\%." [17] In 2002, Kimio Moriyama, vice president of the Japanese Psychiatrists' Association, further admitted, “... [It] is impossible for [psychiatric] science to tell whether someone has a high potential to repeat an offense." [18]

\subsubsection{Searching for Forecasting Cure}

Fundamental and technical analyses are the first two methods used to forecast stock prices. Various technical, fundamental, and statistical indicators have been proposed and used with varying results. However, no one technique or combination of techniques has been successful enough to consistently "beat the market". With the development of neural networks, researchers and investors are hoping that the market mysteries can be unravelled. Although it is not an easy job due to its nonlinearity and uncertainty, many trials using various methods have been proposed, for example, artificial neural networks, fuzzy logic, support vector machine, evolutionary algorithms, statistic learning, Bayesian belief networks, hidden Markov model, granular computing, fractal geometry, and wavelet analysis. Recently, a novel model named procedural neural networks (PNNs) was proposed to deal with spatiotemporal data modeling problems, especially for time series with huge data of multidimensional nature. Different from the traditional multilayer back propagation neural network (BNNs), the data in PNN are accumulated along the time axis before or after combining the contribution of the space components. While collecting these data, different components do not have to be sampled simultaneously, but in the same intervals. The following methods have also been proposed for forecasting the economy and stock market. 


\subsection{Overview of Market Forecasting Methods}

Forecasting method is based on the timescale involved in the forecast i.e. how far forward into the future the forecast is for. Short, medium and long-term are the usual categories but the actual meaning of each will vary according to the situation that is being studied, e.g. in forecasting the price of stock in order manage risk 1 - 6 months would be short-term and 5 years would be longterm, while in forecasting consumer demand in many business situations up to one months would be short-term and over a couple of years long-term. The basic reason for the above classification is that different forecasting methods apply in each situation, e.g. a forecasting method that is appropriate for forecasting the price of sock for day trader (a short-term forecast) would probably be an inappropriate method for forecasting price in one years time (a long-term forecast). In particular note here that the use of numbers (data) to which quantitative techniques are applied typically varies from very high for short-term forecasting to very low for long-term forecasting when dealing with business situations.

In the literatures there are a number of methods applied to accomplish forecasting but here the focus is on equity market. The methods applied to forecasting by economist use various approaches, include: guessing, "rules of thumb," or "informal models"; expert judgment; extrapolation; leading indicators; surveys; time-series models; and econometric systems. With the growth in the field of financial engineering more methods are being introduced to enhance the accuracy for forecast. These methods range from highly informal ways (e.g. the study of a chart with the fluctuation of the market) to more formal ways (e.g. linear or non-linear regressions). Generally the techniques are categorized as fundamental analysis, technical analysis, time series forecasting, machine leaning, investor sentiment, etc.

\subsubsection{Fundamental Analysis}

Fundamental analysis involves assessing the short-, medium- and long-range prospects of different industries and companies. It involves studying capital market conditions and the outlook for the national economy and for the economies of trading partners to shed light on securities' prices. By studying the overall economic conditions, the company's competition, and other factors, it is possible to determine expected returns and the intrinsic value of shares. This type of analysis believes that the price of a company's share and the anticipated return on investment depends on company's intrinsic value. As new information is released pertaining to 
the company's status, the expected return on the company's shares will change, which affects the stock price.

The advantages of fundamental analysis are its systematic approach and its ability to forecast changes before they show up on the charts. Companies are compared with one another, and their growth prospects are related to the current economic environment. This allows the investor to become more familiar with the company. Unfortunately, it becomes harder to formalize all this knowledge for purposes of automation; and interpretation of this knowledge may be subjective. Also, it is hard to time the market using fundamental analysis. Although the outstanding information may warrant stock movement, the actual movement may be delayed due to unknown factors or until the rest of the market interprets the information in the same way. [19] Fundamental analysis has its roots in a value investing approach. In his book "The Intelligent Investor", Benjamin Graham, the father of value investing, refers to fundamental analysis as security analysis (Graham, 1949). He asserts that fundamental analysis deals with the past, the present, and the future of a given security. It identifies business' attractiveness for purchase by estimating its intrinsic value. The process of fundamental analysis is a useful tool for identifying stocks available at a discount to their intrinsic value. Graham has presented the following expression to estimate the intrinsic value of a company:

$$
\text { Value } \approx \operatorname{EPS}(8.5+g)
$$

Where EPS is a trailing twelve-month earnings-per-share (EPS), $g$ is the expected growth in the EPS over the next 7 to 10 years. Since the value computed using equation 1, it cannot be exact. In order to mitigate the effects of inaccurate estimates, Graham advocates the use of Margin-ofSafety (MoS). The MoS is a powerful concept that acts as a risk-inhibitor in the investing process. It provides a price target at which stock may be considered for buying. The goal is to buy a stock at a price sufficiently low compared to its intrinsic value such that errors in the estimation of the intrinsic value can be overcome by a significant upside potential. Value investors believe that the market is irrational when the price is lower than the intrinsic value. Although fundamental analysis can be used as a good leading indicator of a stock future performance, it has several shortcomings that prohibit its use as a stand-alone-tool. The first 
shortcoming is the process and logic of valuation. The equation given by Graham is only an approximation to the actual value and hence, it is probabilistic in nature. Further, it relies on the estimates of EPS growth rate over a period of 7 to 10 years. These estimates are subjective and frequently revised by analysts following a particular company. The estimates change frequently for a company or an industry group due to reasons out of investor's control. The second short coming lies in the assumption that the market price will eventually approach intrinsic value. However, there is limited information in the fundamental analysis to forecast price action. The second assumption can be valid only if the investor has a reliable forecast of the stock price. Such a forecast would enable investors to time their entry more precisely.

Fundamental analysis means studying everything, other than the trading on the securities markets, which can have an effect on a security's value: macroeconomic factors, industry conditions, individual company financial conditions, and qualitative factors such as management performance. By far the most important single factor affecting the price of a corporate security is the actual or expected profitability of the issuer. Are its profits sufficient to service its debt, to pay current dividends, or to pay larger dividends? Fundamental analysis pays attention to a company's debt/equity ratio, profit margins, dividend payout, earnings per share, sales penetration, market share, interest, asset and dividend coverage, product or marketing innovation, and the quality of its management.

\subsubsection{Technical Analysis}

Technical analysis is the process of analyzing historical market action in an effort to determine probable future price trends. Technical analysts view the range of data studied by fundamental analysts as too massive and unmanageable to pinpoint price movements with any real precision. Instead, technical analysts focus on the market itself. This method studies, and plot on charts, the past and present movements of prices, the volume of trading, statistical indicators and, for example in the case of equity markets, the number of stocks advancing and declining in other to identify recurrent and forecastable patterns that can be used to forecast future price moves. Technical analysis also attempt to probe the psychology of investors collectively or, the "mood" of the market. The idea behind technical analysis is to determine probable future price trends and market action which includes three primary source of information - price, volume and time. 
As some people say securities never sell for what they are worth but for what people think they are worth. It is very important to understand that market participants anticipate future development and take action now and their action drive the price movement. Since stock market processes are highly nonlinear, many researchers have been focusing on technical analysis to improve the investment return. [20]They contend that because most investors fail to learn from their mistakes, identifiable patterns exist. Some of the mostly used indicators are as follows:

- Relative Strength Index

- Money Flow Index

- Moving Average

- Stochastic Oscillator

- Moving Average Convergence/Divergence (MACD)

- Candle Stick for stock forecast:

- Fibonacci for Stock forecast

- New High/New Low

- Bollinger Bands

\subsubsection{Time Series Forecast}

The traditional time series forecasting analyzes historic data and attempts to approximate future values of a time series as a linear combination of the historic data. The recurrence relation can then be used to forecast new values in the time series, which hopefully will be good approximations of the actual values. Time series forecasting analyzes past data and projects estimates of future data values. Basically, this method attempts to model a nonlinear function by a recurrence relation derived from past values. The recurrence relation can then be used to forecast new values in the time series, which hopefully will be good approximations of the actual values. To forecast an observed time series $x_{1}, x_{2}, \ldots, x_{N}$. and wish to forecast future values such as $x_{N+H}$. The integer $\mathrm{h}$ is called the lead time or the forecasting horizon (h for horizon) and the forecast of $x_{N+h}$. made at time $\mathrm{N}$ for $\mathrm{H}$ steps ahead will be denoted by $x_{N(h)}^{*}$. Note that it is essential to specify both the time the forecast is made and the lead time. Some of the literature does not do this and instead uses an ambiguous notation such as $x_{N+h}^{*}$ for forecasts of $x_{N+h}$. regardless of when the forecast was made. 
Generally, this procedure computes forecasts from present and past values. As such it may simply be an algorithmic rule and need not depend on an underlying probability model. Alternatively it may arise from identifying a particular model for the given data and finding optimal forecasts conditional on that model. [21] In econometrics there are two basic types of time series forecasting: univariate (simple regression) and multivariate (multivariate regression). These types of regression models are the most common tools used in econometrics to forecast time series. The way they are applied in practice is that firstly a set of factors that influence (or more specific is assumed that influence) the series under forecasting is formed. [22] While univariate methods forecasts depend only on present and past values of the single series being forecasted, possibly augmented by a function of time such as a linear trend, Multivariate methods forecasts a given variable depend, at least partly, on values of one or more additional time series variables, called forecastor or explanatory variables.

Multivariate forecasts may depend on a multivariate model involving more than one equation if the variables are jointly dependent. Multivariate models are univariate models expanded to discover casual factors that affect the behavior of the data. [23] As the name suggests, these models contain more than one variable in their equations. Regression analysis is a multivariate model which has been frequently compared with neural networks. More generally a forecasting method could combine more than one of the above approaches, as, for example, when univariate or multivariate forecasts are adjusted subjectively to take account of external information which is difficult to express formally in a mathematical model. Overall, time series forecasting provides reasonable accuracy over short periods of time, but the accuracy of time series forecasting diminishes sharply as the length of forecasting period increases.

\subsubsection{Machine Learning Methods}

Several methods for inductive learning have been developed under the common label "Machine Learning". All these methods use a set of samples to generate an approximation of the underling function that generated the data. The aim is to draw conclusions from these samples in such way forecast stock market indexes and stock prices. A stock market index represents the movement average of many individual stocks; an index reflects mainly market movement rather than movement of a stock. Firm characteristics are not taken into consideration in the forecasting process. To overcome this limitation, researchers have developed models to forecast individual 
stock prices. As such, soft computing techniques may be and they have been applied to diverse markets to forecast either indexes or stocks, regardless of their daily trading volume. For instance, a number of applications have been proposed to forecast stock market returns with macroeconomic variables with the use of neural networks and Bayesian networks and support vector machines. On the other hand, technical indicators have also been used to forecast stock market movements using neural networks, adaptive fuzzy inference system, and fuzzy logic. [24]

For a list some machine learning methods see [25]. It contributed a cohesive presentation and classification of soft computing techniques applied to different stock markets that may be used for further analysis and evaluation, as well as comparative studies. This research focused on applications of currently available intelligent techniques to forecast stock market indexes and stock prices. An obvious benefit of the study is that if one applies the specifically derived models to the same stock market, stock(s) and/or portfolio(s), valuable results will be obtained, which, when analyzed, may offer additional information to market behavior, correlation among factors influencing performance, input data sensitivity, among other things. Many literatures concluded that neural networks and neuro-fuzzy models are suitable for stock market forecasting. Experiments demonstrate that soft computing techniques outperform conventional models in most cases. They return better results as trading systems and higher forecasting accuracy. The only problem is the difficulties with defining the structure of the model (the hidden layers the neurons etc.). For the time being, the structure of the model is a matter of trial and error procedures.

\subsection{Why Forecast?}

While some expert forecasters claimed to have forecast the collapse of the stock market in 1929, no guru divined the ensuing depression. At the outset, the Great Depression appeared to be an ordinary, though sharp, recession. Most economic indicators had declined almost continuously from August 1929 until the end of 1930. Although consumers and investors seem to have become unusually uncertain after the 1929 stock market crash, many businessmen seemed to believe that it would be only a short contraction. In retrospect, this bullishness amazes, as the only relief from decline was an increase in industrial production and personal income in the first quarter of 1931. Mirroring this positive outlook of some business leaders, Irving Fisher of Yale 
and the forecasters at the Harvard Economic Service remained extraordinarily optimistic two years into the greatest economic recession of the twentieth century. [26]

If the professionals in various fields and market strategist are not exactly sure about their forecast performance then what is the point of asking them what will happen in the market over a period of time? When most of them put out the forecasts, some typically get them wrong. The expert forecasters are not the problem but the user of the forecast. This is how APICS dictionary defines forecast "an estimate of future demand. A forecast can be determined by mathematical means using historical data; it can be created subjectively by using estimates from informal sources; or it can represent a combination of both techniques." Forecasters use very systematic approaches: statistical quantitative methods, qualitative methods, or a combination of methods, and it can be based on extrinsic or intrinsic factors. Various forecasting techniques attempt to forecast one or more of the four components of demand: cyclical, random, seasonal, and trend. Because they have systematic approach to forecasting, they know why they are wrong and how to correct or improve their forecasting procedures. What the experts do is to provide the consumers with "An Estimate". Any forecast will include uncertainty and will be subject to many variables, such as the economy, changing tastes, new technology and competitive activities. Complete accuracy is not important, as forecasting is about anticipating the trends and recognising the unexpected early and putting in place an effective reaction.

Forecasts are important for meeting market demand, managing lead-times, reducing inventory, avoiding over production, minimising, stock-outs, supporting, budgeting, increasing buying power, scheduling resources, guiding individual and company strategies, defining promotions, maintaining pricing structure, measuring awareness of demand, driving continuous improvement, creating stability in the supply chain and many more. The type of Forecast solution that is needed will vary depending in the reasons selected but the key drivers will probably be to:

- Reduce uncertainty: Forecast future demand and as such reduce uncertainty, leading to reduced costs, increased responsiveness and improved customer service.

- Anticipate change: Plan for future change and drive / support company strategy

- Improve communication between all departments and affiliates. 
- Drive continuous improvement and migrate to intelligent models.

- Provide elements of Realism to reduce inventories driven by fanciful sales targets

- Increase knowledge: Project production capacity, project future costs and revenues, compare forecast and actual to budget, evaluate marketing initiatives and decipher correlations between casuals and actual.

- Increase Profitability: forecasting helps in analysing trade trends and projecting resource requirements. Forecasting is important for every size of business, from the self-employed to the largest multi-national corporation. Fast, efficient and regular forecasts can help to create a more stable and profitable business.

\subsection{Measuring the Success or Failure of a Forecast}

A forecast might reasonably be judged successful if it was close to the outcome, but that judgment depends on how "close" is measured. For example, the statement that "the moon is exactly 5,000 miles away" is very precise but wholly inaccurate and taken literally would be associated with a forecast interval of length zero. On the other hand, the statement that "the moon lays between 1,000 and 1billion miles away" is correct, but very imprecise, having a huge forecast interval. It is apparent that accuracy and precision are two dimensions along which forecasts may be judged. Failure is easier to discern: a forecast is a failure if it is inaccurate by an amount that is large relative to its claimed precision. Thus, forecasters are squeezed between wanting accurate and precise forecasts, yet not claiming so much precision that they regularly fail. The notion of "unbiasedness," whereby forecasts are centered on outcomes, is used in technical analyses to measure accuracy; whereas that of small variance, so only a narrow range of outcomes is compatible with the forecast statement, measures precision. In principle, in any specific instance, the costs attached to bias and variance will depend on the purposes to which the forecast is to be put, via the costs of any actions taken on the basis of the forecast.

Unfortunately, no unique measure of a "winner" is possible in a forecasting competition involving either multi-period or multi-variable forecasts, which are the norm in economics forecasting say unemployment and inflation up to two years ahead for a "misery index." Surprisingly, that claim remains true even when the metric for "closeness" is agreed. To explore the difficulty of judging the winner of a forecasting competition further, consider two friends 
passing time while waiting at a bus-stop. Sue challenges Peter to forecast the behavior of a student who is standing inside the bus shelter: every 30 seconds they will both write in their diary a forecast for the next 30 seconds as to whether or not the student will have left. Sue realizes that she will only ever make a single mistake if she adopts the following strategy: always forecast that the current state will persist. When the student is there, she forecasts he will still be there in 30 seconds' time; and when he has left, she simply writes that. Thus, in the 5 minutes' wait before the student departs, Sue is correct 10 times, then wrong once, but thereafter correct for ever. Peter, however, is an economist, so he uses a "causal model": students stand at bus stops to get on buses.

Thus, if no bus approaches, Peter forecasts the student will stay; but when a bus appears, he forecasts the student will board the bus. Unfortunately, four different buses come by, and the student remains stubbornly at the bus stop - then his girlfriend appears on her motor bike, the student climbs on, and they go away. Peter is wrong four times in the 5 minutes, and if he stuck to his causal model, wrong ever after since the student never got on a bus! Sue wins easily: or does she? Substitute the phrase "the volcano will not explode" for "will remain at the bus stop," and the vacuous nature of Sue's forecast is clear, even if she did appear to win. On any reasonable loss function, the ability to anticipate a volcanic eruption, however imperfectly which her "no-change" forecast is inherently unable to do - should score highly. The appearance of winning is dependent on agreeing on a particular "metric," whereas only awarding a "win" for correctly forecasting the specific event could yield a different winner.

In addition to bias and variance considerations, point forecasts are often judged on criteria such as the efficient use of information. Also, forecasts often include forecast intervals, and sometimes of the complete density of outcomes, so these are required to be "well calibrated." Because it is seldom the case that only a single forecast exists of any economic phenomenon of interest, rival forecasts are often available to allow comparisons of one against the other, ex post. A natural focus of attention is then whether a combination of one or more forecasts is better than any one forecast alone, or whether one forecast contains all the useful information in another (so that it encompasses that forecast). We may wish to test whether, given a particular loss function, one forecast is statistically better than another, and further, whether allowing for the uncertainty inherent in the estimates of a model's parameters affects the inferences made. [14] 


\subsection{Economic Forecast}

This is economist's forecast for the outcome of a particular economic indicator or event, including the release of economic data, the contents of an important policymaker's speech, or the results of a planned central bank decision on interest rates. Economic forecasts are used both inside and outside the investment industry. Corporate budgets and government fiscal outlooks all start with a set of assumptions about the macroeconomic situation. Even if an economics department does not have a direct business relationship with companies or governments, that department's view on the economy and interest rates can still contribute to the general outlook. Companies develop hiring plans or capital expenditure plans based on forecast. Governments alter spending and taxation according to the economic outlook. Central banks, even though they tend to set monetary policy in an independent framework, also reconcile their outlook with the forecasts of private-sector economists.

Forecasts for many variables are created estimating underlying economic components based on available information and the expected relationship between this information and the variable(s) being estimated. Then the components are aggregated to produce a sector or macro forecast. The easiest illustration of a bottom-up model is the one used to forecast expenditure-based Gross Domestic Product (GDP), which is a measure of the total output of an economy based on spending. GDP is the sum of four variables. An easy way to build a bottom-up model of expenditure-based GDP is the use of spreadsheet program. The model contains variables for a given time period; the variables are used to forecast future values of GDP by using projections for each of the components and then adding them up.

Economic theory usually forms the basis for the relationships between variables in a particular model, such as the effect of higher interest rates on a forecast of automobile purchases. Since such purchases are normally financed through a personal loan or a lease, the level of interest rates determines the cost of financing and therefore the effective cost of the vehicle. Higher financing charges, without a commensurate increase in household income or a decrease in the prices of other items in the consumption basket, result in either a drop in demand for or spending on vehicles or a move away from other purchases to maintain the same level of spending on vehicles. [27] 


\subsubsection{Survey of Professional Forecasters}

The Survey of Professional Forecasters (SPF) is the oldest quarterly survey of macroeconomic forecasters in the United States. The survey began in 1968 as a joint project by the Business and Economic Statistics Section of the American Statistical Association (ASA) and the National Bureau of Economic Research (NBER) and was originally known as the ASA-NBER survey. The original objectives of the survey, is to provide an assessment of its achievements over its first twenty-two years. In June 1990 the Federal Reserve Bank of Philadelphia, in cooperation with the NBER, assumed responsibility for the survey, at which time it became known as the Survey of Professional Forecasters. The Survey of Professional Forecasters offers the actual releases, documentation, mean and median forecasts of all the respondents as well as the individual responses from each economist. The individual responses are kept confidential by using identification numbers. [28] [29]

\subsubsection{Historical Forecast Data}

- Baseline Variables

- Download one variable at a time

- Download all variables: mean, median, cross-sectional dispersion, and individual forecasts

- Probability Variables: Excel file containing mean probabilities of annual inflation and output growth falling into various ranges and the mean probability that quarter-overquarter output growth will be negative.

- Short-Term and Long-Term Inflation Forecasts: Expected inflation over the next year and the next 10 years.

- Anxious Index: The probability of a decline in real GDP in the quarter following the quarter in which the survey is taken.

\subsubsection{Special Variables and Special Questions}

- Extended Forecasts for Growth in House Prices

- Extended Forecasts for Real GDP, Unemployment, and 3-month and 10-year Treasuries

- Extended Horizon for Real GDP, Unemployment, and 3-month and 10-year Treasuries

- Extended Horizon for Real GDP and Unemployment

- Inflation Targeting 


\subsection{Forecasting Market Returns}

Many studies claim that considerable evidence exists and show that market returns are to some extent forecastable. Most of the research are conducted using data from well-established stock markets such as the US, Western Europe, and Japan. [30] For the US, several studies have examined the cross-sectional relationship between stock returns and fundamental variables. Variables such as earnings yield, cash flow yield, book to market ratio, and size have been found to have some power in forecasting stock returns in these cross-sectional studies. [31] [32] [33] are examples of such cross-sectional studies. These studies in general find positive relationships between stock returns and earnings yield, and between cash flow yield and book-to-market ratio, and a negative relationship between stock returns and size.

Fundamental variables are not the only type of cross-sectional variables that contain information for forecastability. Literatures also document that a stock's ranking in terms of its performance relative to the market can contain forecastability. Extreme loser have been shown to outperform the market over subsequent years. Three common risk factors - the overall market factor, factors related to firm size and book-to-market equity were identified that seem to explain average returns on stocks and bonds. [34] He found in his research that macroeconomic variables such as short-term interest rates, expected inflation, dividend yields, yield spreads between long and short-term government bonds, yield spreads between low grade bonds and high grade bonds, lagged stock price-earnings ratios, and lagged returns have some power to forecast stock returns. The changes in aggregate production, inflation, the short-term interest rates, the slope of term structure as measured by the return difference between long-term and short-term government bonds, and the risk premium as measured by the return difference between low grade bonds and high grade bonds are other macroeconomic factors that have some power to forecast stock returns.

Forecastability is not limited to stock returns. Literature have shown that expected returns are a function of business conditions in that the expected market premium is negatively related to the recent growth of economic activity proxies for the health of the current economy and positively related to the expected future growth of economic activity and its conditional variance. [35] studied the relation between changes in financial investment opportunities and changes in the economy. He provides additional evidence that variables such as the default spread, the term 
spread; the 1-month T-bill rate, the lagged industrial production growth rate, and the dividend price ratio are important determinants of future stock market returns. He interprets the ability of these variables to forecast future stock market returns in terms of their correlations with changes in the macroeconomic environment.

It is a well-established practice in the recent empirical finance literature to account for the forecastability of market returns given the investors information set by using macroeconomic variables that are public information. For example, an event study of insider trading by [36] shows that the omission of variables like lagged stock returns and previous interest rates could lead to misleading results. Stock returns forecastability given aggregate variables in the investors information set is a well-accepted fact. The question that remains is how to use the information set in an optimal way for forecasting and trading. [37]

\subsection{Use of a Forecast}

The financial crisis of 2008 that ultimately brought the world markets to the brink of failure heightened awareness of the many latent, destabilizing influences that can be triggered unexpectedly and then progress in unforecastable ways, culminating in periods of contagion and wild swings in asset values. The events also underscored the difficulty of forecasting financial markets by unleashing a series of cascading events that made visible hidden risks that were previously far from the minds of many investors. Although forecasters did their job but the investors failed in theirs. Even when a forecast is suspected to be wrong, it can still be very useful for investors. Forecasts can point toward the best and worst outcomes you can reasonably expect in a given time period and give an idea of how to set your confident level.

Apart from the methods already discussed, many forecasters use many other methods that are either more sophisticated or more diabolical methods beyond this book. For example, in ancient Mesopotamia, according to research by historian Alice Louise Slotsky, references are made of omens that were believed to forecast commodity prices, such as "the raven is for a steady market." The ancient Egyptians, Greeks, and Romans relied heavily on oracles to provide guidance; Astrology is one ancient forecasting tool that is still very popular. All great religions have sacred scriptures through which God speaks to believers. If God is all-knowing, eternal and has a plan for the world, then these texts are likely to contain accurate revelations of what lies 
ahead. Really, there are many forecast poured out weekly, monthly quarterly and annually, but which one is preferred? The ways forecasts are applied is most important.

\subsubsection{No Surprises, No Fun}

Forecasting the future accurately would take the fun of surprises out of life and since the goal of the human race is to be very happy, the Infinite Intelligence has intentionally made available the critical element of happiness - missed forecasts. So, no expert can reliably forecast the market and how investors will react consistently. Hence the cluster of forecasters around a safe consensus, a few stake out the risky but potentially lucrative ground of extremely bullish or bearish forecasts. If it turns out to be right, their accuracy will seem miraculous and they become famous. Sometimes forecasters miss huge surprises no one was expecting and overcompensate for small ones. According to Paul Kasriel, chief economist at Northern Trust, forecasters get caught up in what he called 'currentitis,' where one see some numbers that are not expected, so the forecaster must have missed something, and then he end up just getting constantly whipsawed around in response to the latest data. Does this suggest investors should abandon hope? To the contrary, it underscores the importance of acknowledging uncertainty, and then redirecting attention that was previously focused on efforts to forecast the future market movements toward the more achievable.

\subsubsection{A Decision Making Tool}

Forecasts are highly effective planning tool when use wisely as it can enable an investor to better understand where it is headed on a investment trajectory and provides a context from which to understand and evaluate other scenarios outcomes by evaluating future outcome based upon the variables presented by the forecast, plan major capital outlay say for risk management, plan for capital replacement needs and financial impact of adverse economic conditions or events. It is true that there has been a permanent increase in the unforecastability related to trying to forecast financial market activity. The primary implication is that, in order to maximize the probability of achieving optimal long-term capital growth, investors need to constantly ask and objectively consider the reaction of their portfolio to the scenario presented by the forecast, the range of possible market outcome that could develop, what can be done to the portfolio to maximize the

full spectrum of possibilities and what ongoing activities has to be incorporated to manage the portfolio risk as market condition evolve and asset valuation changes. 


\subsubsection{A Management Tool}

Forecasts must not be seen by investment manager as a tool for questioning or reassessing performance targets. Nor must they be used to demand changes or improvements. If forecasts are used to micro-manage or demand immediate action, then trust and confidence will rapidly evaporate. The only time such questions can fairly be asked is if forecasts show a significant change and such a change has not been explained beforehand. It is the investment manager's responsible to deal with problems in a portfolio and to reflect any corrective actions that they have taken in the revised forecasts. Again, if managers see that forecasts have an impact on their investment plans, they will be reluctant to present an unbiased picture. This was borne out at Danish petrochemicals company Borealis. [38] When rolling forecasts were introduced, the initial response of managers was to include their capital expenditure commitments thinking it would influence their approval ratings, but when they realized that this had no affect (these investment decisions were taken over by a quarterly review committee), they gradually adjusted their forecasts to reflect a more realistic view of essential project expenditure.

Investment managers should use forecasts to support strategy reviews, rather than simply check where they are against the investment plan. It is important to note that forecasts are now completely separate from any form of target-setting or performance measurement; thus managers can give their best estimates based on an open and unbiased view of the most likely future outcome.

\subsubsection{A Near Visibility Tool}

Forecasts are more accurate in the short-term than in the long-term. The Federal Reserve Bank of Philadelphia, which runs the Survey of Professional Forecasters, keeps a database of decades' worth of median and individual forecasts from dozens of experts on a wide range of economic and financial variables. Near-term forecasting is invariably confined to asking the question, "Am I on track to meeting my targets and, if not, what action do I need to take?" When forecasting variables such as inflation, unemployment and economic growth (as measured by the change in real GDP), the survey is considerably more accurate than just extrapolating the latest trend - but only for one or two calendar quarters. Over the following few months, the accuracy of most forecasts falls very quickly, according to research by Tom Stark, who 
manages the Philadelphia database, and other researchers. By one year into the future, the expert forecasts lose virtually all of their edge over a simple extrapolation of the recent trend.

\subsubsection{Expectation Adjusting Tool}

Investment complexity has increased exponentially as an ever-growing set of influences, factors and participants' interaction, impacting financial markets in ways that make errors in forecast inherent. This reflects a convergence of disparate factors that impact markets, investor behavior and the varied decision making processes of a growing number of participants transacting across markets globally. Does this mean these forecasts are worthless? By seeing how wide the potential range of error is, investors can adjust their own expectations to make sure they don't make an overconfident decision. Investors who like to hedge their bets, meanwhile, can get a better sense of how much protection they might want.

Forecast error statistics can be verified in the Philadelphia Fed website to see how accurate the past forecasts have been. For example, the average forecast for housing starts in 2011, for example, calls for an annual rate of 700,000 new units by year end, up from an estimated 554,000 in 2010. But, based on the past accuracy of the historical forecasts collected by the Philadelphia Fed, investor can be about $80 \%$ confident that the actual result will fall between 400,000 and 1,000,000. That means an investor would be wise to expect surprise - either the upside or the downside. Also, while the consensus forecast for the yield on the 10-year Treasury bond is $3.25 \%$ by the end of 2012 , based on the historical error rate, however, all that a prudent consumer of forecasts should conclude is that there is roughly an $80 \%$ chance that the 10-year bond yield will finish the year somewhere between $2.0 \%$ and $4.5 \%$. That, in turn, implies that bond prices could rise as much as $9 \%$ or fall as much as $10 \%$.

\subsubsection{A Risk Management Tool}

Uncertainty fuels the need for risk management, although risk if adequately measured, may be less than uncertainty, if measurable. Forecasting may be viewed as a bridge between uncertainty and risk if a forecast peels away some degrees of uncertainty. Therefore, forecasting continues to present significant challenges. [39] Financial market forecasts are and should be a key element of the investment manager risk management process. Financial market forecasters are frequently

inaccurate in consistently forecasting financial market movements. Does this mean that forecasts 
should be ignored and their role in the risk management process eliminated? The answer to this question will often depend on exactly how a forecast is used within the risk management process. The preparation of market forecasts encourages an analysis of the factors which may drive underlying market movements, and reviewing alternative forecasts requires the consideration of different possible scenarios and outcomes. Both of these activities are beneficial, ensuring market dynamics are better understood, and the effectiveness of potential hedging strategies can be reviewed under different future outcomes.

Given the limitations involved in forecasting financial markets, it is important to consider the appropriate role of market forecasts within the risk management process. Forecasts are most valuable when they help treasurers to explore the range of factors that are influencing the markets, and the range of potential future outcomes, which may occur. Equally, forecasting can be dangerous when it encourages users to ignore alternative scenarios and emphasises a directional view. Incorporating a probabilistic, rather than a deterministic, approach to forecasting is an effective way of ensuring that forecasts support the risk management process by encouraging consideration of various alternative outcomes. If the weather forecast calls for a $40 \%$ chance of rain - in effect, a forecast of no rain - it might still be a good idea to bring your umbrella. [40]

\subsection{Forecast Averaging}

Forecast combination has a long history in econometrics. An abundance of evidence suggests that model averaging can improve forecast accuracy relative to model selection. Empirical examples of this evidence include, but are certainly not limited to the following studies: [41] [42] [43]. Theoretical results include [44] [45] [46]. In some instances some experts forecast with model averages accounts for the real-time nature of the data. [47] [48] While a broad consensus is that forecast combination improves forecast accuracy, there is no consensus concerning how to form the forecast weights. The most recent literature has focused on two particularly appealing methods simple averaging and Bayesian averaging. The simple averaging method picks a set of models and then gives them all equal weight for all forecasts. The Bayesian averaging method computes forecast weights as a by-product of Bayesian model averaging (BMA). 
Instead of relying only on the Survey of Professional Forecasters or the consensus of Wall Street economists or strategists, forecast averaging suggest that investor cast a wider net. Forecasts from different sources tend to draw on varying information and divergent methods. The idea is that their errors will frequently offset one another. Averaging estimates is an effective way to improve accuracy when combining expert judgments, integrating group members' judgments, or using advice to modify personal judgments. If the estimates of two judges ever fall on different sides of the truth, which we term bracketing, averaging must outperform the average judge for convex loss functions, such as Mean Absolute Deviation (MAD). The hypothesis is that people often hold incorrect beliefs about averaging, falsely concluding that the average of two judges' estimates would be no more accurate than the average judge. [49] [50] Illustrated, imagine two forecasts: One call for stocks to go up $20 \%$, the other $4 \%$. Now imagine that stocks actually rise $12 \%$. The first forecast was eight percentage points too hot. The second was eight percentage points too cold. But the average of the two was just right, even though each forecast was wildly inaccurate.

While forecast averaging has many benefits, literatures caution against the use of single-point forecasts data for averaging. Single-point forecast averaging enforces a deterministic mentality, and reduces the value of the forecasts themselves, which individually might encourage the consideration of different scenarios. Crucially, using an average forecast will necessarily reduce the focus on potential extreme events, the awareness of which should really be the priority of the risk investment manager. Another danger of deterministic forecasting occurs when too much confidence is placed in the forecast, and alternative scenarios are ignored. This can lead to hedging activity, which is essentially speculative in nature, where risks are either over or underhedged based upon an expectation of future market movements.

Professor Armstrong of Wharton University, an internationally known for his pioneering work on forecasting methods, suggested the extrapolation of long-term trend, say over the past decade. Next, take the median forecast from the Survey of Professional Forecasters or the Wall Street consensus. Government and or international forecast data are suggested to be included. A statistical model, such as the ones available for various measures at Yale University economist Ray Fair's forecasting website, will add another level of diversity. Finally, "consult a "forecast market" like Intrade.com. Give equal weight to each number; if five sources of forecasts are 
available, simply add up the forecast and divide by five. Unfortunately, not all of these forecasts are available at the same time. The Fair and Philly Fed numbers are updated only every few months, while Intrade.com's forecasting are not yet posted. But staggering the numbers over several months' isn't so bad: In general, you get more of a benefit from drawing on a diverse group of figures than you lose by sacrificing some freshness", Prof. Armstrong says. He has found that this technique reduces forecasting errors by up to 58\%, a significant improvement over individual forecasts. 


\section{CHAPTER TWO}

\section{INVESTOR SENTIMENT}

Investor sentiment has been traditionally regarded as a myth by classical financial theories and has received little attention by researchers prior to 1990. The standard argument was that in the highly competitive financial market, suboptimal trading behaviors such as paying attention to sentiment signals is unrelated to fundamental value. The traditional asset pricing models to explain some of the most striking events in the history of stock markets, such as the Nifty Fifty bubble, the Black Monday crash, and the internet or Dot.Com bubble. Since the 1980s, there have been several attempts to carry out asset pricing studies by assuming the efficient market hypothesis may be violated, at least in the short-run. A body of research has emerged from this [51] [52] [53] [54] which argues that some of the anomalies observed in the stock market can be attributed to noise created through trades which are motivated by sentiment.

Modern finance theory also suggests that investor sentiment should not be priced as the mispricing induced by sentiment and can be removed by trades of rational investors and arbitraging. However, research in recent decades illustrates that if investor sentiment induces uninformed demand shock, and the cost of arbitrage is high, the influence of investor sentiment cannot be ignored. In reaction to the activities of this period many researchers appealed in hindsight to behavioral explanations such as investor sentiment. Thus, from a historical perspective investor sentiment is important since it is a plausible explanation for the speculative

episodes of the 1990's: extreme bullish sentiments pushed prices far above fundamentals, leading to an inevitable return and crash in 2000 and 2007.

\subsection{Investor Sentiment Research}

Many researchers have now agreed that investor sentiment can be economically significant but the concept itself is still largely regarded as abstract. At the crux of the problem is the fact that the term sentiment is used in different ways among economic researchers, professional traders, and the media. 
Investor sentiment can be thought of as potentially erroneous beliefs that investors have about an aggregate economic variable, such as stock price. Before clarifying the later sentence however, it is useful to have in mind a mapping of how economists have traditionally viewed sentiment. The

first approach is based on the traditional asset pricing theories of classical finance, which argue that asset prices are rational assessments of expected future payoffs. Traditionally, this view makes no room for investor sentiment, since price changes only react to the arrival of external news about future cash-flows and interest rates. An alternative approach is behavioral finance, suggests instead that that investor sentiment may significantly distort market outcomes thereby affecting asset prices in equilibrium. Specifically, the noise trader model posits that if there are limits to arbitrage and investor beliefs are correlated, then noise unrelated to fundamentals, such as sentiment, may lead asset prices to deviate from what is expected from the benchmark of market efficiency.

\subsubsection{Investor Sentiment and Classical Finance}

Classical finance believes that investor sentiment does not affect prices, because the demands of any sentimental investors are neutralized by arbitrage. Such theories have mostly ignored or assumed away investor sentiment, arguing that in the highly competitive financial market, suboptimal trading behaviors such as paying attention to signals unrelated to fundamental value will be quickly eliminated. Classical finance revolves around two basic premises, that when taken together implies the lack of prolonged arbitrage opportunities: Financial markets are informational efficient and market participants are rational.

\subsubsection{Efficient Market Hypothesis (EMH)}

The first argument for EMH deals with investor rationality. In efficient markets, investors are assumed to be rational in the way they base their stock valuation on company fundamentals. These fundamentals are the discounted future cash flows, whereas the discount rate is founded in the risk characteristics of the rational investor. The fundamental value of a company is therefore the equilibrium price assumed by the EMH and new information available is directly priced in the stock price. This means that the price immediately increases with new positive information about fundamentals available whereas the stock price decreases with bad news releases. This rationality means that no risk-adjusted abnormal returns are possible in stock market investments 
and that the EMH is a consequence of investor rationality and the resulting stock pricing. [55]. Figures 1 shows the different reactions to stock price.

The second foundation of the EMH shows that even if investors are not rational, markets can be efficient. As in large volume markets divergences from rationality can be assumed to be independent, market prices will still reflect fundamental values of companies. Independence of differences in rationality implies that on average the differences will be zero, thus on average there is rationality among investors. Arbitrage is the third foundation of the EMH - The arbitrage argument leads market efficiency even if investors' trading strategies are correlated. Arbitrage conducted by rational investors is described as the mean to bring over - or underpriced assets back to their fundamental values. Arbitrage works as follows: If irrational investors invest heavily in a stock which leads to overpricing, arbitrageurs would short the stock and simultaneously buy another similar stock to hedge the risk associated with their sale. In this way arbitrageurs can make a profit and securities are forced back to their fundamental value. The same holds for underpriced securities which arbitrageurs would buy and at the same time they would sell short similar securities.

Many literatures state that, in the case of availability of close substitutes securities are priced at their fundamental value. In the long run the described market forces destroy the wealth of irrational investors as they lose money by their investments, e.g. bidding up prices of stocks which are forced back to fundamental value by arbitrage. Thus, in the long run there will be market efficiency.

\subsubsection{Behavioral Finance}

However, behavioral finance questions these foundations of traditional finance theory due to human fallibility in investment decisions and emphasizes the role of sentiment especially in short-term asset pricing as people's irrationality and biases are hardly independent from each other. [56] Standard financial theories still have a hard time explaining prolonged mispricing and unexploited arbitrage opportunities. [57] For example, financial puzzles such as the closed-end fund discount and IPO under pricing are empirical observations that provide evidence that markets may not always be informationally efficient. To explain these anomalies, one approach 
has been to appeal to behavioral explanations that relax the strict rationality requirement of standard theories.

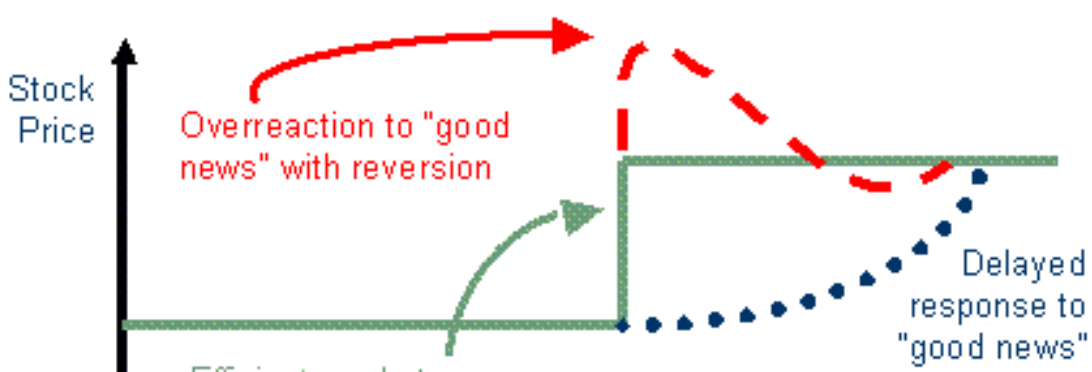

Efficient market response

to "good news"

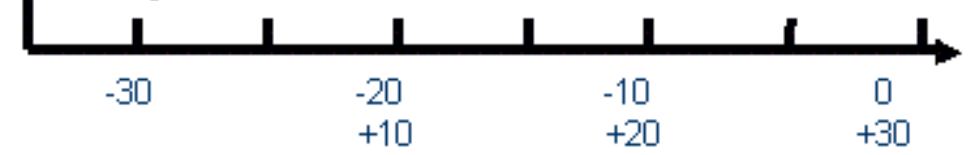

Davs before (-) and after (+) announcement

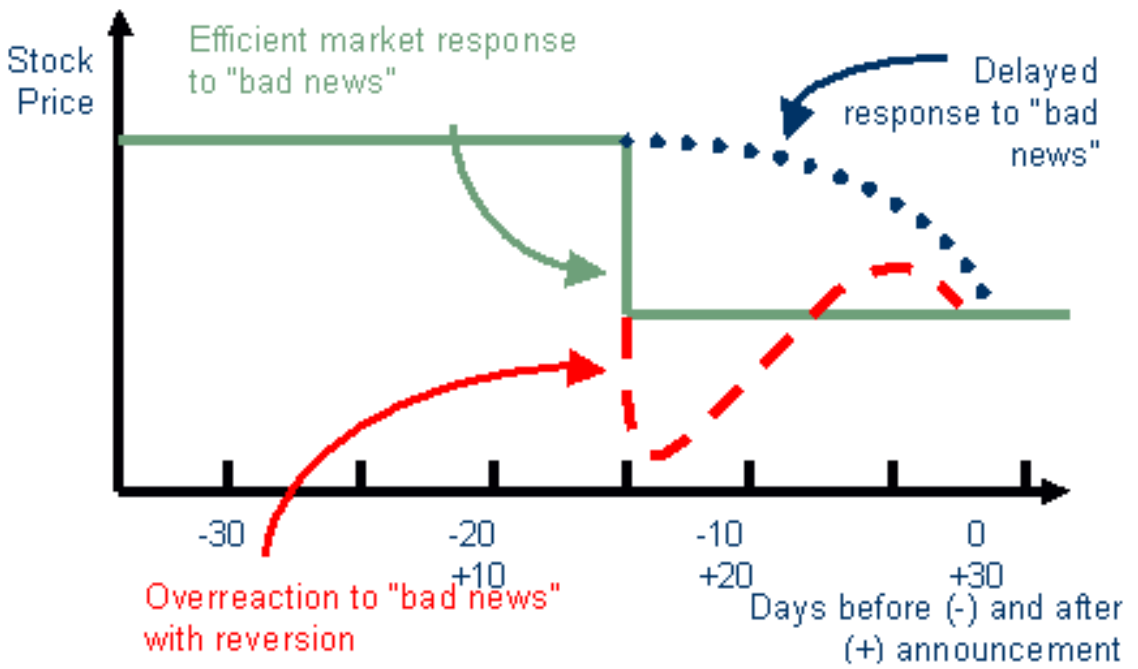

Figure 1 Reactions of stock price to new information in efficient and inefficient markets (Source: www.freerisk.org)

In particular, behavioral finance has been an increasingly fruitful branch of research that, in short, takes account of deviations from perfect rationality and explores the ways this may affect market outcomes, asset prices, and even the behavior of other investors. With regards to investor sentiment, behavioral finance offers models that are much more flexible about investor behavior and in doing so, can explain financial anomalies such as limited arbitrage. 


\subsubsection{Dual Process Theory and Rationality}

Two systems, intuition and reasoning, help in decision making. [58] and [59] refers to this dualprocess theory as human behavior following cognition on the one hand and affection on the other. Reasoning or cognition, respectively, follows a rational way to form decisions contrasting affection and intuition which are driven by emotions. The importance of intuition and affection in decision making increases with task complexity due to human kind's bounded mental capacity. As intuitive decisions are formed quickly, automatic and effortless as they need less mental capacity and are more often formed for high complex task. However, these decisions are also emotional, thus sentiment driven, and often this intuition also drives financial decisions in stock investments. Intuitive decisions are full of the biases and errors. These biases and errors in human judgments lead to systematic irrationality in investing causing divergence from the EMH and forming the foundation for investor sentiment, one of the two pillars of behavioral finance. Let us now see how this theory's applicability to traditional finances being based on rationality and behavioral finance as well as investor sentiment representing affection and intuition.

\subsubsection{Investor Sentiment and Behavioral Finance}

Behavioral finance is a contemporary research stream which study human fallibility in competitive markets. It explains stock pricing patterns which are not in line with classical finance theory and aims to integrate insights from psychology with neo-classical economic theory. It rests on two major assumptions, namely limited arbitrage and the presence of investor sentiment. Researches in the field of behavioral finance have concluded that emotions, biases and social norms in order to understand human's decision making process compromising the affective and emotional side in dual process theory.

The first major foundation of behavioral finance is limited arbitrage. Arbitrage is defined as the simultaneous purchase and sale of the same or essentially similar security in two different markets for advantageously different prices. [60] This means arbitrage is based on the valuation difference between the security and its substitute, i.e. an essentially similar security which possesses the same risk characteristics. In the real-world, however, many securities do not have close substitutes, making arbitrage more difficult if not impossible for rational investors. Moreover, even when good substitutes are available, prices often do not converge to their 
fundamental prices instantaneously because irrational traders continue to move prices further away. Arbitrageurs then face the risk that they have to liquidate their positions before prices converge to their fundamental values. Due to the short time horizon of arbitrageurs, arbitrage remains risky and is therefore limited resulting in inefficient prices.

One way behavioral finance formalizes the possibility of limited arbitrage is through the noise trader model, which is arguably one of the most cited alternatives to the Efficient Markets paradigm. The model claims that because investors are risk-averse and have short horizons, reallife arbitrage must take account of the fact that arbitrageurs may not want to expose themselves too much undiversifiable. In particular; an important consideration for rational arbitrageurs is the behavior of other investors who may be prone to exogenous sentiment. These noise traders are not fully rational in the sense that they may trade on the basis of noisy sentiment rather than information. Although noise traders have no access to insider information, they trade on noisy sentiment as if it were valuable information that would give them an edge on the trading floor.

This inefficiency is affected by the second major foundation of behavioral finance, investor sentiment. Investor sentiment is the theory of how individuals actually form their beliefs about the market and future securities prices. In the real-world, investors make decisions not only on the basis of simple facts and obvious information but also - and very often - on the basis of their gut-feeling, comments and opinions of other investors, and many more psychological traits. Therefore, it is very important to assess which psychological biases have the greatest influence on decision-making in certain situations. The theory of investor sentiment tries to provide answers to this question. [61]

\subsection{Defining Investor Sentiment}

As at this time, there is no single commonly accepted definition of investor sentiment. Existing definitions of sentiment in the literature range from vague statements about investors' mistakes to specific psychological biases that are model-specific. The term, sentiment itself is subject to a wide spectrum of classifications and is used in different ways by academic researchers, financial analysts, and the media. [62] [63] [64] [65] [66] While some researchers may refer to investor sentiment as a propensity to trade on noise rather than information, the same term is used 
colloquially to refer to investor optimism or pessimism. The term sentiment also has connotations with emotions, so the media may refer to it as investor fear or risk-aversion.

Investor sentiment is the theory of how investors form their beliefs. A formal model presented by [62] takes both the available empirical evidence as well as the known psychological theories of belief formation into account. Their theory is based on the empirical observation of both overreaction and underreaction of investors inconsistent with the weak-form and the semi-strong form of the EMH. On the one hand, the underreaction evidence shows that security prices tend to underreact to news announcements: After good news, prices show an upwards trend after the initial price reaction, and after bad news, prices trend downwards indicating that they have not fully adjusted to the news. This phenomenon is also called momentum, i.e. the nature of prices to trend expressed by the positive autocorrelation of returns over relatively short horizons. The overreaction evidence, on the other hand, shows that over longer horizons security prices overreact, especially if there is a longer pattern of the same type of news. From the study done by [67], investors overreact to a series of either good or bad news, and as a result, winners underperform and losers outperform in the following years. Eventually, prices revert to the mean after a period of exaggeration. Figure 2 shows investor sentiment cycle.

The classical notion of a rational agent is one who has well-defined preferences and forms correct beliefs through Bayesian updating. The assumption here is that, investors are susceptible to erroneous beliefs but are otherwise rational in the sense that their preferences satisfy standard preference axioms. This simplification allows for a simple definition of investor sentiment, defined in terms of erroneous beliefs. More precisely, Investor sentiment represents market participants' beliefs about future cash flows relative to some objective norm, namely the true fundamental value of the underlying asset. Sentiment corresponds to erroneous beliefs that investors have against some kind of objective benchmark. One possibility for this benchmark is the true fundamental value of the underlying asset, defined as the discounted sum of future cash flows and investment risks. 
There are two possibilities for why erroneous beliefs occur: individuals correctly use wrong information, or that they wrongly use correct information. In other words, sentimental investors may update their beliefs through news about fundamentals in addition to noisy signals unrelated

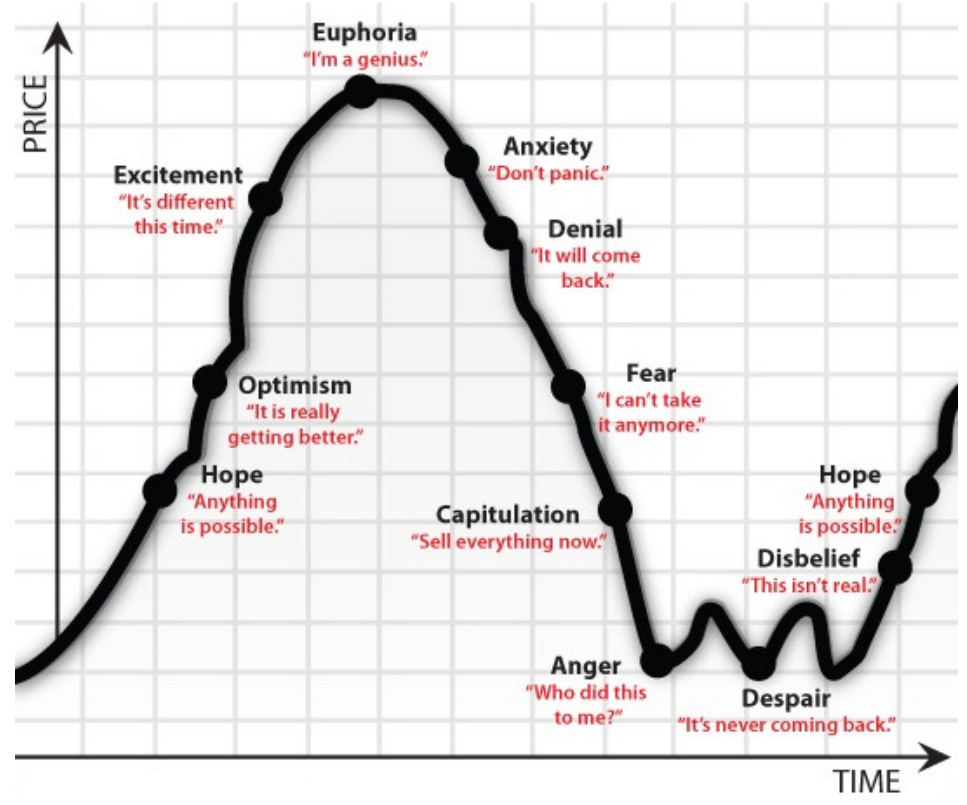

Figure 2 Investor sentiment cycle [68]

to fundamentals, and may do so in a way that is statistically incorrect. In this way, sentiment can be expressed as the component of expectations about asset returns not warranted by fundamentals and Bayesian updating alone. This could be because some investors are overconfident in their stock-picking abilities and act on their beliefs in a way different from a Bayesian updater who bases trading decisions on news about fundamental value alone.

\subsection{Investor Sentiment and Emotion}

An emotion is a cognition which has one or more of the specific forms of a certain generic kind of psychical quality. To like apple stock, e.g., is to be cognising something - correctly or incorrectly - like a particular stock, and for that cognition to be toned with likeness. In general, to likeness for $X$ is to be cognising $X$ with liking; to be admiring $X$ is to be cognising $X$ admiringly. Suppose that a certain stock has been repeatedly perceived or thought of by an investor. Suppose they are repackaged complex and attractive derivative stock and that this investor has perceived it or thought of it in many different contexts on various occasions. These 
various cognitions of the object will have produced a highly complex trace, i.e., a very complex dispositional idea of the stock.

Suppose that this trace has become associated with the traces of certain names, phrases, or symbols, which have often been heard or seen or uttered in intimate connexion with perceiving or thinking of this stock. Lastly, suppose that, on many occasions when this stock has been perceived or thought of, strong emotions have been felt towards it by this investor. When the stock is thought of or perceived in certain situations, or when the investor specially attended to certain aspects of it, the investor's cognition of it had the emotional tone X. When the investor perceived or thought of it in certain other situations, or when he specially attended to certain other aspects of it, his cognitions of it had the emotional tone Y. And so on. The result is that the dispositions corresponding to the emotions $\mathrm{X}, \mathrm{Y}$. etc. will have become associated with his dispositional idea of this object. Henceforth anything that excites the dispositional idea of the stock, e.g., perceiving of it, thinking of it, or perceiving or thinking of any word or phrase or symbol connected with it, will tend to excite all these emotional dispositions. These are all sum up by saying that the investor has formed a sentiment about this stock. [69]

\subsubsection{Types of Sentiment}

According to social psychology, sentiment is an organised system of emotional dispositions centred about the idea of some object. The organisation of the sentiments is determined by the course of experience; that is to say, the sentiment is a growth in the structure of the mind that is not natively given in the inherited constitution. In dealing with the emotions, they are classified according to their nature as states of affective consciousness and as tendencies to action; and we may at-tempt to name and classify the sentiments also according to the nature of the emotional dispositions that enter into the composition of each one. [70]. From the behavioral finance perspective, emotion biases investor decisions.

A bias can be described as a preference or an inclination (especially one that inhibits impartial judgement) or an unfair act or policy stemming from prejudice [71]. In the investment realm, behavioral biases are defined as systematic errors in financial judgement or imperfections in the perception of economic reality. Investor sentiment is a theory of how investors make investment decision. Over the past 27 years or so, researchers have identified a long list of what influences 
investors decisions, categorizing them according to a meaningful framework. Investor sentiments are further classified as either emotional or cognitive. Cognitive bias can be technically defined as basic statistical, information processing or memory errors that are common to all human beings. They can be thought of also as "blind spots" or distortions in the human mind.

Emotional bias is a mental state that arises spontaneously, rather than through conscious effort. Emotions are physical expressions, often involuntary, related to feelings, perceptions or beliefs about elements, objects or relations between them, in reality or in the imagination. Cognitive biases do not result from emotional or intellectual predisposition toward a certain judgement, but rather from subconscious mental procedures for processing information. Investors are subjected to large volumes of information and data, and to make sense of it all, they opt for simplified information processing when making investment decisions. A good example of this is evaluating a class of stocks, say U.S. small-capitalization. Even using a research database, the information flow is so immense that they inevitably rely on shortcuts such as "best 12-month return" to make investment decision. Because cognitive biases stem from faulty reasoning, better information and advice can often correct them. Cognitive biases include heuristics, such as anchoring and adjustment, availability and representativeness biases. Other cognitive biases include ambiguity aversion, self-attribution and conservatism. Emotions can be undesired to the individual feeling them; she may wish to control them but often cannot. Investors can be presented with investment choices, and may make sub - optimal decisions by having emotions affect these decisions. Often, because emotional biases originate from impulse or intuition rather than from conscious calculations, they are difficult to correct. Emotional biases include endowment, loss aversion and self-control. [27]

\subsection{Investor Sentiment or Consumer Sentiment}

Is there any difference between investor sentiment and consumer sentiment? Not all consumers are investor but all investors are consumers. Both investors and consumers have expectations. Investors' expectations come into existence via the stock market or investment in other asset class. Optimism in the stock market can lead to stock market boom whereas investor pessimism can lead to a declining stock market. These market movements come about through the buying and selling of stocks to reflect the corresponding sentiment at the time. On the other hand, 
consumers' expectations typically come into existence in the form consumption and saving; optimistic consumers can result in higher aggregate consumption and lower savings for consumers, whereas more pessimistic consumers can result in the opposite. Many sentiment researches have focused on how to measure investor sentiment and its interaction with the stock market [72] [54].

Consumer sentiment data, unlike investor sentiment data, is tracked and made available to include the age of the survey respondent. This is an important aspect about sentiment research that has yet to have been fully investigated is how the age of the person impacts their outlook. Consumer sentiment has the ability to provide researchers with many avenues to test behavioral economic theories. This is possible because consumer sentiment surveys ask individuals how the consumers feel about their current economic situation and how they perceive their future economic situation to be. By having data from individuals regarding their feelings and perceptions, the behavioral data are incorporated into econometric modeling to test for statistical and economic significance in relation to variables such as stock returns, inflation, consumer spending and many others. [73]

\subsection{Investor Sentiment Literature Review}

Classical finance theory as has been discussed gives no role to investor sentiment. Investors are considered to be rational and diversify to optimize the statistical properties of their portfolios. Competition among them is assumed to leads to an equilibrium in which prices equal the rationally discounted value of expected cash flows, and in which the cross-section of expected returns depends on the cross-section of systematic risks. [74] Even if some investors are irrational, classical theory argues, their demands will be offset by arbitrageurs and similar conclusions for prices will obtain. Here we discuss empirical from various publications evidence that suggests investor sentiment has strong effects on stock prices.

\subsubsection{Sentiment and Expected Returns}

New York Stock Exchange (NYSE) data has been used to study the relationship between sentiment and expected returns directly, employing closed-end fund discounts as a proxy for sentiment. [75] Their finding was that after controlling for size effects, closed-end fund discounts are negatively correlated with portfolio returns, which means that high sentiment may normally induce lower returns. One possible explanation is that if sentiment at the beginning of a period 
was high, irrational investors were more likely to over-estimate the value of some stocks. For this reason, they had a high motivation to purchase these stocks, which would push up their trading prices. At the end of the same period, as the ending prices of the stocks would normally be determined by their actual fundamental characteristics which might fall distinctly with the expectations of the irrational investors, the realized returns would be lower. [76] [77] Conducted a similar study by using the same dataset and proxies, they concluded that investor sentiment can significantly explain the variation of stock returns over their entire sample period, which ran from July 1965 to December 1994. However, this relationship disappeared in their second subperiod which is from April 1980 to December 1994.

\subsubsection{Forecasting Power of Sentiment Proxies}

Re-examination of the forecasting power of several investor sentiment proxies proposed in prior research was done by [78]. Additionally, they constructed a sentiment measurement using survey data. In contrast with previous research, they also constructed a single sentiment index, employing Principle Component Analysis (PCA) to abstract the correlated component among several sentiment proxies. Furthermore, they employed Vector Auto Regression to investigate the causal relationship between sentiment index and expected returns. Their results showed that the majority of the sentiment proxies are highly correlated with the direct sentiment proxy they constructed.

\subsubsection{Daily Mutual Fund Flows}

The result of the study by [79] using daily mutual fund flows to construct their sentiment index, supports the hypothesis that the sentiment factor should be priced. In addition, they also revealed that sentiment proxy is negatively correlated with stock performance in the Japanese market, but positively in the U.S. market. Although the changes of sentiment level are strongly linked to contemporaneous market performance, the forecasting power in sentiment index for near-term future stock returns is relatively weak and rarely significant.

Following a similar methodology as proposed by applying PCA to six sentiment proxies suggested in previous studies [54] construct a single sentiment index (which included closed-end fund discounts, the number of IPO, averaged first day return of IPO, market turnover, share of equity issues and dividend premium). In addition, they controlled for firm-specific characteristics, and introduced macroeconomic factors in their asset pricing model. Their results 
illustrate that when the beginning-of-period sentiment index is low, small stocks, young stocks, growth stocks, and poor performance stocks tend to have relatively high returns. These stocks are hard to value objectively, and thus, are also rarely monitored by arbitragers. [80] For this reason, these stocks are more likely to be influenced by changes in sentiment. When sentiment is low at the beginning of year, the prices of these stocks may be less likely to be over-estimated and more likely to be under-estimated, thus, their returns may be relatively high. According to this logic, if

sentiment at the beginning of a set period is high, the returns of these stocks should be relatively low as high sentiment may induce over-valuation on these stocks, and reduce the realized returns. [66]

\subsubsection{Consumer Confidence Indexes}

On the other hand, [81] employed consumer confidence indices which were conducted through surveys of the Conference Board and the University of Michigan Survey Research Center to construct a sentiment index. The empirical results showed that a sentiment index could significantly forecast the returns of small stocks and stocks with dispersive ownership. Consistent with previous studies, they also suggested that sentiment was negatively correlated with stock returns, and that their sentiment index could successfully explain the size premium. [82]. [83] Applied the methodology developed by [81] to a study of global markets. They included both global and local factors to determine the differences in impact of sentiment across different countries, and measure the contribution of the global component of sentiment on the stock pricing mechanism of highly integrated markets. Consistent with previous work, this study also supported the theory that stocks which are difficult to value and arbitrage tend to be more influenced by the fluctuation of sentiment. The fluctuation of sentiment is inversely correlated with stock returns.

\subsubsection{Power of Three Sentiment Proxies}

The explanatory power of three sentiment proxies which included closed-end fund discounts, the ratio of odd-lot sales to purchases, and net mutual redemptions on stock returns was studied by [84]. Using data from 1933 to 1993 supplied by Wall Street, the study provided significant evidence showing that discounts and net redemptions induce a size premium between large firms and small firms and that the explanatory power of odd-lot ratios is relatively weak compared with the other two proxies. 


\subsubsection{Impact of Individual Investor Sentiment on Trading}

The impact of individual investor sentiment on the trading and pricing of equity options used for speculation and hedging has been studied in many literatures. In their study [62] constructed the positive exposure demand (PD) for stock and index options that measures non-market maker net option demand with positive exposure to the underlying stock or index. They then use PDs for index calls, stock calls and puts as proxies for demand of speculators, and PD for index puts as a proxy for option demand driven by hedging motives. They found that speculation demand is positively related to investor sentiment, while hedging demand is invariant to sentiment. The cross-sectional analysis suggests that sentiment has stronger effects on the PD for options with higher concentration of trading by discount brokerage customers and in options with higher underlying stock volatility.

\subsubsection{Bearish vs. Bullish and Fear vs. Exuberance Sentiments}

The research by [85] distinguished between the "bearish versus bullish" and "fear versus exuberance" sentiments and examines how these two types of sentiment affect market liquidity and net buying volume. They found that when investor sentiment becomes more bullish, there is a reduction in market spread and an increase in buy orders. The trading behaviors of individual investors are more sensitive than institutional investors when investors are more fearful of the future market movements. Overall, the findings obtained from their exploration of the relationship between investor sentiment and net buying volume help to provide a better understanding of the relationship between investor sentiment and market liquidity.

\subsubsection{Investor Sentiment and Societal Mood State}

According to behavioral economists, emotions play obvious role in anomalies arising from motivation conflict such as cognitive dissonance or impulse control. However, there is evidence that emotions play a role in information processing anomalies as well, several of which arise because information is ignored or improperly weighted in decision-making. Examples of the presence of emotion in irrational investor decision-making causing bubbles and subsequent crashes are numerous: the Great Crash of 1929, the Black Monday crash of October 1987, and the Dot-com bubble in the late 1990s are perhaps the most notorious examples. Standard financial theories, where emotions play no role in investor decision making, have a hard time explaining these events. 
Adopting the risk-as-feelings idea in the investor decision-making framework could provide some of the explanation for irrational investor behavior. Thus, as stated above: "when cognitive evaluations on one side and emotions on the other guide the decision maker in opposing directions, emotions often exert dominating influence on behavior." The study by [86] describes how emotional "somatic markers" seem to signal the results of unconscious processes that judge the salience of different information to a decision. Emotions also seem to play a role in evoking rational thought. The question has been whether it applies to societies at large, i.e. can societies experience mood states that affect their collective decision making? By extension is the public mood correlated or even forecasting the stock market? Another question is what creates the societal mood?

\subsubsection{Collective Mood and the Stock Market}

The question of whether measurements of collective mood states derived from large-scale Twitter feeds are correlated to the value of the Dow Jones Industrial Average (DJIA) over time was studied by [87]. They analyze the text content of daily Twitter feeds by two mood tracking tools, namely OpinionFinder that measures positive vs. negative mood and Google-Profile of Mood States (GPOMS) that measures mood in terms of 6 dimensions (Calm, Alert, Sure, Vital, Kind, and Happy). The research cross-validate the resulting mood time series by comparing their ability to detect the public's response to the presidential election and Thanksgiving Day in 2008. A Granger causality analysis and a Self-Organizing Fuzzy Neural Network are then used to investigate the hypothesis that public mood states, as measured by the OpinionFinder and GPOMS mood time series, can forecast changes in DJIA closing values. The results indicate that the accuracy of DJIA forecast can be significantly improved by the inclusion of specific public mood dimensions but not others. They find an accuracy of $87.6 \%$ in forecasting the daily up and down changes in the closing values of the DJIA and a reduction of the Mean Average Percentage Error by more than $6 \%$. In conclusion they stated that when the emotions on twitter fly high, that is when people express a lot of hope, fear, and worry, the Dow goes down the next day. When people have less hope, fear, and worry, the Dow goes up. Does it seem that just checking on twitter for emotional outbursts of any kind gives a forecast of how the stock market will be doing the next day? 


\subsubsection{Sentiment and its Relationship with Macro-Economic Indicators}

To capture the overall investor mood in the market, RavenPack construct a sentiment index based on the Event Sentiment Score (ESS). The index is constructed using a simple, intuitive, yet robust approach capturing the sentiment momentum from news on the US market over a three month period. The RavenPack Sentiment Index is not only closely related to financial markets but also to widely accepted as macro-economic indicators. From January 2000 to September 2011, the contemporaneous correlation between the RavenPack Sentiment Index and the S\&P 500 is $79 \%$. The RavenPack Sentiment index is consistently highly correlated with the S\&P 500 across different market trends. The RavenPack Sentiment Index is consistently positively correlated with widely used macro-economic indicators, both at a monthly and quarterly horizon. The quarterly contemporaneous correlation between changes in the RavenPack Sentiment Index and in real GDP is 56\%. Including a sentiment lag with up to three quarters improves the correlation to almost $70 \%$. [88]

\subsubsection{Media and Social Networks}

News plays important role for investors when judging fair stock prices. In fact, news carries information about the firm's fundamentals and expectations of other market participants. From a theoretical point of view, an efficient valuation of a firm is based on the firm's expected future cash flows. Expectations crucially depend on the information set that is available to investors. The set consists of qualitative and quantitative information of different kind and from various sources, e.g. corporate disclosures, news articles and analyst reports. Due to improved information intermediation, the amount of available information especially qualitative information increased substantially during the last decades. Since it is getting increasingly difficult for investors to consider all available information, automated classification of the most important information becomes more relevant. Research in this area is still in its infancy. Despite numerous attempts, forecasting accuracies for the stock price effect (i.e. positive or negative) following the release of corporate financial news rarely exceeded 58\% - an accuracy level still close to guessing probability for a binary forecasted parameter (50\%) leaving room for substantial improvements. [89]

Systematic exploration of the interactions between media content and stock market activity was studied by [90]. He constructed a straightforward measure of media content that appears to 
correspond to either negative investor sentiment or risk aversion. Pessimistic media content variables forecast patterns of market activity that are consistent with the [51] models of noise and liquidity traders. High values of media pessimism induce downward pressure on market prices; unusually high or low values of pessimism lead to temporarily high market trading volume. Furthermore, the price impact of pessimism appears especially large and slow to reverse itself in small stocks. This is consistent with sentiment theories under the assumption that media content is linked to the behaviors of individual investors, who own a disproportionate fraction of small stocks. The study also concluded that the pessimistic media factor and the underlying General Inquirer (GI), a quantitative content analysis Program, category variables are proxies for decreases in volatility. The risk premium hypothesis is that investors require lower returns on the Dow Jones on days in which there are many negative words in the Wall Street Journal column because holding the Dow Jones stocks is less risky on these days.

The theory that the content of asset specific news can be used to forecast abnormal market behaviors was supported by the evidence presented in the literatures. [91] The results of their research show that over $80 \%$ classification accuracy can be achieved for every country. The most directly comparable results by other authors are those found where 58\% accuracy was achieved for press announcements in the US. However, it should be noted that above result was trying to forecast the direction of the return, not just whether the market would react, which is harder to do.

\subsection{Market Sentiment and the Economy}

Our discussion so far is about investor sentiment so far only pertains to individual markets. Let us now make the critical point that even if all investors falsely believe that their private signal contains relevant forecasting information, this kind of collective sentiment will only matter in equilibrium under certain conditions. That is, in order for investor sentiment to matter in the aggregate, at least two necessary conditions must hold: Sentimental investors make up a big enough proportion of all traders. Or alternatively, sentimental investors disproportionately hold certain assets. And beliefs are correlated across investors in a way that cannot be perfectly forecasted by rational arbitrageurs. If these conditions hold simultaneously, it is possible for sentiment to affect asset prices and hence potentially distort market outcomes. 
The two conditions above also imply that there may be limits to arbitrage. First and most obvious is that sentimental investors must make up a substantial proportion of the population of investors. In the literatures, it is common to identify less than-rational traders to be retail investors. Retail, or small, investors are defined as non-professional, non-institutional traders. If retail investors make up a substantial enough impact on all trades, then their aggregate effect can matter in equilibrium. For example, consider the extreme case where the entire market is comprised of small investors subject to erroneous beliefs. Even in this extreme case, sentiment would only matter if the aggregation of beliefs does not cancel out. Hence, another necessary condition for investor sentiment to have a market-wide effect is that their trades are not independent, which leads to the next condition. Individual sentiment will only matter in the financial market if investor beliefs are not independently distributed so that the aggregate effect of sentiment does not cancel out in equilibrium. Intuitively, this means that not only are investors on average, optimistic together and pessimistic together, but that future changes in sentiment cannot be forecasted by arbitrageurs. Hence, beliefs must be correlated in a way that the risk of further changes in sentiment cannot be diversified away [51]

Considering all the research interest in investor sentiment study and analysis, the investor sentiment measures still faces a number of challenges: characterizing and measuring uninformed demand or investor sentiment; understanding the foundations and variation in investor sentiment over time; and determining which particular stocks attract speculators or have limited arbitrage potential. Much remains to be done in terms of spelling out this framework, but the potential payoffs of an improved understanding of investor sentiment are substantial. For example, the standard methodology for estimating fundamental market betas - an input to long-term capital budgeting and other important financial decisions, does not account for sentiment. Doing so might improve estimates and clarify their interpretation. Also, we have seen that sentiment is a major source of risk for investment managers and their portfolios. Therefore it may have real consequences for the allocation of corporate investment capital between safer and more speculative firms. 


\subsection{Market Sentiment Indicators}

The Organisation for economic Co-operation and Development (OECD) has defined an indicator as "A parameter, or a value derived from parameters, which points to or provides information about or describes the state of a phenomenon or environment with a significance extending beyond that directly associated with a parameter value". An indicator is a piece of information which is part of a specific management process, and has been assigned significance beyond its face value. The Scientific Committee on Problems of the Environment (SCOPE) described indicators in terms of two key characteristics: they quantify information so that its significance is more readily apparent, and they simplify information about complex phenomena so as to improve communication. [92] [12]

However they are defined, indicators form part of information systems, but they are distinct from statistics and primary data in that they represent more than the data on which they are based. Indicators thus give data added value by converting them into information which is of direct use to the decision-maker, helping to shed light on a problem. They have become well-established and are widely used in many fields, from economics to ecology to health, and can be used at the global, regional, national and local or neighbourhood levels. An example an indicator is the gross domestic product (GDP), which is a way of assessing aspects of economic development in a country. The infant mortality rate is an indicator of the health status of a community. The rise in ambient temperatures worldwide is an indicator of climate change. The number of public complaints received by a local authority is an indicator of the level of satisfaction with the quality of services provided. In the field of ecology, the presence or absence of an 'indicator species' can be used to assess the conditions that prevail in an ecosystem.

So, an indicator is succinct measure that is aim to describe as much about a system as possible in as few points as possible. Indicators help to understand a system, compare it and improve it. Indicators are extremely important forms of measurement, but they can also be controversial. Like all powerful tools, they can easily do as much harm as good. The world is becoming a more transparent and competitive place, where people want instant summary information. Indicators appear to fit this need and are therefore becoming an increasingly important part of how everybody works. Indicators, like many other forms of measurement, can be used in three broad 
ways: For Understanding: to know how a system works and how it might be improved; For Performance: monitoring if and how a system is performing to an agreed standard For Accountability: allowing us to hold ourselves up to patients, the government and taxpayers and be openly scrutinised as individuals, teams and organisations.

\subsubsection{Functions of Indicators}

Imagine a car dashboard; an indicator on the dashboard is fed by one of many streams of data maybe oil level, transmission fluid level, temperature, windshield washer fluid, etc... It flashes when all is not well, suggesting action that is needed. The indicator alerts us to something worthy of further investigation. On the whole, an indicator would only perform the functions mentioned. Expecting more from it is inviting trouble.

Indicators only indicate: an indicator will never completely capture the richness and complexity of a system. Even human being gets nervous when they are judged unfairly on the basis of only one fact. A set of indicators will usually not improve things much. Indicators are designed to give 'slices' of reality. They might provide the truth, but they rarely give the whole truth. This leads to people's understandable fear that they are being unfairly measured and judged. Like any reductionist approach, an indicator must be understood in context.

Indicators encourage explicitness: indicators forester clarity and explicitness about where the company or establishment is going or trying to do. Not everyone establishment feels comfortable with this as there is often a desire to retreat to non specifics rather than face important differences in understanding.

Indicators usually rely on numbers and numerical techniques: A lot of people - even competent professionals - fear numbers. Yet, in order to be able to use indicators properly or challenge them, we need a basic understanding of elementary statistics. Although many statistical methodologies can be difficult and counterintuitive to learn, indicators don't always use complex methods.

Indicators are not fault-finding: people often assume that indicators are designed to find fault. In fact, they can help us understand performance, be it good or bad. Well-designed measurement systems identify high performers as well as systems that may warrant further investigation and intervention. [93] 


\subsubsection{Types of Indicator}

Indicators can be classified in many ways, for example according to whether they are concerned with impacts, process or outcomes or whether they are quantitative or qualitative. The European Environment Agency (EEA) has developed a useful typology of indicators [94]. A descriptive indicator is defined as one that indicates what is happening to the environment or to human health, while a performance indicator is linked to a reference value or policy target, illustrating how far the indicator is from the desired level. Performance indicators of the achievement of agreed targets and goals have been extensively used in the private sector. Indicators can be typified as follows:

Descriptive Indicators: indicators of what is happening in the establishment

Performance indicators: indicator linked to a reference value

Efficiency indicators: Indicator that illustrating the efficiency of the establishment

Welfare indicators: This aggregate economics, social and environmental dimensions to illustrate whether, overall, welfare is increasing

Indicators that are primarily descriptive can be useful in obtaining baseline information on which to formulate subsequent policy options and plans, and to assess trends. At all levels, indicators that describe the overall quality of human health and the environment, and that highlight the factors that affect environmental quality and human health can be useful, as they can provide an overview, snapshot or profile of environmental and health conditions, thereby demonstrating trends. Reports on the state of health and the environment have often served as a basis for the subsequent development of health and environmental action plans. Some indicators are more relevant to specific industry while others are more to the general economy. Many issues, such as management and control of air pollution, require action across various tiers of government: the setting of standards may be relevant at the national level, monitoring and control at the local level and assessment of trends in greenhouse gas emissions in relation to climate change at the global level.

\subsection{Classification of Economic Indicators}

Anything that can be used to forecast future financial or economic trends is an economic indicator but official indicators must meet certain set criteria. Economic indicators have three major attributes - relation to business cycle or an economy, frequency of data, and timing. In 
relation to business cycle or economy, indicators have one of three different economic relationships i.e. pro-cyclic, counter-cyclic, and a-cyclic.

\subsubsection{Time Based Classification}

Economists typically classify economic indicators into three categories according to their usual timing in relation to the business cycle: leading indicators, lagging indicators, and coincident indicators. Figuratively speaking, one views them through the windshield, the rear view mirror, or the side window. But how can an investor determine the direction of the economy considering the enormous amount of data available today? Coincident and lagging indicators provide investors with some confirmation of where we are and where we have been.

Figure 3 shows a graph of economic indicators covering Historical Consumer Price Index (CPI) inflation, Historical Producer Price Index (PPI) inflation, Historical Consumer Price Index excluding interest rates on mortgage bonds in South Africa (CPIX), for a much shorter period since the index was created in the late 1990s, Banks Prime rate of interest (PRIME) starting from 1980. The bank prime rate affects consumers through house and vehicle finance. And the Reserve Bank's REPO rate for repurchase agreements with the banks since inception in 1999.

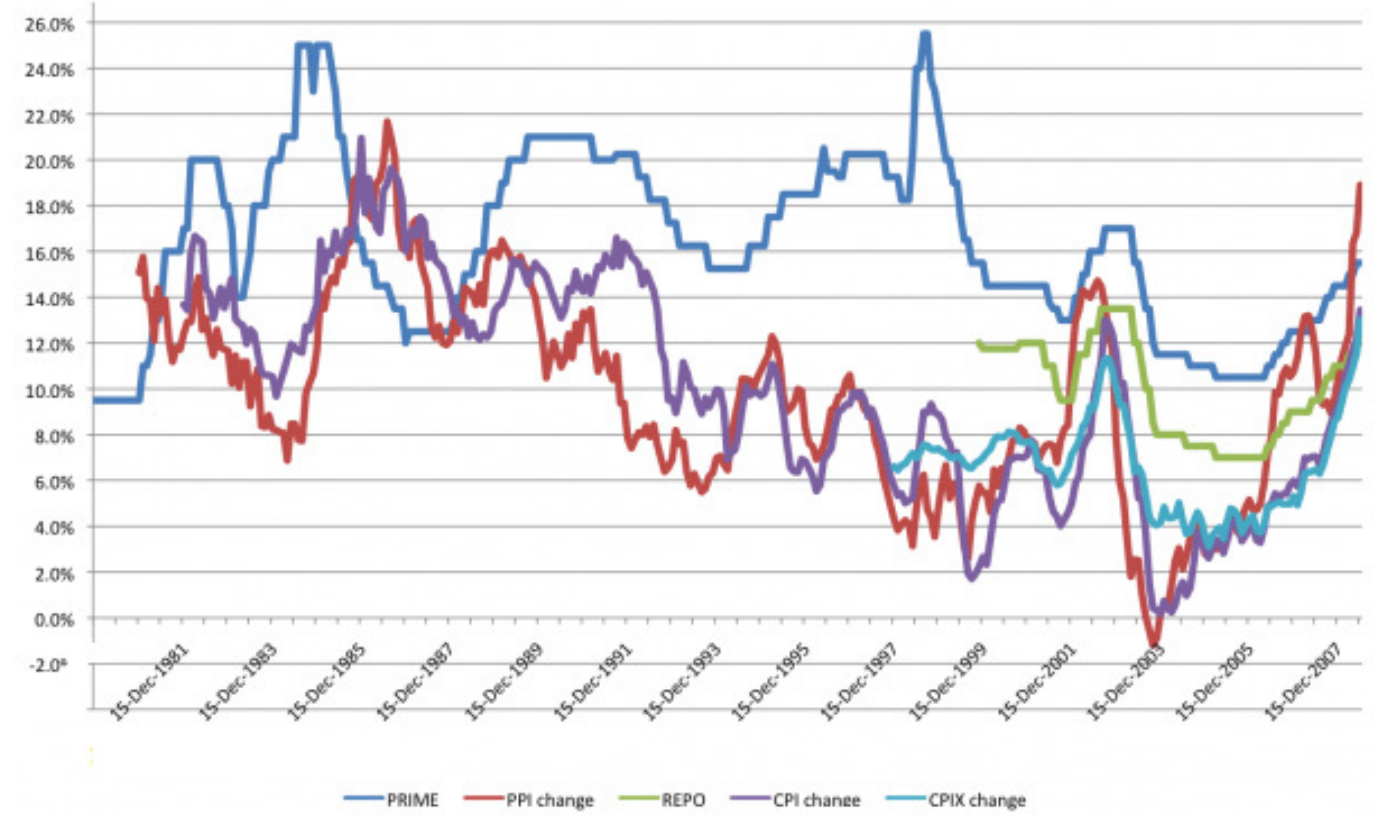

Figure 3 Historical graph of economic indicators (Source: www.twentythirdfloor.co.za) 
Leading Indicators: These types of indicators signal future events. Leading indicators tend to peak and trough before the overall economy. They anticipate emerging trends in economic activity. They are the most useful and widely used of the economic indicators since they anticipate change by indicating what businesses and consumers have actually begun to produce and spend. Among the most important leading data series are housing starts, and manufacturers' new orders, especially for durables, which indicate expectations of higher levels of consumer purchases of such items as automobiles and appliances. Others include spot commodity prices that reflect rising or falling demand for raw materials, average hours worked per week, which rise or fall depending on the level of output and therefore anticipate changes in employment, stock prices which suggest changing levels of profits and the money supply (which indicates available liquidity and thus has an impact on interest rates. Statistics Canada for example combines 10 leading indicators into a single index of leading indicators, called the Composite Leading Indicator.

To forecast stock market price movements, investment strategists use leading indicators that precede changes in the business cycle by a longer time period than the stock market does. There are problems implicit in relying on composite leading indicators to forecast changes in the business cycle. On occasion, a trend in published statistics is observable only after the economy has already moved into the stage of cycle the trend forecasts. Sometimes a false signal is given. In any case, the magnitude of the anticipated new trend is not signalled, it may be a pause, an economic slowdown or a recession). However, if all indices are signalling the same trend for a similar period of time, the probability of accuracy is higher.

Lagging Indicators: Lagging indicators are those which change after the economy as a whole changes. The importance of a lagging indicator is its ability to confirm that a pattern is occurring or about to occur. Unemployment is one of the more popular lagging indicators because a rising unemployment rate is an indication that the economy is doing poorly or that companies are anticipating a downturn in the economy. Other examples of lagging indicators include private sector plant and equipment spending, business loans and interest on such borrowing, labour costs, the level of inventories and the inflation rate. 
Coincident Indicators: Indicators which change about same time and in same direction with economy are called coincident indicators. Rather than forecasting future events, these types of indicators change at the same time as the economy or stock market. Personal income is a good example because if it is rising, economic growth will typically follow. Other coincident indicators include GDP, industrial production and retail sales. A coincident index may be used to identify, after the fact, the dates of peaks and troughs in the business cycle. A coincident index can be used to identify troughs and peaks in a business cycle.

\subsubsection{Relationship Based Classification}

Economic Indicators can have one of three different relationships describing relative to the general economy.

Pro-cyclic Indicators (PI): Pro-cyclic indicators move in the same direction as the general economy. The numbers increase when the economy is doing well and decrease when the economy is doing badly. GDP is an example of pro-cyclic indicator.

Counter-cyclic Indicators (CI): A counter-cyclic economic indicator's numbers increases when the economy is doing badly. Simply put, countercyclical indicators move in the opposite direction to the general economy. The unemployment is an example of these indicators.

A-cyclic Indicator (AI): A-cyclic indicators are those with little or no correlation to the business cycle - they may rise or fall when the general economy is doing well, and may rise or fall when it is not doing well. The number of home runs the New York Yankee hit in a year generally has no relationship to the health of the economy, so we could say it is an acyclic economic indicator.

\subsection{Composite Indicators}

Indicators may be specific or they may be composite, which means that they condense a wide range of information on different but related phenomena into a single measure or index, such as the Composite Index of Leading Indicators, An index published monthly by the Conference Board used to forecast the direction of the economy's movements in the months to come. The index is made up of ten economic components, whose changes tend to precede changes in the overall economy. These ten components include: the average weekly hours worked by manufacturing workers; the average number of initial applications for; unemployment insurance; the amount of manufacturers' new orders for consumer goods and materials; the speed of 
delivery of new merchandise to vendors from suppliers; the amount of new orders for capital goods unrelated to defence; the amount of new building permits for residential buildings; the S\&P 500 stock index; the inflation-adjusted monetary supply (M2); the spread between long and short interest rates and consumer sentiment.

In practice, however, the construction of such composite indicators is challenging, and high levels of competence in statistics and measurement are needed in order to weight and combine different variables. In addition, the choice of components and the manner in which they are weighted may be largely subjective. It can be difficult to test or verify composite indicators, since they may not relate to specific, measurable conditions. Confusion may arise if the effects of the individual components are variable and if significant trends in an underlying component are masked by other components. Such indices may not be readily understood by the public, who could feel that their actions had no effect on the indicator.

Composite indices can nevertheless be useful in summarizing data and information for decisionmakers and may be particularly valuable for drawing comparisons between countries. For example, in the construction of indicators for global climate change, the individual greenhouse gases contributing to global warming can be weighted by their global warming potential or health-absorbing capacity and can be expressed in terms of "carbon dioxide equivalents". A

similar approach has been adopted in a weighting scheme for ozone-depleting gases [95]. Many air quality indices have been devised, such as the pollutant standard index developed in the USA in the 1970s, and water quality indices that make it possible to aggregate variables associated with water use. The human development index has been widely used for inter-country comparisons.

\subsection{Use of Economic Indicators}

Investing is the art of valuation. While there is certainly a scientific side to determining security values, the art side plays the stronger role. If stock values were purely scientific, we would not see daily price fluctuations, or volatility, like we do. That volatility is largely due to the subjective changes in investors' outlooks rather than a scientific proof by, say, an accounting 
firm. Price volatility is art in action. So while we can never be sure why a security is valued at the price we see quoted, the market at least allows us to see the consensus opinion of that value.

A stock's value is based on subjective opinions of the company's ability to generate and sustain sales and profits. It's important to understand that we must be concerned with "sales" and cannot be content with just recognizing "profits." The reason is that profits can be generated in two distinct ways: We can increase sales or decrease liabilities. Closing factories and laying-off employees, for example, can yield a profitable earnings report for the company. In most cases though, you'd see selling pressure on the stock as investors react to management's signal of the company's questionable future. Wall Street would rather see strong sales as the source of profits. So not only does Wall Street look for profitability but it also keeps a watchful eye on the quality of those earnings. This is not to say that a stock with no earnings cannot rise in price. Many stocks operate in the red quarter after quarter but continue to increase in value. In these cases, investors are bidding up the share prices based on expected future earnings.

So what drives investors' perception of earnings? First and foremost, different attributes of the company. Management styles, philosophies, patents, new products and promotions all help to drive the long-term value for shareholders. If investors feel the company has the right product at the right time and managing those opportunities efficiently, you can be sure it will be reflected in the stock's price. However, corporate earnings are not solely determined by management or products. No matter how fast a product is moving off the shelves or how skilled the management team, there are external factors the company cannot control. Interest rates, investor sentiment, inflation, and unemployment rates also play key roles for corporate earnings and investor perceptions. These factors provide the soil richness for earnings to grow.

To succeed as a long-term investor, you must understand two important characteristics of your investments. First, you must understand how your holdings are likely to react under different economic environments. Will lower interest rates be beneficial? Will rising inflation be harmful? Should you be concerned if new home sales are declining or retail sales are rising? Second, you must anticipate when those changes are likely to occur. And it is for this very reason that economic indicators were developed. They allow you to catch a glimpse of when market conditions appear to be changing so that you can buy, sell, or hedge your investments accordingly. Security prices are nothing more than collective opinions of investors from around 
the world who are all trying to determine the market's next move. If you wait for that moment before you react, it's probably too late.

Short-term traders can benefit from knowledge of economic indicators too. If you know that a particular indicator is due for release and how the market will likely react to various outcomes, it helps you prepare for any potential turbulence. In some cases, you may choose to avoid trades that will span across one or more key economic releases. In others, you may choose to speculate on the market's reaction. While investing is the art of valuation, it helps to unite the science of forecasting when those valuations may change. The economic indicators add a little bit of science to help you with such forecasts. They represent the economy's report card. This reference guide helps you interpret the grades.

\subsection{The Need for New Indicators}

In a provocative new study, a pair of Nobel Price -winning economists, Joseph E. Stigitz and Amatya Sen, urge the adoption of new assessment tools that incorporate a broader concern for human welfare than just economic growth. By their reckoning, much of the contemporary economic disaster owes to the misbegotten assumption that policy makers simply had to focus on nurturing growth, trusting that this would maximize prosperity for all. What you measure affects what you do and if you don't measure the right thing, you don't do the right thing. According to the report, much of the world has long been ruled by an unhealthy fixation on swelling the GDP, or the quantity of goods and services the economy produces. With a singular obsession on making G.D.P. bigger, many societies — not least, the United States — failed to factor in the social costs of joblessness and the public health impacts of environmental degradation. They allowed banks to borrow and bet unfathomable amounts of money, juicing the present by mortgaging the future, thus laying the ground for the worst financial crisis since the 1930s.

In their report they elucidates in general terms why leaning exclusively on growth as an economic philosophy may yield unhappiness, and it suggests that the incomes of typical people should be weighed more heavily than the gross production of whole societies. But it sidesteps the thorny details of slapping a cost on a ton of pollution or a waylaid career, leaving a great mass of policy choices for others to resolve. The resulting report amounts to a treatise on the inadequacy of G.D.P. growth as an indication of overall economic health. It cites the example of increased 
driving, which weighs in as a positive within the framework of economic growth, as it requires greater production of gasoline and cars, yet fails to account for the hours of leisure and work time squandered in traffic jams, and the environmental costs of pollutants unleashed on the atmosphere.

During the real estate bubble that preceded the financial crisis, the focus on economic growth helped encourage overbuilding and investment in real estate. Mr. Stiglitz argues that the singleminded focus on growth gave American policy makers a false sense of assurance that their policies were virtuous, as they allowed financial institutions to direct virtually unlimited sums of money into real estate and as consumer debt levels built with unrestrained momentum. Credit enabled spending and spending translated into faster growth - an outcome that was intrinsically good, and never mind how long it might last or the convulsions that would accompany the end of easy money.

A growth-oriented policy encouraged homeowners to borrow as if money need never be repaid, and industry to produce products as if the real cost of pollution were zero, Mr. Stiglitz added. "We looked to G.D.P. as a measure of how well we were doing, and that doesn't tell us whether it's sustainable," he said at the briefing. "Your measure of output is grossly distorted by the failure of our accounting system. What began as a measure of market performance has increasingly become a measure of social performance, and that's wrong." Instead of centering assessments on the goods and services an economy produces, policy makers would do better to focus on the material well-being of typical people by measuring income and consumption, along with the availability of health care and education, the report concludes [96]. 


\section{CHAPTER THREE}

\section{INVESTOR SENTIMENT IN EQUITY AND DEBT MARKETS}

This chapter explores the effect of investor sentiment in the equity and debt market. The conclusion reached by literatures result shows that sentiment indices have forecasting power on market returns for various long-short portfolios based on size, volatility, profitability, dividend payment, fixed assets, research and development, book-to-market ratio, and sales growth in other markets, especially in the developed markets, and that the forecastability can lasts for at least two years. The forecasting power of an index remains strong when the well-known market, size, book-to-market, momentum factors, and a local consumer confidence index are controlled. Researches have considered whether greater integration with the global market or a richer information environment could strengthen the forecasting power of the sentiment index. While there is some weak supportive evidence for each of these channels, collectively, they are far from complete. So, the degree to which the markets are affected by investor sentiment is not clear before it occurs. [97] [54] [66] As a result of the potential importance of investor sentiment in the price formation process, previous research investigated the relative importance of sentiment in public and private asset markets. This and the following chapters bring together the relation between investor sentiment and returns in equity, debt, conventional managed products, nonconventional managed products and derivative markets. [98]

\subsection{Investor Sentiment in Equity Securities}

Economists have devoted substantial attention to trying to understand the determinants of wild movements in stock market price response to extraneous variables that convey no information about fundamentals, since the coining of the term "animal spirits" 76 years ago. Noise traders are unimportant in the financial asset price formation process because trades made by rational arbitrageurs drive prices close to their fundamental values some literatures argue. Continuing evidence of market anomalies, for example, the under reaction and overreaction of stock prices and the closed-end mutual fund premium/discount puzzle, however, challenge efficient markets theory. The extent to which arbitrage can eliminate the divergence between prices and 
fundamental values has come into question in recent literature. [99] [100] [101] The recent study by [102] on messages in Internet chat rooms focused on stocks, characterizing the content of the messages as "buy," "sell," or "hold" recommendations. Although they do not find a statistically or economically significant effect of "bullish" messages on returns, the study found evidence of relationships between message activity and trading volume and message activity and return volatility.

Theoretical models of the effect of investor sentiment on stock market pricing make two important assumptions:

i. These models posit the existence of two types of traders, sentiment traders who hold random beliefs about future dividends and rational arbitrageurs who hold Bayesian beliefs. For example, when sentiment traders have expectations of future dividends that are below the expectations of rational arbitrageurs.

ii. These models assume that both types of traders have downward sloping demand for risky assets because they are risk averse, capital constrained, or otherwise impaired from freely buying and selling risky assets.

These assumptions lead to equilibrium in which sentiment traders' random beliefs about future dividends influence prices. Specifically, when sentiment traders experience a negative belief shock, they sell stocks to arbitrageurs, increasing volume and temporarily depressing returns. However, because these shocks are stationary, on average returns rebound next period when there is a new belief shock. [51] Forecasted models for investor sentiment shows that low sentiment generates downward price pressure and unusually high or low values of sentiment will generate high volume and suggest that a change in a set of asset prices may, especially in the short run, trigger changes elsewhere because such a change engenders shifts in the market's attitude towards risk because there is a change in investor sentiment. [51] [103] [104] Such shifts in risk attitudes may explain short term movements in asset prices better than any other set of fundamental factors. Other studies have also recognized that investor sentiment is an important component of the market pricing process [72] [54] 


\subsection{How Investor Sentiment Affect Stock Price}

If arbitrage is partly restricted or limited, the influence of sentiment on stock prices can be reflected as a uniform demand shock. The shift of demand can be categorized into two parts. One is the demand driven by rational investors whose expectations are related to quality information and rational evaluations. Therefore, the shift in demand induced by this part is foreseeable and hence may have already been reflected in the stock prices. The other part of the demand relates to the influence of the sentiment which reflects the expectation of the irrational investors. As the sentiment factor may be biased by information that is not related to the fundamental characteristics of stocks, an unexpected wave of sentiment may shift demand by an unforeseeable amount, and lead to unexpected changes in the stock price. For example, the propensity to speculate during a bubble period is high. This may increase the sentiment of investors. Sentiment investor may become over-optimistic about the future performance of the market and provide extra liquidity to the market. Consequently, this may induce the stock prices in the market to be pushed up or down by an inappropriate percentage that does not reflect the fundamental value of the stocks. Irrational investors in recessionary period may be less willing to provide capital to the stock market even when some stocks are probably under-estimated as they become over-pessimistic. [64] [66] [77]

Another research asked what makes some stocks more speculative than others? [105] It is the difficulty and subjectivity of determining their true values. For instance, in the case of an emerging company, currently unprofitable but potentially extremely profitable growth firm, the combination of no earnings history and a highly uncertain future allows investors to defend valuations ranging from much too low to much too high, as befits their prevailing sentiment. During a bubble, when the propensity to speculate is high, investment bankers can join the chorus arguing for high valuations. By contrast, a firm with a long earnings history, tangible assets, and stable dividends is much less subjective to value, and thus its stock is likely to be less sensitive to sentiment. One could appeal to psychological foundations here. Uncertainty means that the effect of overconfidence, representativeness, and conservatism is more pronounced. And, differences of opinion, even when investors have the same basic information, can be large. The changes over time in these biases, we would call shifts in the propensity to speculate. [105] 


\subsubsection{Investor Sentiment and Stock Return}

Sentiment traders acting in concert on non-fundamental signals can introduce a systematic risk that is priced. The deviations in price from fundamental value created by changes in investor sentiment are unforecastable. Arbitrageurs betting against mispricing run the risk, at least in the short run, that investor sentiment become more extreme and prices move even further away from fundamental values. The potential for loss and the arbitrageurs' risk aversion reduce the size of positions they are willing to take. Consequently, arbitrage fails to completely eliminate mispricing and investor sentiment affects security prices in equilibrium. [51] Sentiment trading may affect expected return through its impact on the market's formation of risk. Existing empirical tests focus primarily on first moment contemporaneous correlations between returns and sentiment changes with a few exceptions.

Sentiment trading may influence higher moments of return such as volatility. Using a sentiment measure compiled by American Association of Individual Investors (AAII), it was found that unusual levels of individual investor sentiment are associated with greater volatility in closedend fund returns. Literatures estimate that about $7 \%$ of the variation in fund discounts/premiums can be explained by noise trading. The sampling of 237 investment newsletters, found no evidence of market timing ability but that disagreement among newsletters is associated with volatility. None of these papers however directly address whether noise trader risk is a systematic risk that is priced in financial markets. [106] [51] [107] [108] Figure 4 shows S\&P 500 on pace to close lower for the fourth straight day, its no surprise that individual investors turned less bullish in the week. As shown in the chart, the American Association of Individual Investors (AAII) weekly poll of bullish sentiment dropped from $37.9 \%$ to $35.46 \%$. The AAII Investor Sentiment Survey measures the percentage of individual investors who are bullish, bearish, and neutral on the stock market for the next six months; individuals are polled from the ranks of the AAII membership on a weekly basis. Only one vote per member is accepted in each weekly voting period. 


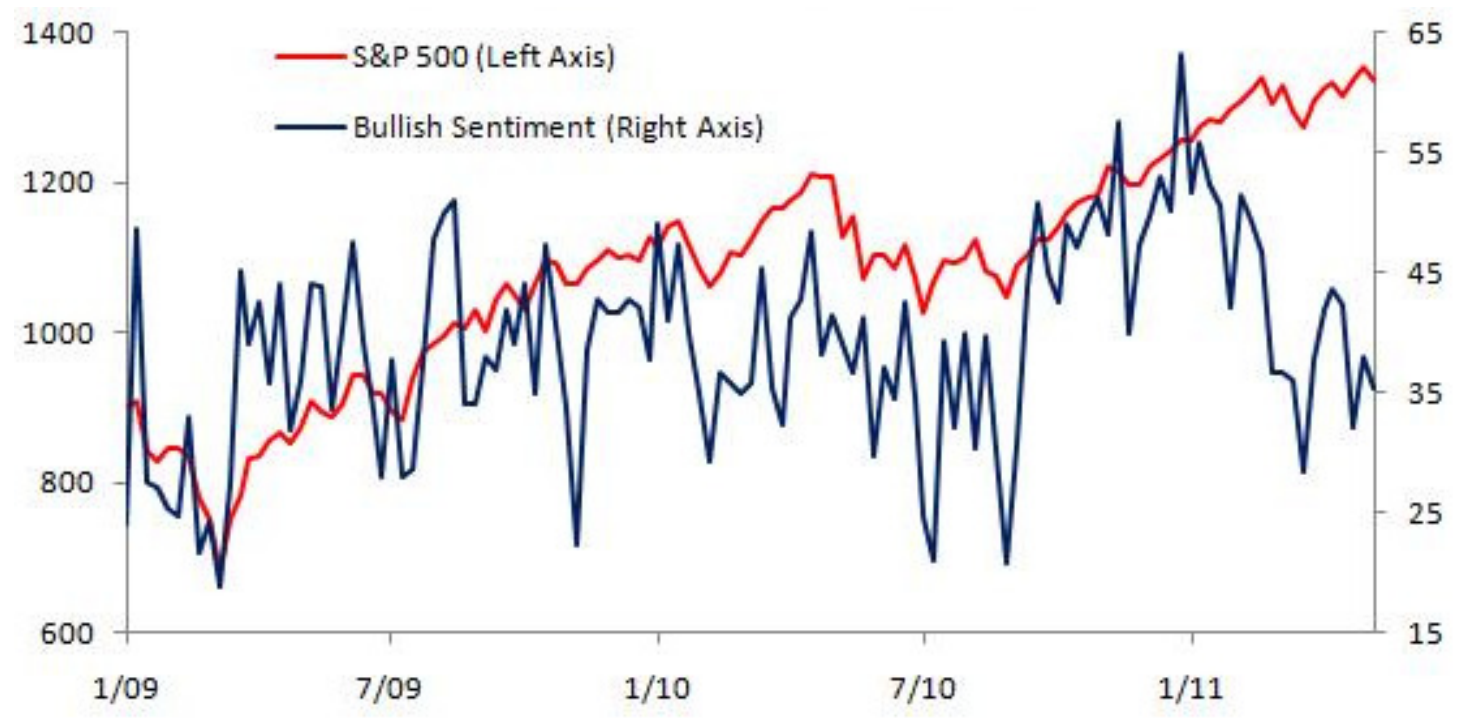

Figure 4 AAII Bullish sentiment 2009 - 2011 (Source: AAII)

To address this issue it was proposed that a return-generating model that explicitly tests the impact of noise trader risk both on the formation of conditional volatility and expected return as suggested in previous studies. In a market environment where noise traders are present, the holdmore effect implies that sentiment trader' increased holdings of risky assets when their sentiment becomes more bullish raises market risk and thereby increases expected returns; and when they are bearish the opposite is the case. However, sentiment traders overreact to good and bad news. Consequently, asset prices are either too high or too low depending on whether noise traders are on average optimistic or pessimistic. [51] [106] The overreaction induces pressure on price and lowers expected returns. Market returns will correlate with changes in investor sentiment and the direction of the correlation depends on which effect dominates.

Also, the size of the changes in perceptions about the asset's risk by noise traders associated with their shifts in sentiment also impact expected returns. Sentiment traders usually have poor market timing due to their inclination to transact together with other noise traders. Their capital losses from poor market timing are larger the greater is the magnitude of the change in their misperceptions. The Friedman effect implies that such changes result in higher market risk and lower expected returns. The extent of the adverse impact that the Friedman effect has on expected returns depends on the 'space' noise trading creates. A rise in sentiment traders' misperceptions increases price uncertainty and crowds out risk-averse informed investors. Consequently, the larger is the proportion of noise trading, the higher will be expected returns. 
Numerous studies have examined the tradeoffs between risk and expected return in securities markets. The collective evidence so far is inconclusive. Some literatures also provide empirical evidence of a positive relationship between market excess returns and forecasted volatility. The research examine the relationship between market volatility, excess returns, and investor sentiment for three different market indices, the Dow Jones Industrial Average (DJIA), the Standard and Poor's 500 (S\&P500) and the NASDAQ, from the beginning of 1973 through October 6, 1995. The widely publicized Investors' Intelligence of New Rochelle, NY, sentiment index was used as a direct measure of investor sentiment. The main findings suggest that sentiment is a significant factor in explaining equity excess returns and conditional volatility. The results consistently show that sentiment is a priced risk factor. Excess returns are contemporaneously positively correlated with shifts in sentiment. Some employed the generalized autoregressive conditional heteroscedasticity $(\mathrm{GARCH})$ to show that both the conditional volatility and excess returns are affected by investor sentiment. [106] The studies concluded that the magnitude of shifts in sentiment has a significant impact on the formation of conditional volatility of returns and expected returns. Bullish (bearish) shifts in sentiment lead to downward revisions in the volatility of returns and are associated with higher future excess returns. The significance of investor sentiment in explaining the formation of conditional volatility and expected return is robust across different indices.

Evidences on the effects of sentiment almost exclusively focus on cross sectional in local stock market, e.g. for value versus growth stocks or small versus large stocks. Analyzing the effects of investor sentiment on international aggregate stock markets is interesting for several reasons. It investigates whether consumer confidence - as a proxy for individual investor sentiment and concluded firstly that, there is a significant impact of investor sentiment on aggregate stock returns across countries on average. This effect remains significant even after controlling for other standard risk factors and expected business conditions. Secondly, in cross-sectional regressions we provide some first evidence that the impact of sentiment on stock returns is stronger in countries that have less market integrity and in countries that are culturally more prone to herd-like behavior as forecasted by [109] [110]

Other studies investigated the effect of global and local components of investor sentiment on major stock markets, at the level of both the country average and the time-series of the cross- 
section. They also consider whether and how sentiment spreads across markets. Evidence was consistent with investor sentiment playing a significant role in international market volatility and generates return forecastability of a form consistent with corrections of overreaction. In one of the literatures, quantitative sentiment indices were constructed to follow six stock markets: Canada, France, Germany, Japan, the United Kingdom, and the United States. The research also constructed indices of "total" investor sentiment for each country by forming the first principal component of several time-series proxies for sentiment and decomposed the six total sentiment indices into a single "global" index and six "local" indices. The data are annual from 1980 to 2005 and drawn from several international sources. The study concluded that investor sentiment affects the time-series of international market-level returns as well as the time-series of the crosssection of international stock returns. It was found that that global sentiment is a statistically and economically significant contrarian forecaster of market returns. Both global and local components of sentiment help to forecast the time-series of the cross-section; namely, they forecast the returns on high sentiment-beta portfolios such as those including high volatility stocks or stocks of small, distressed, and growth companies. Finally, global sentiment emerges and propagates in part because sentiment is contagious across markets, and at least one of the mechanisms at play is international capital flows. [111]

\subsection{Investor Sentiment and Pre-IPO and IPO}

The market for newly listed companies is a good setting to study the effect of investor sentiment on stock prices. Such companies by definition have no prior share price history and tend to be young, immature, and with very little information. As a result, they are hard to value, and it seems reasonable to assume that investors will have a wide range of priors about their market values. Studies argue that over enthusiasm among retail investors may explain the much documented price jumps once trading in newly listed stocks begins, as well as the subsequent low returns over the first few years of trading. [112] [113] [114]There are several anomalous aspects to the process by which firms go public. Initial public offerings (IPOs) exhibit positive first-day returns on average and so seem to be underpriced. The initial price run-up appears to be undone in subsequent months as IPO stocks underperform the market. Hence, from the vantage of a longer horizon, IPOs can arguably be regarded as overpriced in the after-market. The strength of these patterns varies over time, with both the initial price run-up and subsequent 
underperformance more dramatic in 'hot' periods of high IPO volume. Firms may even be able to time their IPO to coincide with periods of excessive valuations [115]

There are numerous models of IPO underpricing, typically based on investor rationality in incomplete information settings, but these have shed little light on the long-run performance of IPOs. Work on long-run performance is primarily empirical and emphasizes the role of investor sentiment and bounded rationality in explaining the price behavior of IPO stocks. The impact of investor sentiment is regarded as particularly acute in hot markets. Over time, investor exuberance fades, resulting in long-run underperformance. Issuers 'time' their IPOs to coincide with periods of excessive optimism. More companies go public when investor sentiment is high. [77] So, what really drives IPO underpricing? By first analyzing the cyclical behavior of IPO volume and underpricing, studies finds that issue activity is influenced by past IPO volume and underpricing. As price support truncates the distribution of underpricing and, therefore, influences the cross-section analysis quite substantially. Underpricing is mainly influenced by investor sentiment and, therefore, by the demand of potential investors, and less by ex-ante uncertainty. [116] [117]

\subsubsection{Facebook}

We can conclude that the initial success of Facebook was due mainly to irrational investors. Investor sentiment was at a very high level with total disregard to the underlying financials/trend lines. GM's releases a statement saying that Facebook ads don't work. While insiders were dumping their personal shares the offering was oversubscribed, so Facebook continued to inch up the offering price. General Sentiment, who track and analyze the online chatter from 60 million online sources, including Twitter. First, they examined the discussion volume when they announced their IPO in early February. It chronicles the start of the frenzy: from a few dozen speculative comments a day, chatter across the Internet surged past 10,000 daily. Few months later the level of interest, while fluctuating daily, still regularly hits that level. The total mentions of Facebook on a typical weekday hits 800,000. General Sentiment's analytic tool assigns positive or negative value to every comment, and aggregating it all into an index. Sentiment is then gauged on a -100 to +100 scales. Figure 5 shows what people thought of the IPO when it was announced. 


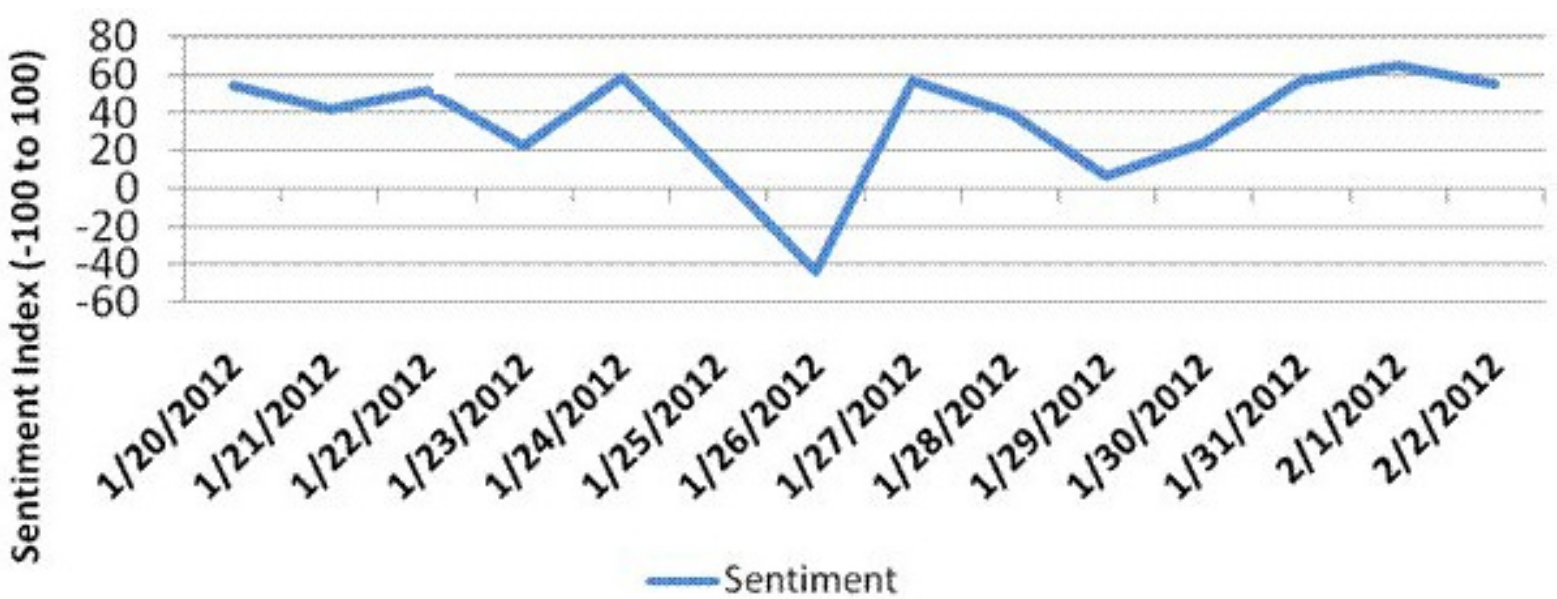

Figure 5 Facebook Pre-IPO investor sentiment (Source: General Sentiment 2012)

\subsection{Investor Sentiment and IPO Volume}

There are substantial fluctuations in IPO volume, but not many literatures have examined the underlying cause of this variation. IPO volume tends to be higher following periods of especially high initial returns, and their findings suggest that this relation is driven by information learned during the registration period. [117] Specifically, more positive information leads to higher initial returns for those offerings and more companies filing to go public soon thereafter. The findings suggest that IPO volume is related to various forms of market irrationality. The results suggest that periods of low IPO volume represent times when private firms can not access the equity markets on favorable terms, thus forcing them to enter into less favourable financing arrangements. Specifically, they find that during periods of low equity issuance the agreements signed between small biotechnology firms and major corporations are less successful and more likely to be renegotiated, compared to those agreements signed during periods of higher equity issuance. [118] [77] [119]

Another literature study why IPO volume vary by employing a 37 -year time series of U.S. IPO volume and investigating the extent to which efficient- versus inefficient market factors can explain the observed fluctuations. The objective of the study was to explore three potential explanations for the variation in IPO volume. One common perception regarding IPO volume is that it simply varies with the business cycle. During economic expansions, economy-wide demand for capital is higher and more firms therefore go public. [120] A second widely held viewpoint is that the variation in IPO volume is primarily driven by changes in investor 
optimism. The popular press contains many examples of this viewpoint. Finally, the lower numbers of IPOs during periods of high uncertainty potentially reflect a lemons problem, and this is a third explanation of the observed fluctuations in IPO volume. Variation in investors' uncertainty regarding the true value of firms may cause the adverse-selection costs and therefore IPO volume to fluctuate over time. The result of the study indicated that IPO volume is positively related to companies' demands for capital and the level of investor optimism explain a substantial portion of the variation in IPO volume. Adverse selection costs are marginally significant and appear to be of secondary importance. While sentiment does appear to affect the timing of IPOs, evidence indicates that it is not the only relevant factor.

\subsubsection{More on Facebook}

On May 18, 2012, the market started trading Facebook. Initial trading saw the stock shoot up to as much as $\$ 45$. But the early rally was unsustainable. The stock struggled to stay above the IPO price for most of the day, forcing underwriters to buy back shares to support the price. Only the technical glitches that happened earlier in the trading day and underwriter support prevented the stock price from falling below the IPO price on the first day of trading. At closing bell, shares were valued at $\$ 38.23$, only $\$ 0.23$ above the IPO price and down $\$ 3.82$ from the opening bell value. The opening was widely described by the financial press as a disappointment. Other securities fell much more as investors sentiment as the IPO excitement cooled. Individuals are influenced by sentiment. When investor sentiment is high about a product, it leads to overvaluations of stocks in the high sentiment sectors.

The financial media's attention to help fuelled Facebook's IPO but Facebook is not the only stock that can rise and fall far more than the actual value of their holdings. Some closed-end investment funds trade at prices that can be far different than their net asset value. Many research concluded that prices straying from their NAV were likely caused by sentiment-driven investors, not rational, informed investors. Long-run reversal of IPO stocks, which is likely to be a consequence of overoptimistic sentiment towards IPO firms, is also reported in many studies. [121] [122] 


\subsection{Investor Sentiment and Financial Market Crises}

Capital Asset Pricing Model (CAPM) suggested has long been a basic pricing theory in finance. [123] [124] However, plenty of works have suggested that stock returns are determined not only by the market risk, but also by size, book value to market value, momentum, liquidity, etc. Except for firm-specific factors, literatures suggested that investor sentiment serves a crucial role in determining stock returns [55] [51]. A study to investigate the effect of investor sentiment on the price of stocks traded in the Korean stock market finds that sentiment effect for the small cap portfolio after controlling market anomaly factors and price effects, returns of low price portfolio are still significantly affected by investor sentiment. These results imply that investor sentiment systematically affects the stock price of Korean firms with small cap, low price, and low book/market value. [125]

The crash of October 1987 and 2007 remains enigmatic for researchers. During the crash, the Dow Jones Industrial Average dropped significantly, further than what can be explained by changes in economic variables. Investor Sentiment theories being developed in the research community recognizes that investors are not rational but normal, and that systematic biases in their beliefs induce them to trade on non-fundamental information. The empirical question of a relationship between investor sentiment and stock market crises remains under-researched and unresolved. Extreme fluctuations in investors' sentiment often are mentioned as a factor that could explain the financial crises but rarely are analysed [2] [126] Few literatures attempt to directly link sentiment indicators to market crises.

The ability of sentiment indicators to forecast the occurrence of international stock market crises was researched in the literature but it focuses on stock market crises, rather than events of abnormal price run-ups. [127] Literatures also show that negative news and positive news produce different sentiment driven biases. [128] [129] In their study, a leading indicator of crises using data from 16 countries was built. The research empirically examines the influence of investor sentiment on the probability of occurrence of stock market crises during 1995-2009 by using panel data of 15 European countries and the United States to estimate a multivariate logit model. They concluded that investor sentiment positively influences the probability of the occurrence of stock market crises within a one-year horizon. The study further concludes that investor sentiment provides an incremental forecasting power of crises compared to other 
variables routinely used in existing studies. The impact of investor sentiment on stock markets is stronger for countries culturally more prone to herd-like behavior and overreaction and countries with low efficient regulatory institutions. Since investor sentiment is a good forecaster of securities overvaluation, portfolio manager can benefit by paying attention to it for profit, risk management and to anticipate stock market crises.

\subsection{Investor Sentiment in Debt Securities}

The market for debt securities is very large, both in size and breadth. Fixed-income markets are populated with a vast range of instruments, so in this section we mainly refer to bonds and money-market instruments. A debt security, or a bond, is a financial claim by which the issuer, or the borrower, is committed to paying back to the bondholder or the lender, the cash amount borrowed, called principal, plus periodic interests calculated on this amount during a given period of time. It can have either a standard or a nonstandard structure. A standard bond is a fixed-coupon bond without any embedded option, delivering its coupons on periodic dates and principal on the maturity date. The purpose of a bond issuer is to finance its budget or investment projects, construction of roads, schools, development of new products, and new plants at an interest rate that is expected to be lower than the return rate of investment. Through the issuance of bonds, it has a direct access to the market, and so avoids borrowing from investment banks at higher interest rates. In the context of financial disintermediation, this practice tends to increase rapidly. One point to underscore is that the bondholder has the status of a creditor, unlike the equity holder who has the status of an owner of the issuing corporation. This is by the way the reason why a bond is, generally speaking, less risky than equity. [130]

Investor sentiment is one of the most reliable ways to forecast price changes in the debt market. Extreme bullishness and extreme bearishness have foretold key turning points in asset prices for centuries. There is a growing literature studying the role of investor sentiment in asset classes including debt securities that ask how sentiment affects international stock markets. The basic supposition is that if sentiment drives prices too far, then corrections may be observed in the form of return forecastability. Using regressions to forecast market returns and pooling six markets together for power in our short sample in their research, [83] they found that the total sentiment, and particularly the global component of total sentiment, is a contrarian forecaster of 
country-level market returns. These results are similar for both value- and equal-weighted market returns and for non-U.S. markets. In addition to the papers above, there is evidence for the role of investor sentiment in the debt security market and market returns. [53] [81] [63] Some of the studies argue that the trade-off between risk and expected return applies only in low sentiment periods. One concluded that the forecasting power is concentrated in high-sentiment periods and in stocks in short legs. Researches also investigate how sentiment connects the cross-section of stock returns and government bonds and some discuss sentiment and the time-series relationships between government bond and stock market returns and these papers concluded that sentiment affects aggregate financing patterns. [131] [132] [133]

\subsubsection{Bond and Stock Inter-Relationship}

Debt securities, especially bonds have the added advantage that they are linked to the equity market especially corporate bond at the firm level. Bonds and stocks are different claims to the same underlying operating cash flows, and are, therefore, affected by the same fundamental risk although to varying degrees. The implications of unforecastability of investor sentiment even without taking a position on how investor sentiment moves, it can be observed that it moves in part. Even if arbitrageurs know that noise traders are pessimistic today and hence will on average become less pessimistic in the future, it cannot be certain when this will happen. There is always a chance that noise traders become even more pessimistic first. This unforecastability contributes to resale price risk, since the resale price of an asset depends on the state of noise trader sentiment. If investor sentiment affects a broad range of assets in the same way, this risk from its unforecastability can becomes systematic.

Systematic risk has a price in equilibrium. Consequently, assets subject to whims of investor sentiment should yield higher average returns than similar assets not subject to such whims. Put differently, assets subject to unforecastable swings in investor sentiment must be underpriced in the market relative to their fundamental values. [51] Therefore stocks are probably subject to larger fluctuations of investor sentiment than bonds. In this case, equilibrium returns on stocks must be higher than warranted by their fundamentals-the latter being given by dividends and by co-variation of dividends with consumption. In particular, the difference between average returns on stocks and on bonds-the risk premium-must be higher than is warranted by fundamentals. 
Such excess returns on stocks are in fact observed in the U.S. economy. The argument can even be reverse to say that the high average risk premium is evidence of unforecastability of investor sentiment about stocks.

\subsection{Bond Traders and Speculation}

The type of extreme speculation that has roiled other markets has rarely infected the bond market, speculative excess and extreme emotions have played a large role in the bond market's behavior. It is easy to see how considering the size of the bond market, there are obviously large numbers of participants - who are subject to the same human emotions that create excesses in other markets. Tracking investor sentiment in the bond market can enhance investment returns in bonds significantly and help enhance the returns on other financial investments too, mainly by helping to time investments better. If, for example, market sentiment appears to be at a level that historically has indicated that investors may be excessively bullish, delaying a purchase of bonds until prices retreat a bit may be a option. Similarly, if market sentiment appears to indicate excess bearishness, purchases of bonds or perhaps be opportunistic and buy bonds for a capital gain if achieving capital gains is one of your investment objectives may be a better option. It is also a good idea to look for signs of extreme sentiment within the various segments of the bond market in order to help decide on which segments to avoid and or invest in.

Tracking investor sentiment in the bond market also helps investor forecast changes in stock prices and the economy. The basic premise is this: Because the bond market's behavior tends to be influenced strongly by its expectations about the economy and other macro influences, when bond market sentiment reaches an extreme, that extreme can reflect sentiment about the future direction of the economy as well as about bond prices. In other words, when bond market sentiment is at an extreme, sentiment about the economy must be at an extreme too. Bond sentiment analysis can help spot turning points in the economy and/or stock prices. In the bond market one of the indicators of investor sentiment is to track the aggregate positions of bond investors. This means the long and short position with respect to duration exposure, curve positioning, futures exposure, and exposure to riskier types of bonds. Here are some key indicators that gauge inventor's sentiment in the bond markets. 


\subsubsection{Market Data Measure: Put/Call Ratio}

In the traditional options market, call products give a right to buy an underlying asset whereas put products entitle the holder to sell the underlying asset at a predetermined price. Most investors are by nature optimistic, and a falling market is usually an opportunity for them to find the bottom. However, in recent years investors have gained more and more experience with the opportunity to speculate on falling markets, so that put products have become popular instruments for retail investors. The put/call ratio is a popular gauge of market sentiment that is used by stock and bond investors alike. It is simply a measure of the daily trading volume in put options compared with the daily trading volume in call options. Since puts are a bearish bet on the future direction of the market and calls are a bullish bet, extreme volume in either one is a sign of excess sentiment. Most stock exchanges compute a put/call ratio. The most widely-used put/call ratio in research is the one computed by the Chicago Board Options Exchange (CBOE). Half-hourly, the CBOE collects data on put and call options traded on equities and indices. Hence it publishes three put/call ratios: the equity $\mathrm{p} / \mathrm{c}$, the index $\mathrm{p} / \mathrm{c}$ and the total $\mathrm{p} / \mathrm{c}$ ratio. The CBOE estimates the ratios by dividing the volume of put options contracts by the volume of call options contracts. A high ratio suggests a negative market sentiment. Some research papers also concluded that $\mathrm{p} / \mathrm{c}$ ratio can forecast $\mathrm{S} \& \mathrm{P}$ futures returns.

Bond investors in the 1990s looked at the inverse of the put/call ratio because call volume generally exceeded put volume, resulting in a put/call ratio of over 1.0, where 1.0 indicates that one call traded for every put. Investors prefer to quote ratios where they are over 1.0. Although a value of 1.0 might seem to be a neutral reading, empirically it has been observed that there are more calls than puts bought on what would be considered an average day. As a result, a put/call of approximately 0.80 is considered normal. Markets are considered strong when the ratio falls below 0.7 since the optimists clearly outweigh the pessimists. Markets are considered weak when the ratio rises above 1.1 since the pessimists outweigh the optimists. [134] So whenever market participants discussed or analyzed options activities the put/call ratio was used. In the stock market put volume typically exceeds call volume; that is, the put/call ratio is generally greater than 1.0. Equity investors therefore prefer to follow the put/ call ratio. Trading volume in the CBOT's contracts is quite high, and participation in Treasury options includes a wide variety of investors. The CBOT's options therefore capture investor sentiment well. Trading volume in 
Eurodollar options actually exceeds by a very large margin the trading in Treasury options. The message embedded in trading volume in Eurodollar options is quite useful, but it is narrowly focused on sentiment toward the short end of the yield curve, and therefore it is not as indicative of the risk-taking mindset of the speculative element of the bond market, which is what we are trying to capture $\cdot$ when tracking trading volume. [135]

The best way to use the put/call ratio is to compare its 10-day average to its one-year average. The 10-day average works well because it removes a great deal of daily noise from the analysis. When the 10-day average moves sharply above or below the one-year average, it generally indicates that market sentiment is moving toward an extreme. From the middle of 2001 through the middle of 2008, the one-year average of the put/ call ratio increased steadily, from about 1.3 to around 1.4. The daily put/call ratio began to fall when in the fourth quarter of 2008 the financial markets became unstable and money drifted toward Treasuries. [135] Conclude that tracking the put/call ratio is very easy. The 10-day average, of course, is simply the average of the 10 previous trading sessions. You should compute this average yourself since it is not readily available. The core elements of the put/call analysis can be readily applied to other markets and have proven to be a very useful gauge of investor sentiment in the bond market.

\subsubsection{COT Report}

Commitments of Traders (COT) reports that have been published periodically by the CFTC since early 1980s, detail positions taken by categorized traders in US futures markets. The CFTC annually classifies the reportable positions as either commercial or non-commercial. Traders who take commercial positions to hedge a specific risk are referred to as large hedgers, those who take non-commercial positions for reasons other than hedging are referred to as large speculators, and traders whose positions do not exceed the CFTC's reporting threshold are referred to as small traders. Based on net positions by a type of traders, the investor sentiment index, COT index, is often promoted as a useful timing indicator. Compared to other bullish sentiment indices that are based on analysts' opinions, the COT index may be more closely related to private information in futures markets. One study wrote that the Commitments reports can be followed much like SEC insider-transactions numbers to spot special situation ... commercials are typically value buyers. When their net buying is near its historical top, it is a tip-off that they 
think bargains is available. When their net position reaches its lower historical boundary, it usually means that they think tulip-mania has griped a market. [136]

The largest traders in each market are required to disclose their positions to their agency on a daily basis and are separated groups: Commercial traders represent companies and institutions that use the futures market to offset risk in the cash or spot market. This class of trader is not going to be very helpful for retail investors and we don't pay much attention to them. The nonCommercial includes large institutional investors, hedge funds and other entities that are trading in the futures market for investment and growth. They are typically not involved directly in the production, distribution or management of the underlying commodities or assets. This category attracts the greatest attention. The reports also show the positions of "small traders," which are not required to report and whose holdings can be calculated by subtracting the total of contracts held by the reporting groups from all the contracts outstanding. A small trader can be a speculator or a hedger. The position size that triggers a reporting requirement varies by market. For instance, for Comex gold: 200 contracts; for the S\&P 500 index, 300 contracts; for T-bond futures, 500. The COT report essentially shows the net long or short positions for each available futures contract for three different types of traders. If traders are overwhelmingly long or increasing their long positions then we will have a bullish bias on that market. Similarly, if traders are short or increasing their short positions then we will have a bearish bias. Not all traders in the report are of equal importance. In fact, of the three types of traders, investors usually pay attention to the one type with requirements most like the individual trader.

Is investor sentiment based on trader positions forecast future market movements in futures markets? How do traders forecast market movements? What makes traders bullish or how do changes in sentiment affect futures prices? Which type of traders may be better informed in the market? These are the questions asked in the literature. [137] The research concluded its findings, saying that the sentiments of both large speculators and large hedgers are useful market timing indicators, but they provide opposite forecasts. Large speculator sentiment is a price continuation indicator. Contrary to popular beliefs, large hedger sentiment is a (weak) contrary indicator. Small trader sentiment hardly forecasts future market movements. We proceed to investigate various timing strategies based on investor sentiment, and find that extreme levels and the combination of extreme levels of sentiments of large speculators and large hedgers 
provide a more reliable tool for forecasting. The evidence may suggest that large speculators as a whole are associated with superior forecasting ability, large hedgers behave like positive feedback traders who often overreact to non-fundamental information, and small traders are liquidity traders whose trading motives reflect liquidity needs. Thus, that the informativeness of trades differs across trader types may explain the usefulness of sentiment by type of trader for forecasting.

To substantiate this claim and check the robustness of our results, he further investigate the relation between future returns and past returns, the relation between the level of sentiment by type of trader and past returns, the relation between changes in sentiment by type of trader, past returns and past volatility, and the relation between absolute changes in sentiment by type of trader and futures volatility. The study shows that future returns are not forecasted by past returns in the futures market, and the investor sentiment does not appear to be significantly affected by past returns. However, there exists a negative and statistically significant relation between small trader sentiment and past volatility, and a positive relation between absolute changes in hedger sentiment and futures volatility. Generally consistent with standard market microstructure models and noise trading theories, the empirical evidence supports our conjecture on the informativeness trades by type of trader. The differential informativeness of trades by type of trader thus explains the usefulness of the sentiment by type of trader for forecasting the S\&P 500 futures returns. [137]

Commercial traders in bond futures are the true end users of the contracts: the hedgers and those who are in the business of buying and selling fixed-income securities. Commercial traders are known as the "smart money." They can be primary dealers, insurance companies and pension funds. Market tops and bottoms frequently have been foreshadowed by extreme positions taken by non-commercial traders. This is the case largely because speculators have relatively less information than do commercial players about market fundamentals and the true level of underlying demand for fixed-income securities. In addition, speculators frequently have a herd mentality and are therefore more likely to alter their positions when commercial players ignite a change in the market's direction. Moreover, speculators have a tendency to accumulate relatively large positions toward the end of a market trend, when they let human nature get the best of them 
by letting greed dictate their actions. COT provides data for the analysis of these behaviors. So savvy traders use the commitments report lo forecast important trends, not only in futures prices but also in related primary markets. Bond traders look for signs of imminent changes in likely interest- rate environment, and mutual-fund manager's use the data to anticipate shifts in the fortunes of stock sectors. Let us look at these examples provided by [136]:

A report issued on Jan. 21 allowed that large commercial hedgers had held an unusually large number of 30-day Treasury-bill futures during the preceding two weeks. In fact, they held 16,545 more short than long contracts when the report was tabulated on Tuesday, Jan. 18. This represented their lowest net position (long contracts minus short contracts) in more than two years. Obviously, the "non-commercials" had suddenly changed their outlook on short-term rates. This was a dear sell signal to perceptive readers of the report, which was released just five days before the market topped and interest rates spiked.

Last year, silver was a hot stock-market sector, as well as one of the brightest commodities. Gold and silver ruining shares rallied smartly from a mid-January low of 93 and never looked back. The commitments report published on Jan. 22 showed that commercial purchasers had pushed their net position to an 18-month high in gold and a three-month high in silver. A second buy signal was apparent in the March 7 report, delayed one week as a result of a catastrophic event, commercials were aggressive purchasers of both gold and silver contracts. The silver net position reached a 16-month high. Gold and silver futures in the Commodity Exchange bottomed on March 10. Later in the year, unprecedented commercial hedger selling preceded the Aug. 4 market peak. Subsequent re-buying triggered buy signals at the reaction low in August as commercials paid up to re-establish their position. The recent market top was tipped off when record commercial selling (and a new net short record in silver) was noted in the April 1 report.

The study report concluded that investors believe in the underlying fundamentals, that monetary policy will take an accommodative stance. In turn, this says a great deal about how investors expect the evolution of economic data to fair, which is to say, traders would expect economic data to reflect economic growth and inflation to stay low enough to keep the federal bank sideline. When focusing on the combined activity of non-commercial traders across the yield curve rather than on a single maturity, one can get a better sense as to whether an extreme long or short in a single maturity is indicative of sentiment toward the overall market or toward a segment of the yield curve. So, the Commitments of Traders (COT) report can provide important insights. Analyzing it can be like turning on a, light to reveal the sickly cattle or the prise steers. [136] [135] 


\subsubsection{Bond Yield Spread}

Analysts often use financial variables to help forecast real activity and inflation. Financial variables offer readily accessible information and, because market participants base their investment decisions on their forecasts of real activity and inflation, the information in financial market variables is deemed to be reliable. One of the most popular financial market variables is the spread between yields on long-term and short-term government instruments, also known as the yield spread. Researchers have shown that the spread is a good forecaster of real activity, and its forecasting power also has been recognized beyond academic research circles. For instance, the Conference Board uses the yield spread in constructing its Index of Leading Indicators. Studies found that the spread helps forecast real activity over the next year, the next two years, and the next three years. [138]

The yield on a government bond is the annual rate of return, or interest rate that would be earned by an investor who holds the bond until it matures. Time-until-maturity, or maturity, of a bond is an important feature of a bond because yields differ with maturity. The yield curve describes the relationship between yields and maturities. Yield curve information is published daily by the financial press. The shape and level of the yield curve change daily as investors reassess current and expected future economic conditions. The yield spread is the difference between yields on two different debt securities. The yield spread also provides information on the slope of the yield curve. The larger the spread is between a long-term and short-term bond, the steeper the slope of the yield curve will be. Analysts look to the yield spread as a potential source of information about future economic conditions. Several hypotheses argue that the information in the yield curve is forward-looking and therefore should have forecasting power for real growth and inflation. Flurry of literatures tested and verified the well-known proposition that a flattening of the yield curve is a strong signal of an impending recession. Though different studies use different maturities for the long and short rates, generally the same result obtains: the yield spread significantly forecasts GDP for horizons from one to eight quarters ahead. In fact, for forecast horizons of greater than two quarters the yield spread considerably outperforms specially constructed indices such as the Commerce Department's index of leading economic indicators. [139] 


\subsubsection{Yield Spread and Monetary Policy}

The yield spread reflects the stance of monetary policy. A low yield spread reflects relatively tight monetary policy and a high yield spread reflects relatively loose monetary policy. This interpretation is based on an economic theory which equates long-term yields with a risk or term premium plus a weighted average of expected future short-term yields. Because they reflect what market participants expect short-term yields will average over a relatively long time interval, long-term yields are a reasonable benchmark against which current short-term yields can be compared. So, when current short-term yields are high relative to long-term yields, so the yield spread is low, this view holds that the current stance of monetary policy is relatively tight. Yield spread may reflect the stance of monetary policy. [138] Short-term yields move closely with the interest rate that serves as an instrument of monetary policy (i.e., the federal funds rate in the United States). When monetary policy is tightened, short-term interest rates rise. Although longterm yields may react to policy, they rarely rise one-for-one with short term interest rate increases. As a result, the yield spread usually falls when monetary policy is tightened.

The yield spread model developed during his study does not forecast movements in output because the shape of the yield curve causes output to behave as it does; rather the yield curve is shaped as it is because it responds (through the rational expectations of the policymaker and the public) to the expected future values of economic variables. As is true with many financial variables that forecast real variables, the ability to forecast should be carefully distinguished from the ability to cause. The yield spread extracts expected inflation and output from the expected path of interest rates, which is determined by the central bank's policy reaction function. In other words, the yield spread does not tell us anything that the central bank and bondholding households don't implicitly already know. [140] The study was tempted to take issue with [141] and others who believe the forecasting power of the yield spread should be used as a guide to monetary policy. After all, the shape of the yield curve is determined by a bond market operating with the same information set as the central bank. However, if the public and the central bank are operating with different information, unlike the model presented in this paper, then the central bank could actually gain new information from the yield spread regarding the public's expectation of the future course of real economic variables, information that could be useful in the setting of monetary policy. 


\subsubsection{Yield Spread and Credit Market}

The yield spread contains information on credit market conditions. Long-term yields reflect equilibrium between supply and demand conditions in credit markets. Long-term yields are determined in financial markets and, although they may react to policy shifts, they also may change in the absence of an explicit shift in monetary policy. Thus, although much of the variation in the yield spread is due to policy-driven shifts in short-term yields, the spread also changes with shifts in long-term yields. The most common version of the credit market theory forecasts that an increase in the spread caused by an increase in long-term yields will precede stronger real growth and higher inflation. This forecasting is based on the assumption that the rise in long-term yields is caused by an increased demand for credit. An increase in the demand for credit likely portends a pickup in economic activity as credit financing facilitates increased investment and personal consumption expenditures. [140]

\subsubsection{Yield Spread and Inflation}

The yield spread reflects the direction of future inflation changes. This hypothesis stresses the links between the yield curve and expected inflation. When long-horizon expectations of inflation change, long-term interest rates change. For instance, improved credibility of monetary policy may result in lower expected future inflation, lower long-term yields, and a lower spread. Under this view, a decrease in the spread will forecast a decrease in inflation if investors' forecasts are on average correct. [140]

\subsubsection{Yield Spread and Growth}

The level of the yield curve may also provide useful information for helping forecast real growth and inflation. Since overall demand for and supply of credit are reflected in the general level of interest rates across the maturity spectrum, this information may provide forecasting information in addition to that summarized by the yield spread. The yield spread does not contain information on the general level of interest rates because it is constructed as the difference between two rates. The level of the yield curve as measured by short rates might help forecast real growth and inflation because short rates may provide information on the stance of monetary policy. Shortterm interest rates move closely with the interest rate that serves as an instrument of monetary policy. [141] While fluctuations in the yield spread may reflect shifts in policy, they may also be 
caused by shifts in risk premium. Thus, the level of short rates may provide a better measure of the stance of monetary policy than the yield spread.

\subsection{Bond Maturity, LIBOR and Investor Sentiment}

While it is common to refer to the 10-year T-note, there is often an overlooked maturity that may be a better benchmark than all the rest and may better capture market sentiment and forecast turning points in the market. What about the yield rate between corporate bond and treasuries on investor sentiment? Another important sentiment indicator is the LIBOR and Federal Funds rate. A sharp widening in the spread can indicated that banks were fearful of lending to each other. A widening spread indicates as much because when the LIBOR moves above the cost of money set by the Federal Reserve fund rate it means that banks are concerned about both counterparty risk and liquidity. Such concerns compel banks to demand a higher interest rate banks that borrow money from them. See [135]

\subsection{Investor Sentiment and Sovereign Bond Yield Spreads}

Theory does not provide any specific with respect to the variables that determine yield spreads but empirical work suggests that yield spreads reflect mainly three different types of risk: general market risk, default risk and liquidity risk. [142] Studies suggest that liquidity risk is an important determinant of bond spreads even after controlling for macroeconomic influences, while other literatures find that liquidity is an important explanatory variable along with default risks [143] and that euro area sovereign spreads are affected risk premium in international financial markets and factors that are related to local bond market credit and liquidity risk, [144] although since the collapse of Lehman Brothers local risk factors have gained importance. Previous studies on yield spread determinants, however, concentrate on fundamental economic variables and neglect variables that may capture other aspects of market behavior, such as sentiment and behavioral biases.

During the past decade the results of many empirical studies indicate that investor sentiment has a significant effect on stock returns. The use of consumer confidence measures of the University of Michigan and the Conference Board as proxies of sentiment and find that consumer confidence has some forecasting ability on stock returns; a negative relationship is found between the level of consumer confidence and subsequent Nasdaq and small cap stock returns.

Other studies examine consumer confidence as a proxy for individual investor sentiment for 18 
industrialized countries and finds that sentiment negatively forecasts aggregate stock market returns, on average, across countries. [145] The effect of investor sentiment on corporate bond yield spreads and finds that bond yield spreads co-vary with sentiment and it seems that sentiment driven mispricing documented for stock markets may be present in bond markets as well. [53] [83] [146]The Greek yield spread study estimate models of the yield spread where the explanatory variables proxy not only for economic fundamentals such as economic activity, default risk, liquidity risk, and general market conditions but also for biases in investor sentiment. [147] The investigation was done in the light of the 2011 Greek's financial crisis. The results indicate that a significant determinant for both the level and the changes in yield spread, along with local economic activity is dependent on the local and international investor sentiment, especially during the crisis period.

\subsection{Mortgage Back Security}

Mortgage-backed securities (MBS) are debt obligations that represent claims to the cash flows from pools of mortgage loans, most commonly on residential property. Mortgage loans are purchased from banks, mortgage companies, and other originators and then pools by a governmental, quasi-governmental, or private entity. The entity then issues securities that represent claims on the principal and interest payments made by borrowers on the loans in the pool, a process known as securitization. Most MBSs are issued by the National Housing Agencies, Freddie Mac, CHMC and Government Sponsored Agencies (GSA). MBS issued by government are backed by the full faith and credit of the government, guarantees that investors receive timely payments. Fannie Mae and Freddie Mac also provide certain guarantees and, while not backed by the full faith and credit of the U.S. government, have special authority to borrow from the U.S. Treasury. CHMC issued MBS is backed by the credit of the Canadian government. Some private institutions, such as brokerage firms, banks, and homebuilders, also securitize mortgages, known as "private-label" mortgage securities.

Mortgage-backed securities exhibit a variety of structures. The most basic types are pass-through participation certificates, which entitle the holder to a pro-rata share of all principal and interest payments made on the pool of loan assets. More complicated MBSs, known as collaterized mortgage obligations or mortgage derivatives, may be designed to protect investors from or 
expose investors to various types of risk. An important risk with regard to residential mortgages involves prepayments, typically because homeowners refinance when interest rates fall. Absent protection, such prepayments would return principal to investors precisely when their options for reinvesting those funds may be relatively unattractive. A large part of the money used to fund mortgage loans comes from investors who purchase mortgage-backed securities (MBS). As a result, the demands and sentiments of these investors heavily influence mortgage rates.

MBS being a bond product is affected by all the factors that concern the bond market. These include the health of the overall economy, the prevailing appetite for risk, expectations for inflation or deflation, and the performance of the stock market. Not withstanding all of these things, however, an investor's taste for MBS is ultimately rooted in how competitive the MBS is relative to other investment options available. The yield to investor is driven by the mortgage rates on the underlying loans and the rates are mostly determined by the bond market. As we have already discussed, an investor looking for a fixed-income security has many options within the overall bond market: government, corporate, municipal, and MBS, among others. While investors evaluate these options relative to one another, the overriding benchmark for the bond market is typically the U.S. Treasury, because it's essentially viewed as risk-free. All other bond investments not backed by the U.S. government, including MBS, must therefore pay a higher yield-to compensate the investor for the additional risk.

The 10-year Treasury is a good benchmark for mortgages, because most such loans are paid off or refinanced within 10 years. If the risk premium for MBS was stable, then the 10-year Treasury Constant Maturity would be a reliable tracking tool for mortgage rates. Unfortunately, investor sentiment is not so forecastable. In reality, the 10-year Treasury tracks with mortgage rates over longer periods of time, but it isn't a reliable indicator of short-term mortgage rate fluctuations. In the short-term, MBS investors are motivated by the same factors that influence other bond investors. Any factor that adds risk will put upward pressure mortgage rates, while factors that reduce risk will induce a downward pressure on mortgage rates. 


\section{CHAPTER FOUR}

\section{INVESTOR SENTIMENT IN MANAGED FUNDS AND ALTERNATIVE INVESTMENTS}

\section{Managed Funds}

Conventionally managed funds also called mutual funds are a type of collective investment vehicle. These vehicles invest the pooled resources of individuals and firms into a wide range of equity, debt, or other investment portfolios. An investor in an investment fund owns a pro rata share of the assets in the fund's investment portfolio. Investment funds can be either open-end or closed-end. Open-end funds issue new shares to investors and use the proceeds to make individual investments. Open-end funds typically stand ready to buy back their funds shares at the shares net asset value (NAV). Therefore, asset valuation and NAV pricing are major issues for open-end funds. Closed-end funds issue a fixed number of shares only. Shareholders in a closed-end fund access the value of their investments by selling their shares in the market, often at a discount or premium to NAV. Investment funds perform important functions such as divisibility, store of value, liquidity, price discovery, and enterprise monitoring.

Well-run investment funds offer individual investors an efficient means of diversification. By adding liquidity to their holdings, through either the buy-back of open-end fund shares or a stock market listing of closed-end shares, investment funds offer investors much greater flexibility in managing their investments. This represents an expansion in the range of investment opportunities that could potentially contribute to larger savings. Investment funds and other institutional investors can also contribute to market turnover and liquidity, more effective price discovery, and lower cost of capital, potentially improving the level and quality of capital formation. Furthermore, institutional investors can also have a positive impact on corporate governance, either by directly voicing shareholders' interests to corporate management or through direct monitoring and possible exit. [148] Investors can redeem conventional mutual funds at any time for their proportionate interest of the fund's net assets. Because conventional 
mutual funds do not trade on an exchange, the only way an investor can get their money out of the conventional mutual fund is by redeeming their investment in the fund. [149]

\subsection{Mutual Funds Flow}

Mutual fund flow is net new cash flow to the amount of cash either flowing into or out of mutual funds. It is derived by subtracting the redemption of shares from investors' purchases of mutual fund shares. Included in the calculation is the net amount of exchanges, which occur when shareholders switch money among different funds within the same mutual fund family. Excluded from net new cash flow is the value of shares purchased by shareholders when they reinvest dividends back into their funds. An outflow occurs when the amount of shares redeemed exceeds the amount of new sales and net exchanges of mutual funds. Mutual fund flow reports provide investors with critical monthly mutual fund money flow trends and analysis. With this information managers and marketing analysts know about which types of funds investors have been putting their money in and why. The reports also provide an important resource that can help market strategists, hedge fund managers, and all types of asset managers to project which asset classes, regions, sectors, and investment styles may potentially see the largest money inflows in coming months, depending on specific future market movements.

The research using a sample of daily net flows to nearly 1,000 U.S. mutual funds over a year and a half period identify a set of systematic factors that explain a significant amount of the variation in flows. [150] This suggests the existence of a common component to mutual fund investor behavior and indicates which asset classes may be regarded as economic substitutes by the participants in the market for mutual fund shares. The study found that flows into equity funds both domestic and international - are negatively correlated to flows to money market funds and precious metals funds. This suggests that investor rebalancing between cash and equity explains a significant amount of trade in mutual fund shares. The negative correlation of equities to metals suggests that this timing is not simply due to liquidity concerns, but rather to sentiment about the equity premium. The question of whether behavioral factors spread returns by using the mutual fund flow factors as pre-specified repressor in asset pricing framework. 
The study also found that the factors derived from flows alone explain as much as $45 \%$ of the cross-sectional variation in mutual fund returns. The fund flow factors provide significant incremental explanatory power in the cross-sectional regressions on daily returns. The study concluded that investor supply and demand on a small group of funds is an instrument for market-level shifts in supply and demand for different types of assets on a daily basis. This may be due to the existence of behavioral factors per se such as market sentiment, or alternatively, flows and returns may both be correlated to an unidentified additional factor in the economy.

A daily panel dataset of United States and Japanese mutual fund flows was also used in a study. The Japanese dataset contains a number of funds explicitly named "Bull" and Bear," reflecting investor opportunities to effectively bet on the rise or fall of the Japanese stock market. The study found that that the daily flows to bull and bear funds in Japan are strongly negatively correlated. [151] This pattern is consistent with a strong, common sentiment factor among Japanese mutual fund investors. Our evidence supports that this sentiment factor is priced. These results further suggest that the structure of correlation in daily mutual fund flows both in the U.S. and Japan is a useful measure of attitudes beyond the simple domestic equity markets. It was argue that herding may take place in subsectors of the equity universe, not simply with respect to the stock market as a whole. Japanese mutual funds flow data is consistent with the existence of a foreign-domestic sentiment factor as well as a domestic equity factor. [152]

While theory suggests that a pervasive sentiment factor might well be priced, the quest for a concrete measure of that factor has been somewhat illusive. The Japanese mutual fund data used for the study allows a direct observation of flows of small, retail investors in the Japanese market into funds that explicitly speculate on the direction of the stock market. This study reveals a number of results that are of potential interest to both asset pricing and behavioral research. First, the structure of flow correlations across funds representing major asset classes is strong and significant. Investors make correlated rebalancing decisions on a daily basis. In the U.S., where mutual funds are a major factor in the securities markets, these choices appear to be simultaneously correlated to asset class returns. In Japan, the correlation is significantly weaker. 
The negative correlation of bull and bear fund flows is strongly suggestive of speculative herding by retail investors in the Japanese market. Studies suggest that exposure to this sentiment factor may be priced. [51] Applying the two-stage procedure to fund returns, using return based factors and flow factors, found that in the period of the analysis, sentiment factors add significant incremental explanatory power beyond that of return factors. [153] [151] A comparison of the sentiment structure in the U.S. and Japan is itself instructive. Attitudes towards different asset classes differ across countries. While U.S. investors regard foreign securities as economic substitutes for domestic equities, Japanese investors appear to treat them as complements.

\subsection{Mutual fund Sentiment Trading Strategy}

Research and empirical results have shown that stock prices are affected by sentiment. According to previous work, the presence of limits to arbitrage, a broad-based wave of sentiment is forecasted to have cross-sectional effects when sentiment-based demands vary across stocks or when arbitrage constraints vary across stocks. [105] More specifically, when investor sentiment is high, the prices of high-sentiment stocks - i.e., the stocks with higher loading on sentiment, are inflated and the subsequent returns are lower. In contrast, when investor sentiment is low, the prices of high-sentiment stocks are lower than they should be and the subsequent returns are relatively higher. This effect is however asymmetric as, on average, the lower return following high sentiment periods is larger than the higher return following low sentiment periods. That is, high sentiment stocks deliver higher returns following periods of low sentiment but underperform too much following periods of high sentiment. [66] Investors who are able to forecast sentiment and to forecast its future development should load up mostly on highsentiment stocks during periods of low sentiment and load up on low-sentiment stocks during periods of high sentiment.

According to literatures, being consistently loaded on low-sentiment stocks does generate a superior performance as it greatly over performs during periods of high-market sentiment and does not differ drastically during periods of low market sentiment. [154] This strategy would be even more efficient in the case the asset manager were not only able to identify the degree of sentiment loading of the stocks, i.e. whether they are high or low-sentiment stocks - but also able to determine/forecast the degree of market sentiment. Mutual funds are positioned in terms of having superior information about sentiment. It can be simply stated that sentiment is the 
aggregated short-term behavior of many potentially irrational investors. Mutual funds have access to the flows of the investors in the funds and can use this information to determine the stocks that are more sensitive to market sentiment, i.e. high sentiment stocks. Using mutual fund flows as a measure for individual investor sentiment and concluded that institutional flows can affect individual stock returns. [155] [156] In particular, in order to maintain their optimal portfolio weights, mutual fund managers tend to scale up (down) their existing holdings in response to capital inflows (outflows). To the extent that capital flows are not entirely random and thus inflow-induced purchases do not offset outflow-induced sales, investment flows to mutual funds can generate significant demand shocks in individual stocks. Information and data providers like Lipper, a Thomson Reuters company, are a global leader in supplying mutual fund information, about daily flows in individual mutual funds. If the information contained in these flows has forecasting value, the information contained in the detailed breakdown should help the fund manager to acquire superior information about sentiment.

The ability of funds to forecast sentiment is amplified by the family-based structure. Most mutual funds are affiliated with fund families. This implies that the ability of the family research department to gather sentiment-related information is extensive. Information about sentiment should be one of the main advantages of the family structure and should increase with the number of funds it manages. However, while following a low fund sentiment loading strategy helps to deliver superior performance, still it may have negative marketing implications. Given that sentiment is the potential irrational behavior to an asset, the very same investors who determine the overvaluation of these stocks are also likely to require the funds in which they invest to hold them. Morningstar and Lipper and fund prospectuses contain detailed information on the main portfolio holdings of the funds. Therefore, a fund that is loaded on high sentiment stocks at the very moment in which the market displays a high degree of sentiment is more likely to capture investor attention.

The question asked is whether the mutual fund industry exploits market sentiment? If so, does it do it to boost performance or to attract investor attention? [154] The study provides strong evidence of a relation between fund sentiment loading and performance. The evidence is based on both portfolio-based and multivariate analysis showing that low fund sentiment loading (FSL) funds outperform high FSL funds after controlling for risk factors and fund characteristics. This 
performance difference cannot be explained in terms of potential survivorship bias. Quite to the contrary, it is very persistent up to 8 month. Nor can this performance differential be explained in terms of active management of the portfolio or its degree of illiquidity. In contrast, high FSL funds tend to be less actively managed and more liquid. Moreover, even controlling for the degree of liquidity of the fund does not alter either the statistical or the economic significance of the FSL-performance relationship.

The study also concluded that the funds that engage in such performance-destroying strategies are the relatively more informed ones. Indeed, these funds tend to have a very low reliance on public information and tend to belong to big families. In fact, high FSL is a very highly persistent family strategy. Funds deliberately sacrifice performance in order to have a portfolio composition that attracts investors. Funds that had a portfolio composition highly loaded on sentiment at the time when sentiment is high are in demand and display much stronger flows.

\subsection{Closed-End Funds and Sentiment}

Open-end mutual fund shares can be redeemed from the fund at net asset value (NAV) but not so with closed-ended funds CEF The closed-end fund has been the focus of several past studies because, on the average, the closed-end fund trades at a discount from the value of its assets it holds, to NAV. The disparity between NAV and the price at which they are traded has been the subject of many researches including [157] [158] [159] [160]. Some of these research primarily addresses the impact of various market frictions, including commissions, fees, taxes, and portfolio characteristics, on the pricing of CEF shares. The conclusion reached by is that, discounts are a function of these frictions to some extent, but that the magnitude and variability of discounts are not fully explained by frictions. [157] [160]

Others show that the closed-end fund discount reflects investor sentiment and, therefore, it affects the equity risk premium. [159] [158] They also argue that the investor sentiment factor has more bearing on the return pattern of closed-end funds and small cap stocks. In a study by [161] refute the conclusion of some literature's argument that stock prices are influenced by the investor sentiment factor. [161] Some argued that the investor sentiment explanation for the closed-end fund discount proposed is based on the misspecification of the return generating process. [159] In another study unique dataset was used to examine whether the investor 
sentiment, measured by the change in the discount on closed-end funds, enters the return generating process of common stocks, and especially, if closed-end funds, shown to be very sensitive to this factor yield a higher return to compensate for the risk associated with the erratic and unforecastable nature of investor sentiment.

While the evidence provided against the idea that investor sentiment is priced in the US capital market, [161] it cannot be ruled out that the result was limited to the US market. Without testing the robustness of the findings outside the environment in which they were discovered, it remains unclear whether these empirical results are merely spurious correlations that they may not be confirmed outside the US capital market. The use of non-US market data set, increases the outof-sample power of our tests because economic factors, stock return movements or investor biases are unlikely to be the same between the US and the Greek capital market at the period of the investigation and, therefore, allows the study to provide more conclusive evidence on the merits of investor sentiment as a source of systematic risk [162]. Using Greek data over the period January 1997 to January 2002, the study concluded that no evidence supporting sentiment as an independent source of systematic risk in the return generating process. The non-US evidence not only contradicts the claim that investor sentiment affects the risk of common stocks, [159] it is also consistent with the findings that investor sentiment does not represent systematic risk even in a market environment that is more likely to be influenced by investors sentiment than the USA. [161]

Another interesting study examines the pricing of closed-end funds in an emerging market using the Istanbul Stock Exchange. [163] First, it is shown that closed-end funds in the Istanbul Stock Exchange (ISE) trade at discounts as well. The size of the discount in the ISE is larger than that observed for closed-end funds in the U.S. market. Furthermore, the discount on Turkish closedend funds fluctuates widely over time just like the discount on the U.S. funds does. After documenting the discount and its variability, the factors affecting this discount is investigated for the funds traded on the ISE with a cross-sectional analysis. The results indicate that when analyzed in a univariate setting, there is a difference between discounts on bank and non-bank affiliated funds. This finding supports the perceived (sentiment) strong role of banks in the financial system of Turkey. However, when analyzed in a multivariate setting, this difference in 
discounts on bank and non-bank affiliated funds disappears. Moreover, multivariate analysis support agency cost explanation of the discount. Furthermore, return on the market index, degree

of diversification, the stock holdings and liquidity of funds are found to be important factors explaining the discount on closed-end funds.

The research on CEF is more than half a century old and it is unlikely that any single theory is going to be adequate to explain all discounts at all times. Nevertheless, the role of investor sentiment in such discounts is perhaps the most prominent theoretical suggestion as seen from the literatures. In addition, the influence of arbitrage costs and other possible sources of these discounts are not inconsistent with the sentiment story. A new analysis of closed-end fund discounts issue was presented in literature that used dynamic factor analysis to extract the sources of observed discounts for a sample of funds over the 2004-2011 periods. [164] It then investigated the dynamic conditional correlation between this factor and a popular measure of investor sentiment or perhaps "fear", the VIX. The study found a strong relationship between discounts and VIX after the initiation of the market meltdown in 2007, and this finding is consistent with the sentiment interpretation.

\subsection{INVESTOR SENTIMENT IN ALTERNATIVE INVESTMENTS}

Alternative Investments is quite broad. Alternative investments are investment in asset outside the three traditional asset types; stocks, bonds and cash. Most alternative investment assets are held by institutional investors or accredited, high-net-worth individuals because of their complex nature, limited regulations and relative lack of liquidity. Alternative investments include hedge funds, managed futures, real estate, private equity, commodities and derivatives contracts.

Alternative investments, operates differently than a conventional mutual fund usually for two reasons: investors in the non-conventional investment fund may or may not be able to redeem their investment on demand for a proportionate interest of the fund's net assets, or the nonconventional investment fund may be listed on an exchange. For non-conventional investment funds that list their securities for trading on a stock exchange, investors get their money out of the fund primarily by trading their investment over the exchange. Some of these nonconventional investment funds also permit investors to get their money out by redeeming their investment for a proportionate share of the fund's net asset value. The regulatory requirements 
applicable to non-conventional investment funds vary depending on whether an investor can redeem the investment for a share of the fund's net asset value and whether the fund is traded on a stock exchange. If an investor can redeem their investment in a non-conventional investment fund for a proportionate interest of the fund's net assets more than once a year, then the fund is considered to be a mutual fund (regardless of whether or not it is listed) and is subject to the same operational requirements as conventional mutual funds

\subsubsection{Investor Sentiment in Real Estate}

Behavioral finance relies on the incorporation of cognitive psychology into finance and limit to arbitrage that explain why psychological factors are important in the same market. Behavioral Finance uses model in which some agents are assumed to be not fully rational. Deviations from rationality are due to individuals' actual preferences and beliefs. They update their beliefs when new information is received using Bayes' Law and make choice using their beliefs that maximize their expected utility. Expected utility theory has dominated the analysis of decision making under risk and it has been generally accepted as a normative model of rational choice. The noise trader theory explains time varying nature of discount to NAV in real estate stocks. Studies document common REIT sector effect in the pricing of individual REITs relative to their NAVs, and suggest that investor sentiment is the major cause of discounts to NAV. [165]

Some other literatures also shed light on changes in liquidity to determine whether noise traders or rational investors dominate the public real estate market. Intuitionally, if the transaction cost decreases (meaning liquidity increases), the discount to NAV increases, because more noise traders enter into market than rational investors. It implies that there is positive relationship between liquidity and existence of noise traders. Their results are consistent with noise trader theory, but liquidity just partially explains a common element in REIT discounts. They also find the impact of noise trade is more pronounced in down market. In short, the results suggest changes in discount to NAV are related to fundamentals at turning points of real estate cycle, but the magnitude of the swings is exacerbated by noise traders and investor sentiment appears to be the major determinant of REIT and stock pricing. The questions researches want to address is the question of whether REITs suffer from stock market sentiment, following the presence of noise traders in the stock market, or is real market sentiment the most important force in REIT

pricing? The following paragraphs provide a literature review of the main puzzle in real estate 
pricing in order to identify the main reasons why the real estate sector is an interesting laboratory where to investigate the role of the investor sentiment.

There are several reasons that make the commercial real estate market to be an appealing area to examine. Relative to more liquid public markets, private investment markets exhibit significant information asymmetries and illiquidity. Moreover, the lack of continuous price revelation in private markets suggests that the potential impact of investor sentiment on market values may be revealed with significant lags. Indeed, the authors analyze the impact on the market value of private/public real estate in short and long run and the role of investor sentiment to forecast the time series of market returns. They find a positive relation between investor sentiment and subsequent quarter returns in both public and private real estate market. More precisely, the short run effect is larger in the public real estate market, which is consistent with private market investors being better informed and more sophisticated. [98]

The other reason is the long run results provide evidences of price reversals in public real estate market. Private real estate markets are more susceptible to prolonged periods of sentiment induced mispricing. Their results support the hypothesis that limits to arbitrage and delay in price revelation play important roles in determining the time it takes for prices to revert to fundamental values. The price to net asset value (NAV) of Real Estate Investment Trusts (REITs) to directly test Miller's overvaluation hypothesis on how short sales influence the deviation from fundamental value of a security in the presence of differences of opinions was studied in the literature. The study relate the cross sectional variation in premiums to NAV to differences in short sales while controlling for firm-specific NAV determinants, sentiment and known mispricing patterns. They argue that both the magnitude and constraints in short sales affect the valuation of stocks. Short sales alleviate overvaluation above and beyond rational and sentimental drivers of deviations from fundamental value. In the cross-section, REITs with prior short sales trade closer to fundamental value. [166] Contemporaneously, high short sale activity increases the difficulty to short at the margin and as such increases the overvaluation. Their evidences indicate that short sales do not depress prices, there is no greater short sale demand for undervalued stocks, nor they observe that short sales further reduce valuation levels. 
The existence of adverse opinions affects market valuation of a stock in those evaluations are likely to diverge, nonetheless it is the short sale limitation that drives overvaluation. Various short constraint specifications and find that REITs that are hardest to arbitrage trade further from fundamental value by [167]. The empirical findings indicate that the investor sentiment indeed plays a significant role in REIT pricing and sentiment behaves differently over time, which is consistent with behavioral finance theory. The explanatory power of the pricing model increases significantly with the inclusion of sentiment. With regard to the evidence of price discovery the results show that the transmission mechanism of sentiment runs from the stock market onto the real market, corroborating that irrational sentiment affects fundamentals. The empirical results support that the sentiment index is "institutional-oriented". That is institutions and individuals respond differently to signals in the formation of their sentiments and it may be the case that although both exhibit significant degree of sentiment, only institutions have enough market power to affect prices.

Investor Sentiment has played a significant role in past bubble, therefore, measuring and understanding the dynamics of investor sentiment is necessary in order to answer the question of whether is possible to identify and manage bubbles. The analysis of the role played by both the stock market and the real estate public and private market sentiment is crucial to address policy questions. The work by [167] highlight that the late 2002 through early 2007, usually described as a property boom period, are associated with general higher sentiment. Moreover, as of March 2007, U.S REIT entered into the most serious crash in history- the Subprime Crisis, and indeed the sentiment index declined rapidly as of the first quarter of 2007.

\subsubsection{Sentiment in Public and Private Real Estate Market}

The degree to which private markets are affected by investor sentiment is not ex ante clear. To the extent that private market investors are better informed and more sophisticated, asset prices could potentially be less prone to the influence of investor sentiment in these markets. At the same time, because of the illiquidity, information asymmetries, and more limited price revelation inherent in private markets, investor sentiment may instead play a more persistent role in pushing asset prices away from their fundamental values than in public stock markets. The inability to short-sell in private markets, for example, impedes the opportunity for arbitrageurs to counteract mispricing. Thus, sentiment could lead to prolonged periods of mispricing in private markets. In 
contrast, price revelation occurs more rapidly in public stock markets where the ability of informed investors to short-sell exists, albeit with limits. Therefore, the reversion of prices to fundamental values should occur more quickly in public markets

Literatures examine the relation between investor sentiment and both short- and long-horizon returns in public and private commercial real estate markets. [168] The commercial real estate market provides an appealing testing ground for examining sentiment's pricing role for several reasons. First, private real property markets exhibit the segmentation, information asymmetries, and illiquidity that characterize other private equity markets. Second, unlike the private equity market, several representative total return indices for private commercial real estate are available; permitting us to calculate time-weighted returns that can be compared directly to corresponding returns in public real estate markets. Finally, the underlying properties held by the publicly traded real estate firms we analyze are similar to the property holdings of the institutional real estate investors whose private market returns we also track. Thus, disparities in sentiment's effects on returns in public and private real estate markets can be ascribed to differences in the characteristics of these two markets, not to fundamental differences in the types of assets owned.

The questions [168] seeks to answer are whether investor sentiment can forecast short-run returns and if returns forecast short-run changes in sentiment? More studies were done to examine whether a negative relation exists between investor sentiment and subsequent longhorizon returns in public and private commercial real estate markets. [98] If excessive investor optimism (pessimism) leads to market overvaluation (undervaluation), then periods of high (low) sentiment should be followed by low (high) cumulative long-run returns since the market price should revert to its fundamental value in the long-run. Moreover, given the greater limits to arbitrage, short-sale constraints, information externalities, and delays in information transmission that characterize private real estate markets, it expect the impact of investor sentiment on market values in private real estate to be more persistent.

The conclusion shows that investor sentiment plays a more persistent role in pushing asset prices away from their fundamental values in private markets because of increased illiquidity, 
information asymmetries, and more limited price revelation relative to public markets. The inability to short-sell in private markets, for example, impedes the opportunity for informed arbitrageurs to counteract mispricing. Thus, sentiment could lead to prolonged periods of mispricing in the private market. No previous research, however, has directly investigated the relative importance of sentiment in public and private asset markets. This paper provides a contribution to the investment sentiment literature by examining the short- and long-run relation between sentiment and the pricing of similar underlying assets that are owned and traded in two distinct investment environments. Using long horizon regressions, the study also provide evidence that periods of sentiment-induced mispricing are followed by quicker price reversals in public real estate markets. In contrast, private real estate markets are more susceptible to prolonged periods of sentiment-induced mispricing.

\subsubsection{Investor Sentiments and Hedge Funds}

Hedge Fund concept was introduced by A.W. Jones in 1949 by combining a leveraged long stock position with a portfolio of short stocks in an investment fund with an incentive fee structure. Other hedge fund strategies evolved A.W. Jones small beginning. As a result, many hedge fund characteristics have changed significantly, but many of the fundamental features have remained the same. In the United States and Canada, hedge funds normally offer their shares in private placements and are limited to high net-worth investors in order to make use of regulatory exemptions provided security regulatory bodies. Assets managed by hedge funds have increased six-fold over the past decade to $\$ 1.43$ trillion by June 2009 ; this amount is relatively small in comparison to other major global investment pools. The chart on page four shows that hedge funds represent 1.1 percent of the total funds and assets of financial institutions. Nevertheless, studies show they account for a significant amount of the trading volume in U.S. equities and an even higher share in more complex financial instruments. [169]

Although hedge funds invest in a variety of liquid assets similar to mutual funds, they are quite different. Under current law in U.S and Canada, hedge funds have no limitations on management, virtually no limits on the composition of the portfolios, and no mandatory disclosure of information about holdings or performance. Hedge funds are an attractive tool to provide a relatively sound investment option for investors due to their intrinsic characteristics such as offering objective compensation contracts that preclude fund managers payments beyond 
management fees if certain performance goals are unmet. [170] Hedge funds are flexible regarding the types of securities they hold and the type of positions they take. As seen in the financial market, hedge funds may include positions in international and domestic securities usually in debts as well as long and short strategies. Hedge funds are not subject to disclosure, which is often is linked to a greater exposure to a variety of economic risk elements

\subsubsection{Hedge Funds in Literature}

As seen in chapters 2 and 3, academics and investors agree that behavioral factors such as investor sentiments play an important role in determining stock prices. Studies have followed several approaches to test whether rational and irrational components of investor sentiments play a role in hedge funds returns. [171] This study chooses to utilize hedge funds because these would be the type of funds that would exhibit relatively larger rational behavior. Investor sentiments were divided into individual and institutional investor sentiments to analyze the postulated impact of each on hedge fund returns. The first approach directly use raw hedge fund returns and analyze which type of investor sentiment helps explain hedge fund returns. In the second approach, the study use the forecasted values of hedge funds returns from CAPM, Fama and French three factors, Carhart four factor, and APT models. It then tests whether the forecasted values from these estimations are affected by irrational individual and institutional investor sentiments.

The inter-relationships of behavioral aspects of investors, expected return, and systematic risk stems from the presence of heterogeneity in sentiment of market participants in the presence of market imperfections as defined in [172] was the first to explain irrational actions of individuals. According to Keynes, actions induced by animal spirits are irrational since they are not acting on rationally held beliefs. Developing on Kaynes theory, other literatures discussed the concept of noise trading and argue that "noise" makes trading in financial markets possible but also makes it imperfect. In the basic model of financial markets, literatures contrasts noise with information and suggest that people sometimes trade on noise as if it were information. The work of other literature was extended to assert that noise trading must be an important factor in securities markets and explains why anyone would rationally want to trade on noise. [173]

Quantify risks associated with investor behavior using several different asset pricing models and hedge fund data, the study obtain the raw returns and obtain generalized impulse response 
functions on rational and irrational sentiments of individual and institutional investor sentiments. The response of raw returns to a one time shock in both the unexpected individual rational and irrational sentiments appears to be statistically significant. The response of raw returns to rational institutional sentiments is also statistically significant, but the response to irrational institutional sentiments does not appear to be statistically significant. In the case of fitted returns, the only significant response occurs during a shock to rational institutional returns. The results are consistent with the view that institutional investor sentiments exhibit more rational behavior than individuals. In the light of this result, the study extends the analysis into hedge fund strategies; the evidence suggests that statistically significant irrational components are linked to the risky strategies. The study concluded that investors can use irrational beta to gauge the extent of irrational sentiments prevailing in markets and compare the values in turbulent periods with more tranquil periods for the purpose of re-adjusting their portfolios and use the betas as an early warning sign. It can also guide investors in avoiding those funds that display greater irrational behavior.

To test the hypothesis of investor sentiment, a study sorts all the hedge funds on the basis of the differential flow (inflow and outflow) of funds experienced by individual hedge funds and different categories. The study found overwhelming evidence of investor sentiment in the hedge fund industry for both individual hedge funds and categories. For individual hedge funds it analyzes to see if category membership has any impact on the differential flow of funds. The funds that have experienced differential net outflow belong to the category 'Global Macro' for 1994 to 1998, and 'Market Neutral' for 1999 to 2004 with the exception of the year 2001. [174] In aggregate it appears that category membership does not impact the flow of funds. Even for the results across the years, category membership does not seem to be a dominant feature that would explain the differential flow of funds. The study further analyze to see if the investor sentiment is driven by the fundamental characteristics of hedge funds, namely size, leverage, and portfolio allocation. Leverage and size do not appear to be the discerning factor for investor sentiment. There does not appear to be any threshold size for hedge funds that is favored by investors. The study also concluded that portfolio allocation has no effect on net differential flow of funds. Investor sentiment is not governed by the fundamental characteristics of the hedge funds. 


\subsubsection{Investor Sentiment and Commodities}

Literatures have investigated the dependence between investor sentiment and commodity futures returns. Construction of market sentiment index by the Partial Least Squares regression (PLS) with non-return based stock market proxies was researched, in particular higher option implied moments. [175] Consistent with the expectation, the research identifies a strong dependence between market sentiment and commodity futures returns but show that not all commodity groups react equally strong to market sentiment impacts. In the study, the author explores commodity futures returns in light of positive and negative sentiment shifts. It is well-known that asset returns tend to be more sensitive to downward than upward sentiment changes. All commodity groups exhibit stronger sentiment exposure to the negative shifts, both in terms of statistical magnitude and economic significance. For instance, a one-standard-deviation decrease in sentiment is associated with a $2.6 \%$-loss in the expected commodity return. The same extent of increase is associated with a mere additional return of $0.7 \%$. The study disclose the strong impact of investor sentiment, even after controlling for macro-economic influences, equity returns, as well as commodity related factors, such as open interest, futures basis, and momentum. [176]

In 2011 and early 2012 Commodities values rose and fell as sentiment improves over Greece, became positive or negative about the potential outcome of Greece's sovereign debt bailout. Investor sentiment helped dampen or boost prices of commodities such as oil and precious metals to their highest or low levels in almost six months. Global stocks rallied when there was renewed hope that an agreement for a $€ 130$ billion bailout can be reached by one Monday. On that day the MSCI All-Country World Index started the day strongly, rising by 0.5 per cent, while S\&P's GSCI Index, which lists 24 commodities, was also up by 0.3 per cent. Commodities are traditionally a popular choice for investors looking to protect the value of their private wealth when paper currencies are fluctuating, as these have intrinsic value. Baclays Capital Commodity Research reported the following on February 2012

Sentiment has improved in commodity markets in the past month, as a string of betterthan-expected data has confirmed that the global economy is in a recovery phase. Activity and employment data in the US point towards a solid recovery, China is on a soft landing and even in Europe business confidence has improved. Investors are again seeking exposure to commodities with a strong fundamental case, but are testing the 
ground to see whether the recovery is sustainable. As a result of this relatively more bullish outlook, investors have returned to commodity investments. Following the second-largest monthly outflow ever from commodities, in December $(-\$ 7.7 \mathrm{bn})$, investments rebounded in January with an inflow of $\$ 3.7 \mathrm{bn}$. it was the first time since July 2011 that all investment categories and commodity sectors had inflows, with precious metals ETPS receiving the largest share of investment at $\$ 1.1 \mathrm{bn}$. We expect commodity investment flows to continue to rebound in 2012 after last year proved the weakest for inflows into the sector since 2002. Our latest survey of commodity investor sentiment (reproduced in our focus section this month) shows that $56 \%$ of respondents expect to initiate or increase their commodity exposure over the next three years.

And in April, 2012 Reuters reported the following:

Investor sentiment in commodity markets was buoyed on Tuesday by positive earnings reports from U.S. companies and a seamless Spanish bond sale that curbed worries of euro zone debt problems.

i. The Thomson Reuters-Jefferies CRB Index, a global commodities benchmark, was up more than a half a percent at 0.54 percent on Tuesday, snapping two days of losses.

ii. Commodity markets recovered as Spanish 10-year bond yields dipped back below the 6 percent level hit on Monday after sales of the nation's debt went smoothly.

iii. U.S. stock indices were trading higher as Coca-Cola Co, Goldman Sachs Group Inc and Johnson \& Johnson reported earnings that beat analysts' forecasts.

iv. Copper was off its three-month low and broke above $\$ 8,000$. Three-month copper on the London Metal Exchange was trading 0.9 percent higher at $\$ 8,055$ a tonne at 12:21 p.m.

v. EDT (1621 GMT), from the $\$ 7,980$ close on Monday. Worries over China's slack GDP report released on Friday, which weighed on Monday's trading, were replaced by market chatter that the top soybean importer was buying U.S. soybeans

vi. Chicago Board of Trade May soybeans rose 0.7 percent to $\$ 14.29-1 / 4$ a bushel by 1620 GMT, after sliding 1.2 percent on Monday.

vii. U.S. crude oil futures, which lost ground on Monday, were trading $\$ 1.63$ per barrel higher at $\$ 104.56$ as of 12:05 p.m. EDT (1605 GMT).

viii. Brent crude oil prices dipped as a major pipeline reversal in the U.S. Midwest promised to release trapped U.S. supplies.

ix. Natural gas, which rose on Monday, lost ground on Tuesday, brought down by a slack outlook for demand on milder weather forecasts. 
Commodities trade in the form of futures contracts with monthly maturities that stretch several years into the future. This is not dealing with a single pricing as it is equities. So the object of interest is not just one price but an entire forward curve, which is a multidimensional object. News sentiment may affect the returns of different maturities differently. Furthermore, it is not immediately clear whether sentiment measures will work as well for commodities as they do for equities, as commodity prices are driven by supply and demand rather than by present value of future cash flows. So while one would presume that just about any article with lots of positive words and a reference to Greece would correlate with upward pressure in its stock price, it is not clear whether an article with lots of positive words and a reference to crude oil would correlate with upward or onward pressure on the oil price.

Another study focused on crude oil and is primarily concerned with daily aggregated news sentiment and its effect on daily settlement prices. [177] The study employed event studies to relate the daily aggregated news sentiment to crude oil futures returns for different maturities and investigate how the impact of news sentiment on futures prices vary with time to maturity of the contract. In the research, Reuters newswire articles that are tagged as referring to a given energy commodity (crude oil) from 2003 to 2008 was considered. For each of these articles, Thomson Reuters provides a measure of sentiment, determined by a proprietary machine-reading algorithm: the Reuters NewsScope Sentiment Engine. We aggregate and normalize these sentiment marks to form a daily index of sentiment, and establish that particularly high or low levels of sentiment constitute an event. The analysis of cumulative returns of commodity futures of various maturities in the days surrounding these events was conducted.

The research concluded that, for all maturities, positive respectively negative news events follow long periods of higher respectively lower returns, suggesting that news are correlated with price momentum. Abnormally high or lower returns precede positive or negative news sentiments by as much as 80 to 100 days, but after approximately 15-20 days the study observe a return to fundamentals. After a positive news event occurs, returns continue increasing for 20 days. This is especially pronounced for more distant maturities, whose returns increase by $3 \%$ on average. After a negative news event, returns fall on average by $3 \%$ for nearby maturities and stay flat for more distant maturities. These effects are both statistically and economically significant. These 
findings suggest that the degree of backwardation in the forward curve is reduced after both positive and after negative news events. On the contrary, the contango state seems to deepen after a significant news event, whether it was a positive or a negative one. However, positive events seem to cause this effect by raising more distant future prices, while negative events cause nearby prices to fall relatively more.

\subsubsection{Private Equity}

Private equity firms operating as privately held partnerships organizing the acquisition and privatization of public companies. The activities of this group are growing rapidly in number and size. The hallmark of private equity firm is secrecy, with industry leaders operating as secretive partnerships that negotiate buyouts behind closed doors and restructure portfolio companies outside the public gaze. The very essence of private equity is exemption from the public securities laws. Private equity funds make investments in non-public portfolio companies, and the funds themselves are typically structured as private limited partnerships. Staying below the regulatory radar is paramount. The breadth of the law's reach, and what one must do to escape it, largely defines private equity.

According to the Centre for Management Buyout Research, there has been a significant increase in public to private transactions in the US, UK and continental Europe since the early 1980s.

The first peak occurred in the mid-to-late 1980s with the second one coming around the year 2000 with another upward trend from 2003. While total transaction volume was $\$ 192$ billion in 2000, it increased to more than $\$ 686$ billion in 2007 [178] A number of explanations have been proposed for this increase including, one of which is the gaining of the support of existing shareholders through irrevocable commitments, [179] and the feeling that smaller quoted companies tend to be ignored by institutional investors. A further important factor has been the presence of private equity investors that have been willing to finance deals. It was found in the US that $62.5 \%$ of their sample of buyouts involved private equity investors. Data provided by the Centre for Management Buyout Research, covering the period 1998-2006, show that 63\% of going private transactions in the UK involved a private equity investor. [180] While the existing evidence points to a positive effect of private equity investments, it is not very clear what drives this positive effect. In this section we investigate this question by focusing on the effect of investor sentiment towards private equity. 


\subsubsection{Investor Sentiment in Private Equity}

This section focuses on the question on finding out the extent to which returns are triggered by fund inflows into the private equity industry. What makes money chase deal? Does market sentiment have impact on returns in private equity market? The management of a private equity fund raises money from wealthy individuals and institutional and invests it into entrepreneurs who seem to have attractive ideas. If there is a perfectly frictionless and competitive market where the supply of money committed by investors equals the demand of capital from entrepreneurs with positive net-present-value-ideas, then perfect market conditions neither an overinvestment nor an underinvestment into business ventures should arise. This will be true even if the market is hit by a technological shock, like the development of the personal computer or the internet. All projects that promise to generate a positive net present value on the basis of currently available information will be funded. However, if we relax the assumption of a perfect frictionless capital market it may well be that a technological shock, which is likely to affect the profitability distribution in the private equity industry, causes a non synchronous change in the supply and demand of capital. It is interesting in this regard that the venture capital industry is known to be highly cyclical with periodic changes in supply and demand.

This investigation where the so called 'money chasing deals' phenomenon was first proposed and analyzed in [181] [182] [183] ; the impact of GPs' fund raising and draw down behavior on fund performance is investigated and developed a theoretical equilibrium model describing the particular supply and demand conditions in the venture capital industry. In the study presented by [184] it corroborate the view that deal valuations are significantly affected by the amount of funds flowing into the industry. In contrast to [182], however, it set-up a direct test of this phenomenon, i.e. they present evidence that the private equity funds' returns are negatively correlated with excess capital pouring into the industry. The critical part of this analysis is, of course, the measurement of excess capital.

Another aspect is whether one regards the 'money chasing deals' phenomenon as having behavioral causes or as being a fully rational equilibrium outcome. The study argue that it may be that the overshooting of capital investments in the private equity industry is due to some kind of herding behavior, where investment opportunities are systematically over- or underestimated by investors. It was pointed out that it could also simply be a consequence of the stickiness of 
private equity fund investments. [183] argue that the supply of venture capital is related to entry cost and transparency of the venture market. To some extent we will be able to present evidence in favour of the behavioral based view. The study shows that funds raised in vintage years with above average stock market returns have lower returns. Similar evidence has also been presented by [185]. The study concluded that apart from the importance of fund flows and market sentiment, GPs' skills as well as the stand-alone investment risk of a fund have a significant impact on its returns. This suggests that the market sentiment might have an impact on fund returns beyond the mere liquidity driven effects.

\subsubsection{Private Equity Post Meltdown}

The levels of private equity fundraising have undeniably been affected by the outcomes of financial downturn. The global financial crisis of 2008 brought the booming private equity equity market to a halt. Illiquid markets, cash-strapped investors and the scarcity of credit conspired to bring a multi-year bull run to an end. As confidence, economic stability and liquidity returned in 2009, public markets rallied sharply. Private equity activity, however, remains sluggish. The SEI Knowledge Partnership surveyed institutional investors in order to gauge their sentiment regarding their private equity investments. The survey was completed by senior investment professionals at 51 organisations ranging in size from less than \$548 million to more than \$23.9 billion in assets. Most participating organisations were foundations, endowments, or public pension funds. Toward 2010 thaw returned. Credit was more readily available, though terms are still not particularly favorable. The number of initial public offerings is rising, providing an exit for some existing private equity investments. Risk premiums have reached more attractive levels, and while still modest compared to the past few years, fund raising is on pace to exceed the annual amounts raised from 2001 through 2004 (see Figure 3). These trends highlight the relatively robust appetite for private equity among institutional investors, although both fund raising and investments are substantially lower than recent record years. In summary, investors may be more sceptical and risk averse than pre-crisis, but many continue to view private equity as an important source of returns potential and diversification. [186]

Preqin indicated in 2011 that, almost two-thirds of investors had made new commitments in the

year, 57\% of LPs interviewed planned to make new fund commitments before the end of 2011. Despite this, the recent developments in the Eurozone and worldwide economic volatility have 
prompted further questions about the future of the private equity industry. In order to determine investor sentiment towards current opportunities being offered by GPs, and whether the recent instability in the financial markets has changed their attitudes towards the asset class, Preqin interviewed a sample of 70 investors from across the world in October 2011. The attitudes of $64 \%$ of LPs have not been affected by the latest difficulties within the global economy. In fact, $23 \%$ of investors found the private equity industry more positive in the light of recent market fluctuations, compared to a smaller $14 \%$ of LPs that feel more negative towards the asset class.

\subsubsection{Investor Sentiment in Derivatives Market}

Derivatives are designed to create market price exposure to changes in an underlying commodity, asset or event. In general they do not involve the exchange or transfer of principal or title but they serve the purpose of capturing some underlying price change or event. The term derivative refers to how the price of contracts is derived from the price of some underlying security or commodity or from some index, interest rate, stocks, exchange rate or event. Examples of derivatives include futures, forwards, options and swaps. These can be combined with each other or traditional securities and loans in order to create hybrid instruments or structured securities. Derivatives are traded on derivatives exchanges, such as the Chicago Mercantile Exchange (CBOE). Derivatives play a very important role in hedging and risk management, but they also pose several dangers to the stability of financial markets and thereby the overall economy. The size of derivatives markets is enormous, and by some measures it exceeds that for bank lending, securities and insurance. Data collected by the Bank of International Settlements (BIS) show that the amounts outstanding in the over-the-counter (OTC) market exceed $\$ 638.9$ trillion and those at derivatives exchanges exceed \$66.6 trillion for a total of $\$ 705.5$ trillion by June 2012 .

Derivatives are used for hedging risks normally associated with commerce and finance. Farmers can use derivatives to the hedge the risk that the price of crops may fall before they are harvested and brought to the market. Banks use derivatives to reduce the risk of short-term interest rates paid depositors will rise and reduce the profit earned on fixed interest rate loans and securities. Mortgage insurers like Fannie Mae in US and CHMC in Canada use interest rate swaps and options to hedge against the prepayment risk associated with home mortgage financing. Electricity producers hedge against unseasonable changes in the weather. Pension funds use 
derivatives to hedge against large drops in the value of their portfolios, and insurance companies sell credit protection to banks and securities firms through the use of credit derivatives. In addition to risk management, derivatives markets play a very useful economic role in price discovery. Price discovery is the way in which a market establishes the price or prices for items traded in that market, and then disseminates that price as information throughout the market and the economy as a whole. In this way market prices are important not just to those buying and selling but also those producing and consuming in other markets and in other locations and all those affected by commodity and security price levels, exchange rates and interest rates.

The derivative market has enough power to totally destabilize the economic environment. LongTerm Capital Management collapsed with $\$ 1.4$ trillion in derivatives on their books and froze up the U.S dollar fixed income market. Sumitomo Bank in Japan used derivatives in their manipulation of the global copper market in the 1990s. Barings Bank, one of the oldest in Europe, was quickly brought to bankruptcy by over a billion dollars in losses from derivatives trading. Derivatives dealer Enron collapsed in caused collateral damage throughout the energy sector in 2001. Enron and other derivatives dealers used derivatives to manipulate electricity and gas markets during California's energy crisis. In 2002, the Allied Irish Bank's Allfirst lost $\$ 750$ million trading in foreign exchange options. Both the Mexican financial crisis in 1994 and the East Asian financial crisis of 1997 were exacerbated by the use of derivatives to take large positions involving the exchange rate. In 2003, New York Attorney General Elliot Spitzer disclosed how derivatives were used to capture gains from "late trading" and "market time" of mutual funds offered by Bank of America. [187] Human behaviors are evident in all the actions outlined in the benefits and disbenefits of derivative market. The question this section seeks to answer is if there are proofs in literature that investor sentiment plays any role in the derivative markets.

Derivative securities permit individuals and corporations to achieve payoffs that other securities cannot provide thus making them indispensable tools for risk management. In addition, because of their high leverage, they are also perfect vehicles for speculation. Although a large literature exists that examines the application and pricing of derivative securities, there is relatively little evidence regarding the extent to which investors use derivatives for speculation, and whether speculative trading affects derivative prices, despite the fact that speculation in derivatives 
markets is often singled out as one of the factors contributing to price bubbles and crashes. [188] takes a step toward filling this void by linking speculative trading behavior in equity options to measures of investor sentiment and examining the extent to which sentiment related trading affects option prices. Our focus on the link between investor sentiment and trading in the options markets is motivated by the fact that sentiment can be interpreted as capturing the correlated beliefs of investors that are unrelated to which is also a definition of speculation [105] and from the behavioral finance point of view investors' behavior could be influenced by the psychology or the bullish/bearish sentiment proxies.

Many studies whether investor sentiment affects S\&P 500 index option exist. [189] [190] They found that the slope of the option implied volatility smile changes dramatically from month to month. They examine whether variation in the slope of the index volatility smile is related to change in market sentiment. The empirical tests focus on the time-series relation between sentiment proxies and skewness of the risk-neutral density of monthly S\&P 500 index return. If investor sentiment affects index option prices, then Arrow-Drebreu state prices [191], which can be inferred from option prices [192] would also be distorted by sentiment. Hence, the pricing kernel, which is the Arrow-Debreu state price per unit probability, would depend on investor sentiment in addition to state variables that proxy for risks in the real economy. The literature recognizes the possibility that the pricing kernel can be disconnected from the marginal rates of substitution or transformation in the real economy without requiring arbitrage. So, whether the slope of the pricing kernel depends on investor sentiment was tested. The study also examines the impact of investor sentiment on index option prices and the pricing kernel and whether sentiment drives variation in the index risk-neutral skewness. When investors are more bearish, they would have a stronger demand and be willing to pay more for state contingent claims that pay more when the index level is low. This leads to a more negatively sloped pricing kernel, and thus a more negative index risk-neutral skewness. This time-series relation between index riskneutral skewness and sentiment is the key test.

The study concluded that a variety of proxies for market sentiment are significantly related to the risk-neutral skewness of the index return. The risk-neutral density for the index return is more negatively skewed when the market sentiment turns more bearish. On the other hand, a more 
bullish market sentiment is associated with a less negative index risk-neutral skewness. These results hold after controlling for a set of rational factors that may be related to the sentiment proxies, and after controlling for variables related to index risk-neutral skewness. The relation between index risk-neutral skewness and sentiment proxies is stronger when there are more impediments to arbitrage in the index options market. Furthermore, several popular rational perfect-market based option pricing models can not explain these findings. Finally, the index option volatility smile becomes steeper (flatter) when investor sentiment is more bearish (bullish). These results support the idea that investor sentiment is an important determinant of index option prices.

\subsubsection{Investor Sentiment and Energy Futures}

The effect of news sentiment on energy futures returns was studies to relate the daily aggregated news sentiment to crude oil futures returns for different maturities and investigate how the impact of news sentiment on futures prices vary with time to maturity of the contract. [177] Consideration was given to newswire articles that are tagged as referring to a given crude oil from 2003 to 2008. For each of these articles, Thomson Reuters provides a measure of sentiment, determined by a proprietary machine-reading algorithm: the Reuters NewsScope Sentiment Engine. The research aggregate and normalize these sentiment marks to form a daily index of sentiment, and establish that particularly high or low levels of sentiment constitute an event. After the analysis of cumulative returns of energy futures of various maturities in the days surrounding these events. It was discovered that, for all maturities, positive respectively negative news events follow long periods of higher respectively lower returns, suggesting that news are correlated with price momentum.

The study concluded that abnormally high or lower returns precede positive or negative news sentiments by as much as 80 to 100 days, but after approximately 15-20 days, a return to fundamentals was observed. After a positive news event occurs, returns continue increasing for 20 days. This is especially pronounced for more distant maturities, whose returns increase by $3 \%$ on average but after a negative news event, returns fall on average by $3 \%$ for nearby maturities and stay flat for more distant maturities. These findings suggest that the degree of backwardation in the forward curve is reduced after both positive and after negative news events. On the contrary, the contango state seems to deepen after a significant news event, whether it was a 
positive or a negative one. However, positive events seem to cause this effect by raising more distant future prices, while negative events cause nearby prices to fall relatively more. Thus, if positive sentiment causes the price of distant futures to rise more than that of nearby futures, positive events should reduce the degree of backwardation or deepen the contango, depending on the market state. Similarly, if negative sentiment causes nearby prices to fall by more than distant prices, the degree of backwardation is also reduced and contango is deepened. However, positive events seem to do so by raising more distant future prices, while negative events cause nearby prices to fall relatively more. Surprisingly, the shape of the forward curve reacts to the extreme news events in a similar way, regardless whether the news was positive or negative.

Another literature examined empirically how the prevailing sentiment influences market response to news. Specifically, it tests the hypothesis that prevailing sentiment sways market response to news in the direction of the sentiment. That is, market response to good news is greater during high sentiment periods than that during low sentiment periods. Similarly, market response to bad news is greater during low sentiment periods than that during high sentiment periods. [193] The study relies on the proxies of the sentiment developed by [54] [66] It examine the market returns in the 60 days following the announcement of earnings news to see if the effect of sentiment persists or reverses during this period.

The results indicate that sentiment continues to impact the market price behavior in the period subsequent to the earnings announcement. That is, the upward stock price drift following positive earnings news, commonly documented by prior literature, is greater when earnings are announced in high sentiment periods than those that are announced during low sentiment periods. Similarly, the downward stock price drift following negative earnings news is greater for earnings that are announced during low sentiment periods. In fact, there is no drift associated with negative earnings shocks that are announced during high sentiment periods. This is probably not surprising given that the sentiment measure used has very high persistence 


\section{CHAPTER FIVE}

\section{INVESTOR SENTIMENT PROXIES}

Investor sentiment has become the focus of many studies on asset pricing. Research has demonstrated that changes in investor sentiment may trigger changes in asset prices, and that investor sentiment may be an important component of the market pricing process. Some literatures suggest that shifts in investor sentiment may in some instances better explain shortterm movement in asset prices than any other set of fundamental factors. In this chapter, we survey investor sentiment measures and indicators. The reason investor sentiment measure is of tremendous interest, perhaps in part due to historical events and empirical puzzles that seem to defy the standard financial theory of market efficiency. Scores of sentiment measures currently exist, ranging from boutique measures derived for the purpose of an academic paper to daily indices used for contrarian purposes by options traders. The sheer number of existing measures reaffirms the fact that there is no clear, general conception of sentiment, especially between academic researchers and professional traders. While the former may use investor sentiment measures to make arguments for or against market efficiency or to explain specific empirical puzzles, the latter is likely to use sentiment indicators as a potential trading tool.

As a result, current measures of sentiment are constructed based on what a particular researcher or market practitioner has in mind. Since options traders are interested in sentiment for entirely different reasons than a financial academic, we see a variety of sentiment measures that exist in practice. In general, the main difficulty with measuring sentiment is that researchers may not have a clear idea of what they are purporting to measure. As discussed in chapter two, the term sentiment itself has many connotations and could be interpreted differently depending on its context. And even if a clear conception of sentiment exists to one researcher, another may entirely disagree. For example, while some may refer to sentiment as the same thing as investor optimism, another may define it in terms of prevailing risk appetites. Since most researchers cannot even agree on a simple definition of sentiment, they are obviously even more at odds regarding how to measure it. 


\subsection{Investor sentiment Proxies}

Measuring investor sentiment is like forecasting, it is not straightforward, but there is no reason for not finding perfect proxies that remain useful over time. An exogenous shock in investor sentiment can lead to a chain of events, and the shock itself could in principle be observed at any or every part of this chain. Limited arbitrage implies that these demand pressures might cause some mispricings, which might be observed using benchmarks for fundamental value like the book-to-market ratio. These mispricing might engender an informed response by insiders, such as corporate executives, who may have both the superior information and the incentive to take advantage of it, and the patterns of firms choosing to adjust their balance of equity or debt could be observed.

The bad news is that each part of this chain is also subject to confounding influences. Economists always treat surveys with some degree of suspicion, because of the potential gap between how people respond to a survey and how they actually behave. Trades net to zero, so measuring sentiment with trading activity means taking a stand on the identity of irrational investors. Market prices of securities normally reflect fundamentals, by and large, with sentiment playing a lesser role. Corporations may alter their financial structure for many reasons, including a change in business fundamentals, rather than simply acting as corporate arbitrageurs. Such considerations suggest that the practical approach is to combine several imperfect measures. Some of the methods of measuring investor sentiment are surveyed here.

\subsection{Optimism and Pessimism Measures}

The economy can grow. The free market system brings prosperity. Of course, economic optimism has its drawbacks. The optimist tends to underrate certain problems. He sees that the market brings people together; that international conflicts can be solved by commerce; that ethnic strife can be mitigated, and poverty overcome. Investors are mostly optimists because optimism makes them feel good. Investors cling to economic optimism even after the crash of 2008 and optimism has wrought a supposed recovery. Without economic optimism, the investor would not invest. It is the pessimist who buys gold. Optimism and pessimism are basic to the market. There are bears and bulls, waves of optimism followed by waves of pessimism. It is true, of course, that markets track with moods and are cyclical in nature. In this, however, the inclination to believe that moods have some basis in reality is strong. Loss follows upon bad 
investment. Pessimism is more likely in the wake of failure. [194] The real question is how can investor/market optimism and pessimism be measured?

\subsection{Sentiment Survey}

Perhaps just by asking investors how optimistic they are, we can gain insight into the marginal irrational investor. Robert Shiller has conducted investor attitude surveys since 1989. These types of surveys randomly-selected investor households, and Investors Intelligence surveys financial newsletter writers. Literature point out that although consumers polled for the University of Michigan Consumer Confidence Index are not asked directly for their views on securities prices, changes in that consumer confidence index nonetheless correlate highly with changes in the UBS/Gallup index. They show that changes in the consumer confidence measure correlate especially strongly with small stock returns and the returns of firms held disproportionately by retail investors.

\subsubsection{Consume Confidence Index}

Consumer confidence index expresses public views of economic conditions. It is a closely watched in economic indicator that is widely discussed. Consumer spending accounts for about 70 percent of economic activity in the united state and $64 \%$ in Canada. To the extent that consumer confidence interacts with consumer behavior, and with other economic factors, it may provide important information as to the economy's current condition and future direction alike. Policymakers and economists track consumer confidence closely in the apparent belief it serves as a useful economic forecasting tool. Economic analysts and the news media report its ups and downs prominently. The release of confidence numbers has been cited as a force in the movement of the stock markets. Confidence also has a strong political connection; it's virtually axiomatic that presidential approval suffers, and political discontent grows, as consumer confidence deteriorates. [195] While the political importance of consumer confidence is widely accepted some commentators have questioned the usefulness of measuring and reporting consumer confidence as a purely economic indicator, expressing doubt as to its meaning or value in this realm. Confidence surveys have also been criticized recently on methodological grounds for the types of questions and response categories they use [196] 
The Thomson Reuters/University of Michigan's index of consumer sentiment is a consumer confidence index published monthly by the University of Michigan and Thomson Reuters. The index is normalized to have a value of 100 in December 1964. The consumer confidence measures were devised in the late 1940s by Professor George Katona at the University of Michigan. They have now developed into an ongoing, nationally representative survey based on telephonic household interviews. The index is created by the Survey Research Center at the University of Michigan undertakes a monthly Survey of Consumers that is conducted with a randomly selected, representative sample of approximately 500 U.S. households. Each household is asked a series of questions that seek to identify attitudes concerning current and expected conditions of the economy. Within this survey are five key questions used to calculate the Index of Consumer Sentiment. Each question has three basic responses - better, same, or worse.

i. An evaluation of the respondent's current financial situation.

ii. Expectations of the respondent's financial situation in one year.

iii. Expectations of the economy's overall financial situation in one year.

iv. Expectations of the economy's overall financial situation over the next five years.

v. An evaluation of the economy's overall suitability for making major purchases.

The Survey of Consumers also poses questions dealing with government stabilization policies; expectations of economy-wide unemployment, interest rates, and inflation; expectations of family income; and possible plans to purchase housing, cars, furniture, appliances, and other durable goods. The five main questions are used to generate three separate confidence indices. The first step in the derivation of each index is to calculate relative scores for each question. The relative score is the percent of favourable responses to a question, minus the percent of unfavourable responses, plus 100, the result of which is then rounded to the nearest whole number. Index of Consumer Sentiment is the primary index generated from the study. It is calculated by summing the relative scores for all five questions and dividing by the relative score in the base year of 1966. Index of Current Economic Conditions: is calculated as an average of the relative scores to questions 1 and 5. Both questions reveal how respondents feel about current personal and economy-wide conditions. It too is indexed against the relative score for 1966 and a constant value of 2.0 is added. Index of Consumer Expectations is also calculated as an average of the relative responses to questions 2,3 , and 4 . These three questions reveal expectations that respondents have about future personal and economy-wide conditions. It is indexed against the 
relative score for 1966 and a constant value of 2.0 is added, as well. Figure 6 shows the University of Michigan consumer sentiment from January 1978 to January 2013. The preliminary consumer sentiment index for January declined to 71.3 from the December reading of 72.9 and it was below the consensus forecast of 75.0. There are a number of factors that can impact sentiment including unemployment, gasoline prices and other concerns such as for January, the payroll tax increase and the United States Congress threat to not pay the bills. Also, in August 2011, sentiment declined sharply due to the threat of default and the debt ceiling debate.

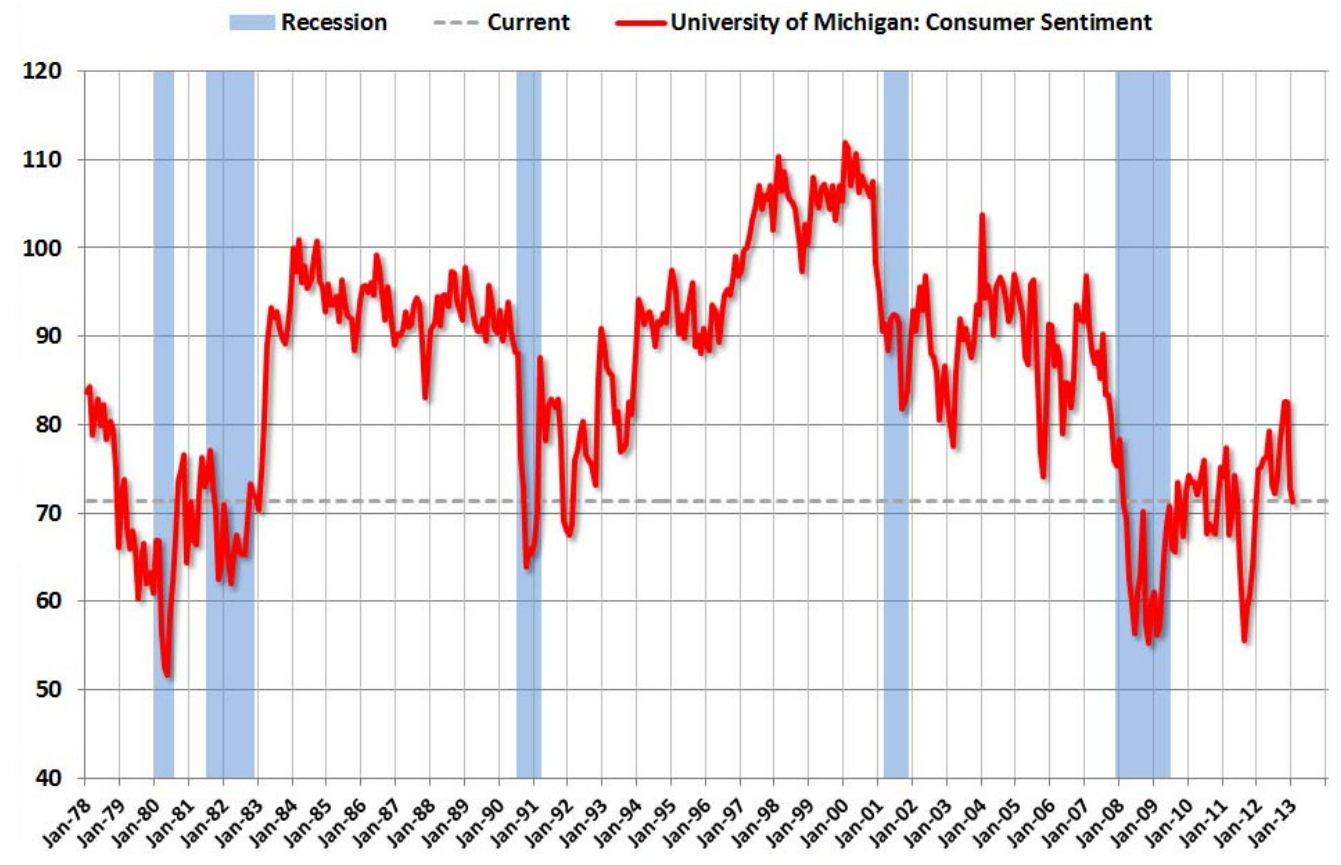

Figure 6 University of Michigan Consumer sentiment (Source: www.calculatedriskblog.com)

The consumer confidence index is the combined expectations and beliefs of investors on the fundamentals of the economy and markets. Literatures argue that the consumer confidence index forms a direct measure of the general feeling of investors, and changes can measure the fluctuation of the stock returns, especially for small firms. [81] [63]

\subsubsection{Index of Consumer Confidence}

The Conference Board in Canada, measures the Index of Consumer Confidence by surveying Canadian households has been ongoing since 1980. It measures consumers' levels of optimism regarding current economic conditions. This is a crucial indicator of near-term sales for companies in the consumer products sector. It is constructed from responses to four attitudinal 
questions posed to a random sample of Canadian households. Those surveyed are asked to give their views about their households' current and expected financial positions and the short-term employment outlook. They are also asked to assess whether now is a good time or a bad time to make a major purchase such as a house, car or other big-ticket items. [197] The Index of Consumer Confidence survey is based on four attitudinal questions. Data is collected on each respondent's age, sex, marital status, and geographic location of residence. The four questions are:

i. Considering everything, would you say that your family is better or worse off financially than six months ago?

ii. Again, considering everything, do you think that your family will be better off, the same or worse off financially six months from now?

iii. How do you feel the job situation and overall employment will be in this community six months from now?

iv. Do you think that right now is a good or bad time for the average person to make a major outlay for items such as a home, car or other major item?

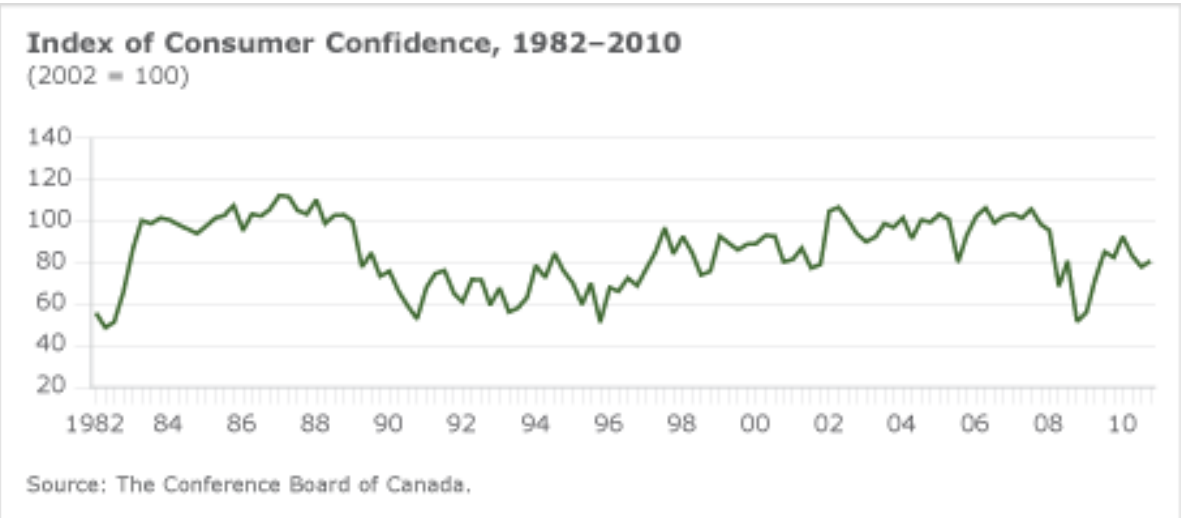

Figure 7 Index of consumer confidence (Source: Conference Board of Canada)

To construct the Index of Consumer Confidence, the percentages of positive and negative responses are calculated, by question, at the regional and national levels. Positive responses are those in which the respondent says his or her financial situation improved over the past six months or will improve over the next six months, that more jobs will be available over the near term, or that now is a good time to make a major purchase. Negative responses are defined as those in which a respondent reports a worsening of a household's financial situation over the previous six months, expects that his or her financial position will worsen or that the number of jobs will decline over the near term, or indicates that it is a bad time to make a major purchase. The index of consumer confidence is not seasonally adjusted. Periodically, the Conference Board 
tests the historical data to determine if seasonal patterns do exist, however, to date, there is insufficient evidence to conclude that seasonality is present. Figure 7 shows a graph of index of consumer confidence.

\subsubsection{Bloomberg Consumer Comfort Index}

The Bloomberg Consumer Comfort Index measures Americans' perceptions on three important variables: the state of the economy, personal finances and whether it's a good time to buy needed goods or services. A new index reading is generated every week, making it a timely sentiment gauge. The responses are broken down by participants' sex, age, income level, race, region of residence, political affiliation, marital and employment status, giving a more detailed picture of what is driving changes in confidence. The data's history goes back to 1985, making it a valuable tool for investors and economists.

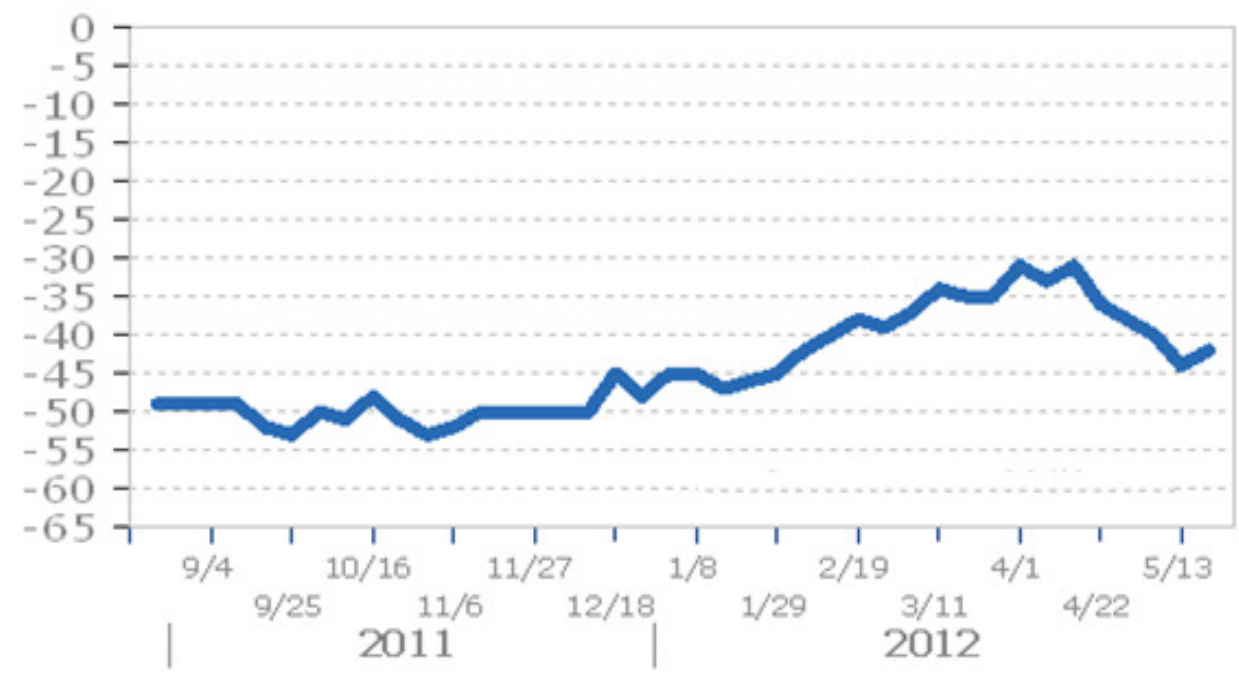

Figure 8 Bloomberg Confidence Index (Source: www.pollingreport.com)

The report is based on Americans' ratings of the national economy, the buying climate and their personal finances, reported in a four-week rolling average of 1,000 random-sample telephone interviews of about 250 consumers a week aged 18 or over, and is based on a four-week moving average of 1,000 responses. The percentage of households with negative views on the economy, personal finances and buying climate is subtracted from the share with positive outlooks and the difference is divided by 3 . The results can range from 100, indicating every participant in the survey had a positive response to all three components, to minus 100 , signalling all views were 
negative. The margin of error is 3 percentage points. This index is produced by Langer Research Associates in New York. [198] Figure 8 is a graph of Consumer Confidence Comfort Index of 2011 and 2012.

\subsubsection{AAII Sentiment Survey}

The American Association of Individual Investors (AAII) is affiliated with the National Association of Investors Corporation (NAIC), the organization that helped so many investment clubs get started in the late 1990's and was founded in 1978. Their focus is on individual investors, and not professional traders, pension funds, or anything else institutional. Their membership focus is on long-term fundamental analysis of sound companies using a very minimal amount of technical analysis for decision-making purposes.

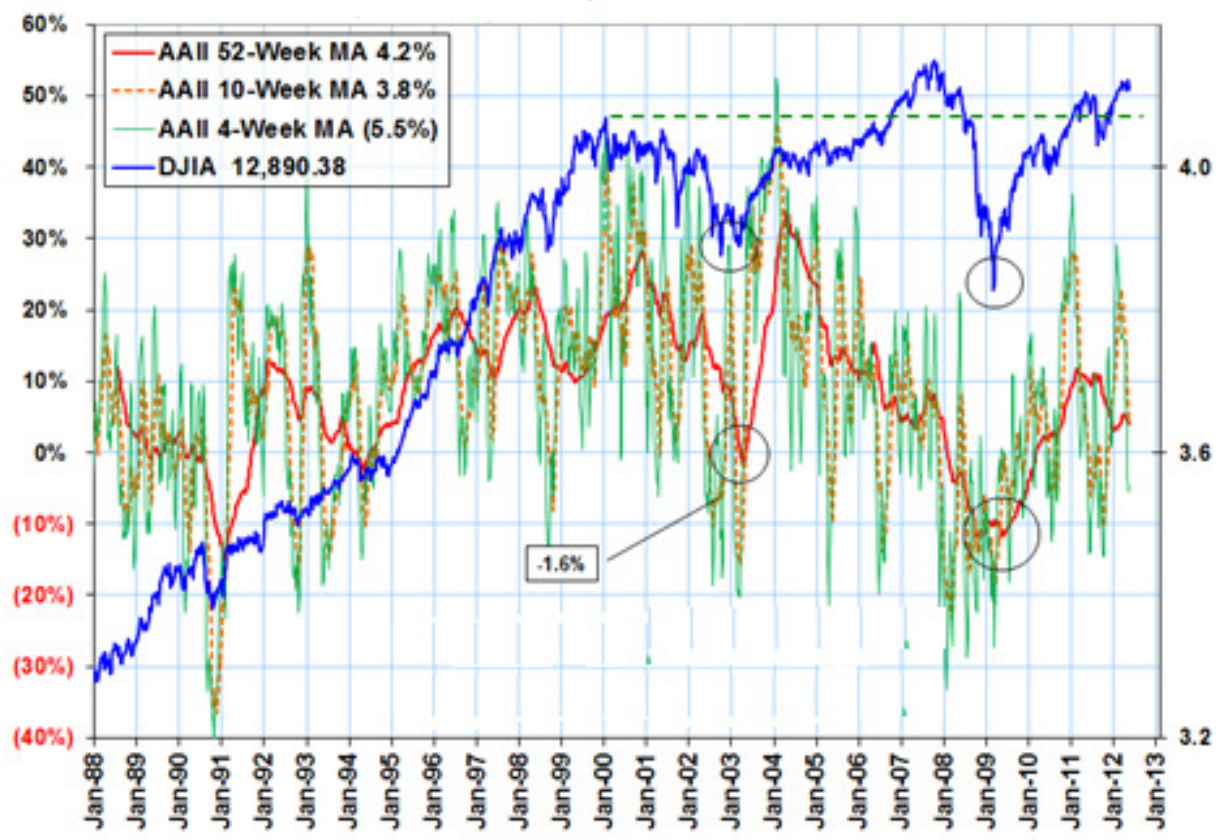

Figure 9 AAII Survey vs Log DJA (Source: www.kirklindstron.com)

The AAII sentiment survey is a weekly poll conducted by that organization which intends to gauge the overall sentiment of their membership. They ask their membership where they think the market will be in six months, and group the responses into three categories: bullish, bearish or neutral. Like most contrarian indicators, when the survey shows too many investors as being bullish, it very often corresponds to market highs. Conversely, too many bears suggest that the market may soon find a low. Figure 9 shows the AAII Survey vs. DJIA. From my chart of the 
various AAII averages vs. the DJIA chart that, the 52-week moving average of sentiment peaked in early 2011 then fell until the start of 2012 before moving higher. The 4-week moving average of sentiment fell from early 2012 through January 2013 where it is now in the rare negative zone.

\subsubsection{ABC News Consumer Comfort Index (CCI)}

ABC News began conducting this measure of consumer attitudes in December 1985. The Post replaced Money magazine as co-sponsor of the index in January 2005. The Washington Post$\mathrm{ABC}$ News Consumer Comfort Index (CCI) is a rolling average based on telephone interviews with 1,000 randomly selected adults nationwide conducted over the previous four-week period. New data is released every Tuesday at 5 p.m. The index is computed by subtracting the negative response to each question from the positive response. The three resulting numbers are then averaged. The scale can range from +100 (if every respondent gave positive responses to each of the three questions) to -100 (if all respondents expressed consistently negative views.) In practice, over its 19-year history it has ranged from a high of 38 in January 2000 to a low of -50 in February 1992.

The index is based on three core questions. These questions ask respondents to rate the condition

of the national economy, the state of their personal finances and whether now a good time to buy things is. Margin of sampling error for the results of each of the component questions is plus or minus 3 percentage points. [199] The three core questions asked of survey respondents are:

i. Would you describe the state of the nation's economy these days as excellent, good, not so good, or poor?

ii. Would you describe the state of your own personal finances these days as excellent, good, not so good, or poor?

iii. Considering the cost of things today and your own personal finances, would you say now is an excellent time, a good time, not so good a time, or a poor time to buy the things you want and need?

\subsection{Volatility}

Equity market volatility is the fluctuation in price of broad market indexes over a defined period. However, different measures of this volatility exist, each with important nuances. The accurate measurement of equity market volatility is critical for effective investing. Volatility is an important factor in the comparison of risk and reward between stocks and other asset classes. 
This comparison helps to determine the appropriate strategic asset allocation for an investor, given his objectives and risk tolerance. Volatility is not the same as risk. When it is interpreted as uncertainty, it becomes a key input to many investment decisions and portfolio creations. Investors and portfolio managers have certain levels of risk which they can bear. A good forecast of the volatility of asset prices over the investment holding period is a good starting point for assessing investment risk.

Volatility is the most important variable in the pricing of derivative securities, whose trading volume has quadrupled in recent years. To price an option, we need to know the volatility of the underlying asset from now until the option expires. In fact, the market convention is to list option prices in terms of volatility units. It is now possible to buy derivatives that are written on volatility itself, in which case the definition and measurement of volatility will be clearly specified in the derivative contracts. In these new contracts, volatility now becomes the underlying asset. So a volatility measure and a forecast on the volatility of volatility over the defined period are needed to price such derivative contracts. Financial risk management has taken a central role since the first Basle Accord was established in 1996. This effectively makes volatility forecasting a compulsory risk-management exercise for many financial institutions around the world. Banks and trading houses have to set aside reserve capital of at least three times that of value-at-risk (VaR), which is defined as the minimum expected loss with a 1percent confidence level for a given time horizon (usually one or ten days). Sometimes, a 5percent critical value is used. Such VaR estimates are readily available given volatility forecast, mean estimate, and a normal distribution assumption for the changes in total asset value. [200]

\subsubsection{Volatility and Market Performance}

The relationship between volatility and market performance is a very visible one. When volatility declines the stock market rises and increase as the stock market falls. Volatility also associated with risk - when volatility increases, risk increases and returns decrease. In a 2011 report, Crestmont Research examined the historical relationship between stock market performance and the volatility of the market. Crestmont used the average range for each day to measure the volatility of the Standard \& Poor's 500 Index (S\&P 500) index. The research concluded that higher volatility corresponds to a higher probability of a declining market. Lower volatility corresponds to a higher probability of a rising market. The table and graph of figure 10 
shows that, when the average daily range in the S\&P 500 Index is low (the first quartile 0 to $1 \%$ ) the odds are high (about $70 \%$ monthly and $91 \%$ annually) that investors will enjoy gains of $1.5 \%$ monthly and $14.5 \%$ annually. When the average daily range moves up to the fourth quartile (1.9 to $5 \%$ ), there is a probability of a $-0.8 \%$ loss for the month and a $-5.1 \%$ loss for the year.

Monthly Data: S\&P 500 Index Average Daily Range

\begin{tabular}{|c|c|c|c|c|c|c|}
\hline Quartile & $\begin{array}{c}\text { Volatility } \\
\text { Range }\end{array}$ & $\begin{array}{l}\% \% \text { Chance } \\
\text { UpMonth }\end{array}$ & $\begin{array}{c}\text { \%Change } \\
\text { Down } \\
\text { Month } \\
30 \%\end{array}$ & $\begin{array}{c}\text { If Up } \\
\text { Average } \\
\text { Gain } \\
2.9 \%\end{array}$ & $\begin{array}{c}\text { If Down } \\
\text { Average } \\
\text { Loss } \\
-1.9 \%\end{array}$ & $\begin{array}{c}\text { Expected } \\
\text { Gain } \\
\text { (Loss) } \\
1.5 \%\end{array}$ \\
\hline 2nd & $1.0 \%-1.4 \%$ & $61 \%$ & $39 \%$ & $3.0 \%$ & $-2.1 \%$ & $1.0 \%$ \\
\hline $3 \mathrm{rd}$ & $1.4 \%-1.8 \%$ & $59 \%$ & $41 \%$ & $3 . .2 \%$ & $-3.2 \%$ & $0.6 \%$ \\
\hline 4th & $1.8 \%-6.6 \%$ & $41 \%$ & $59 \%$ & $5.2 \%$ & $-5.0 \%$ & $-0.8 \%$ \\
\hline \multicolumn{7}{|c|}{ Annual Data: (1962 - 2009): S\&P 500 Index Aver age Daily Range } \\
\hline Quartile & $\begin{array}{c}\text { Volatility } \\
\text { Range }\end{array}$ & $\begin{array}{l}\% \% \text { Chance } \\
\text { UpMonth }\end{array}$ & $\begin{array}{c}\text { \%Change } \\
\text { Down } \\
\text { Month }\end{array}$ & $\begin{array}{c}\text { If Up } \\
\text { Average } \\
\text { Gain }\end{array}$ & $\begin{array}{c}\text { If Down } \\
\text { Average } \\
\text { Loss }\end{array}$ & $\begin{array}{c}\text { Expected } \\
\text { Gain } \\
\text { (Loss) }\end{array}$ \\
\hline 1st & $0 \%-1.1 \%$ & $92 \%$ & $8 \%$ & $15.8 \%$ & $-1.5 \%$ & $14.5 \%$ \\
\hline 2nd & $1.1 \%-1.5 \%$ & $75 \%$ & $25 \%$ & $15.7 \%$ & $-6.0 \%$ & $10.3 \%$ \\
\hline $3 \mathrm{rd}$ & $1.5 \%-1.8 \%$ & $83 \%$ & $17 \%$ & $14.2 \%$ & $-11.6 \%$ & $9.9 \%$ \\
\hline 4th & $1.8 \%-2.7 \%$ & $38 \%$ & $62 \%$ & $17.7 \%$ & $-19.4 \%$ & $-5.1 \%$ \\
\hline
\end{tabular}

Figure 10 Relationship of volatility and market returns (S\&P 500 Index: 1962 - Dec 31, 2011) [201]

Research has also shown that aggregate net equity fund flows are strongly negatively correlated with changes in expected future stock market volatility as measured by the VIX. This implies that investor purchase decisions are driven by returns and sale decisions by risk perceptions. In [202] the researchers concluded that changes in the VIX primarily impact aggregate equity mutual fund redemptions with little impact on inflows while stock market returns impact inflows but not outflows but that changes in the VIX are positively correlated with the degree of portfolio rebalancing. While the impact on outflows is much larger, both fund inflows and outflows tend to increase (decrease) when the VIX increases (decreases).

This represents an uncanny relationship between stock market performance and the volatility of the market. The research does assert a causal relationship but the interrelationship implies that many measures of risk actually compound in declining markets. As well, the reward-to-risk relationship significantly improves in strong markets. In the context of secular bull and bear markets, the effects of volatility and risk are consistent hence the need to consider risk as well as reward in an investor's investment decisions. 


\subsubsection{Volatility Measures}

It is necessary to understand and measure volatility effectively, keeping in mind possible behavioral biases. The popular measure of market volatility is what is reported by the business news report. The absolute point change in an index such as" The Dow was down over 100 points today." However, a direct comparison of volatility from one period to another should be made using percentage changes in the level of the index, not absolute changes. The absolute change in an index tends to make an event look more volatile than it actually is. [203] This is because round number milestones, like 100 points, tend to stick in people's memories long after they have lost relevance as a percentage of the index level. Since the index generally rises over time, a similar point change becomes smaller and smaller as a percentage change, as shown in Figure 11

\begin{tabular}{|ccc|}
\hline Date & Absolute Change & Percentage Change \\
\hline October 19,1987 & -508.0 points & $-22.6 \%$ \\
August 31,1998 & -512.6 points & $-6.4 \%$ \\
October 7,2008 & -508.4 points & $-5.11 \%$ \\
\hline
\end{tabular}

Figure 11 Percentage change in DJIA (Source: Vanguard \& DJIA)

\subsubsection{Standard Deviation}

Standard deviation is the dry definition of risk and it is the value of the market volatility describing the range of price fluctuations relative to moving average. So, if the value of this indicator is high, the market is volatile, and prices of bars are rather spread relative to the moving average. If the indicator value is low, the market can described as having a low volatility, and prices of bars are rather close to the moving average. The market behavior represents the interchange of high trading activity and a lacking in vitality. So, the indicator can be interpreted easily: if its value is too low, i.e., the market is absolutely inactive, it makes sense to expect a spike soon; or if it is extremely high, it most probably means that activity will decline soon.

Price/Earnings (P/E) values for a particular security or average sales over a specified period are determined by standard deviation. If the data points are normally distributed then standard deviation gives the probability of future data points falling within a certain range of the current mean. This is a base for risk assessment and allows comparison between the data sets of various securities. Standard deviation have been used in the construction of Bollinger bands as an upper and lower band that are a certain standard deviation level away from a 
central moving average. In this way, during times of lower volatility, Bollinger bands contract as the range of prices during the period being used for data points gets smaller, reflecting the lower volatility. When volatility increases for a security, the standard deviation lines widen. John Bollinger developed this technique for looking at expected future price projections and potential reversal points. Mr. Bollinger recommends using a 20 period simple moving average and lines that are 2 standard deviations away from the moving average.

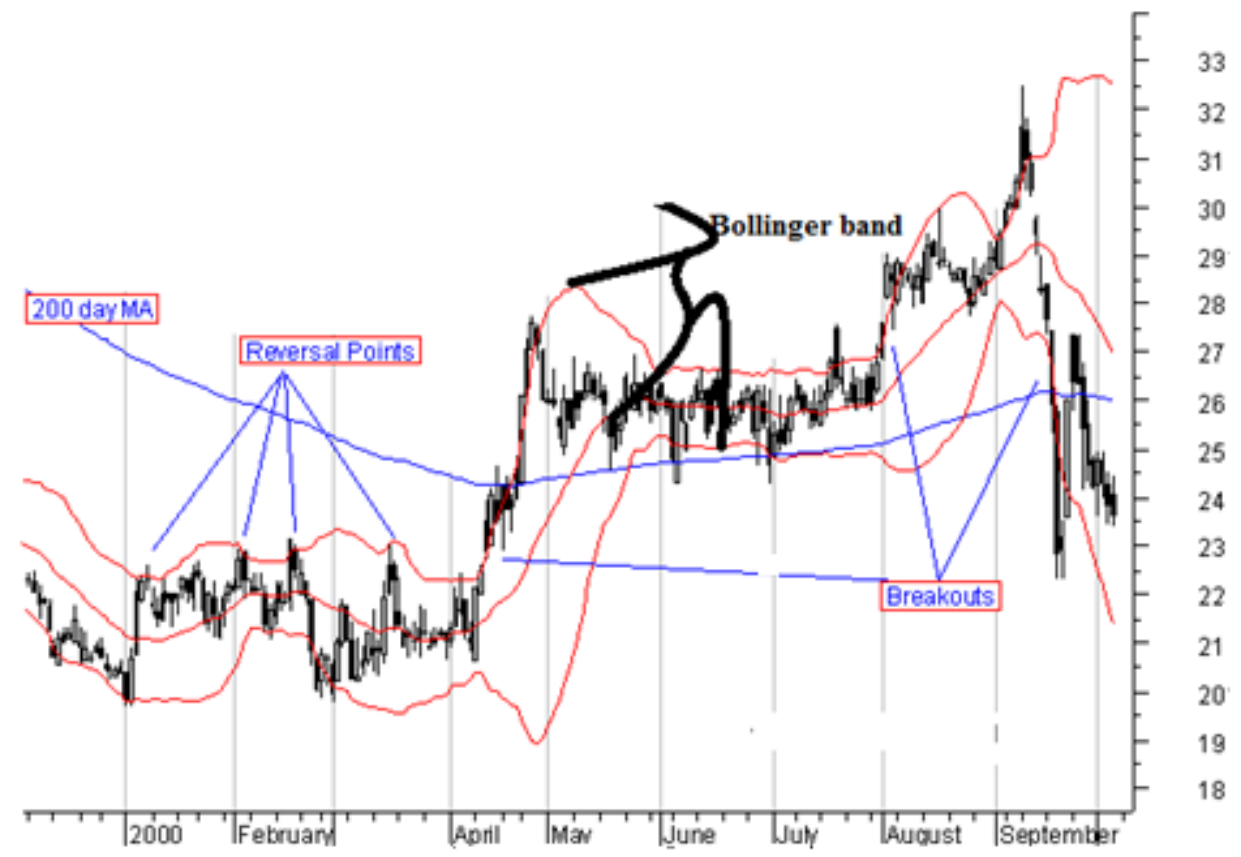

Figure 12 Moving average with Bollinger band 2 standard deviation (www.stockchart.com)

Figure 12 above uses a 23 day moving average with Bollinger bands 2 standard deviations away from the central moving average. Notice that there are a number of reversal points where price touches the upper or lower band, followed by a reversal of the price trend. There are also a number of breakouts where price penetrates either the upper or lower bands. When price breaks outside the bands a continuation of the trend is implied. There are a number of penetrations like late February 2000 where price penetration does not precede a continuation of the trend Investors often wait for penetration by a certain percentage movement of price before considering a breakout signal valid. . 


\subsubsection{VIX}

The Chicago Board Options Exchange (CBOE)'s Market Volatility Index VIX) is an index like the Dow Jones Industrial Average (DJIA), calculated on a real-time basis throughout each trading day. The only meaningful difference is that it measures volatility and not price. VIX was introduced in 1993 with two purposes in mind. First, it was intended to provide a benchmark of expected short-term market volatility. To facilitate comparisons of the then-current VIX level with historical levels, minute-by-minute values were computed using index option prices dating back to the beginning of January 1986. This was particularly important since documenting the level of market anxiety during the worst stock market crash since the Great Depression, the October 1987 Crash, would provide useful benchmark information in assessing the degree of market turbulence experienced subsequently. Also, VIX was intended to provide an index upon which futures and options contracts on volatility could be written. The social benefits of trading volatility have long been recognized. VIX is forward-looking measuring volatility that the investors expect to see. It is not backward-looking, measuring volatility that has been recently realized, as some commentators sometimes suggest. VIX is implied by the current prices of S\&P 500 index options and represents expected future market volatility over the next 30 calendar days. [204]

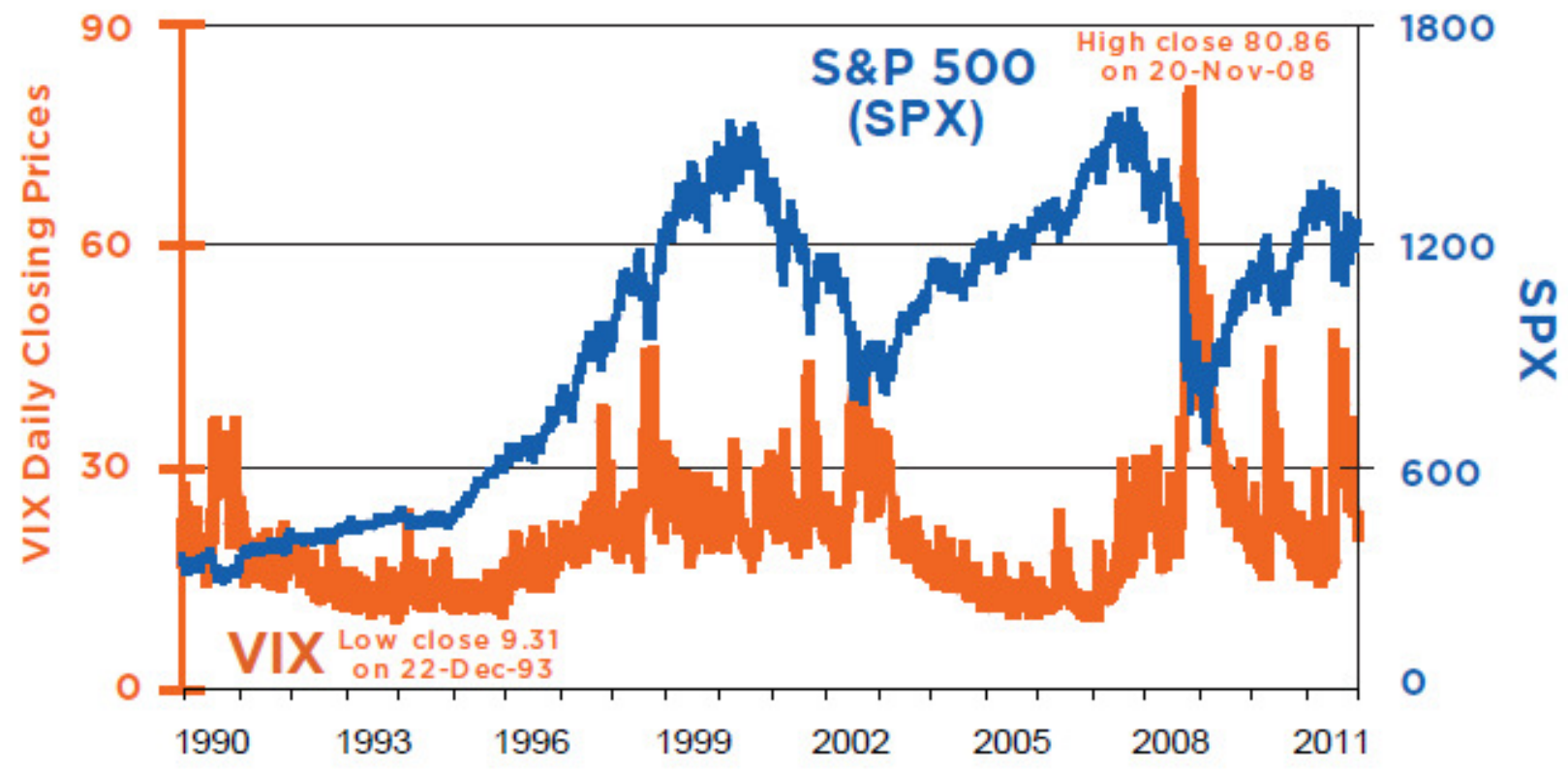

Figure 13 VIX and S\&P 500 Index (1990 - 2011) [205]

The CBOE calculates and updates the values of more than a dozen volatility indexes designed to measure the 30-day implied volatility of different securities. These volatility indexes are key 
measures of market expectations of near-term volatility conveyed by listed option prices. Futures and options contracts now are available on some of these volatility indexes. VIX based on S\&P 500 Index Options, is considered by many to be the world's premier barometer of investor sentiment and market volatility. Www.cboe.com/vix. The reason many investors are intrigued by the VIX Index is its negative correlation of returns vs. many other stock indexes. The high volatility of VIX is also an attractive feature. Figure 13 shows the relationship between VIX and S\&P 500 Indexes (1990 - 2011).

\subsubsection{VXN}

The CBOE NASDAQ-100 Volatility Index (VXN) is a key measure of market expectations of near-term volatility conveyed by NASDAQ-100 Index (NDX) option prices. It measures the

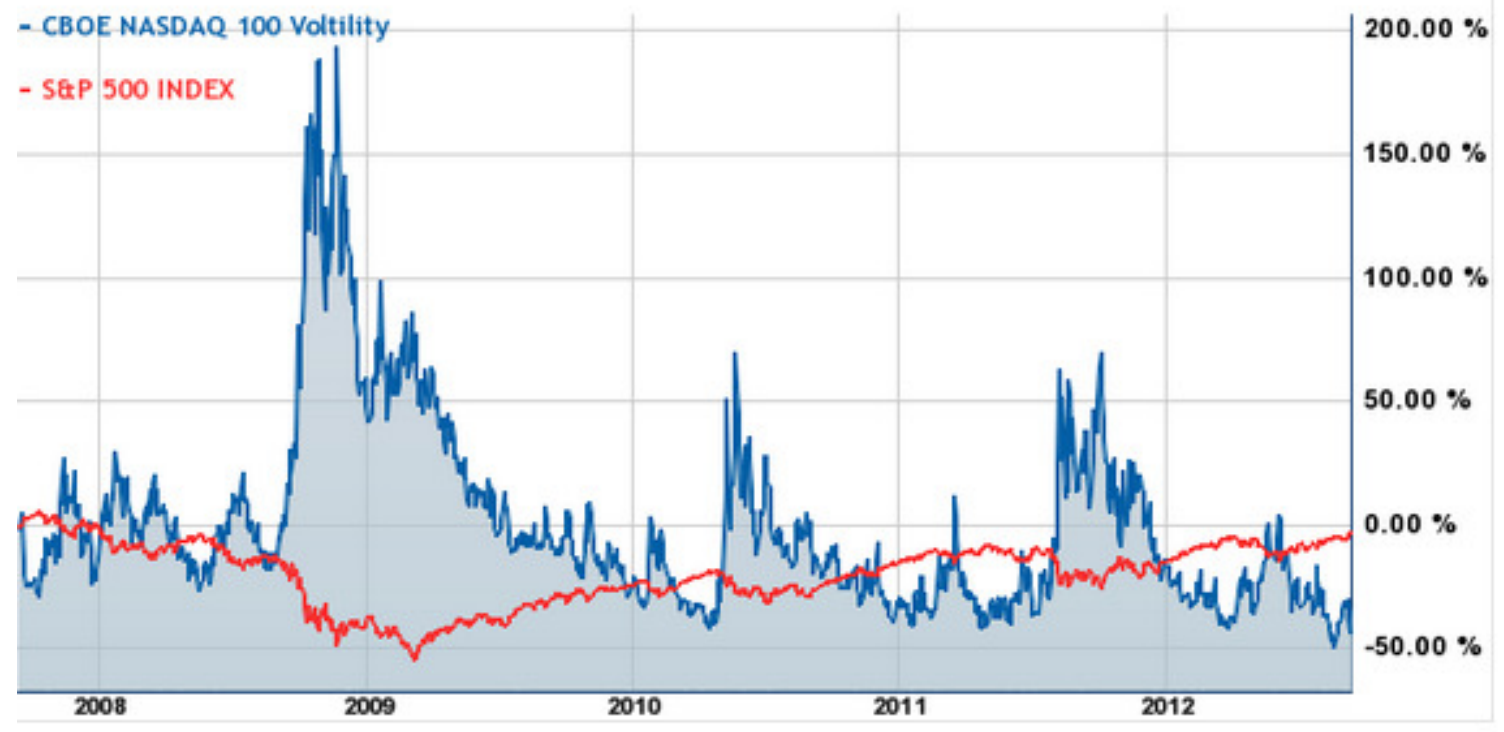

Figure 14 Five years change in CBOE NASDAQ-100 volatility vs. S\&P 500 Index [206]

market's expectation of 30-day volatility implicit in the prices of near-term NASDAQ-100 options. VXN is quoted in percentage points, just like the standard deviation of a rate of return, e.g. 19.36. CBOE disseminates the VXN index value continuously during trading hours. The VXN Index is a leading barometer of investor sentiment and market volatility relating to the NASDAQ-100 Index. CBOE NASDAQ Volatility Index data is compiled by CBOE for the convenience of database users and is furnished without responsibility for accuracy and is accepted by the users on the condition that transmission or omissions shall not be made the basis 
for any claim, demand or cause for action. [206] Figure 14 shows 5 years percentage change in CBOE NASDAQ 100 Volatility versus S\&P 500 Index.

\subsubsection{NYSE Versus NASDAQ Volume}

NYSE/NASDAQ ratio indicator is based on the simple premise that when investors are uncertain, they tend to concentrate their trading on the "safe", blue-chip issues which trade on the NYSE, and they avoid the "risky", more speculative issues that trade on the NASDAQ. Generally, high NYSE volume, relative to NASDAQ volume, is observed near lows as it shows a large amount of uncertainty. Low NYSE volume, again, relative to NASDAQ volume, is seen near highs, as market participants become comfortable with risk and so concentrate more heavily on issues traded on the NASDAQ. According to Sentiment Trader, the guideline is: Very low ratios suggest uncertainty. By "very low", it means anything under 1.0 or so. When heavy NYSE volume compared to NASDAQ volume, relatively confident that investors are excessively uncertain about future market direction is felt and very often a market low will soon follow. When the ratio is over 1.5 or very high NASDAQ volume relative to NYSE volume suggests that there may be too much speculation in the market, and a peak will often follow.

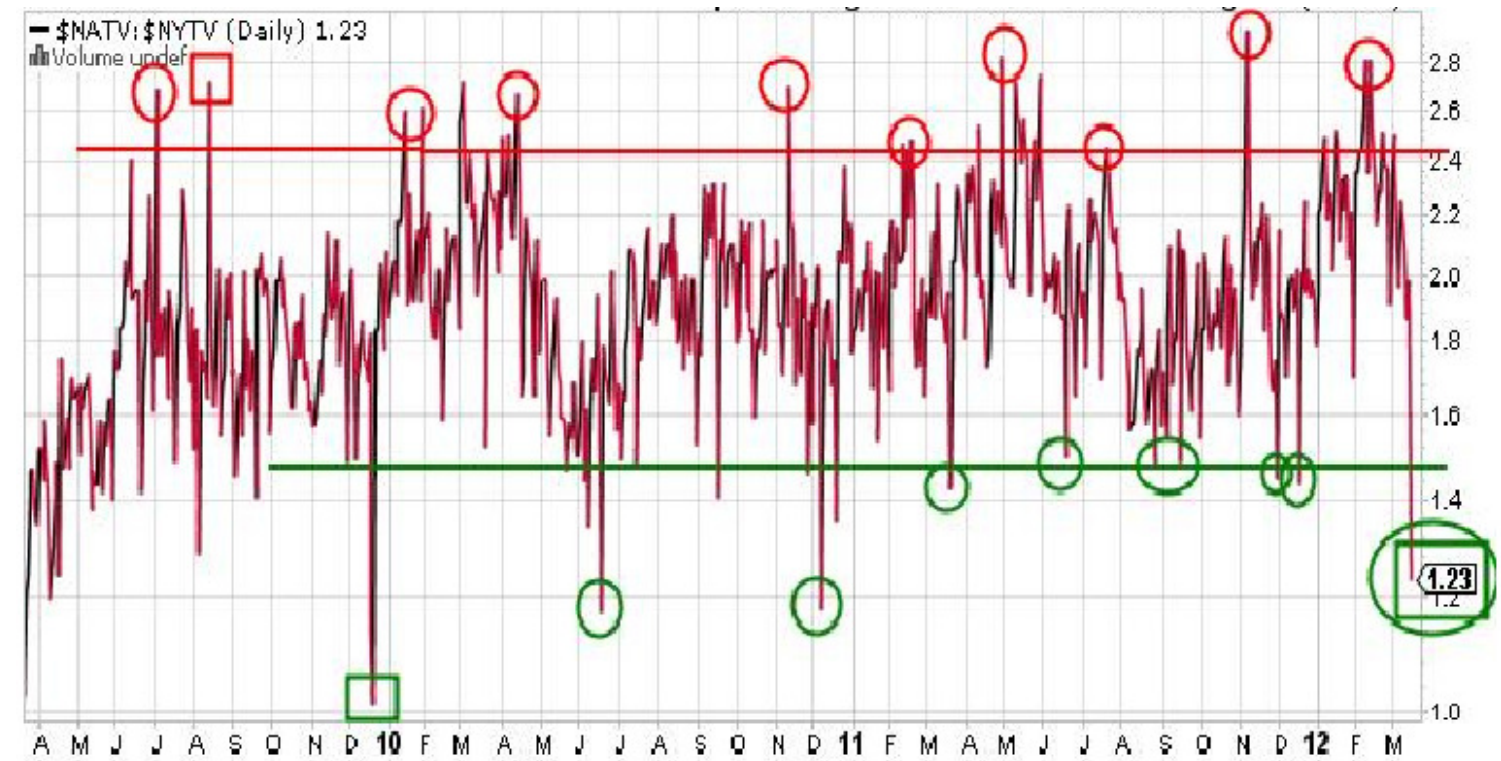

Figure 15 NASDAQ/NYSE volume ratio [207]

Figure 15 shows a graph of traders running into the tech-weighted NASDAQ. This suggests that the markets are strong, tech leads, and the higher ratio values are printed (upper circles). When 
the tech sector lags in volume, it indicates market bottoms (bottom circles). The upper circles show significant market tops and the bottom circles show significant market bottoms. Note that the upper square did not result in a market pull back in 2009, albeit a very slight pull back and then markets kept moving higher until the January 2010 top spanked the markets lower. Conversely, the bottom square did not identify a market bottom in late 2009; the market bottom occurred a month or two later in February 2010. [207]

\subsubsection{Volume}

The total number of shares traded is a confirmation of the market movement. If share prices are rising or falling, it is more meaningful if volume is high. When volume is low, trading is thin, and buy/sell decisions can move the market disproportionately. The volume of trading in a market tend to be a gauge of investors feeling about the market On March , 2011 total trading volume was high with 1,024, 995490 NYSE shares exchanging hands. By breaking down volume into advancing volume and declining volume a better understanding of the market movement is appreciated. The trading volume on March 2 confirms the strong upward movement in the market. Advancing volume outpaced declining volume by $116 \%$.

\subsection{Put/Call Ratio - PCR}

Several Put/call ratios are used in the literature, but the most-utilized one is based on data collected by the CBOE. Each day, the CBOE adds together all of the call and put options that are traded on all individual equities, as well as on various indices, including the S\&P 100. Buyers of put options are betting on stock price drops and may be considered pessimists. Buyers of call

options are betting on stock price increases and may be considered optimists. Using trading volume as the basis of measurement, the Put/call therefore reflects pessimism as a percentage of optimism. If the Put/Call is greater than one, then pessimists outweigh the optimists. If the PCR is less than one, then optimists outweigh the pessimists. Although a value of 1.0 might seem to be a "neutral" reading, empirically it has been observed that there are more calls than puts bought on what would be considered an "average" day. As a result, a PCR of approximately 0.80 is considered "normal". Markets are considered "strong" when the ratio falls below 0.7 since the optimists clearly outweigh the pessimists. Markets are considered "weak" when the ratio rises above 1.1 since the pessimists outweigh the optimists. [208] 
The Put/Call Ratio is used as a contrarian indicator to gauge bullish and bearish extremes. Contrarians turn bearish when too many traders are bullish. Contrarians turn bullish when too many traders are bearish. Traders buy puts to insurance against a market decline or as a directional bet. While calls are not used so much for insurance purposes, they are bought as a directional bet on rising prices. Put volume increases when the expectations for a decline increase. Conversely, call volume increases when the expectations for an advance increase. Sentiment reaches extremes when the Put/Call Ratio moves to relatively high or low levels. These extremes are not fixed and can change over time. A Put/Call Ratio at its lower extremities would show excessive bullishness because call volume would be significantly higher than put volume. In contrarian terms, excessive bullishness would argue for caution and the possibility of a stock market decline. A Put/Call Ratio at its upper extremities would show excessive bearishness because put volume would be significantly higher than call volume.

\subsection{Liquidity}

Empirical evidence from many literatures suggests that liquidity forecasts stock returns, both at the firm level and aggregate market. Increase liquidity, including a low price impact of trade, low bid-ask spreads and high share turnover, are associated with lower future returns in cross sections of individual firms. [209] [210] The traditional explanation for why liquidity might affect expected returns is based on investors anticipating having to sell their shares at some point in the future, and they recognize that when they do so, they will face transactions costs. These costs can stem either from the inventory considerations of risk-averse market makers or from problems of adverse selection. But in either case, when the transactions costs are greater, investors rationally discount the asset in question by more. [211] If two stocks are compared, one is observed to have permanently lower bid - ask spreads and price impacts than the other, as well as higher turnover, it is plausible that the more liquid stock would have a somewhat higher price, and hence lower expected returns.

An alternative theory explains the connection between liquidity and expected returns. [212] The literature focus is on understanding why time-variation in liquidity, either at the firm level or for the market as a whole, might forecast changes in returns. While accepting implicitly the premise that the traditional theory is best suited to explaining why permanent cross-firm differences in liquidity are associated with permanent cross-firm differences in expected returns. The model 
used in their research rests on two sets of assumptions - one about market frictions, and the other about investor behavior. With respect to the former, we assume that there are short-sales constraints. With respect to the latter, it posits the existence of a class of irrationally overconfident investors, where we think of overconfidence as a tendency to overestimate the relative precision of one's own private signals. This form of overconfidence has two distinct manifestations. First, when overconfident investors receive private signals, they tend to overweight them; this leads to sentiment overreactions that can be either positive or negative. Second, when overconfident investors observe the trading decisions of others, they tend to under react to the information contained in these decisions, since they consider others to be less wellinformed than they are. This aspect of overconfidence lowers the price impact of trades, thus boosting liquidity generally.

The study concluded that in a world with short-sales constraints, market liquidity can be a sentiment indicator. An unusually liquid market is one in which pricing is being dominated by irrational investors, who tend to under react to the information embodied in either order flow or equity issues. Thus high liquidity is a sign that the sentiment of these irrational investors is positive, and that expected returns are therefore abnormally low.

\subsection{Market Breadth}

There are many sources of trading statistics that help to indicate the strength, breadth, and current direction of the market in greater detail than following the change in a particular index. Market breadth measures indicate how widely the full ranges of stocks are participating in the movement of the stock market. Charting volume, new high/low and advance/decline data for a given market is one way to confirm the direction of prices. Various calculations can be applied to these values to fine-tune their signals. Market breadth is one of the more useful and popular methods of measuring the participant in the stock market movement.

\subsubsection{Advance / Decline Line}

Market analysts often track the differences between advances and declines, accumulating the difference over some time period. The advance/decline line is the simplest of all breadth measures. It is a cumulative total of the advancing-declining issues indicator. The Advance/Decline Line of a market (such as the NYSE or NASDAQ) moves with the price of the market index. When more stocks advance than decline, the advance/decline line moves up and a 
majority of declining issues pushes the line downward. It is calculated by dividing the weekly advances and declines by the weekly total issues. If prices move steadily upward (strong uptrend) a broad number of stocks should participate. If not there is a negative divergence between the market and market breadth. This could happen, if only heavy weighted stocks in an index are pushing the market higher but the majority of small weighted stocks are already being sold by investors. By separating the advancing from declining issues, investors can get an additional insight about the direction of the market. Divergences between the market and advancing issues should be monitored closely as a trend reversal could be ahead. Figure 16 is a screenshot presents a March-to-October chart for the S\&P 500 Index coupled with a cumulative advance/ decline lines.

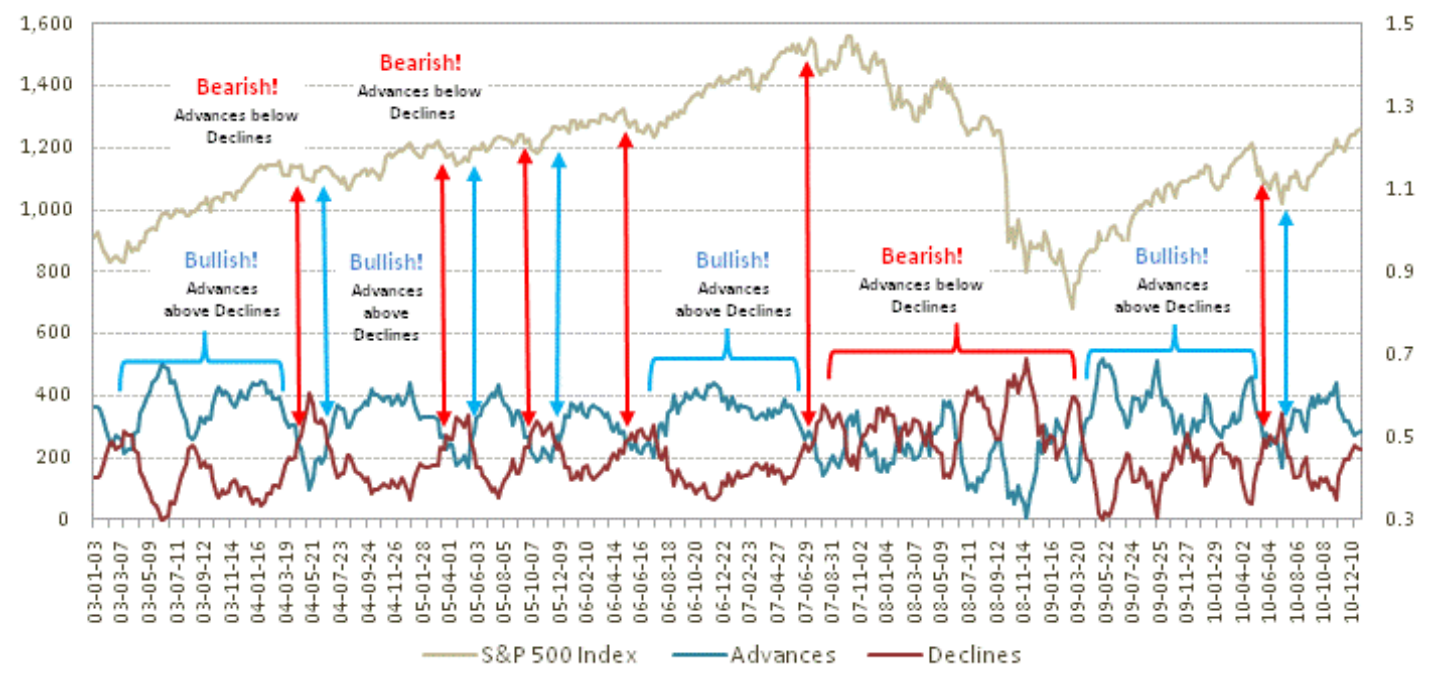

Figure 16 Advance - Decline Lines weekly [213]

\subsubsection{New High - New Low Ration}

This is a breadth ratio constructed from New High / New Low Ratio. New highs are the number of S\&P issues that closed at a new 52-week high. New lows are the number of S\&P issues that reached a new 52-week low. It is expressed as the number of issues that closed at a new high as a percentage of the total. Originally this breadth indicator was used on NYSE to define the U.S. stock market sentiment. At the current moment the New Highs and New Lows are used on different basket of stocks, including but not limited to the NASDAQ 100, S\&P 500 and DJI indexes to describe the sentiment of various stock market sectors. The New Highs and New Lows calculations are simple. New highs represent the number of stock reaching new 52-week 
highs and the number of New Lows represents the number of stocks traded at new 52-week lows. In technical analysis New High/Lows are analyzed as individual indicators as well as in combination together.

The New Highs/Lows Oscillator and New High/Lows Ratio are well known and often used to define overbought and oversold levels. Figure 18 from the Wall Street Journal of shows these statistics for the NYSE although these statistics are also reported for the Nasdaq and Amex. Increasing numbers of stocks reach new highs and fewer stocks reach new lows in bull markets, and the reverse is true in bear markets. On March 2, 2011, 73 stocks reached new highs, while only 18 hit new lows.

\begin{tabular}{|c|c|c|c|c|}
\hline NYSE & $\begin{array}{l}\text { Latest } \\
\text { close }\end{array}$ & $\begin{array}{l}\% \text { Chg from } \\
65 \text {-day avg }\end{array}$ & $\begin{array}{l}\text { Previous } \\
\text { close }\end{array}$ & $\begin{array}{l}\text { Week } \\
\text { ago }\end{array}$ \\
\hline Issues traded & 3,129 & -0.3 & 3,151 & 3,160 \\
\hline Advances & 1,920 & 18.5 & 741 & 1,088 \\
\hline Declines & 1,106 & -22.2 & 2,339 & 1,976 \\
\hline Unchanged & 103 & 6.0 & 71 & 96 \\
\hline New highs & 73 & -64.2 & 190 & 60 \\
\hline New lows & 18 & -22.5 & 17 & 27 \\
\hline Adv. volume ${ }^{*}$ & $619,208,240$ & 14.8 & $129,255,102$ & $446,482,272$ \\
\hline Decl. volume* & $381,248,410$ & -15.8 & $1,047,631,711$ & $865,428,487$ \\
\hline Total volume ${ }^{*}$ & $1,024,995,490$ & 1.5 & $1,180,418,530$ & $1,330,347,648$ \\
\hline Closing tick & +741 & $\ldots$ & +40 & 539 \\
\hline Closing Arms (TRIN)† & 1.07 & $\cdots$ & 2.57 & 1.07 \\
\hline Block trades* & n.a. & $\ldots$ & 5,154 & 6,255 \\
\hline
\end{tabular}

Figure 17 Stock Market diary (Source: Wall Street Journal)

\subsubsection{Absolute Breadth Index}

The Absolute Breadth Index (ABI) is a market activity indicator developed by Norman G. Fosback. The absolute breadth index indicates strong market participation without regard to market direction The ABI is used to determine market volatility levels by showing how much sentiment is affecting the market without considering price direction. High Absolute Breadth Index readings indicate market activity and change, while low readings indicate inactivity or lack of change. It is calculated by examining the absolute difference between the numbers of advancing issues and declining issues and dividing the value by the number of shares traded. 
Expressed as a percentage it is virtually the opposite of the unchanged issues index. From figure 17 above, on March 2, 2011 the ratio was low at 26\% indicating a low level of participation among the NYSE stocks in the market's move. The index is often averaged over a period of weeks to help gauge the consistent participation of the broad market in the overall movement.

\subsubsection{Tick}

One of the most sensitive minute-to-minute measures of market sentiment is the number of stocks trading higher than their previous trade less the number of stocks trading lower. An uptick means more stocks are trading higher than their previous trade - is bullish, and a downtick, more stocks are trading lower - is bearish. A large plus tick indicates that the short-term direction of the market is up, and a large minus tick is an indication that the market is trending down. Since the tick is computed continuously, it is very changeable, giving up-to-the-minute readings on the market mood. The market averages may be up, but the tick can turn negative, indicating that the trading trend has reversed. The closing tick is frozen at the end of the trading day, but provides some insight into the ending market sentiment.

The closing downtick of +741 on March 2, 2011 from figure 18 indicates that stocks were still strongly trending upward when the market closed. This is in contrast to the previous close of +41 and the closing tick one week previously which was a +539 . The tick of the stocks that make up the Dow Jones industrial average is referred to as the ticks and provides a quick indication of the direction of the Dow Jones industrial average. The ticks add up the plus and minus ticks for the Dow Jones stocks, so its range is +30 to -30 . [214]

\subsubsection{Traders Index (TRIN)}

The Traders Index (TRIN) was developed by Richard Arms and it is also called after the developer as Arms index. The TRIN measures the distribution of the up and down volume to the advancing and declining issues. It is computed by dividing the ratio of advances to declines by the ratio of advancing volume to declining volume. A ratio of 1 means the market is in balance; above 1 indicates that more volume is moving into declining stocks; and below 1 indicates that more volume is moving into advancing stocks. The TRIN is computed continuously during the day and has the advantage of weighting the number of issues moving up or down with the volume behind the movement. The closing TRIN of 1.5 was very bearish, pushed up by an overwhelming ratio of declining volume to advancing 


\subsubsection{Block Trade}

Large block trades help to indicate the participation of large institutions in the market. Block Trades are privately negotiated stock, futures, options or combination transaction that is permitted to be executed apart from the public auction market. Participation in block trades is restricted to Eligible Contract Participants as that term is defined in the Commodity Exchange Act. Block trades are permitted in specified products and are subject to minimum transaction size requirements which vary according to the product, the type of transaction and the time of execution. Block trades may be executed at any time at a fair and reasonable price. [215] A single block trade is calculated as a trade that is greater than or equal to 10,000 shares. There are block trades screener that gauges institutional sentiment for stocks. The net cash flow is calculated as the composite dollar value of buy side block trades minus the dollar value of sell side block trades. The bought/sold ratio reflects the volume of block shares that were traded on the buy side relative to the volume of block shares that were traded on the sell side.

As shown in figure 17, the Wall Street Journal provides a total count of the number of block trades that occurred on a given day for each exchange. Barron and other financial date provide a daily breakdown by exchange listing the number of block trades that occurred on up ticks, down ticks, and without change. Investors look at this information as an indication of whether the buyer or seller was more eager to complete the trade. An increasing number of block trades with up ticks helps to indicate an increasing interest in the market by the institutional marketplace and tends to track a rising market.

\subsubsection{Commitment of Trader (COT)}

The COT report has its origins in an annual report first published in 1924 by the U.S. Department of Agriculture's Grain Futures Administration. The annual report covered hedging and speculation in the regulated futures markets. In June of 1962, the COT report began publication on a monthly basis and in 1990 became a bi-monthly publication. In the year 2000, the COT report became weekly, with data released on the third business day after the "as of" date. The "as of" date refers to the day a position was initiated. The Commitment of Traders Report (COT), now released weekly by the Commodity Futures Trading Commission (CFTC), provides information on the long and short positions of traders in different futures contacts. The 
report is mostly used by traders to monitor market sentiment and to determine which side of the market will have the least resistance to price movement.

The information contained in the COT report illustrates how large traders, hedgers and small traders position themselves in the market. Nevertheless, the report is just a snapshot of one week's worth of activity, so the real value of this information is in the net changes of futures positions over time. For example, an increase in open interest seen along with a rise in short positions can indicate that the market may be under pressure and ready to decline. Conversely, an excess of shorts in the market could prompt a short squeeze, which would drive the market higher. The chart below clearly illustrates how large and small traders have increased and decreased their positions over time, with clear indications of buying and selling trends. While the information might be misinterpreted if used as a timing indicator, the way in which large and small traders behave gives clear indications of market sentiment. [216]

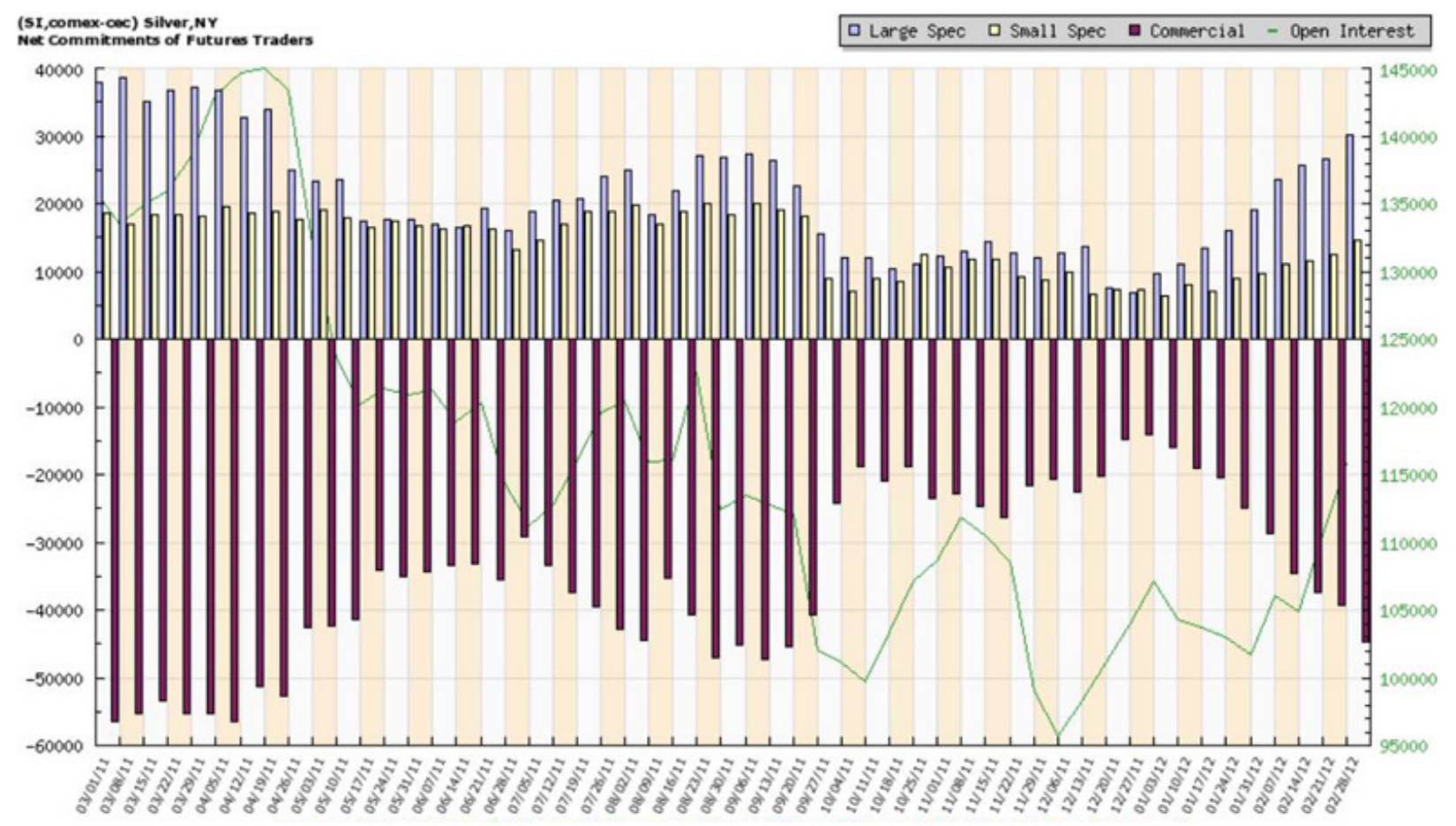

Figure 18 Commitment of Traders historical graph showing open interest, large and small speculators and commercial traders [217]

The figure 18 shows an increase in commercial short positions that have been keeping the silver market from trading higher. Without these commercial shorts, the price of silver would be 
significantly higher than the levels where it is currently trading. While the commercial short position holders may not be in any rush to cover their positions, the fact that their positions have gotten so large indicate the level of price depressive manipulation that the silver market is

presently operating under. Nevertheless, with concentrated short positions such as those seen in both the silver and gold markets, if the price unexpectedly spikes to the upside, the market could experience a substantial short squeeze, possibly driving the price to new all-time highs in both silver and gold.

\subsection{News Analytics and Investor Sentiments}

News-analytics software is part of a technological revolution that is reshaping investments in Wall Street. Stock trading is a business in which news and other data is one of the most valuable commodities. Information flow from news reports and social media can quickly shift investor sentiment from gloom to doom and investor with the best data and the smartest, fastest computers can outmanoeuvre rivals. Investors are thus increasingly using news analytics to stay on top of developments and ahead of market trends. Ravenpack and Thomas Reuters have consistently said, News-sentiment [analysis] is shown to outperform one-month price momentum when predicting future returns of the S\&P 500. The idea behind these new analytics technologies is to automate human thinking and reasoning. Traders, speculators and private investors anticipate the direction of asset returns as well as, the size and the level of uncertainty before making an investment decision. They carefully read recent economic and financial news to gain a picture of current situation. News Analytics automate this process.

A Los Angeles psychiatrist and investor-behavior researcher Richard L. Peterson developed news-analytics software in 2008 to improve stock-trading performance. Following that year's stock-market slump, he also created the MarketPsy Long-Short Fund. The fund's managers bought stocks based largely on investor sentiment as determined by his software's analysis of online business news, financial social media, and corporate interviews, explained Peterson, now managing partner of investment-consultancy MarketPsych LLC. His software quantified 400 types of investment-related sentiment and topics - including optimism, anger, and product releases - relating to 6,000 US stocks and exchange-traded funds. Despite investing in some then-disfavored stocks, the now-closed fund outperformed Standard \& Poor's 500-stock index from September 2008 through the end of 2010. [218] 
Security analysis was traditionally conducted by focusing on responses to quantitative or hard measures the industry and company fundamental and a few selected variables intended to proxy for some qualitative characteristic. Over the past decade, with it advancements is computer science and engineering, has provided academics and practitioners with a wealth of digitized text containing qualitative information and the processing power to apply algorithms that seek to quantify soft aspects of this text, such as relevance, sentiment and novelty. Thomson Reuters and RavenPack have News Analytics Engine, which is based on powerful linguistic analysis techniques. Computer analysis of thousands of news articles determines whether the news is positive, negative or neutral, and whether an article is relevant to a specific company, index or a commodity. In the past few years, even before the emergence of computer-aided news analysis such as Thomson Reuters NewsScope and RavenPack, several articles appeared that have analyzed the effects of volume and "tone" of news on equities - specifically stock index and individual stock returns, volumes and volatilities and company earnings. The forerunners of such research are two articles by [90] [219]. The first research studies the relationship between daily DJIA returns and sentiment, measured by Harvard IV-4 Psychosocial Dictionary (HPSD), in the Wall Street Journal. The main findings of this article is that low sentiment forecasts low returns followed by a rebound, low returns forecast low sentiment and high absolute sentiment forecasts high trading volume. This is inconsistent with the theory that news provides information about fundamental asset values.

The second research, [219] use event studies to investigate the relationship between a sentiment index based on the HPSD and stock returns and earnings of specific S\&P500 companies. In contrast to [90] this article finds that sentiment forecasts fundamentals (firm earnings) over as much as 18 months while stock returns under react very slightly and briefly (only 1 day) to sentiment information. Broadly, the existing research in this area finds that sentiment can help forecast stock returns and fundamentals such as earnings. In the case of forecasting the returns of stock indices, there is indication that news is largely noise: it drives down returns for a few days, but prices subsequently rebound to fundamentals. Research into the effects of sentiment on the returns of other assets such as commodities, however, is virtually nonexistent. So in this paper, we provide the first attempt at analyzing the relationship between news sentiment and energy, specifically crude oil futures. [177]Investor sentiment did not have an effective scientific measure until two decades ago with the emergence of behavioral finance theories. Classical 
finance theory states that the effects of sentiment on stock prices could be easily arbitraged away by rational traders and investors. However, numerous researches have concluded that the effects of sentiment could persist in stocks given the nature of uncertainty in some stocks. Studies suggest that some assets are more heavily traded by individual investors and have such high transaction costs so that the stock prices of these assets are more influenced by sentiment and these influences are not easily arbitraged away. [51]

It is not until the last decade, however, when an abundance of individual proxies, some discussed in this and previous chapters, for sentiment has been studied and researchers came out with a combination of these proxies to form sentiment indices that might better measure sentiment. A combination of six previously studied sentiment proxies formed a sentiment index and was tested against various portfolios of stock returns. [54] Other research also combined twelve direct and indirect measures of sentiment to form an index and tested it on both contemporaneous and nearterm stock returns. [78] They found that their index correlates strongly with contemporaneous returns but not with future returns. Despite the results, both papers point to the robustness of combining different sentiment proxies together to generate a better measure of investor sentiment. Drawing on these two papers and using some of there their variables to test again a more expansive set of data and extend the data set by at least ten years and also testing two survey-based measures of sentiment that are not widely tested as sentiment proxies. [220] It found that by combining different variables, better sentiment measures, as they correlate more significantly and highly with future returns, especially those of small stocks and the spread between small and large cap stocks. The study concluded that aggregate investor sentiment measures can forecast small stock returns. 


\section{CHAPTER SIX}

\section{NEWS ANALYTICS AND ITS APPLICATION IN FINANCE}

News analytics measures news attribute like sentiment, relevance and novelty by expressing news stories as numbers permits the management of everyday information in a mathematical and statistical manner. News analytics are used in finance particularly in quantitative and plotting and characterizing company behaviors over time and thus yield important strategic insights about rival company. Predicting the market has always been one of the hottest topics in research, so is the challenge due to its complex, non-stationary, noisy, chaotic, nonlinear and dynamic system but it does not follow random walk process [30]There are many factors that may cause the fluctuation of financial market movement including economic condition, political situation, traders' expectations, catastrophes and other unexpected events. Therefore, predictions of stock market price and its direction are quite difficult. As we have seen chapter five of this survey, researchers have proof that suggests that financial time series is predictable. Numerous publications have attempted to construct an accurate model for the stock market. Most of these works focus on time series prediction with various models, such as Artificial Neural Networks [221] [222] Hybrid Genetic Algorithm and Particle Swarm Optimization [223], Fuzzy Logic [224] and some hybrid combinations like the use of ten data mining techniques that include Linear discriminant analysis (LDA), Quadratic discriminant analysis (QDA), K-nearest neighbor classification, Naive Bayes based on kernel estimation, Logit model, Tree based classification, neural network, Bayesian classification with Gaussian process, Support vector machine (SVM) and Least squares support vector machine (LS-SVM). [225]

Companies that are listed in the public stock exchange are required to fully disclose material information to the public. This is Information which would be likely to affect stock price once it becomes known to the public, such as a purchase/sale negotiation, divestiture, significant management change, and new product introduction. Since most of this information can be obtained from the news articles, major financial newspapers become a good source of information in assisting the traders. The influence of public information on stock returns has 
been an ongoing focus of financial research. Previous research has indicated that, in the aggregate, public information plays a relatively minor role in influencing stock returns. New information leads investors to revise their expectations of future cash flows, the risk to cash flows and, hence, the expected return and price of the asset. Given that new information arrivals have the potential for causing a response, market participants are naturally interested in knowing if and, more importantly, how the market responds to different types of information.

Traditionally, the response researchers are interested in is that of price; and the major set of studies that identify the timing and magnitude of a firm's stock price response to information arrivals are event studies. However, investors can also respond to new information by reassessing their expectations regarding the underlying risk-return trade-off. That is to say, even though information events can, at least potentially, elicit a market response in the form of price. [226] So the arrival of news continually updates investor's understanding and knowledge of the market and influences investor sentiment as concluded in many literatures about the influence of media on investor sentiment. Significant news will often affect investors' beliefs and portfolio goals heterogeneously, resulting in more investors trading than is usual [90] [227] [228] Traders and other market participants digest news rapidly, revising and rebalancing their asset positions accordingly. Most traders have access to newswires at their desks. As markets react rapidly to news, effective models which incorporate news data are highly sought after. This is not only for trading and fund management, but also for risk control. Major news events can have a significant impact on the market environment and investor sentiment resulting in rapid changes to the risk structure and risk characteristics of traded assets. Though the relevance of news is widely acknowledged how to incorporate this effectively, in quantitative models and more generally within the investment decision making process, is a very open question. [229]

\subsection{News Analytics and Data Mining}

Analytics is a term that refers to the various modes of using information to make decisions. Traditionally, this is called decision support, and it is mostly accomplished through, the decisionsupport tools, data warehouse and business intelligence tools, which have become more sophisticated for data access, data analysis, data manipulation, data mining, forecasting, trend analysis and other metric-based presentations. Analysis tools include packaged analytical applications for specific business domains, such as supply chain analysis, sales channel analysis, 
performance analysis, etc. Data mining refers to extracting or "mining" knowledge from large amounts of data. Data mining is often treated as a synonym for another popularly used term, Knowledge Discovery from Data, or KDD. Alternatively, others view data mining as simply an essential step in the process of knowledge discovery.

Knowledge discovery as a process consists of an iterative sequence of data cleaning, data integration, data selection, data transformation, data mining, pattern evaluation and Knowledge presentation. [230] So, data mining is a method of pattern discovery against a pool of data using specialized data mining tools. These tools use a sophisticated blend of classical and advanced components like artificial intelligence, pattern recognition, databases, traditional statistics, and graphics to present hidden relationships and patterns they find in any given data pool. Based on this view, the architecture of a typical data mining system may have the following major components figure 19. While both analytics and data mining are aimed at information that is actionable; however, analytics and data mining are different. Analytics usually comes with hypotheses testing. The analyst has something in mind and is looking to answer a question and has hypotheses about the question. Data mining is more the act of discovery that lacks hypotheses. Data mining looks, in some cases, for patterns, often through vast amounts of data, and data mining is looking for patterns and relationships that were not anticipated.

The sources and volume of news have increase significantly over the years; as a result the consumers of financial news have work hard on achieving superior investment returns by using the information available to them. News Analytics offers automatic analyses of published news. One of the tasks of News Analytics (NA) is determining novelty of the published text, i.e. automatically deciding whether the news story at hand is reporting about some new event, or it is merely introducing new facts about an event that is already known. Another example of a NA task is detecting sentiment of the published news item. Analysing the language of a text, and the selection of the words author used, it is possible to determine whether the analysed text is positive or negative in sentiment, and also the degree of positivity or negativity. The texts lacking high levels of positivity or negativity are usually denoted as neutral. Such measure we call text sentiment measure. 


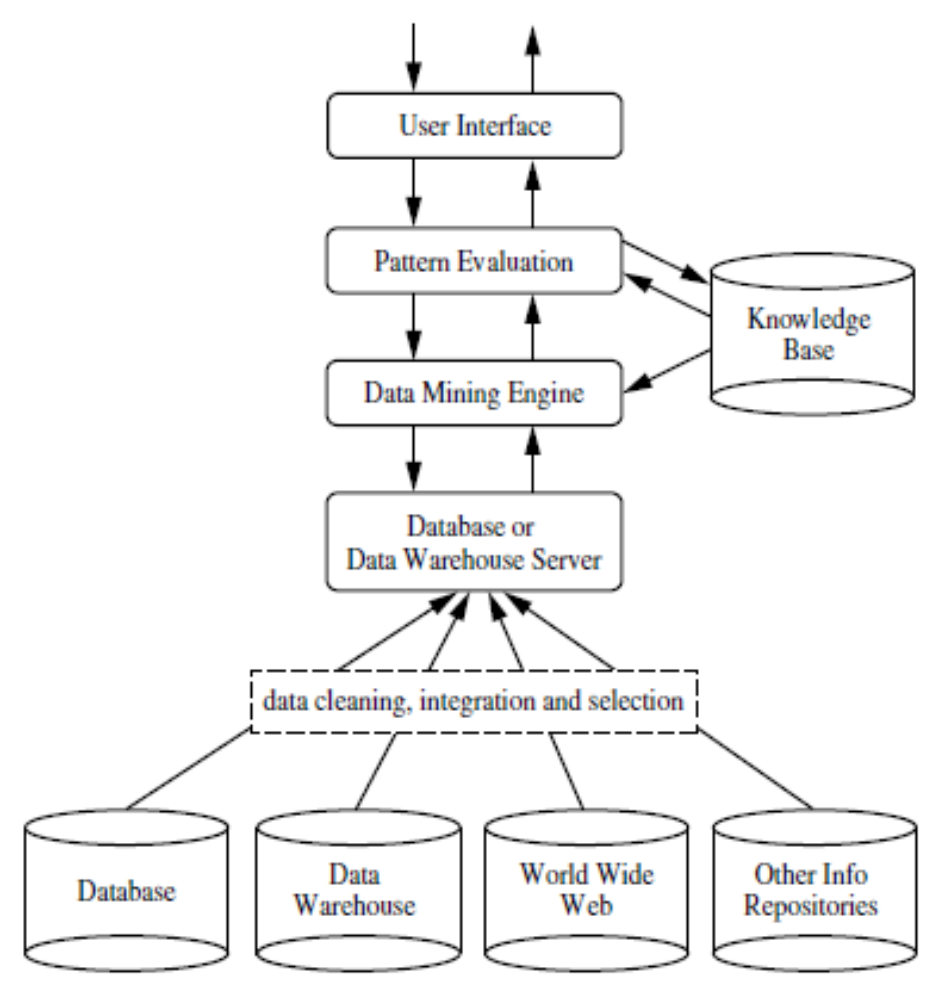

Figure 19 Architecture of typical data mining system [230]

Automated news analysis can form a key component driving algorithmic trading desks' strategies and execution, and the traders who use this technology can shorten the time it takes them to react to breaking stories. News analytics technology can also be used to aid traditional non-quantitative fund managers in monitoring the investor sentiment for particular stocks, companies, brands and sectors. These technologies are deployed to automate filtering, monitoring and aggregation news to understanding the financial markets. Investment firms are embracing new data, tools and techniques to help make sense of the massive amounts of unstructured data available. When applied properly, this data can complement a firm's trading and investment strategies and give it a competitive edge. Trading and investment firms are therefore can model crowd sentiment and behavior by making sense of all the unstructured news and opinion distributed every day over financial news sites, chat rooms, blogs and other social media channels. With NA, investors now have additional capabilities to gauge stock, sector, and market sentiment, and to translate these emerging sources of market insight into data that can be 
incorporated into both quantitative strategies and as a way to provide a broader context to human analysts.

News analytics has introduce technology to automate or semi-automate this approach. By automating the judgement process, the human decision maker can act on a larger, hence more diversified, collection of assets. These decisions are also taken more promptly. Automation or semi-automation of the human judgement process widens the limits of the investment process. [229] The goal of NA to investors in all market sectors is to help augment trading and risk models with alpha-generating and risk-mitigating properties and better identify changing market cycles; understand market cycles based on the psychological perceptions in each market and asset class and make better asset allocation decisions then drill down into sectors and choose strategy; identify news and social media flow that might impact investment theses; assess and understand qualitative psychological perceptions in the market to better support investment hypotheses; monitor risk perceptions identify fear in different locations to change the pricing of products in response; hedge effectively in times of high uncertainty, monitor risk perceptions in different currencies, interest rates in certain economic sectors, and conflict in select countries or ascertain levels of concern about unemployment and layoffs which may affect policy decisions and help new companies focus on the subjects people care about the most and understand why and how they care about them.

\subsection{History of News Analytics}

When sentiments are expressed through language, certain literal and metaphorical words are used to convey what is believed to be right or agreeable. One of the pioneers of political theory and communications in the early $20^{\text {th }}$ century has used sentiment to convey the idea of an attitude permeated by feeling rather than the undirected feeling itself. [231] In 1970 a study looked at the Republican and Democratic Party platforms in two periods 1844-64 and 1944-64 to see how the parties were converging and how language was used to express the change. The effect of word dictionary was created and used the frequency counts of these and other words to quantify the convergence. This approach to analysing contents of political and economic documents - called content analysis, now News Analytics - was given considerable boost in the 1950's and 1960's by Philip Stone of Harvard University who created the General Inquirer System [232] [233] and 
a large digitised dictionary of over 8,500 words carefully selected using a criterion developed by the psychologist Charles Osgood including positive/negative words, words to express strength and weakness, and words to describe activity and arousal. Recently, the digitised Harvard Dictionary of Affect has been used to measure sentiment in the financial markets. [90] The study analysed a commentary column in the Wall Street Journal using the GI Dictionary of Affect and correlated the frequency of affect words with trading volumes of shares in the New York Stock Exchange and concludes that high media pessimism predicts downward pressure on market prices followed by a reversion to fundamentals, and unusually high or low pessimism predicts high market trading volume. This is amongst the first reported study in financial sentiment analysis that is rooted strongly in econometric analysis that has analysed the contents of the news in conjunction with the study of information arrival. [234]

\subsection{News Analytics Framework}

News analytics is a broad field, encompassing and related to information retrieval, machine learning, statistical learning theory, network theory, and collaborative filtering. NA in finance is a multi-disciplinary field which draws on financial economics, financial engineering, behavioral finance and Artificial Intelligence, in particular Natural Language Processing. Expertise in these respective areas needs to be combined effectively for the development of successful applications in this area. Sophisticated machine learning algorithms applied without an understanding of the structure and dynamics of financial markets and the use of realistic trading assumptions can lead to applications with little commercial use. [235] [236] [229] News analytics can be thought of as in three levels: text, content, and context. Text-based applications exploit the intuitive components of news, i.e., words, phrases, document titles, etc. The main role of analytics is to convert text into information.

This is done by signing text, classifying it, or summarizing it so as to reduce it to its main elements. Analytics may even be used to discard irrelevant text, thereby condensing it into information with higher signal content. A second layer of news analytics is based on content. Content expands the domain of text to images, time, form of text (email, blog, page), format (html, xml, etc.), source, etc. Text becomes enriched with content and asserts quality and veracity that may be exploited in analytics. For example, financial information has more value when streamed from Dow Jones, versus a blog, which might be of higher quality than a stock 
message-board post. A third layer of news analytics is based on context. Context refers to relationships between information items. Context may also refer to the network relationships of news. News analytics is where data meets algorithms and generates a tension between the two. A vigorous debate exists in the machine-learning world as to whether it is better to have more data or better algorithms. The tension between data and algorithms is moderated how much customization is needed to implement the news analytic. [236]News data is significant information that enhances investment analysis.

\subsubsection{Type of News Data}

Financial news is mostly two types: regular synchronous announcements which are schedule news that is expected by investors and event driven asynchronous announcements which is unscheduled and unexpected. Main stream news rumours and social media normally arrive asynchronously in an unstructured textual form. A substantial portion of pre news arrives at pre scheduled times and generally in a structured form. Scheduled announcements often have a well defined numerical and textual content, and may be classified as structured data. These include macroeconomic announcements and earnings announcements. Macroeconomic news, particularly economic indicators from the major economies is widely used in automated trading. They have an impact in the largest and most liquid markets, such as foreign exchange, government debt and futures markets. Firms often execute large and rapid trading strategies. These news events are normally well documented, thus thorough back testing of strategies is feasible. Since indicators are released to a precise schedule, market participants can be well prepared to deal with them. These strategies often lead to firms fighting to be first to the market; speed and accuracy are the major determinants of success.

\subsubsection{Crawlers and Scrapers}

The internet has grown from a few thousand pages in 1993 to more than fourteen billion pages at present. Due to this explosion in size, web search engines are becoming increasingly important as the primary means of locating relevant new to investors. Such search engines rely on massive collections of web pages that are acquired with the help of web crawlers, which traverse the web by following hyperlinks and storing downloaded pages in a large database that is later indexed for efficient execution of user queries. [237] A crawler is a software algorithm that generates a sequence of web pages that may be searched for news content. The word crawler signifies that 
the algorithm begins at some web page, and then chooses to branch out to other pages from there, i.e., crawls around the web. The algorithm needs to make intelligent choices from among all the pages it might look for. One common approach is to move to a page that is linked to, i.e., hyper-referenced, from the current page. Essentially a crawler explores the tree emanating from any given node, using heuristics to determine relevance along any path, and then chooses which paths to focus on. [236] Researchers have studied web crawling strategies, storage, indexing, ranking techniques, and a significant amount of work on the structural analysis of the web and web graph. See the following literatures for overviews and techniques of crawling technologies. [238] [239] [240] [241] Figure 20 shows and architecture of web crawler.

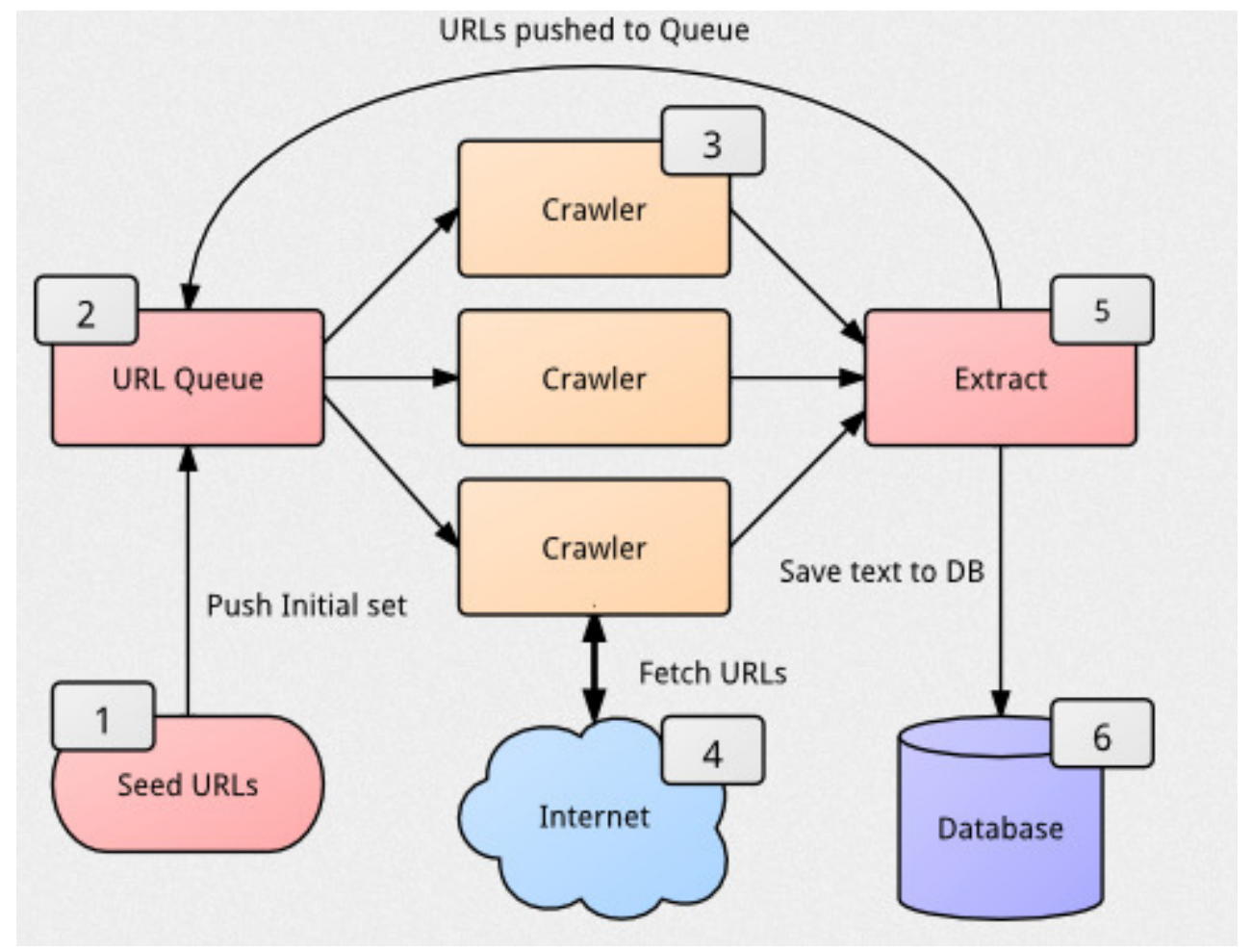

Figure 20 Architecture of web crawler (Source: http://pravin.insanitybegins.com)

A web scraper is a software system that automatically and repeatedly extracts data from web pages with changing content and delivers the extracted data to a database or some other application. The task of web scraper performed by such a system is usually divided into five different functions: (i) web interaction, (ii) support for wrapper generation and execution, (iii) scheduling, (iv) data transformation, and (v) delivering the resulting structured data to external 
applications such as database management systems, data warehouses, business software systems, content management systems, decision support systems, RSS publishers, email servers, or SMS servers. Alternatively, the output can be used to generate new web services out of existing and continually changing web sources. [242] Almost all programming languages contain modules for web scraping. These inbuilt functions open a channel to the web, and then download userspecified URLs. The growing statistical analysis of web text has led to most statistical packages containing inbuilt web scraping functions. [236] Figure 21 shows and architecture of web scraper

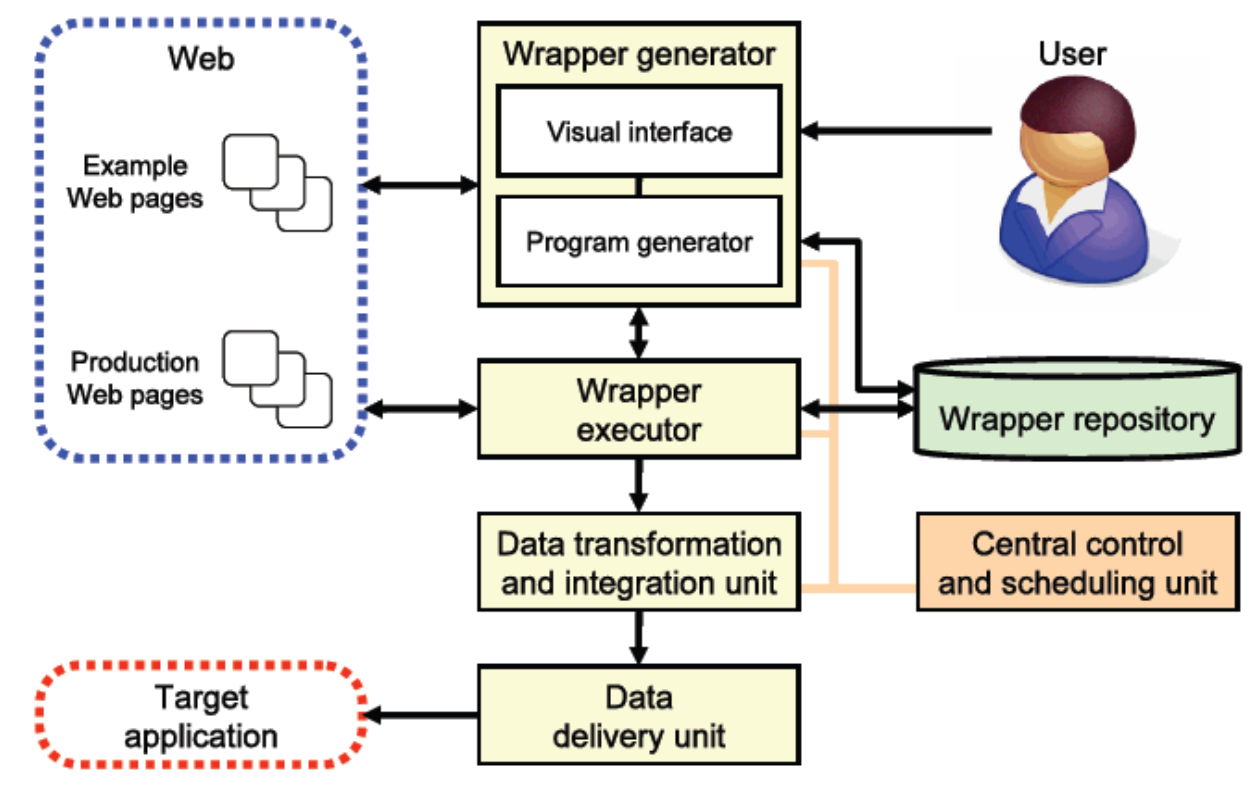

Figure 21 Architecture of a web scraper system [242]

\subsubsection{Types of News}

The different types of news and information flows that can be applied for updating investor beliefs were discussed books and literature. [229] [243]. The study distinguishes four broad classifications of news. Figure 22 show news flow architecture.

News This refers to mainstream media and comprises the news stories produced by reputable sources. These are broadcast via newspapers, radio and television. They are also delivered to traders' desks on newswire services. Online versions of newspapers may also exist.

Pre-News This refers to the source data that reporter's research before they write news articles. It comes from primary information sources such as, Securities and Exchange Commission reports and filings, court documents and government agencies. It also includes scheduled 
announcements such as macro economic news, industry statistics, company earnings reports, analyst reports, annual reports and other corporate news.

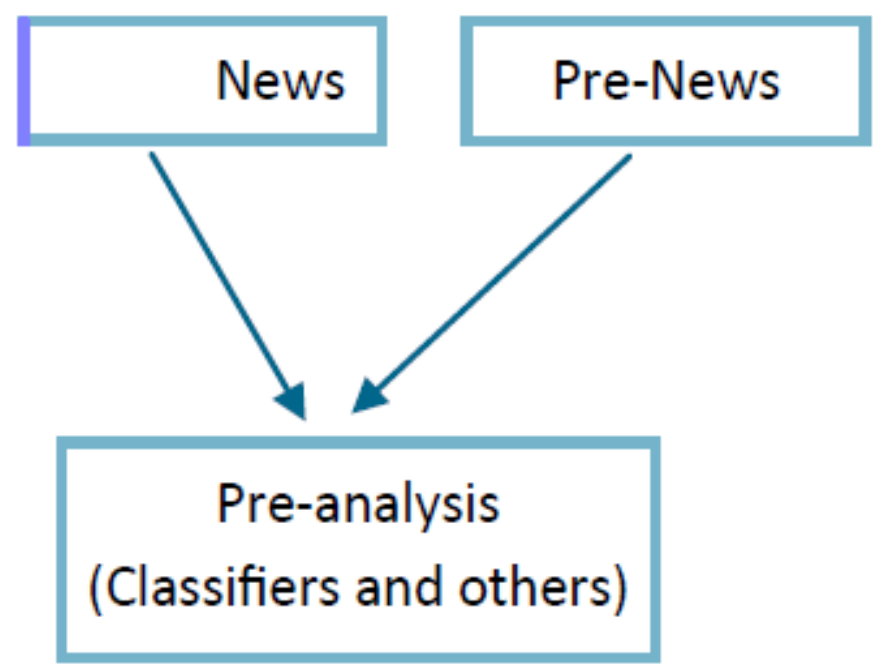

Figure 22 News flow

Rumours These are blogs and websites that broadcast "news", and are less reputable than news and pre-news sources. The quality of these varies significantly. Some may be blogs associated with highly reputable news providers and reporters. At the other end of the scale some blogs may lack any substance and may be entirely fuelled by rumour.

Social media These websites fall at the lowest end of the reputation scale. Barriers to entry are extremely low and the ability to publish "information" easy. These can be dangerously inaccurate sources of information. However, if carefully applied (with consideration of human behavior and agendas) there may be some value to be gleaned from these. At a minimum they may help us identify future volatility.

\subsubsection{Pre-processing News Data}

News data from public and web sources are not clean so algorithms are needed to clean it up before news analytics can be applied. This is known as pre-processing. First, there is HTML Cleanup, which removes all HTML tags from the body of the message as these often occur concatenated to lexical items of interest. Second, expand abbreviations to their full form, making the representation of phrases with abbreviated words common across the message. Third, handle negation words. Whenever a negation word appears in a sentence, it usually causes the meaning 
of the sentence to be the opposite of that without the negation. For example, the sentence "It is not a bullish market" actually means the opposite of a bull market. Words such as "not", "never", "no", etc., serve to reverse meaning. We handle negation by detecting these words and then tagging the rest of the words in the sentence after the negation word with markers, so as to reverse inference. This negation tagging was first introduced in [244] [245]. To see a successfully implemented pre-processing elsewhere, see [246]. Another aspect of text preprocessing is to stem words. This is a process by which words are replaced by their roots, so that different tenses, etc. of a word are not treated differently. There are several well-known stemming algorithms and free program code available in many programming languages.

Major Newswire providers tag incoming news stories. A reporter entering a story on to the news systems will often manually tag it with relevant codes. Further, machine-learning algorithms may also be applied to identify relevant tags for a story. These tags turn the unstructured stories into a basic machine readable form. The tags are often stored in XML format. They reveal the story's topic areas and other important metadata. For example, they may include information about which company a story is about. Tagged stories held by major newswire providers are also accurately time-stamped. Rich Site Summary (RSS) allow customized, automated analysis of news events from multiple online sources. Tagged news stories provide hundreds of different types of events to enable effective use of the stories. Machine readable XML news feeds can turn news events into exploitable trading signals since they can be used relatively easily to back test and execute event study based strategies. [247] Uses Thomson Reuters tagged news data to investigate several news based event strategies. Elementised news feeds mean the variety of event data available is increasing significantly. News providers also provide archives of historic tagged news which can be used for back testing and strategy validation.

\subsection{Classification}

Classification is a form of data analysis that can be used to extract models describing important data classes or to predict future data trends. Such analysis can help provide a better understanding of the data at large. Classification predicts categorical (discrete, unordered) labels. Figure 23 shows information flow in the classification. Many classification methods have been proposed by researchers in machine learning, pattern recognition, and statistics. Most algorithms 
are memory resident, typically assuming a small data size. Recent data mining research has built on such work, developing scalable techniques capable of handling large disk-resident data. [230]

Converting text into a machine readable form is a major challenge in NA. The goal of news analytics is to; determine the sentiment in a story and to identify the level of positivity or negativity of the story. In practice, this is done by assigning a quantified sentiment score or index to each story.

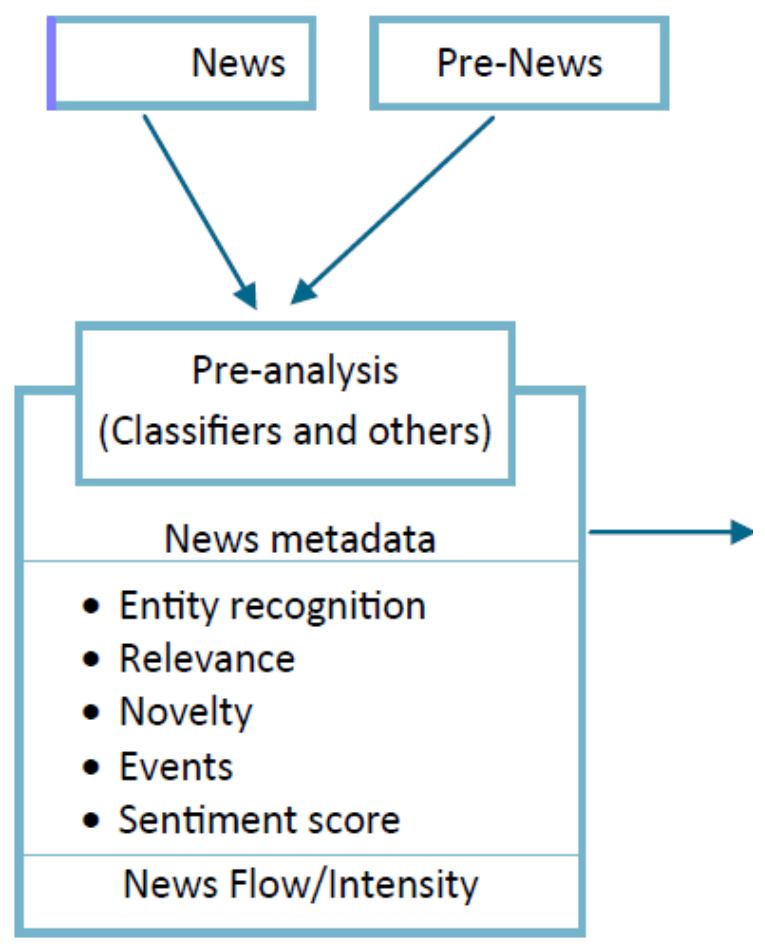

Figure 23 Classification information flow

A major difficulty in this process is identifying the context in which a story's language is to be judged. Sentiment may be defined in terms of how positively or negatively a human (or group of humans) interprets a story. That is the emotive content of the story for that human. In particular standards can be defined using experts to classify stories. Given a definition of sentiment, machine learning and natural language techniques are frequently used to determine the sentiment of new incoming stories. Hence we can determine sentiment scores over time as news arrives. Such sentiment indices then allow us to develop systematic investment and risk management processes. Once a sentiment index is constructed, to use it effectively, we must be able to find evidence of a relationship with relevant asset returns, trading volumes or volatility. The definition of market sentiment is very much context dependent. In general we are interested in 
discovering the "informational context of news". For the leading methods of quantifying sentiment using different types of classifiers and other related measures see [236] [229]

\subsubsection{Sentiment Extraction}

A methodology was developed using statistical and natural language techniques for extracting small investor sentiment from stock message boards. [244] The algorithm comprises different classifier algorithms coupled together by a voting scheme. Three supplementary databases are used in the classification algorithms. Dictionary for determining the nature of the word; Lexicon for collection of hand picked finance words which form the variables for statistical inference within the algorithms and Grammar for training corpus of base messages used in determining the in-sample statistical information. The lexicon and grammar jointly determine the context of the sentiment. Each of the classifiers relies on a different approach to message interpretation. They are all analytic, hence computationally efficient. They apply their method for 24 technology stocks present in the Morgan Stanley High Tech (MSH) Index. Five classifier algorithms used relies on a different approach to message interpretation. Some of them are language independent, and some are not. Each approach is intuitive. They are all analytical, and do not require any lengthy optimization or convergence issues, hence they are computationally efficient, making feasible the processing of huge volumes of data in real time. The classifiers used are:

i. Naive classifier (NC) is based on a word count of positive and negative connotation words

ii. Vector distance classifier. Each of the D words in the lexicon is assigned a dimension in vector space.

iii. Discriminant based classification NC weights all words within the lexicon equally.

iv. Adjective - adverb phrase classifier is based on the assumption that phrases which use adjectives and adverbs emphasize sentiment and require greater weight.

v. Bayesian classifier is a multi-variate application of Bayes Theorem. It uses the probability that a particular word falls within a certain classification and is hence indifferent to the structure of language.

See [248] for detail description of the classifiers. Figure 24 shows the Schematic of the Algorithms and System Design Used for Sentiment Extraction

A voting scheme is then applied to all five classifiers. The final classification is based on achieving a majority amongst the five classifiers. If there is no majority the message is not 
classified. This reduces the number of messages classified but enhances the classification accuracy.

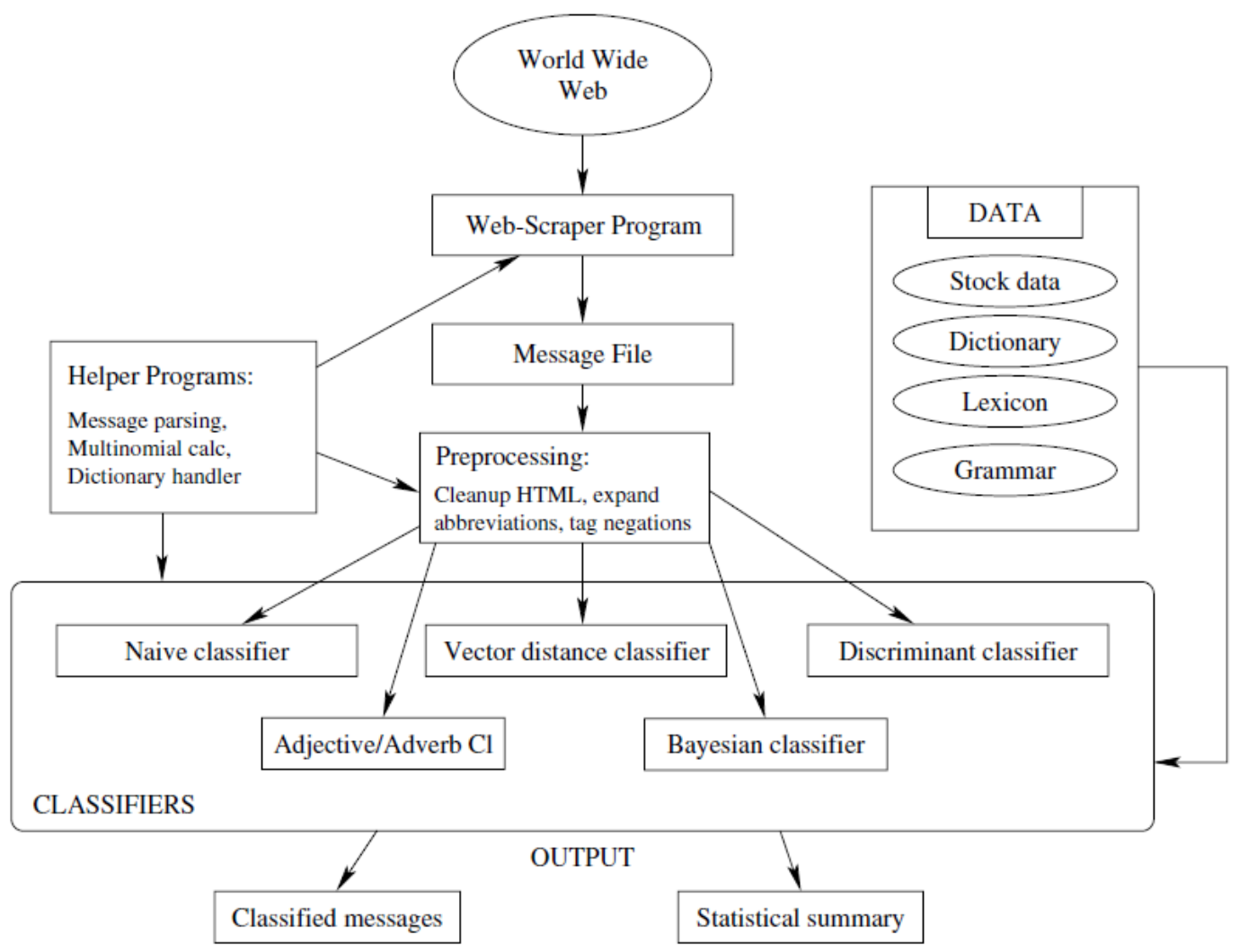

Figure 24 Schematic of the Algorithms and system design used for sentiment extraction [244]

Messages posted on stock message boards are often highly ambiguous. The grammar is often poor and many of the words do not appear in standard dictionaries. They note "Ambiguity is related to the absence of "aboutness". The General Inquirer has been developed by Harvard University for content analyses of textual data. They use is to determine an independent optimism score for each message. By using a different definition of sentiment it is ensured there is no bias to a particular algorithm. The optimism score is the difference between the number of optimistic and pessimistic words as a percentage of the total words in the body of the text. This score allows the ranking of the relative sentiment of all stories within a classification group. They filter in and consider only highly optimistically scored stories in the positive category. For example only those stories with optimism scores above the mean value plus one standard deviation are considered. Similarly they filter in and consider only the most highly pessimistic 
scores in the negative category. Once the classified stories are further filtered for ambiguity, it is found that the number of false positives dramatically declines. [244]

Once the sentiment for each message is determined using the voting algorithm, a daily sentiment index is compiled. The classified messages up to $4 \mathrm{pm}$ each day are used to create the aggregate daily sentiment for each stock. A buy (sell) message increments (decrements) the index by one. These indices are further aggregated across all stocks to obtain an aggregate sentiment for the technology portfolio. The result show accuracy levels are similar to widely used Bayes classifiers, but false positives are lower and sentiment accuracy higher. Time series and crosssectional aggregation of message information improves the quality of the resultant sentiment index, particularly in the presence of slang and ambiguity. Empirical applications evidence a relationship with stock values-tech-sector postings are related to stock index levels, and to volumes and volatility. The algorithms may be used to assess the impact on investor opinion of management announcements, press releases, third-party news, and regulatory changes. [244]

\subsection{News Analytics Architecture}

The information flow and computer architecture of news analytics is shown in figure 25 . Two mail types of data flows simultaneously for analysis, news data and financial market data. Preanalysis is applied to news data to attempt to fill in missing values, smooth out noise while identifying outliers and correct inconsistencies in the data and it is further filtered and processed by classifiers to relevant metrics. This is then consolidated with the market data of prices, together they constitute the classical data mart which feed into a gateway that integrate and feed the investment firm's API or whatever relevant model based applications. A key aspect of these applications is that they set out to provide technology enabled support to investors and traders.

Business-focused news agencies such as Bloomberg, Dow Jones, and Thomson Reuters, RavenPack, General Sentiment now offer services that promise to help investors and decision makers sift through information automatically. For example, Bloomberg, Dow Jones who is a partner of RavenPack and Thompson Reuters offering includes an analysis of the most-read financial articles, which gets information from more than 30,000 global information sources. Users of the service include market participants from major global banks, investment firms, and financial institutions. Because of such services, even small traders are now starting to use 
computers to comb through and analyze news reports, editorials, company websites, blog posts, and even twitter messages to help determine the best transactions to undertake.

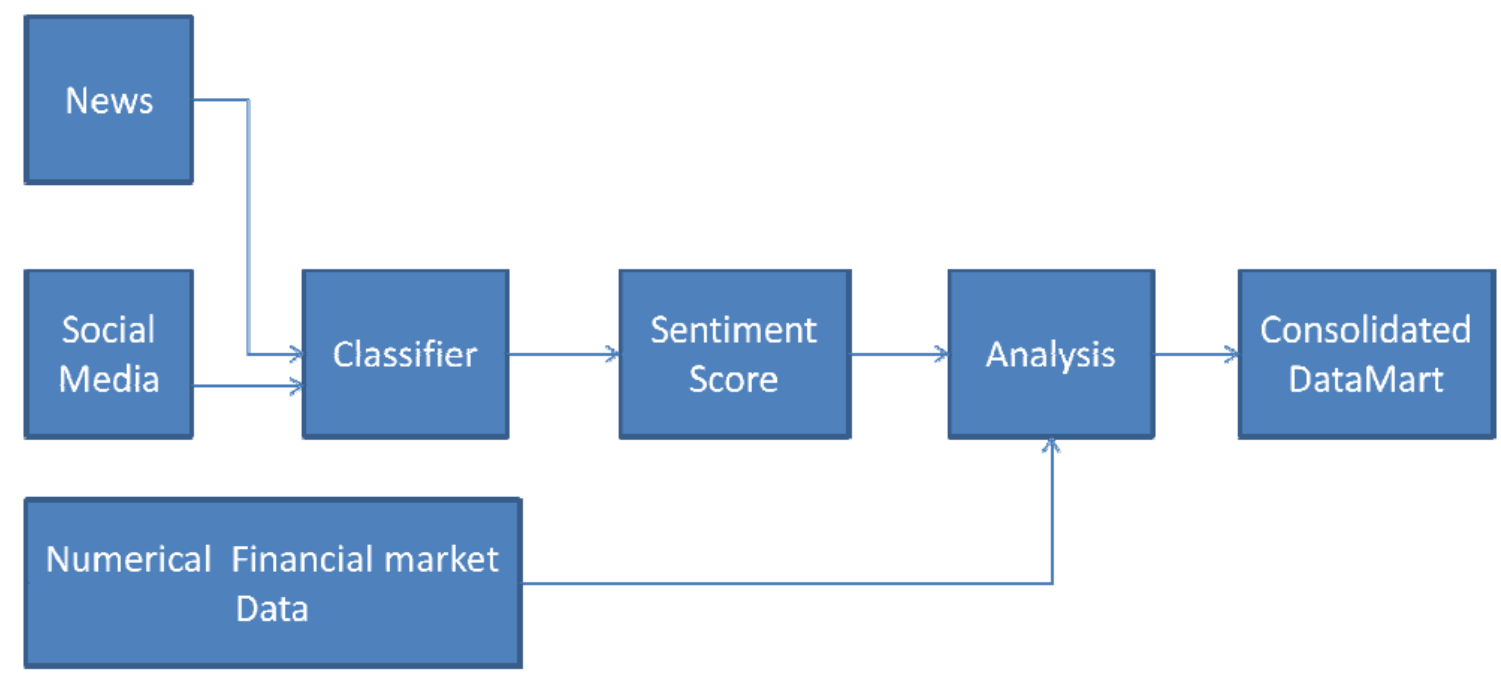

Figure 25 Information flow and computer architecture of News Analytics

RavenPack launched in September 2012 a new version of its News Analytics product which, in addition to nearly doubling the number of corporate events tracked, now detects and analyzes news on global macroeconomic entities and events as they happen. RavenPack News Analytics version 3.0 will now automatically detect news events and sentiment on every major geographical location, government organization, company, currency, and traded commodity. RavenPack computers sift through thousands of unstructured news stories in milliseconds searching for information likely to impact financial markets. Figure 27 illustrates the relationship between the S\&P 500 and the RavenPack Sentiment Index.

Over 1,200 macroeconomic, geopolitical, and corporate events are systematically detected and the analysis delivered as a real time data feed. Sources include reputable publishers such as Dow Jones Newswires, all editions of the Wall Street Journal and Barron's. For the first time, financial firms can automatically react to unexpected events such as terrorist attacks, natural disasters or industrial accidents within milliseconds of them being reported. Historically, such event detection relied on manual tagging which risked inconsistency and delays, but we have now 
developed a leading solution that delivers value, regardless of asset classes or how short the investment horizon. [249]

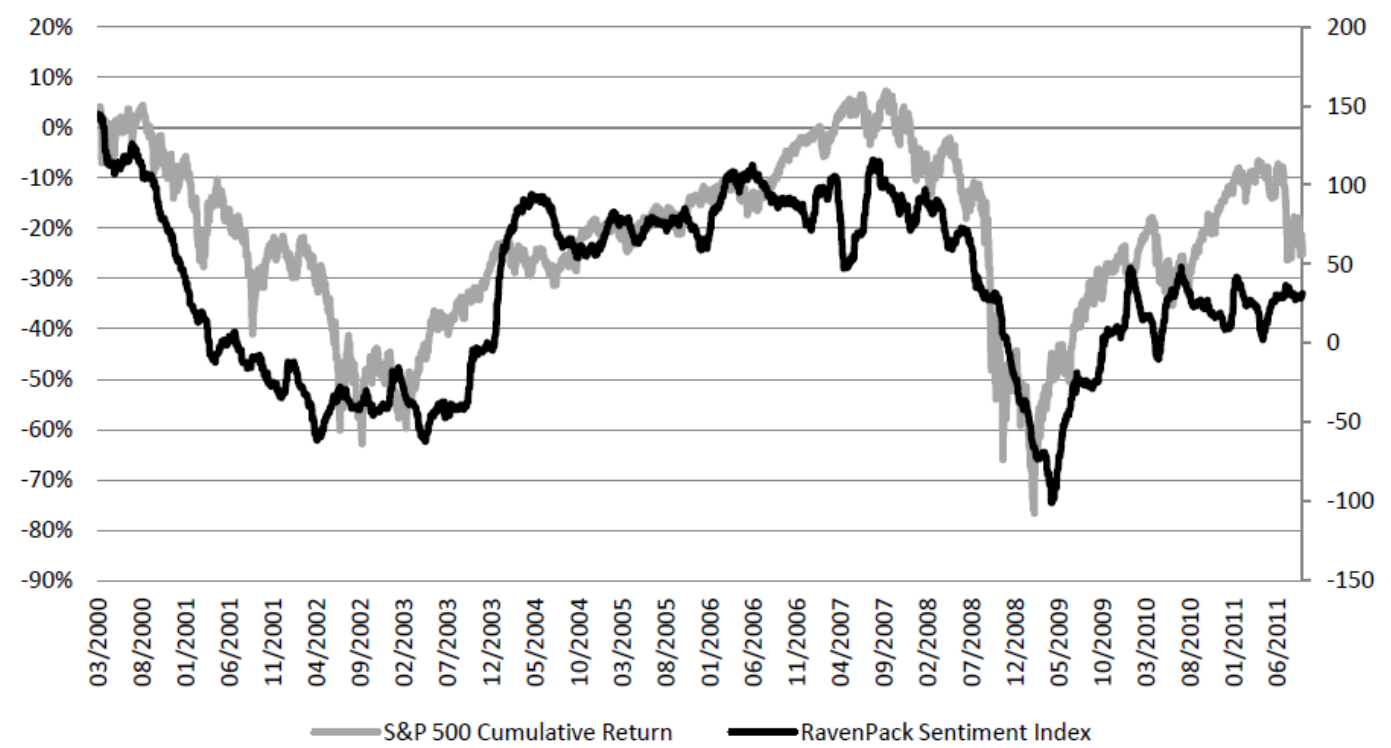

Figure 26 Relationship between S\&P and Ravenpack Sediment Index (Ravenpack)

As concluded in the study, in the end, news analytics are just sophisticated methods for data mining. For the top ten algorithms in data mining, see [250]. This paper discusses the top 10 data mining algorithms identified by the IEEE International Conference on Data Mining (ICDM) in December 2006. These algorithms are: C4.5, k-Means, SVM, Apriori, EM, PageRank, AdaBoost, kNN, Naive Bayes, and CART. As algorithms improve in speed, they will expand to automated decision-making, replacing human interaction as noticed in the marriage of news analytics with automated trading. [236]

In this survey, many literatures have shown that media influences investor sentiment, and hence market trends and price movements. Since 2011 financial news analytics have been gaining attention from academics, average investor and professional traders to explore and exploit new sources of alpha. In high-frequency trading, news analytics are allows traders to react in realtime to scheduled and unscheduled news events in a fully or semi-automated fashion by the quantitative financial market data and breaking news as textual data that would associate with market movements. Fig 27 provides a view of the close relationship between the S\&P 500 and the RavenPack Sentiment Index. In fact, we observe a close co-movement between market return 
and the sentiment index. Constructed using a bottom-up approach, the sentiment index seems quite promising in capturing the market mood and is closely related to the US financial markets. News studies have also demonstrated how information extraction from this kind of data can detect patterns of positive or negative stories and the corresponding reactions in the price movements for specific asset, market or an industry. Particularly in the case of unstructured nonpre-scheduled text, which arrives in irregular time intervals, one can take the relevance and intensity of news to predict fluctuation in liquidity, future return on financial indexes, and shortterm potential risk. 


\section{CHAPTER SEVEN}

\section{INVESTOR SENTIMENT APPLICATION IN FINANCE}

In the popular work titled, "Twitter mood predicts the stock market" [87], that investigated whether public mood as measured from large-scale collection of tweets posted on twitter.com is correlated or even predictive of DJIA values, with the assumption that One could speculate that the general public is presently as strongly invested in the DJIA as financial experts, and that therefore their mood states will directly affect their investment decisions and thus stock market values, but this too remains an area of future research. Their results show that changes in the public mood state can indeed be tracked from the content of large-scale Twitter feeds by means of rather simple text processing techniques and that such changes respond to a variety of sociocultural drivers in a highly differentiated manner. [87]

Based on this study, Paul Hawtin made headlines in 2010 when his hedge fund Derwent Capital Markets became the first to use Tweeter data to make investing decisions. DCM fund had a $1.85 \%$ return in its first month, seemingly proving the power of social media as a trading tool. DCMDealer also turns Twitter into a stock trading tool for the masses by providing average investors with real-time sentiment analysis for stocks based on tweets. DCMDealer, receives a pipeline of Twitter data from social data platform DataSift and uses several algorithms to weigh the meaning of the tweet for the stock, including analyzing keywords, looking at the number of followers the user has and his or her relationship to the company in question and factoring in how old the tweet is. The end result is a Twitter sentiment score of 0 to 100 , with the higher numbers being more positive. [251]

\subsection{Risk Monitoring and control}

The Risk Monitoring \& Control process involves the identification, analysis, planning and tracking of new risks, constantly reviewing existing risks, monitoring trigger conditions for contingency plans and monitoring residual risks, as well as reviewing the execution of risk responses while evaluating their effectiveness. The risk structure of assets may change over time, in response to news. Literature investigated if the systematic risk (beta) of stocks increases in 
response to firm specific news. The study undertakes an event study on the beta of stocks around their earnings announcement dates. The change in beta on announcement date is decomposed into the change due to an increase in volatility of that stock and the change due to an increase in the covariance with the index. They concluded that news releases do have an important impact on the risk of stocks. Further much of the beta increase arises from an increase in covariance with other stocks. This suggests there could be a contagion effect in the information releases for one stock on the price movements of other stocks. This supports anecdotal evidence that investors will monitor earnings of related stocks when investigating the earnings of a particular stock. [252]

The following relationship between macroeconomic announcements and foreign exchange and interest rate futures return volatility are available for review in literature. The influence of macroeconomic announcements on stock prices on S\&P500 reported in [253]. GARCH model for equity returns which incorporates asset specific news gives improved volatility forecasts. [254] This study was extended and considers a GARCH model which accounts for "content aware" measures of news. It was observed that volatility is higher in down markets. This is sometimes referred to as the "leverage effect". [255] [256]. Another investigation concludes that volatility symmetry is likely to be driven by the over reaction of private investors to bad news. In line with this theory, they find an increase in private investor attention to negative news can predict a rise in volatility. Increased private investor attention to negative news, is measured by a change in the level of Google searches for negative words related to the macro economy, such as recession [257]

News data can also be used for non-quantitative risk control. Wolf detectors (circuit breakers) are a risk control feature for algorithmic trading built on machine readable news. Essentially they "break the circuit" stopping an automated algorithm from trading on a certain asset when particular types of news are released. It is important to try not to shout "Wolf!" when no wolf has actually appeared. These risk control features can be customized to only be tripped when substantive news events have occurred. Alternatively the algorithms can be turned back after the nature of the news has been programmatically analysed. This can be done using different features of machine readable news data. [258] [229] 


\subsection{Asset management}

Jan. 21, 2013, Canadian News Wire reported the asset managers' sentiment survey - Manulife Financial and John Hancock Investor Sentiment Index surveys. The surveys was conducted in Canada and the U.S in December 2012 and it measure the affluent investors' feelings about whether or not this is a good time to invest in a variety of savings and investment vehicles and the likelihood of purchasing specific financial products and services. The reported concluded that affluent North American investors are feeling very optimistic about their personal finances heading into 2013.

\subsubsection{Portfolio Management}

Investor sentiment information is used by professional and individual investor to identify trading behaviors for particular stocks and portfolios. Alternatively analysts may use factor models which are applied to give updated estimates of future asset returns and volatility, and allow managers to determine an optimal future portfolio to hold in what proportion, to process new sources of news data. Asset managers may also use news data to identify and exploit behavioral biases in investor behavior arising due to the market and analysts' misreaction to new information. In particular this can arise due to delayed information diffusion or due to investors' inattention and limited ability to process all relevant information instantaneously.

\subsubsection{Product Selection}

Asset manager also use news data to rank stocks and identify which stocks are relatively attractive or unattractive. They may then buy (sell) the highest (lowest) ranking stocks, thereby rebalancing a portfolio composed of desired weights on the selected stocks. Similarly the news data may be used to identify trading signals for particular stocks. Investment analysts collect process and disseminate information on companies to investors. In particular they use their research to form earnings forecasts and revision for companies. Earnings momentum strategies, thus proxy for corporate news flow. These strategies do not explicitly identify the piece of information that has triggered the change in earnings forecast. News data can be used to reinforce proxies for news already incorporated in models and a strategy based on earnings momentum reinforced by news flow is found to be effective. [229] 


\subsubsection{Product Ranking}

The task of assigning ratings to different stocks is based on its forecast to help investment managers facilitates the construction of a high performance portfolio. The process is a dynamic, non-linear, non-mathematical problem, driven by individual and collective judgement. The prices of stocks have unfathomable relationships with a number of parameters which changes over time. In 2006 a study examined form 10-K Securities and Exchange Commission (SEC) filings for non-financial firm's between1994-2005. [259] It examines the implications of corporate annual reports' risk sentiment for future earnings and stock returns and measures the risk sentiment of annual reports by counting the frequency of words related to risk or uncertainty in the 10-K filings. The research concluded that an increase in risk sentiment is associated with lower future earnings: Firms with a larger increase in risk sentiment have more negative earnings changes in the next year. Risk sentiment of annual reports can predict future returns in a crosssectional setting: Firms with a large increase in risk sentiment experience significantly negative returns relative to those firms with little increase in risk sentiment in the twelve months after the annual report filing date. He creates a "risk sentiment measure" which is formed by counting the number of times the words risk, risks, risky, uncertain, uncertainty and uncertainties occur within the management discussion and analysis sections. A strategy which goes long in stocks with a low risk sentiment measure and short stocks with a high risk sentiment measure is found to produce a reasonable level of returns. A hedge portfolio based on buying firms with a minor increase in risk sentiment of annual reports and shorting firms with a large increase in risk sentiment generates an annual Alpha of more than 10\%.

\subsubsection{Multi-Factor Modelling}

Factor models are based on one of the basic tenets of financial theory that no reward without risk. In contrast to the Capital Asset Pricing Model (CAPM) [123] [124] [260] that uses the stock beta as the only relevant risk measure, empirical studies could not confirm this very restrictive statement. [32] The Arbitrage Pricing Theory already posited a more general multiple factor structure for the return generating processes. However, it neither specified the nature nor the number of these factors. [261]

Multiple factor models have been applied early in investment practice, mainly because they allow a differentiated risk-return analysis. The applications of multiple factor models are various 
and are based on the analysis and prognosis of portfolio risk. Multiple factor models can give valuable insights especially in performance and risk attribution. They provide prospective for a better basis for portfolio construction because of an improved risk prognosis as well as the basis for deliberate deviations from a benchmark portfolio. Fund managers are always seeking new sources of advantage. This can be data and factors which translate to "quantitative knowledge". [219] [262] A "quantcentration" effect is frequently observed. That is, since most fund managers have access to the same sources of data, it is difficult to distinguish between their models and performance. Active portfolio managers seek to incorporate their investment insight to "beat the market". An accurate description of asset price uncertainty is a key to the ability to outperform the market. An investor's perceptions about the future asset returns are determined by their knowledge about the company and its prospects, that is, by their "information sets". They note that these are determined from three main sources: analyst's forecasts, quantifiable publicly disclosed accounting variables and linguistic descriptions of the firm's current and future profit generating activities. If the first two sources of information are incomplete or biased, the third may give us relevant information for equity prices. [263] [229]

\subsubsection{Behavioral Bias}

Over the past 27 years researchers have identified a long list of what influences investors decisions, categorizing them according to a meaningful framework. Investor sentiments are further classified as either emotional or cognitive. Cognitive bias can be technically defined as basic statistical, information processing or memory errors that are common to all human beings. They can be thought of also as "blind spots" or distortions in the human mind.

Emotional bias is a mental state that arises spontaneously, rather than through conscious effort. Emotions are physical expressions, often involuntary, related to feelings, perceptions or beliefs about elements, objects or relations between them, in reality or in the imagination. Cognitive biases do not result from emotional or intellectual predisposition toward a certain judgement, but rather from subconscious mental procedures for processing information. Investors are subjected to large volumes of information and data, and to make sense of it all, they opt for simplified information processing when making investment decisions. A good example of this is evaluating a class of stocks, say U.S. small-capitalization. Even using a research database, the information flow is so immense that they inevitably rely on shortcuts such as "best 12-month return" to make 
investment decision. Because cognitive biases stem from faulty reasoning, better information and advice can often correct them. Cognitive biases include heuristics, such as anchoring and adjustment, availability and representativeness biases. Other cognitive biases include ambiguity aversion, self-attribution and conservatism. Figure 29, shows the average stock price reaction around negative, neutral and positive after news events respectively. Investors can be presented with investment choices, and may make sub - optimal decisions by having emotions affect these decisions. Often, because emotional biases originate from impulse or intuition rather than from conscious calculations, they are difficult to correct. Emotional biases include endowment, loss aversion and self-control. [27]

Individual investors have a tendency to buy popular stocks. [264] Popular stocks are defined as ones that display abnormal trading volumes, extreme one day returns or are mentioned on major indexes. An example in 2013 is Apple. Institutional and other professional investors look at a wider range of stocks are less prone to buying popular stock. Institutional investors normally specialise in a particular sector and may consider only those stocks that meet certain criteria. Another research also found that individual investors tend to buy stocks that hit an upper price limit. [265] In there study, they examine a group of traders who profit by accumulating shares during days stocks hit their upper price limits. The traders then sell out quickly the next day for an average overnight return of $0.80 \%$ after transaction costs. The magnitude of observed profits cannot be explained by a liquidity premium nor does it appear to be compensation for increased risk. There finding is consistent with behavioral theories regarding popular stocks. They concluded that attention-based buying by unsophisticated individual investors fuels the smart trader profits.

Media coverage can help predict the cross-section of future stock returns. [266] This study found that, stocks with no media coverage outperform widely covered stocks even after allowing for well-known risk factors. Using the frequency of Google searches for a particular company as a measure of the amount of attention a stock receives, [267] consider how the amount of attention a stock receives affects its cross-section of returns. They find some evidence that changes in investor attention can predict the cross-section of returns. This is most pronounced amongst the small cap stocks. Some researchers consider how informational flows cause investors to update their expectations, in order to explain momentum and reversal effects. 

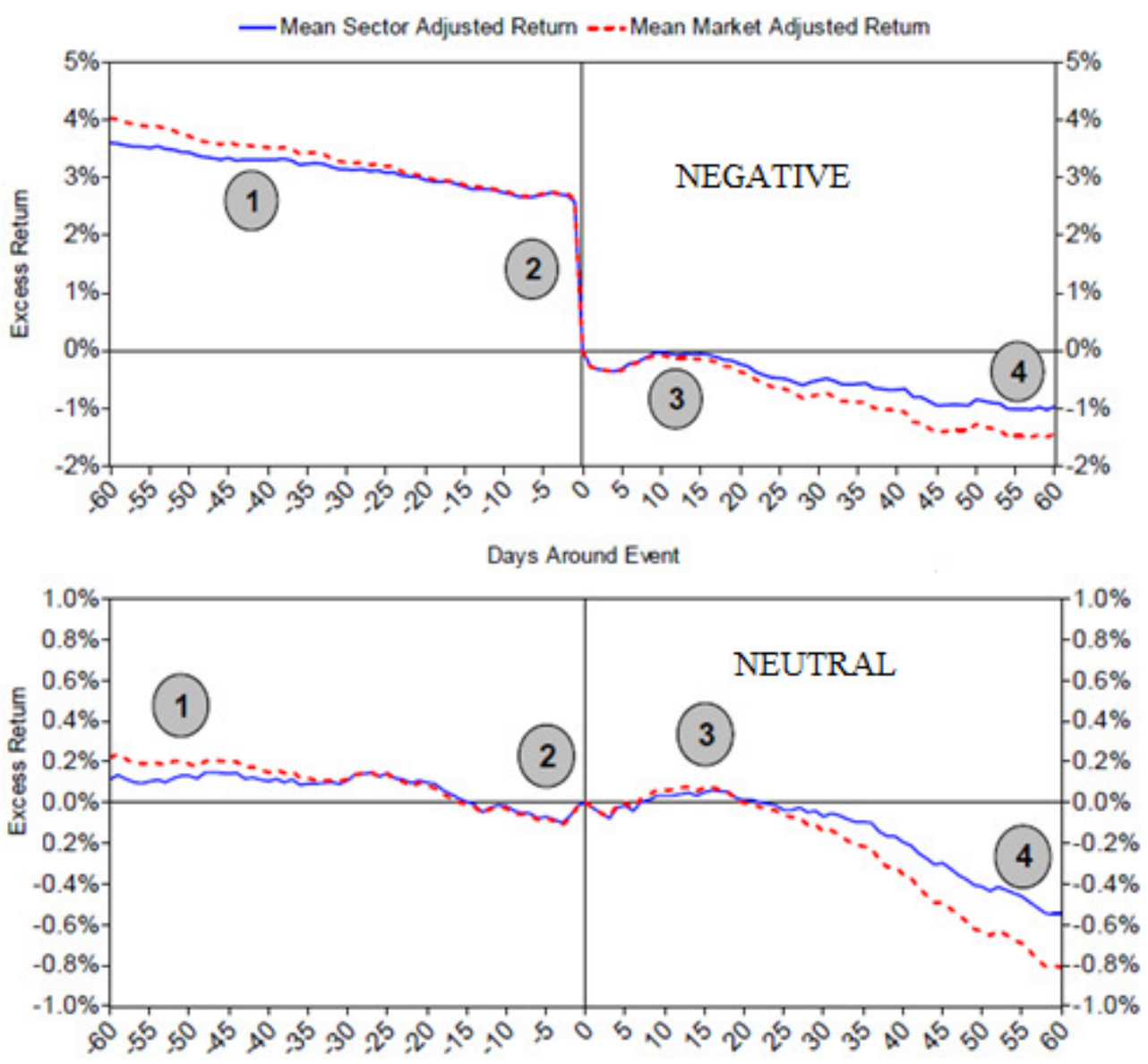

Days Around Event

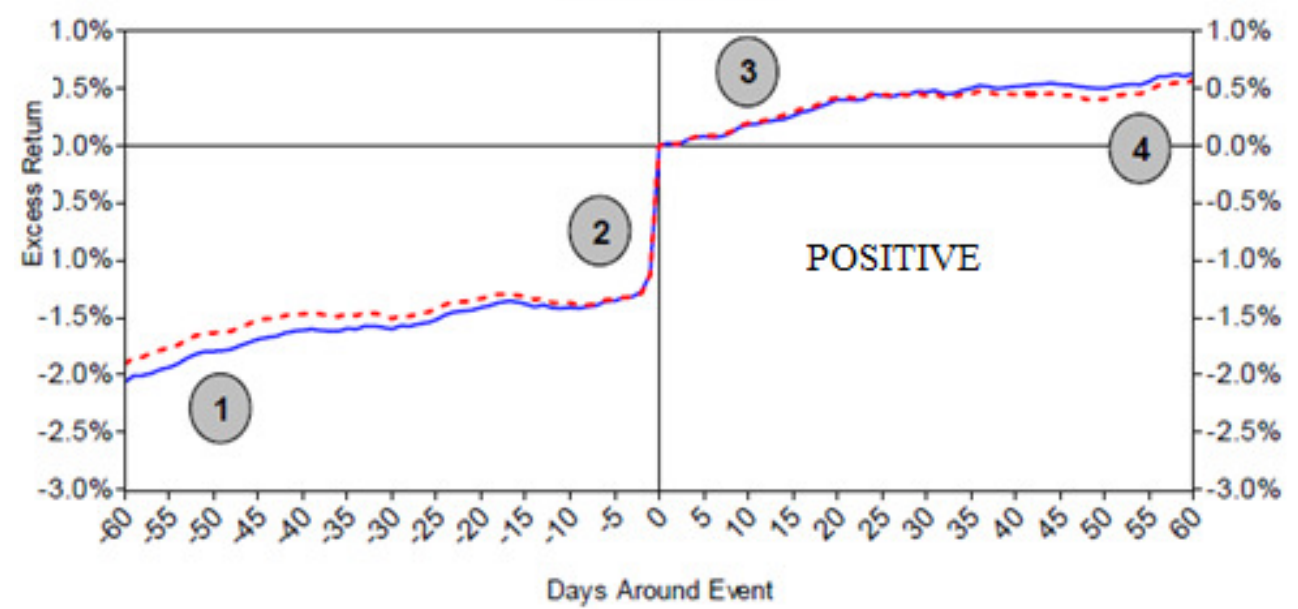

Figure 27 Average Stock price reaction after negative neutral and positive news events (Source: RavenPack, Macquarie Capital (USA), May 2009)

Another study suggest that investors overreact to recent earnings placing less emphasis on long term averages and that price momentum is a result of investors overacting to private information 
causing prices to be pushed away from fundamentals. [67] [129] When there are significant numbers of earnings announcements in the market, investors are distracted and under react to relevant new information and the post announcement drift is strong. Investors fail to price the information efficiently, leaving an opportunity for quantitative investors. [268] [229]

\subsection{More on Investor Sentiment Applications}

Investor sentiment will become will gain more application in finance and economics as research into application grows. Currently, these are areas where it is being used other than in asset management and risk control.

Market surveillance: regulators market surveillance is becoming an important application area of quant models. It is gaining in importance because managers through internal control functions as much as external compliance requirement wish to have surveillance in place to catch rogue trading, insider information based trading.

Trader decision support: Investor sentiment data aid traders in making decisions. News data signals may confirm traders existing analysis or it may cause them to reconsider their analysis. Wolf detection circuit breaker: These are a risk control feature for algorithmic trading built on machine readable news. Essentially, they "break the circuit" stopping an automated algorithm from trading on a certain asset when particular types of news are released [258].

News flow algorithms: It is widely recognized that news flow is a good indicator of volume and volatility. As the flow of news about a company rises, the volume traded rises resulting in more stock price volatility.

Alpha generating signal: News data can be used in alpha generation at various trading frequencies. News sentiment data may be used within factor models. [269] The study considers such an application. Their results are positive and they find that such an approach does add value. News data can also aid quant investors to identify non-rational biased behaviour of investors. These can then be exploited. Ravenpack explore a concept they coined as news beta or the sensitivity of stock returns to changes in market sentiment as reported by the media. After controlling for traditional factors, news beta is found to have strong return predictability over 6 and 12 month horizons. The evidence from this research suggests that market sentiment data is still an untapped source of alpha in financial markets. The correlation between news beta and the 
exposure to market, size, value, and momentum factors is very low. There is no significant difference in company size across news beta deciles. With a 6 or 12 month holding period, stocks that fall into the lower news beta decile generally fetch higher returns. The research result shows that, from February 2002 to September 2011, the value-weighted zero-investment portfolio based on news beta is able to yield an annualized return of $8.9 \%$. The news beta investment strategy works best for large cap stocks. From February 2002 to September 2011, the Hit Ratio and Information Ratio for the value-weighted portfolio in the 10th size decile is $60.3 \%$ and 1.34 respectively. [270]

Stock screening tool: News data can be used to aid stock screening. In particular sentiment data may be used to guess the directional movement of future returns. Very good news stocks (for example top sentiment quintile) might be selected to be held long and very bad news stocks (for example bottom sentiment quintile) might be selected to be held short.

Fundamental research: News analysis tools may aid traditional non-quant managers, by allowing them to undertake market research more efficiently.

Risk Management: The use of news data within risk forecasting allows for dynamic risk management strategies that are forward looking and are based on changing market environments. Further this risk analysis applied using news data helps investors understand event risk and how different kinds of events can impact their portfolio risk profile. Models which forecast volatility and volume on the basis of news will also find important applications within the investment management process like volatility prediction for volatility traders and volume prediction for factor models that use volume as a factor.

Predict Macro and Micro - Economic Indicators: RavenPack sentiment index was constructed to capture the sentiment momentum from news on the US market over a three month period. They find that the RavenPack Sentiment Index is not only closely related to financial markets but also to widely accept macro-economic indicators. The Index is consistently positively correlated with widely used macro-economic indicators, both at a monthly and quarterly horizon. The quarterly contemporaneous correlation between changes in the RavenPack Sentiment Index and in real GDP is $56 \%$. Including a sentiment lag with up to three quarters improves the correlation to almost $70 \%$ [271] [229]. 


\section{CONCLUSION}

With the increase of economic globalization and evolution of information technology, investor sentiment data are being generated and accumulated at an unprecedented pace. As a result, there has been a critical need for automated approaches to effective and efficient utilization of sentiment information to support investment companies and individuals investors in strategic planning and investment decision making. Investor sentiment studies, analysis and techniques have been used to uncover hidden patterns and predict future trends and behaviors in financial markets. The competitive advantages achieved by investor sentiment studies include increased revenue, reduced cost, asset protection through risk management and control and much improved marketplace responsiveness and awareness.

News Analytics techniques to solving financial problems has been widely accepted but so far, there are not enough contributions on this field. Study of implementing data mining approaches and integrating them into stock market only involve a handful of companies. Two are more popular - Thompson Reuters and Ravenpack. This work has provided a broader view of the investor sentiment mining industry, to enable extension of the research involves incorporating some other variables into the criteria for news data mining techniques. These include new variables that reflect future information and those that reflect the impacts of other stock markets to the primary market of concern. The research reviewed in this study looked at forecasting as a field, investor sentiment defined, its measurement and on applications of the algorithms. Major effort is needed in the data preparation process, as this is often simply based on practitioner's instinct and experience. A more generic process for data cleaning is essential to enable the growth of news data mining in financial market.

Most investor sentiment research often does not consider the quality of the rules or knowledge discovered. The knowledge generated is sometimes cumbersome and the relationships obtained are too complex to understand. Future research effort is therefore also needed to enhance the expressiveness of the knowledge. Further research is needed to develop generic guidelines for a variety of different data and types of problems, which are commonly faced by financial markets and new researchers in the area of sentiment. To be successful, an investor sentiment project should be driven by the application needs and results should be tested quickly. Financial 
applications provide a unique environment where efficiency of the methods can be tested instantly, not only by using traditional training and testing data but making real forecast and testing it the same day. This process can be repeated daily for several months collecting quality estimates.

The currently success of investor sentiment exercises has been reported in literature extensively. Typically it is done by comparing simulated trading and forecasting results with results of other methods and real gain/loss and stock. We expect that in the coming years, investor sentiment mining in finance will be shaped as a distinct field that blends knowledge from finance and data mining, similar to what we see now in biomedical engineering where integration of field specifics and data mining is close to maturity. 


\section{REFERENCES}

[1] L. Jiuzhen, S. Wei and W. Mei, "Stock Price Prediction Based on Procedural Neural Networks," in Advances in Artificial Neural Systems, 2011.

[2] D. Long and A. Shleifer, "The stock market bubble of 1929: Evidence from Closed-End Mutual Fund," Journal of Economic History, vol. 51, pp. 675-700, 1991.

[3] E. White, "The stock market boom and crash of 1929 revisited," Journal of Economic Perspectives, vol. 4, p. 67-83, 1990.

[4] R. J. Shiller, Irrational exuberance, New Jersey: Princeton University Press, 2000.

[5] O. A. Lamont and R. H. Thaler, "Can the market add and subtract? Mispricing in tech stock carveouts," Working paper, University of Chicago., http://faculty.chicagobooth.edu/john.cochrane/teaching/Empirical_Asset_Pricing/lamont\%20and \%20thaler\%20add\%20and\%20subtract\%20jpe.pdf 2013, 2001.

[6] M. S. Rashes, "Massively confused investors making conspicuously ignorant choices (MCl-MCIC)," Journal of Finance, vol. 56, p. 1911-27, 2001.

[7] E. Ofek and M. Richardson, "DotCom mania: A survey of market efficiency in the Internet sector," SocialScience Research Network, p. http://papers.ssrn.com/sol3/papers.cfm?abstract_id=268311 2001, 2013.

[8] G. W. Brown and M. T. Cliff, "Investor Sentiment and Asset Valuation," Journal of Business, vol. 78(2), pp. 405-440, 2005.

[9] K. Miao, C. F. and Z. G. Zhao, "Stock price forecast based on bacterial colony RBF neural network," vol. 20, pp. 50-54, 2007.

[10] B. Malkiel, A Random Walk Down Wall Street(Revised Edition)., New York: Norton, 2011.

[11] J. Armstrong and R. J. Brodie, Quantitative Methods in Marketing, Second Edition, London: International Thompson Business Press,, 1999, pp. 92-119..

[12] OECD, Forecasting methods and analytical tools, http://www.oecd.org/eco/economicoutlookanalysisandforecasts/forecastingmethodsandanalytic altools.htm 2013, 2011. 
[13] D. Chen and M. A. Cane, "El Nio prediction and predictability," Journal of Computational Physics 227, http://rainbow.Ideo.columbia.edu/ dchen/collection-dchen/jcp08.pdf 2012, p. 3625-3640, 2008.

[14] M. P. Clements and D. F. Hendry, An Overview of Economic Forecasting, Audtralia: Blackwell Publishing Ltd, 2004.

[15] Right Citizen Commission on Human, "PSYCHIATRISTS CANNOT PREDICT, TREAT OR CURE VIOLENT BEHAVIOR,"

http://www.cchr.org/sites/default/files/Psychs_Cannot_Predict_or_Cure_Violence.pdf 2013, 18 May 1981..

[16] J. J. Cocozza and H. J. Steadman, "The Failure of Psychiatric Predictions of Dangerousness," vol. Vol. 29, no. No. 5, Late Summer 1976,.

[17] M. Hagen, "Whores of the Court, The Fraud of Psychiatric Testimony and the Rape of American Justice,", in citing Terrence W. Campbell, Challenging Psychologists and Psychiatrists as Witnesses, New Yor, Harper Collins Publishers, Inc, 1997.

[18] H. Matsubara, "Diet mulls fate of mentally ill criminals," The Japan Times, 8 June 2002., 2002.

[19] B. Graham, The Intelligent Investo, New York: Harper Collins, 1949.

[20] M. Azo, Neural Network Time Series Forecasting of Financial Markets, New York: Wiley, 1994.

[21] C. Chatfield, Time-series forecasting, C R C Press LLC: Trade Cloth, 2000.

[22] L. Sriram, "An intergrated stock market forecasting model using Neural networks," College of Engineering of Ohio University, 2005.

[23] R. J. V. Eyden, The Application of Neural Networks in the Forecasting of Share Prices, Finance and Technology Publishing, 1996.

[24] S. Lahmiri, "A Comparison of PNN and SVM for Stock Market Trend Prediction using Economic and Technical Information," International Journal of Computer Application, vol. 29(3), pp. 24-30, September 2011.

[25] G. S. Atsalakis and K. P. Valavanis, "Surveying stock market forecasting techniques - Part II: Soft computing methods," Expert Systems with Applications: An International Journa, vol. 36(3), pp. 5932-5941, 2009.

[26] K. M. Dominguez, R. C. Fair and M. Shapiro, "Forecasting the Great Depression: Harvard versus Yale," America Economic Review, pp. 595-612, 1988. 
[27] CSI Global Education Inc., Investment Mangement Techniques, Toronto: CSI, 2010.

[28] The Federal Reserve Bank, "Survey of Professional Forecasters," http://www.phil.frb.org/research-and-data/real-time-center/survey-of-professional-forecasters/ 2013, 2012.

[29] F. Diebold, A. Tay and K. Wallis, "Evaluating Density Forecasts of Inflation: The Survey of Professional Forecasters," R. Engle and H. White (eds.), Festschrift in Honor of C.W.J. Granger, Oxford: Oxford University Press, vol.

http://www.ssc.upenn.edu/ fdiebold/papers/paper20/dtw.pdf 2012, pp. 76-90, 1999.

[30] A. W. Lo and A. C. MacKinlay, "Stock market prices do not follow random walks: Evidence from a simple specification test.," Review of Financial Studies, vol. 1(1), no. http://press.princeton.edu/books/lo/chapt2.pdf 2012, pp. 41-66, 1988.

[31] S. Basu, "The investment performance of common stocks in relation to their price-earnings ratios: A test of the efficient market hypothesis.," Journal of Finance, vol. 32, p. 663-682, 1977.

[32] E. Fama and K. French, "The cross-section of expected stock returns," Journal of Finance, vol. 47, p. 427-465, 1992.

[33] J. Lakonishok, A. Shleifer and R. W. Vishny, "Contrarian investment, extrapolation, and risk," Journal of Finance, vol. 49, p. 1541-1578, 1994.

[34] E. Fama and K. French, "Common risk factors in the returns on stocks and bonds.," Journal of Financial Economics, vol. 33, p. 3-56., 1993.

[35] N. Chen, "Financial investment opportunities and the macroeconomy," Journal of Finance, vol. 46, p. 529-554, 1991.

[36] W. Ferson and R. Schadt, "Measuring fund strategy and performance in changing economic conditions.," Journal of Finance, vol. 51, p. 425-461., 1996.

[37] M. Leunga, H. Daoukb and A. Chenc, "Forecasting stock indices: a comparison of classification and level estimation models," International Journal of Forecasting, vol. 15, p. 173-190, 2000.

[38] Copyright IBM Corporation, "Planning and forecasting:Use continuous planning and rolling forecasts to support adaptive management," ftp://public.dhe.ibm.com/common/ssi/ecm/en/ytl03034caen/YTL03034CAEN.PDF 2012, 2011.

[39] B. Emily, P. Humphreys and R. Mclvor, "Reducing supply chain environmental uncertainty through e-intermediation: An organization theory perspective," International Journal of Production Economics, vol. 114 , p. 347-362, 2008. 
[40] L. Kevin, "The Role of Market Forecasting in Risk Management," gtnews - , 2011.

[41] J. H. Stock and M. Watson, "Combination Forecasts of Output Growth in a Seven-Country Data Set," Journal of Forecasting, vol. 23, http://www.princeton.edu/ mwatson/papers/Stock_Watson_JoForc_2004.pdf 2012, p. 405-430, September 2004.

[42] G. Kapetanios, V. Labhard and S. Price, "Forecasting Using Bayesian and Information Theoretic Model Averaging: An Application to U.K. inflation," Social Science Electronic Publishing, Inc, vol. 26, pp. 33-41, 2005.

[43] C. Kascha and F. Ravazzolo, "Combining Inflation Density Forecasts," Journal of Forecasting, Vols. 29(1-2), http://www.mnb.hu/Root/Dokumentumtar/MNB/Kutatas/mnbhu_seminar/seminar_2009/mnbh u_vita_20091202_2/kascha_20091202.pdf 2012, pp. 231-50, 2010.

[44] B. E. Hansen, "Least-Squares Forecast Averaging," Journal of Econometrics, vol. 146(2), http://www.frbatlanta.org/news/conferen/06bn/BruceHansen.pdf 2012, pp. 342-50, 2008.

[45] G. Elliott and A. Timmermann, "Optimal Forecast Combinations Under General Loss Functions and Forecast Error Distributions," Journal of Econometrics, September 2004.

[46] T. E. Clark and M. W. McCracken, "Improving Forecast Accuracy by Combining Recursive and Rolling Forecasts," International Economic Review, vol. 50(2), http://research.stlouisfed.org/wp/2008/2008-028.pdf 2012, p. 363-395, May 2009.

[47] E. Clark and W. McCracken, "Averaging Forecasts from VARs with Uncertain Instabilities," Journal of Applied Econometrics, vol. 25(1), http://www.federalreserve.gov/pubs/feds/2007/200742/200742pap.pdf, p. 5-29, January/February 2010.

[48] J. Faust and J. H. Wright, "Comparing Greenbook and Reduced Form Forecasts Using a Large Realtime Dataset," Journal of Business \& Economic Statistics, vol. 27(4), http://economics.ucr.edu/fall09/wrightpaper.pdf 2012, pp. 468-479, October 2009.

[49] J. Soll and R. Larrick, "Intuitions about Combining Opinions: Misappreciation of the Averaging Principle," Management Science, Vols. 111-127, no. http://www.chicagocdr.org/papers/larrick.pdf 2012, p. 52(1), January 2006.

[50] R. Larrick, A. Mannes and J. Soll, "The Social Psychology of the Wisdom of Crowds," https://faculty.fuqua.duke.edu/ jsoll/Larrick\%20Mannes\%20Soll\%20WOC\%20chapter\%20Final.p df, 2013. 
[51] J. B. DeLong, A. Shleifer, L. H. Summers and R. J. Waldmann, "Positive Feedback Investment Strategies and Destabilizing Rational Speculation," The Journal of Finance, vol. 45(2) , p. 379-395, June 1990.

[52] F. Black, "Noise," Journal of Finace, vol. 41(3), p. 529-543, July 1986.

[53] G. Brown and M. Cliff, "Investor sentiment and the near-term stock market," Journal of Empirical Finance, vol. 11(1), pp. 1-27, 2004.

[54] M. Baker and J. Wurgler, "Investor Sentiment and the Cross-Section of Stock Returns," Journal of Finance, Vols. LXI, NO. 4, pp. 1645-1695, 2006.

[55] A. Shleifer, Inefficient Markets - An Introduction to Behavioral Finance, New York: Oxford University Press., 2000.

[56] M. C. Steinmetz, "Customer Satisfaction, Investor Sentiment, and Stock Returns," Maastricht University, School of Business and Economics, 2011.

[57] A. Shleife and V. Robert, "The Limits of Arbitrage," Journal of Finance, vol. 52, pp. 35-55, 1997.

[58] D. Kahneman, "A Perspective on Judgement and Choice," American Psychologist, vol. 58(9), pp. 697-720, 2003.

[59] G. Loewenstein, "Emotions in Economic Theory and Economic Behavior," American Economic Review, vol. 90(2), pp. 426-432, 2000.

[60] W. F. Sharpe and G. J. Alexander, Investments, Englewood Cliffs: Prentice Hall, 1990.

[61] M. Burghardt, "Retail Investor Sentiment and Behavior," Karlsruhe Institute of Technology, 2010.

[62] N. Barberis, A. Shleifer and R. Vishy, "A Model of Investor Sentiment," Journal of Financial Economics, vol. 49, http://citeseerx.ist.psu.edu/viewdoc/summary?doi=10.1.1.212.1950 2012, pp. 307-343, 1998.

[63] I. Welch and Q. L., "Investor Sentiment Measures.," National Bureau of Economic Research Working Paper, 2004.

[64] G. W. Brown and M. T. C., "Investor Sentiment and the Near-Term Stock Market," Journal of Empirical Finance, vol. 11(1), pp. 1-27, 2004.

[65] H. Shefrin, "Risk and Return in Behavioral SDF-Based Asset Pricing Modless," Journal of Investment Management, vol. 1-18, p. 6(3) , 2008. 
[66] M. Baker and J. Wurgler, "Investor Sentiment in the Stock Market," Journal of Economic Perspectives, American Economic Association, vol. 21 (2), pp. 129-152, 2007.

[67] W. F. M. De Bondt and R. Thaler, "Does the Stock Market Overreact?," The Journal of Finance, vol. 40(3), pp. 793-805, 1985.

[68] Michael Sincere, "Investor Sentiment Cycle," http://www.michaelsincere.com/articles/3articles/19-investor-sentiment-cycle 2012, 2012.

[69] C. D. Broad, "Emotion and Sentiment," Journal of Aesthetics and Art Criticism, vol. 13, pp. 203214, 1954-55.

[70] W. McDougall, An Introduction to Social Psychology, Boston: John W. Luce \& Co. , 1926 (Revised Edition),164-178..

[71] J. P. Pickett, The American Heritage Dictionary of the English Language, Fourth Edition., Houghton Mifflin Company, 2004.

[72] K. L. Fisher and M. Statman, "Investor Sentiment and Stock Returns," Financial Analysts Journal, vol. 56(2), pp. 16-23, 2000.

[73] M. A. Johnson, "Studying How Changes in Consumer Sentiment Impact the Stock Markets and the Housing Markets," in University of New Orleans Theses and Dissertations. Paper 1113., University of New Orleans, 2010, p. 1113.

[74] J. Gomes, L. Kogan and L. Zhang, "Equilibrium Cross Section of Returns," Journal of Political Economy, vol. 111(4), pp. 693-732, 2003.

[75] M. L. Lemmon and S. X. Ni, "The Effects of Investor Sentiment on Speculative Trading and Prices of Stock and Index Options," Social Science Electronic Publishing, Inc, http://papers.ssrn.com/sol3/papers.cfm?abstract_id=1306237 2012, 2008.

[76] C. Leonard and D. M. Shull, "Investor Sentiment and the Closed-End Fund vidence: Impact of the January Effect," The Quarterly Review of Economics and Finance, vol. 36(1), pp. 117-126, 1996.

[77] C. M. C. Lee, A. Shleifer and R. H. Thaler, "Investor Sentiment and the Closed-End Fund Puzzle," The Journal of Finance, vol. 46(1) , pp. 75-109, 1991.

[78] C. M. Brown, "Investor sentiment and the near-term stock market," Vols. 11(1), 1-27, 2004. 
[79] S. J. Brown, W. N. Goetzmann, T. Hiraki and M. Watanabe, "Investor Sentiment in Japanese and U.S. Daily Mutual Fund Flows," National Bureau of Economic Research, vol. 9470(2), http://www.mendeley.com/catalog/investor-sentiment-japanese-daily-mutual-fund-flows-2/ 2013, p. , 2003.

[80] T. B. Trafalis and H. Ince, "Support Vector machine for regression and application to financial forecasting," Proceedings of the IEEE-INNS-ENNS International Joint Conference on Neural Networks, vol. 6 , pp. $348-353,2000$.

[81] M. Lemmon and E. Portniaguina, "Consumer Confidence and Asset Prices: Some Empirical Evidence," SSRN Electronic Journal , vol. 19(4), https://www.ou.edu/content/dam/price/Finance/CFS/paper/pdf/0501.pdf 2012, p. 1499-1529, 2002.

[82] G. Atsalakis and K. Valavanis, "Surveying stock market forecasting techniques - Part II:," Expert Systems With Applications, vol. 36(3), http://www.sciencedirect.com/science/article/pii/S0957417408004417 2012, p. 5932-5941, 2009.

[83] M. Baker, J. Wurgler and Y. Yuan, "Global, Local, and Contagious Investor entiment," Journal of Financial Economics, vol. 104, http://papers.ssrn.com/sol3/papers.cfm? abstract_id=1364911\&rec=1\&srcabs=1474668 2012, pp. 272-287, 2012.

[84] R. Neal and M. Wheatley, "Do Measures of Investor Sentiment Predict Returns?," The Journal of Financial and Quantitative, vol. 33(4), p. 523-547, 1998.

[85] Wei-Peng Chen, "Investor Trading Behavior, Market Liquidity and the Role of Investor Sentiment," http://69.175.2.130/ finman/Reno/Papers/nFMASession143n_InvestorSentiment_2009_0926.pd , 2013.

[86] A. R. Damasio, Descartes' Error: Emotion, Reason, and the Human Brain, New York: Putnam, 1994.

[87] J. Bollen, M. H. and X. Zeng, "Twitter mood predicts the stock market," Journal of Computational Science, vol. 2(1), pp. 1-8, March 2011.

[88] P. Hafez, "RavenPack Sentiment and its Relationship with Macro-Economic Indicators," RavenPack Research, http://www.sentimentnews.com/2012/01/ravenpack-sentiment-and-macroeconomic.html 2012, January 2012.

[89] M. Hagenau, M. Liebmann, M. Hedwig and D. Neumann, "Automated news reading: Stock Price Prediction based on Financial News Using Context-Specific Features," in System Science (HICSS), 
2012 45th Hawaii International Conference on , 2012.

[90] P. C. Tetlock, "Giving Content to Investor Sentiment: The Role of Media in the Stock Market," Journal of Finance, Vols. LXII, No 3, pp. 1139-1168, 2007.

[91] C. Robertson, S. Geva and R. Wolff, "Can the Content of Public News be used to Forecast Abnormal Stock Market Behaviour?," Seventh IEEE International Conference on Data Mining, vol. 7,http://eprints.qut.edu.au/10458/1/Content_of_Public_News_be_used_to_Forecast_Abnormal _Stock_Market_Behaviour.pdf 2013,pp. 1550-4786, 2007.

[92] United Nations Environment Programme, An Overview of Environmental Indicators: State of the Art, Nairobi, 1994.

[93] P. David, "The Good Indicators Guide:Understanding how to use and choose indicators," in NHS Institute for Innovation and Improvement, 2010.

[94] U.K. Department of Environment, Transport and the Regions (DETR), "Quality of Life Counts: Indicators for a strategy for sustainable development for the United Kingdom," Government Statistical Service,, London, United Kingdom, 1999.

[95] P. Peterson, "Indicators of Sustainable Development in Industrialising," 1997.

[96] P. S. Goodman, "Emphasis on Growth Is Called Misguided," New York Times, September 22, 2009.

[97] Y. Y. Chang, R. Faff and C. Hwang, "Does Investor Sentiment Impact Global Equity Markets?," http://www.efmaefm.org/0efmameetings/efma\%20annual\%20meetings/2009-milan/149.pdf, 2013.

[98] D. C. Ling, A. Naranjo and B. Scheick, "Investor Sentiment and Asset Pricing in Public and Private Markets," in 46th Annual AREUEA Conference Paper, http://www.reri.org/research/article_pdf/wp170.pdf 2013, 2010.

[99] J. M. Keynes, The General Theory of Employment, Interest and Money, England: Palgrave Macmillan, 1936.

[100] M. Friedman, The Case for Flexible Exchange Rates, Essays in Positive Economics, Chicago: University of Chicago Press, 1953.

[101] E. Fama, "The behavior of stock market prices," The Journal of Business, vol. 38 (1), no. http://stevereads.com/papers_to_read/the_behavior_of_stock_market_prices.pdf 2012, p. 34105, 1965. 
[102] W. Antweiler and M. Z. Frank, "Is all that talk just noise? The information content of Internet stock message boardse," The Journal of Finance, vol. 59(3), http://strategy.sauder.ubc.ca/antweiler/public/noise.pdf 2013, p. 1259-1293, 2004.

[103] B. Eichengreen and A. Mody, "Interest Rates in the North and Capital Flows to the South: Is There a Missing Link?," International Finance,, vol. 1(1), http://emlab.berkeley.edu/ eichengr/research/posen.pdf 2012, pp. 35-58, 1998.

[104] I. Baek, A. Bandopadhyaya and C. Du, "Determinants of Market Assessed Sovereign Risk: Economic Fundamentals or Market Risk Appetite?"," Journal of International Money and Finance, vol. 24(4), http://ejournal.narotama.ac.id/files/\%281\%29Determinants\%20of\%20marketassessed\%20sovereign\%20risk\%20Economic\%20fundamentals\%20or\%20market\%20risk\%20appe tite.pdf 2013, pp. 533-548, 2005.

[105] M. Baker and J. Wurgler, "Investor Sentiment in the Stock Market," Journal of Economic Perspectives, vol. 21(2), http://www.people.hbs.edu/mbaker/cv/papers/Sentiment_Draft_19.pdf 2012, pp. 129-152, December 19, 2006.

[106] W. Y. Lee, C. X. Jiang and D. C. Indro, "Stock market volatility, excess returns, and the role of investor sentiment," Journal of Banking \& Finance, vol. 26 https://umdrive.memphis.edu/cjiang/www/teaching/fir87710/paper/lee_jiang_indro_2002_jbf_investor_sentiment.pdf 2013, p. 2277-2299, 2002.

[107] G. Brown, "Volatility, sentiment, and noise traders.," Financial Analysts Journal, vol. 55 (2), http://www.jstor.org/discover/10.2307/4480157?uid=3739448\&uid=2\&uid=3737720\&uid=4\&sid $=21101637460601$ 2013, p. 82-90, 1999.

[108] G. Brauer, "Investor sentiment and the closed-end fund puzzle: A 7 percent solution," Journal of Financial Services Research, vol. 7 (3), p. 199-216, 1993.

[109] M. Schmeling, "Investor sentiment and stock returns:Some international evidence," Journal of Empirical Finance, vol. 16(3), http://www.sciencedirect.com/science/article/pii/S0927539809000048 2013, pp. 394-408, 2009.

[110] A. C. Chui, S. Titman and K. C. J. Wei, "Individualism and Momentum around the World," Journal of Finance, vol. 65(1), http://118.96.136.31/ejurnal/Journal\%20of\%20Finance,\%202010,\%20Vol.\%2065\%20lssue\%201.p df\#page=358 2013, pp. 361-392, 2010.

[111] M. Baker, J. Wurgler and Y. Y., "Global, local, and contagious investor sentiment," Journal of Financial Economics, vol. 104, http://web-docs.stern.nyu.edu/volatility/docs/Wurgler.pdf 2012, pp. 272-287, May 2012. 
[112] F. Cornelli, D. Goldreich and A. Ljungqvist, "Investor Sentiment and Pre-IPO Markets," in AFA 2005 Philadelphia Meetings, 2005.

[113] E. Miller, "Risk, uncertainty, and divergence of opinion?," Journal of Finance, vol. 32, http://web.ku.edu/ finpko/myssi/FIN938/Miller.JF_1977.pdf 2013, pp. 1151-1168, 1977.

[114] J. Ritter and I. Welch, "A review of IPO activity, pricing, and allocation?," Journal of Finance, vol. 52, pp. 1795-1828, 2002.

[115] M. Baker and J. Wurgler, "Market timing and capital structue," Journal of Finance, vol. 57, http://student.bus.olemiss.edu/files/jeggington/OLE\%20MISS\%20PHD\%20Program/FMA\%2OPap er/Fin\%20635/4/Baker\%20and\%20Wurgler.pdf 2013, pp. 1-32, 2002.

[116] A. Oehlera, M. Rummera and P. N. Smithb, "IPO Pricing and the Relative Importance of Investor Sentiment - Evidence from Germany," Department of Economics and Related Studies, University of York, UK, UK, 2004.

[117] M. Lowry and W. Schwert, "IPO market cycles: Bubbles or sequential learning," Journal of Finance, vol. 57, no. http://www.personal.psu.edu/mbl3/jf_cycles.pdf 2013, pp. 1171-1200, 2002.

[118] R. Ibbotson, J. Sindelar and J. Ritter, "The market's problems with the pricing of initial public Offerings," Journal of Applied Corporate Finance, vol. 7, http://bear.warrington.ufl.edu/ritter/ipoisr.pdf 2013, p. 66-74, 1994.

[119] J. Lerner, "Venture capitalists and the decision to go public," Journal of Financial Economics, vol. 35, p. 293-316, 1994.

[120] M. Lowry, "Why does IPO volume fluctuate so much?," Journal of Financial Economics, vol. 67, pp. 3-40, 2003.

[121] C. C. Lee, A. Shleifer and R. H. Thale, "Investor Sentiment and the Closed-End Fund Puzzle," The Journal of Finance, vol. 46.1, pp. 75-109, 1991.

[122] L. Swedroe, "How investor sentiment can get you in trouble," http://www.cbsnews.com/8301505123_162-57438165/how-investor-sentiment-can-get-you-in-trouble/, 22 May 2012.

[123] W. Sharpe, "Capital Asset Prices: A Theory of Market Equilibrium under Conditions of Risk,," Journal of Finance, vol. 19, p. 425 - 442, 1964.

[124] J. Lintner, " Security Prices, Risk, and Maximal Gains from Diversification,", Journal of Finance, vol. 20, p. 587 -615., 1965.

[125] T. Kim and A. Ha, "Investor Sentiment and Market Anomalies," Pusan National University, Pusan, 
South Korea, Pusan, 2010.

[126] R. Shiller, Irrational Exuberance, Broadway Book, 2000.

[127] Z. Mohamed, N. Geneviève and B. Francisca, "How does investor sentiment affect stock market crises? Evidence from panel data," Electronic copy available at: http://ssrn.com/abstract=1584566, 2011.

[128] H. Shefrin and M. Statman, "The disposition to sell winners too early and ride losers too long: Theory and evidence," Journal of Finance, vol. 40, pp. 777-790, 1985.

[129] K. Daniel, D. Hirshleifer and A. Subrahmanyam, "Investor psychology and security market underand over-reactions,," Journal of Finance, vol. 53, pp. 1839-1885, 1998.

[130] L. Martellini, P. Priaulet and S. Priaulet, Fixed-Income Securities: Valuation, Risk Management and Portfolio Strategies, England: John Wiley \& Sons Ltd, 2003.

[131] R. F. Stambaugh, J. Yu and Y. Yuan, "The short of it: investor sentiment and anomalies," University of Pennsylvania., p. Working Paper, 2011.

[132] M. Baker and J. Wurgler, "Comovement and predictability links between bonds and the crosssection of stocks," Harvard Business School., p. Working paper, 2011.

[133] G. Bekaert, L. Baele and I. K., "The determinants of stock and bond return comovements," Review of Financial Studies 23,, vol. 23, pp. 2374-2428, 2010.

[134] A. Bandopadhyaya and A. L. Jones, "Measures Of Investor Sentiment: A Comparative Analysis PutCall Ratio Vs. Volatility Index," Journal of Business \& Economics Research, vol. 6(8), http://journals.cluteonline.com/index.php/JBER/article/view/2458/2504 2012, pp. 27-34, 2008.

[135] A. Crescenzi, The Strategic bond Investor, 2nd Edtion ed., New York: McGraw-Hill, 2010.

[136] S. E. Briese, "Illuminating Data: Commitments of Traders Report Can Disclose Promise Perils in the Market.," Barron, May 2, 1994..

[137] C. Wang, "Investor Sentiment, Market Timing, and Futures Returns," Department of Finance and Accounting, National University of Singapore, Singapore, 2000.

[138] C. Bonser-Neal and T. R. Morley, "“Does the Yield Spread Predict Real Economic Activity? A Multicountry Analysis," Economic Review, vol. issue Q III, http://www.kansascityfed.org/PUBLICAT/EconRev/pdf/3q97bons.pdf 2012, pp. 37-53 , 1997.

[139] A. Estrella and F. S. Mishkin, "Predicting U.S. Recessions: Financial Variables as Leading 
Indicators," NBER Working Paper No. 5379, 1996.

[140] M. Feroli, "Monetary Policy and the Information Content of the Yield Spread," Federal Reserve Board, Washington, D.C., http://www.federalreserve.gov/pubs/feds/2004/200444/200444pap.pdf, August, 2004.

[141] M. Goodfriend, "Using the Term Structure of Interest Rates for Monetary Policy," Federal Reserve Bank of Richmond Economic Quarterly, vol. 84 (3), pp. 13-30, Summer 1998.

[142] L. Codogno, C. Favero, A. Missale, R. Portes and M. Thum, "Yield Spreads on EMU Government Bonds," Economic Poliicy, vol. 18, pp. 503-532, 2003.

[143] J. Hund and D. Lesmond, "Liquidity and Credit Risk in Emerging Debt Markets," http://www.aeaweb.org/annual_mtg_papers/2007/0107_1300_0103.pdf, 2008.

[144] L. Barbosa and S. Costa, "Determinants of sovereign bond yield spreads in the Euro area in the context of the economic and financial crisis," Economic Bulletin Bank of Portugal, pp. 131-150., 2010.

[145] M. Schmeling, "Investor sentiment and stock returns: Some international Evidence," Journal of Empirical Finance, vol. 16, pp. 394-408, 2009.

[146] S. Nayak, "Investor sentiment and corporate bond yield spreads," Review of Behavioral Finance, vol. 2, p. 59-80, 2010.

[147] S. Spyrou, "Are sovereign bond yield spreads affected by investor sentiment? Evidence from the Greek budget crisis," Athens University of Economics \& Business Department of Accounting \& Finance, Athens, 2011.

[148] D. Sourrouille and W. Mako, "Investment Funds in MENA," World Bank, Fnancial Flagship, http://siteresources.worldbank.org/INTMNAREGTOPPOVRED/Resources/MENAFlagshipMutualFu nd2_28_11.pdf 2013, 2010.

[149] Ontario Security Commision, "Conventional Manged Funds," http://www.osc.gov.on.ca/en/InvestmentFunds_ifunds_20120413_practitioner.htm 2012, 2012.

[150] W. N. Goetzmann, M. Massa and K. G. Rouwenhorst, "Behavioral Factors in Mutual Fund Flows," Yale School of Management, http://www.econ.yale.edu/ shiller/behfin/2000-05/goetzmanetal.pdf, 2005.

[151] S. J. Brown, W. N. Goetzmann, T. Hiraki, N. Shiraishi and M. Watanabe, "Investor Sentiment in 
Japanese and U.S.Daily Mutual Fund Flows," Yale School of Management,, 2002.

[152] N. Barberis and A. Shleifer, "Style Investing," Chicago and Harvard University., 2001.

[153] E. F. Fama and J. D. MacBeth, "Risk, Return, and Equilibrium: Empirical Tests," Journal of Political Economy, vol. 81 (3), pp. 607-636, 1973.

[154] V. Yadav and M. Massa, "Do Mutual Funds Play a Sentiment-based Strategy? When Marketing is More Important than Performance," INSEAD, http://phd.insead.edu/students/profiles/0619569/Vijay_Massimo_WP2010_FundSentiment.pdf 2013, 2010.

[155] A. Frazzini and O. Lamont, "Dumb money: mutual fund flows and cross-section of stock returns," Journal of Financial Economics, vol. 88, http://www.econ.yale.edu/ af227/pdf/Dumb\%20money\%20Mutual\%20fund\%20flows\%20and\%2 Othe\%20cross-section\%20of\%20stock\%20returns\%20-\%20Frazzini\%20and\%20Lamont.pdf 2013, pp. 299-322, 2008.

[156] J. D. Coval and E. Stafford, "Asset Fire Sales (and Purchases) in Equity Markets," Journal of Financial Economics, vol. 86, p. 479\{512., 2007.

[157] J. A. Close, "Investment Companies: Closed-End versus Open-end," Harvard Business Review, vol. 30 , pp. 79-88, 1952.

[158] M. Zweig, "An investor expectations stock price predictive model using closed-end fund Premium," Journal of Finance, vol. 28, p. 67-86, 1973.

[159] C. M. Lee, A. Shleifer and R. H. Thaler, "Investor sentiment and the closed-end fund puzzle," Journal of Finance, vol. 46(1), p. 75-109, 1991.

[160] B. G. Malkiel, "The Valuation of Closed-end Investment Company Shares," Journal of Finance, vol. 32(3), pp. 847-859, 1977.

[161] E. Elton, M. Gruber and J. A. Busse, "Do investors care about sentiment?," Journal of Business, vol. 71(4), p. 477-500, 1998.

[162] J. Doukas and N. T. Milonas, "Investor Sentiment and the Closed-end Fund Puzzle: Out-of-sample Evidence," European Financial Management, vol. 10(2), p. 235-266, 2004.

[163] Z. N. Güner and Z. Önder, "Determinants of Closed-End Funds' Discounts: Evidence from An Emerging Market," Middle East Technical University, June 2011.

[164] S. T. Anderson, R. Beard, H. Kim and L. Stern, "Fear and Closed-End Fund Discounts:Investor 
Sentiment Revisited," Tuskegee University and Auburn University, July 2011.

[165] B. R.J. and W. C., "Investor Sentiment and Noise Traders: Discount to Net Asset Value in Listed Property Companies in the U.K.,," Journal of Real Estate Research, vol. 18(2), pp. 291-312, 1999.

[166] L. D.C., P. M. and B. D., "Short Sales and Fundamental," Real Estate Economics (Forthcoming), no. http://ssrn.com/abstract=1469454, May 16, 2012.

[167] E. Giacomini, "The Role of Investor Sentiment in the Real Estate Market," Polytechnic University of Marche, Italy, http://openarchive.univpm.it/jspui/bitstream/123456789/197/1/Tesi.Giacomini.pdf 2013, 2010.

[168] A. N. a. B. S. Ling D.C., "Investor Sentiment and Asset Pricing in Public and Private Market," working paper, 2010.

[169] P. Maier and M. R. King, "Hedge Funds and Financial Stability: Regulating Prime Brokers Will Mitigate Systemic Risks," Journal of Financial Stability, vol. 5, no. Available at SSRN: http://ssrn.com/abstract=, p. 283-297, 2009.

[170] T. Caldwell, "Introduction: The model for superior performance, in: J. Lederman, R.A. Klein.," Irwin Professional Publishing, pp. 1-17, 1995.

[171] A. Bello, "Investor Behavior, Hedge Fund Returns and Strategies," University of Texas-Pan American, Texas, 2011.

[172] J. M. Keynes, The General Theory of Employment, Interest and Money, London: London: McMillan, 1936.

[173] B. Trueman, "A theory of noise trading in securities markets," Journal of Finance, vol. 43(1), pp. 83-95, 1988.

[174] D. Nandita, "Does investor sentiment play a role in hedge fund return?," Indian Journal of Economics and Business, vol. 10(4), http://www.freepatentsonline.com/article/Indian-JournalEconomics-Business/278509635.html, p. 583(22), 2011.

[175] L. G. a. S. Sussa, "Market Sentiment in Commodity Futures Returns," Electronic copy available at: http://ssrn.com/abstract=1934397, 2011.

[176] W. Y. Lee, C. X. Jiang and I. D.C., "Stock Market Volatility, Excess Returns, and the Role of Investor Sentiment," Journal of Banking and Finance, vol. 26(12), p. 2277-2299, 2002.

[177] S. Borovkova and A. Lammiman, "The impact of news sentiment on energy futures returns," Vrije Universiteit Amsterdam, http://www.feweb.vu.nl/en/Images/paper\%20borovkova_tcm97- 
204330.pdf.

[178] P. W. C. a. b. I. Research, "Information on aggregate transaction," Price Waterhouse Coopers and by IFS, 2009.

[179] M. Wright, C. Weir and A. Burrows, "Irrevocable commitments, going private and Private Equity," European Financial Management, vol. 13, pp. 757-775, 2007.

[180] C. A. A. B. a. C. W. Ann-Kristin Achleitner, "Economic Consequences of Private Equity Investments On The German Stock Market," Econstor, Vols. 2008-05, p. http://www.econstor.eu/bitstream/10419/48426/1/577332147.pdf 2013, 2008.

[181] P. A. Gompers and J. Lerner, "Money chasing deals? The impact of fund inflows on private equity valuations," Journal of Financial Economics, vol. 55, p. 281-325, 2000.

[182] A. Ljungqvist and M. Richardson, "The investment behavior of private equity fund managers," NYU Stern Working Paper, 2003.

[183] R. Inderst and M. Muller, "The effect of capital market characteristics on the value of start-up firms," Journal of Financial Economics, vol. 73, no. http://people.stern.nyu.edu/hmueller/papers/vc.pdf 2013, p. 319-356, 2004.

[184] C. Kaserer and C. Christian Diller, "What Drives Private Equity Returns? - Fund Inflows, Skilled GPs, and/or Risk," Journal of Business, vol. 57, http://www.fbv.kit.edu/symposium/10th/papers/Kaserer_Diller\%20\%20What\%20Drives\%20European\%20Private\%20Equity\%20Returns\%20\%20Fund\%20Inflows,\%20Skilled\%20GPs\%20andor\%20Risk.pdf 2013, p. 73-96, 2005.

[185] S. N. Kaplan and A. Schoar, "Private equity performance: Returns, persistence and capital," Sloan School of Management Working Pape, http://www.chicagobooth.edu/news/2004-1112kaplan/pereturns-1.pdf 2013, 2004.

[186] SEI Global Services, Inc, "Private Equity Investors - Committed Yet Concerned," SEI, http://www.seic.com/docs/IMS/SEI-Private_EquityWP_UK_Final.pdf 2013, 2013.

[187] R. Dodd, "Derivatives Markets: Sources of Vulnerability in U.S. Financial Markets," Financial Policy Forum Derivatives Study Center, p. http://www.financialpolicy.org/fpfspr8.pdf, 2004.

[188] M. L. Ni and S. X. Ni, "The Effects of Investor Sentiment on Speculative Trading and Prices of Stock and Index Options," AFA 2011 Denver Meetings Paper , http://www.efa2009.org/papers/SSRNid1340762.pdf, 2008.

[189] B. Hany, "Investor Sentiment and Option Prices," in AFA 2006 Boston Meetings , 
http://rfs.oxfordjournals.org/content/21/1/387.abstract, 2006.

[190] N. Bollen and R. Whaley, "Does Net Buying Pressure Affect the Shape of Implied Volatility Functions?," Journal of Finance, vol. 59, pp. 711-753, 2004.

[191] D. Becherer and M. H. A. Davis, "Arrow Debreu Prices," http://www.math.huberlin.de/ becherer/ArrowDebreuPrices.pdf, 2008.

[192] D. Breeden and R. Litzenberger, "Prices of State-Contingent Claims Implicit in Option Prices," Journal of Business, vol. 51, pp. 621-652, 1978.

[193] G. Mian and S. Sankaraguruswamy, "Investor Sentiment and Stock Market Response to Corporate News," The NUS Business School, National University of Singapore, 2007.

[194] J. R. Nyquist, "Optimism versus Pessimism," http://www.financialsense.com/contributors/jrnyquist/2012/01/17/optimism-versus-pessimism, 2012.

[195] D. Merkle, G. Langer and D. Sussman, "Consumer Confidence: Measurement and Meaning," ABC News, New York, 1994.

[196] J. Dominitz and C. Manski, "How Should We Measure Consumer Confidence," Journal of Economic Perspectives, vol. 18, http://www.jstor.org/discover/10.2307/3216890?uid=3739448\&uid=2129\&uid=2\&uid=70\&uid=3 737720\&uid=4\&sid=21101640922241 2013, pp. 51 - 66, 2004.

[197] The Conference Board of Canada, "Consumer Confidence," http://www.conferenceboard.ca/topics/economics/consumer_confidence.aspx, 2012.

[198] Bloomberg, "Bloomberg Consumer Comfort Index," Bloomberg, 2012.

[199] ABC News, "Consumer Confidence," http://abcnews.go.com/PollingUnit/abc-news-pollconsumer-confidence/story?id=9484225\#.T7_n9UbJq0, 2012.

[200] S. Poon and C. W. J. Granger, "Forecasting Volatility in Financial Markets: A Review," Journal of Economic Literature, vol. XLI, http://www.ses.ac.ir/files/education/dinmohammadi/doc/Risk_modeling/forecasting_volatility_i n_financial.pdf, p. 478-539, 2003.

[201] crestmont Research, "Stock Market Returns and Volitility," http://www.crestmontresearch.com/stock-market/\#70-market-volatility September 2012, 2011.

[202] L. Ederington and E. Golubeva, "The Impact of Stock Market Volatility Expectations on Investor Behavior: Evidence From Aggregate Mutual Fund Flows," Finance Division, Michael F. Price 
College of Business, University of Oklahoma, Oklahoma, USA, 2011.

[203] G. W. Schwert, "Stock Market Volatility: Ten Years After the Crash," Rochester, N.Y.: Simon School of Business, http://schwert.simon.rochester.edu/bw1297.pdf 2013, 1997.

[204] R. E. Whaley, "Understanding VIX," http://ssrn.com/abstract=1296743, Nashville, TN, December 2008.

[205] I. Chicago Board Options Exchange, "Volatility Indexes at CBOE," Chicago Board Options Exchange, Incorporated, www.cboe.com/Volatility 2013, 2013.

[206] CBOE, "VXN," http://www.cboe.com/micro/vxn/, 2012.

[207] The Keystone Speculator, "NATV:NYTV Nasdaq/NYSE Volume Ratio Volume Does Matter," http://thekeystonespeculator.blogspot.ca/2012/03/natvnytv-nasdaqnyse-volume-ratiovolume.html 2012, 2012.

[208] A. Bandopadhyaya and A. L. Jones, "Measures Of Investor Sentiment:A Comparative Analysis PutCall Ratio Vs. Volatility Index," Journal of Business \& Economics Research, vol. 6(8), http://journals.cluteonline.com/index.php/JBER/article/view/2458/2504 2013, pp. 27-34, 2008.

[209] Y. Amihud and H. Mendelson, "Asset pricing and the bid-ask spread," Journal of Financial Economics, vol. 17, p. 223-249, 1996.

[210] M. Brennan and A. Subrahmanyam, "Market microstructure and asset pricing: on the compensation for illiquidity in stock returns," Journal of Financial Economics 4, vol. 41, p. 441464, 1996.

[211] D. Vayanos, " Transaction costs and asset prices: a dynamic equilibrium model.," Review of Financial Studies, vol. 11, pp. 1-58, 1998.

[212] M. Bakera and J. C. Stein, "Market liquidity as a sentiment indicator," Journal of Financial Markets, vol. 7, pp. 271 - 299, 2004.

[213] WallStreetCourier, "Upside-/Downside Volume Index Weekly," http://www.wallstreetcourier.com/v/bi-upside-downside-volume.htm 2013, 2013.

[214] J. Bajkowski, "Measure of Market Breadth: A Look at Trading Statistics," AAll Journal Stock Analysis Workshop, October 1998.

[215] CME Group Inc, "Block Trades," http://www.cmegroup.com/clearing/trading-practices/blocktrades.html, 2012. 
[216] J. Lewis, "The Commitment of Traders Report Market Sentiment Indicator," Lewis and Mariani Publishing, LLC, 2012.

[217] Software North LLC, "COT Historical Graphs," www.softwarenorth.com/, 2012.

[218] B. Ward, "Revolutionizing Wall Street with News Analytics," IEEE Computer Society, http://www.computer.org/portal/web/computingnow/news/revolutionizing-wall-street-withnews-analytics 2013, 2011.

[219] P. C. Tetlock, M. Saar-Tsechansky and S. MacSkassy, "More than words quantifying language to measure firm's fundamentals," Journal of Finance, vol. 63, pp. 1437-1467, 2008.

[220] Z. Jiang, "Theory and Evidence: An Evaluation of Investor Sentiment Measures," New York University - Leonard N. Stern School of Business, New York, 2011.

[221] E. Guresen, G. Kayakutlu and T. U. Daim, "Using artificial neural network models in stock market index prediction," Expert Systems with Applications, vol. 38, no. 8, p. 10389-10397, August 2011.

[222] K. -J. Kim, "Artificial Neural Networks With Feature Transformation Based onDomain Knowledge For the Prediction of Stock Index Futures," Intelligent System in Accounting Management, Finance and Management, vol. 12, p. 167-176), 2004.

[223] T. B. Fakhreldin and M. Fakhreldin, "Prediction of Stock Market Indices using Hybrid Genetic Algorithm/ Particle Swarm Optimization with Perturbation Term," in International Conference on swarm intelligence, http://icsi11.eisti.fr/papers/paper_30.pdf 2013, 2011.

[224] N. L. Suanu, G. Kabari and P. Asagba, "Nigerian Stock Market Investment using a Fuzzy Strategy," Journal of Information Engineering and Applications, vol. 2(8), 2012.

[225] P. Ou and H. Wang, "Prediction of Stock Market Index Movement by Ten Data Mining Techniques," Modern Applied Science, vol. 3(12), http://ccsenet.org/journal/index.php/mas/article/viewFile/4586/3925\%20rel=\%5C\%27nofollow\% 5C\%27, Decemer 2009.

[226] J. E. Burnett, C. Carroll and P. Thistle, "The Relative Impact Of Public Information In Shaping Investor Expectations," The Journal of Applied Business Research, vol. 25(2), pp. 51-68, March/April 2009.

[227] B. M. Barber and T. Odean, "All that glitters: The effect of attention and news on the buying behavior," of individual and institutional investors. Review of Financial Studies, vol. 21(2), p. 785818, 2008.

[228] L. Mitra, G. Mitra and D. diBartolomeo, "Equity portfolio risk (volatility) estimation using market 
information and sentiment," Quantitative Finance, vol. 9(8), p. 887-895, 2009.

[229] L. Mitra and G. Mitra, "Applications of news analytics in finance: A review," CARISMA (Centre for Analysis of Risk and Optimisation Modelling Applications), http://optirisksystems.com/papers/Opt0014.pdf, June 17, 2010.

[230] J. Han and M. Kamber, Data Mining: Concepts and Techniques, Second Edition, Boston: Morgan Kaufmann Publishers, 2006.

[231] H. D. Lasswell, Power and personality, London: Chapman and Hall., 1948.

[232] E. Kelly and P. Stone, Computer Recognition of English Word Senses, Amsterdam: North-Holland Linguistic Series., 1975.

[233] P. J. Stone, D. C. Dunphy, M. S. Smith and Ogilvie D. M., The General A Computer Approach to Content Analysis, Boston: http://www.wjh.harvard.edu/ inquirer(Accessed January 2013), 1978.

[234] K. Ahmad, "The 'return' and 'volatility' of sentiments: An Attempt to Quantify the Behaviour of the quantify the behaviour of the Markets?," in Affective Computing and Sentiment Analysis:Metaphor, Ontology, Affect and Terminology Khurshid Ahmad (Editor), Dublin, https://www.cs.tcd.ie/Khurshid.Ahmad/SurveySite/ ( 2013), 2009, pp. 89-99 .

[235] G. Knolmayer and M. M.A., "Text mining systems for market response to news: A survey," in Proceedings of the IADIS European Conference Data Mining 2007 (2007), http://pdf.aminer.org/000/246/869/forecasting_intraday_stock_price_trends_with_text_mining_ techniques.pdf 2013, 2006.

[236] G. Mitra and L. Mitra, The handbook of news analytics in finance,, Chichester: Wiley \& Sons, 2010.

[237] V. Shkapenyuk and T. Suel, "Design and Implementation of a High-Performance Distributed Web Crawler," http://cis.poly.edu/ suel/papers/crawl.pdf, New York, 2013.

[238] A. Arasu, J. Cho, H. Garcia-Molina and R. S., "Searching the web," in ACM Transactions on Internet Technologies, June 2001.

[239] R. Baeza-Yates and B. Ribeiro-Neto, Modern Information Retrieval, Addision Wesley, 1999.

[240] S. Chakrabarti, B. Dom, R. Kumar, P. Raghavan, S. Rajagopalan, A. Tomkins, D. Gibson and J. Kleinberg, "Mining the web's link structure," IEEE Computer, vol. 32(8), p. 60-67, 1999. 
[241] I. H. Witten, A. Moffat and T. C. Bell, Managing Gigabytes: Compressing and Indexing Documents and Images, Morgan Kaufmann, second edition, 1999.

[242] R. Baumgartner, W. Gatterbauer and G. Gottlob, "Web Data Extraction System," http://www.contrib.andrew.cmu.edu/ gatt/download/Encyclopedia2009_Web_Data_Extraction _System.pdf, 2013.

[243] D. Leinweber, Nerds on Wall Street, New Jersye: John Wiley, 2009.

[244] S. R. Das and M. Chen, "Yahoo! for Amazon! Sentiment Extraction from Small Talk on the Web," Management Science, vol. 53, pp. 1375-1388., 2007.

[245] G. Mitra and L. Mitra, The Handbook of News Analytics in Finance, United Kingdom: John Wiley \& Sons, Inc.,, May 2011.

[246] B. Pang, L. Lee and S. Vaithyanathan, "Thumbs Up? Sentiment Classification Using Machine Learning Techniques," Proc. Conference on Empirical Methods in Natural Language Processing (EMNLP), 2002.

[247] J. Sisk and L. D., "The Handbook of News Analytics in Finance," in Relating news analytics to stock return, United Kingdom, Wiley, 2011, p. Chapter 4.

[248] M. Y. C. Sanjiv R. Das, "Yahoo! for Amazon: Sentiment Extraction from Small Talk on the Web," Management Science (INFORMS), vol. 53(9), pp. 1375-1388, September 2007.

[249] Ravenpack, "Corporate News," http://www.ravenpack.com/newsroom/index.htm 2013, 2012.

[250] X. Wu, V. Kumar, R. Quinlan, J. Ghosh, Q. Yang, H. Motoda, G. Yu, Z. Zhou, M. Steinbach, J. Hand and D. Steinberg, "Top 10 Algorithms in Data Mining,," Knowledge and Information System, vol. 14(1), pp. 1-37, 2008.

[251] DCM Capital, "DCM Dealer Wants to Turn Twitter Into a Stock Trading Tool," http://www.derwentcapitalmarkets.com/dcm_dealer/2013, 2013.

[252] M. Verardo and A. Patton, "Does Beta Move with News? Systematic Risk and Firm-Specific Information Flows," FMG Discussion Papers available from http://eprints.Ise.ac.uk/24421/1/dp630.pdf, 2013, 2009.

[253] J. N. a. P. S. M. Graham, "Relative Importance of Scheduled Macroeconomic News for Stock Market Investors," for Stock Market Investors. Journal of Economics and Finance, 27(2):153-165, 2003., vol. 27(2), pp. 153-165, 2003. 
[254] P. Kalev, W. M. Liu, P. K. Pham and E. Jarnecic, "Public information arrival and volatility of intraday stock returns," Journal of Banking and Finance, vol. 28(6), pp. 1441-1467, 2004.

[255] H. N. Duong and P. S. Kalev, "Firm specific news arrival and the volatility of intraday stock index and futures returns..," in Handbook of News Analytics, Wiley, 2010, p. Chapter 11.

[256] C. S. Robertson, S. Geva and R. C. Wolff, "News aware volatility forecasting: Is the content of news important?," In Proceedings of the sixth Australasian conference on Data mining and analytics, Australian Computer Society, Inc., vol. 70, pp. 161-170, 2007.

[257] M. Dzielinski, M. O. Rieger and T. Talpsepp, "Volatility, asymmetry, news and private investors," in Handbook of News Analytics, Wiley, 2010, pp. Chapter 10,.

[258] Reuters A Team, "Machine readable news and algorithmic trading," Whitepaper produced for Thomson Reuters and Market News International, 2010.

[259] F. Li, "Do Stock Market Investors Understand the Risk Sentiment of Corporate Annual Reports?," Social Science Electronic Publishing, Inc, http://papers.ssrn.com/sol3/papers.cfm?abstract_id=898181 2013, April 21, 2006.

[260] J. Mossin, "Equilibrium in a Capital Asset Market," Econometrica, vol. 34(4), pp. 768-783, 1966.

[261] T. G. Stephan, R. Maurer and M. Dürr, "A Multiple Factor Model for European Stocks," http://www.actuaries.org/AFIR/Colloquia/Toronto/Stephan_Maurer_Durr.pdf 2013, September 2000 .

[262] B. Rosenberg, K. Reid and R. Lanstein, "Persuasive evidence of market inefficiency," Journal of Portfolio Management, pp. 9-16, 1985.

[263] A. Lo, Market efficiency: Stock market behaviour in theory and practice, United Kingdom: Edward Elgar Pub., 1997.

[264] L. S. Bamber, O. E. Barron and T. L. Stober, "Trading volume and different aspects of disagreement coincident with earnings announcements.," The Accounting Review, vol. 72, p. 575-597, 1997.

[265] S. Seasholes and G. Wu, "Profiting from Predictability: Smart Traders, Daily Price Limits, and Investor Attention," University of California, Berkeley, working paper available, http://www3.nd.edu/ pschultz/SeasholesWu.pdf 2013, 2004.

[266] J. Peress and L. H. Fang, "Media coverage and the cross-section of stock returns," The Journal of Finance, vol. 64(5), pp. 2023-2052, 2009. 
[267] Z. Da, J. Engelberg and G. P., "In Search of Attention," Available on SSRN, p. http://papers.ssrn.com/sol3/papers.cfm?abstract_id=1364209 2013, 2009.

[268] D. Hirshleifer, S. S. Lim and S. Teoh, "Driven to Distraction: Extraneous Events and Underreaction to Earnings News (Digest Summary)," CFA Digest, vol. 40(1), 2010.

[269] R. Cahan, J. Jussa and Y. Luo, "Breaking news: How to use news sentiment to pick stocks," MacQuarie Research Report, 2009.

[270] Ravenpack, "Factoring Sentiment Risk into Quant Mod," Ravenpack, 2012.

[271] RavenPack, "RavenPack Sentiment and its Relationship with Macro-Economic Indicators," Ravenpack, 2012. 